\author{
UNIVERSIDADE DE SÃO PAULO \\ PROGRAMA DE PÓS-GRADUAÇÃO EM ENERGIA \\ EP-FEA-IEE-IF
}

SERGIO RICARDO CAMPOS BEZERRA

AVALIAÇÃO DE SISTEMAS DE ATERRAMENTO CONSIDERANDO

A UTILIZAÇÃO DE CONDUTORES E HASTES ENVOLVIDOS EM CONCRETO

SÃO PAULO

2011 


\title{
AVALIAÇÃO DE SISTEMAS DE ATERRAMENTO CONSIDERANDO A UTILIZAÇÃO DE CONDUTORES E HASTES ENVOLVIDOS EM CONCRETO
}

\author{
Dissertação apresentada ao Programa de \\ Pós-Graduação em Energia da Universidade \\ de São Paulo (Escola Politécnica / Faculdade \\ de Economia, Administração e \\ Contabilidade / Instituto de Eletrotécnica e \\ Energia / Instituto de Física) para obtenção \\ do Título de Mestre em Ciências, na Área de \\ Concentração Energia.
}

Orientador: Prof. Dr. Arnaldo G. Kanashiro.

\section{SÃO PAULO}




\section{AUTORIZO A REPRODUÇÃO E DIVULGAÇÃO TOTAL OU PARCIAL DESTE TRABALHO, POR QUALQUER MEIO CONVENCIONAL OU ELETRÔNICO, PARA FINS DE ESTUDO E PESQUISA, DESDE QUE CITADA A FONTE.}

FICHA CATALOGRÁFICA

Bezerra, Sergio Ricardo Campos.

Avaliação de sistemas de aterramento considerando a utilização de condutores e hastes envolvidos em concreto / Sergio Bezerra Ricardo Campos, orientador Arnaldo Gakiya Kanashiro - São Paulo, 2011.

161f..: il.; $30 \mathrm{~cm}$.

Dissertação (Mestrado - Programa de Pós-Graduação em Energia) EP / FEA / IEE / IF da Universidade de São Paulo.

1. Aterramento 2. Proteção de Sistemas Elétricos I. Título 


\section{UNIVERSIDADE DE SÃO PAULO \\ PROGRAMA DE PÓS-GRADUAÇÃO EM ENERGIA \\ EP - FEA - IEE - IF \\ SÉRGIO RICARDO CAMPOS BEZERRA}

"Avaliação de sistemas de aterramento considerando a utilização de condutores e hastes envolvidos em concreto"

Dissertação defendida e aprovada pela Comissão Julgadora:

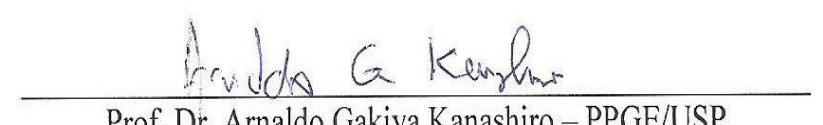

Prof. Dr. Arnaldo Gakiya Kanashiro - PPGE/USP

Orientador e Presidente da Comissão Julgadora

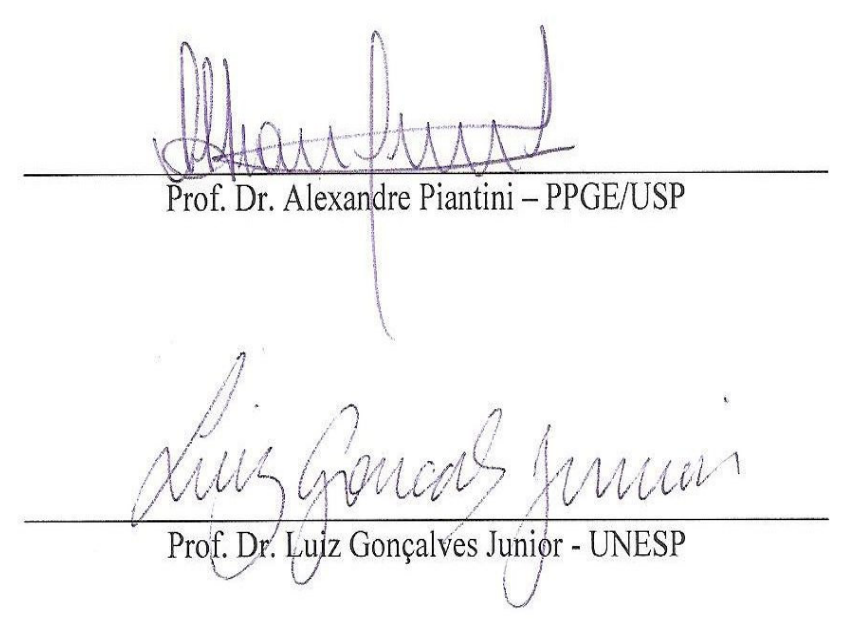


DEDICATÓRIA

A Deus, em primeiro lugar.

À minha amada esposa, Vivian.

Aos meus pais, Abraão e Normélia. 


\section{AGRADECIMENTOS}

A Universidade de São Paulo, em especial ao Instituto de Eletrotécnica e Energia, pela oportunidade de crescimento profissional durante o curso;

Ao Prof. Dr. Arnaldo Gakiya Kanashiro, meu orientador, pelo apoio, dedicação, disposição, cooperação e compreensão. Pessoa atenciosa e solícita, contribuiu em todas as etapas deste trabalho;

Aos meus pais Abraão e Normélia pelo exemplo, carinho e apoio. Eles sempre foram meus amigos de todas as horas;

À minha amada esposa, Vivian Akemi, pelo apoio, compreensão e amizade;

A todos que contribuíram direta ou indiretamente para a construção deste trabalho;

A todos da Seção Técnica de Estudos do IEE-USP, em especial ao Mestre Paulo Futoshi Obase que contribuiu com informações importantes para o desenvolvimento desse trabalho;

Às funcionárias da biblioteca do IEE que sempre foram atenciosas todas as vezes que precisei de alguma informação;

A todos os alunos pela amizade que fiz durante o curso;

A todos os professores do Programa de Pós-Graduação em Energia da USP;

Aos professores Prof. Dr. Fernando Selles Ribeiro e Prof. Dr. Alexandre Piantini, pelas valiosas sugestões para o desenvolvimento desse trabalho;

Ao professor Dr. Luiz Gonçalves Junior, pelas sugestões;

Ao grande amigo, engenheiro químico Renato Mariano Barbosa.

Não desista.

“O vôo até a lua não é tão longe.

As distâncias maiores que devemos percorrer estão dentro de nós mesmos. "

(Charles de Gaulle) 


\section{RESUMO}

BEZERRA, Sergio Ricardo Campos. Avaliação de sistemas de aterramento considerando a utilização de condutores e hastes envolvidos em concreto. 2011. 161f. Dissertação (Mestrado em Ciências) - Programa de Pós-Graduação em Energia da Universidade de São Paulo, São Paulo, 2011.

$\mathrm{O}$ aterramento elétrico cumpre uma função essencial em um sistema de distribuição de energia elétrica, devendo atender, dentre vários requisitos, aqueles estabelecidos quanto aos valores de tensão de passo e de toque. Entretanto, em locais onde o solo apresenta valores elevados de resistividade, surgem dificuldades que nem sempre são superadas no sentido de obedecer às exigências citadas nas normas técnicas e especificações. Dentro deste contexto, este trabalho tem por objetivo avaliar a utilização de condutores e hastes envolvidos em concreto em sistemas de aterramento, visando à redução dos valores de resistência de terra. Inicialmente é abordada uma configuração convencional de malha de aterramento adotada por uma concessionária de energia elétrica, sendo realizados estudos de modo a verificar a influência do espaçamento e da quantidade das hastes nos valores de resistência de terra. São também consideradas modificações nas dimensões da malha e a utilização de hastes profundas e, na seqüência, são analisados os resultados de outras configurações. De modo a verificar a efetividade do uso do concreto, foram realizadas várias simulações computacionais considerando o sistema de aterramento com a utilização de condutores e hastes envolvidos em concreto. Diversas situações foram investigadas, sendo possível concluir que o uso do concreto resulta em menores valores de resistência de terra em relação às malhas convencionais. Esse resultado, de certo modo, vem ao encontro das expectativas, porém deve ser ressaltada a contribuição do trabalho, a qual possibilita a análise, através de cálculos teóricos, do comportamento das malhas de aterramento com o uso do concreto. A literatura pesquisada apresenta poucos resultados teóricos, sendo encontradas algumas investigações nesse tema onde são consideradas somente medições realizadas no campo.

Palavras - chave: Aterramento elétrico, haste envolvida em concreto, malha de aterramento, resistência de terra, resistividade do solo. 


\begin{abstract}
BEZERRA, Sergio Ricardo Campos. Evaluation of grounding systems considering the use of conductors and rods encased in concrete. 2011. 161f. (Master's Dissertation) - Graduate Program on Energy, Universidade de São Paulo, São Paulo, 2011.

The electrical grounding plays an essential role in a system of electric power distribution, and must follow, among many requirements, those ones established as step voltage values and touch voltage values. However, in those places where the soil has high resistivity values, some difficulties arise and may not always be overcomed in order to follow the requirements set forth in technical standards and specifications. In this context, the aim of this study is to evaluate the use of electrical conductors and rods encased in concrete inside grounding systems, in order to reduce the ground resistance values. Initially it was observed a conventional configuration of grounding grid that is used by an electric utility, and studies were made in order to verify the influence of the number of rods and the distance between them in the values of grounding resistance. There are also been taken into consideration the changes in the grounding grid dimensions and the use of deep rods and, right after, the results of other configurations are analyzed. In order to verify the effectiveness of the use of concrete, several computer simulations were performed considering the grounding system that used conductors and rods encased in concrete. Several situations were investigated, and it was possible to conclude that the use of concrete results in lower values of ground resistance compared to conventional grounding grid. This result, in a certain way, matches with the expectations, but it should be emphasized the contribution of the study which enables, through theoretical calculations, the analysis of the grounding grid behavior with the use of concrete. The literature shows few theoretical results and presents only some researches on this issue in which ones only measurements made in the field are considered.
\end{abstract}

Keywords: Electrical grounding, rods encased in concrete, grounding grid, grounding resistance, soil resistivity. 


\section{LISTA DE FIGURAS}

Figura 1 - Sistema de distribuição de energia elétrica. ..........................................................25

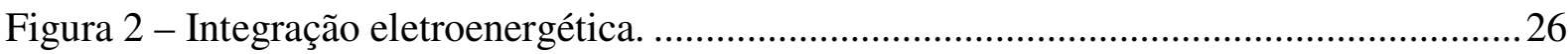

Figura 3 - Configuração das redes de distribuição............................................................ 27

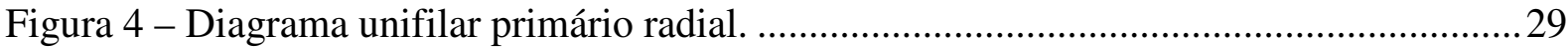

Figura 5 - Diagrama unifilar primário seletivo................................................................ 30

Figura 6 - Diagrama unifilar primário em malha aberta......................................................... 31

Figura 7 - Diagrama unifilar de uma rede spot network. .................................................... 31

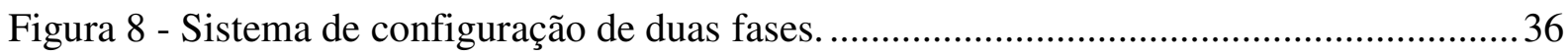

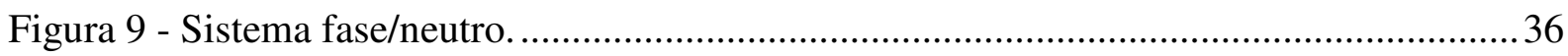

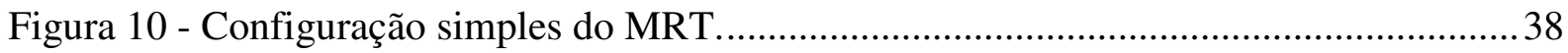

Figura 11 - Sistema monofilar com transformador isolador..................................................39

Figura 12 - Sistema monofilar com neutro parcial............................................................. 40

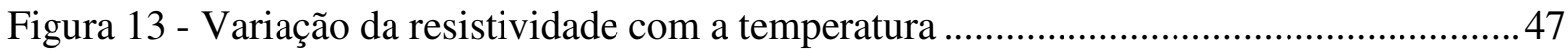

Figura 14 - Método de Wenner para medição da resistividade do solo..................................49

Figura 15 - Método para medição da resistividade do solo utilizando voltímetro e

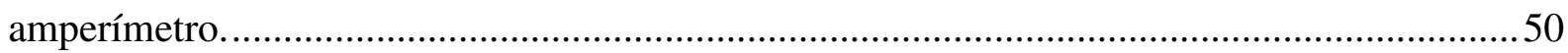

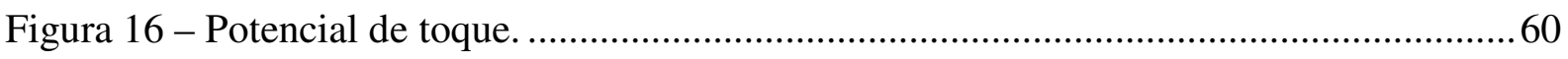

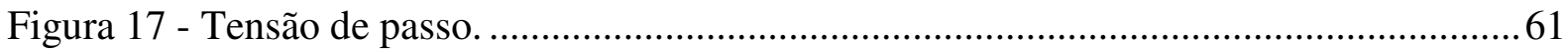

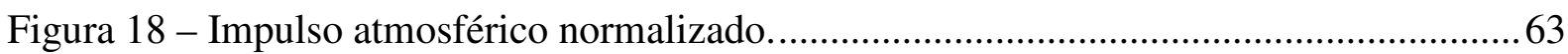

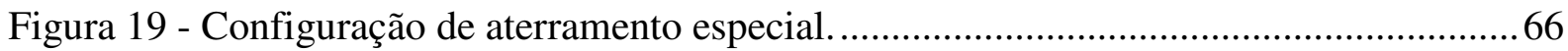

Figura 20 - Configuração de aterramento CEEE-RS 1 $1^{\text {a }}$ opção............................................... 70

Figura 21 - Configuração de aterramento CEEE-RS $2^{\mathrm{a}}$ opção............................................. 70

Figura 22 - Sistema de aterramento com uma haste envolvida em concreto. .........................78 
Figura 23 - Sistema de aterramento com três hastes envolvidas em concreto.

Figura 24 - Valores de resistência de terra para haste de 1,5 m convencional e para haste de $1,5 \mathrm{~m}$ tratada com bentonita

Figura 25 - Valores de resistência de terra para haste de $3 \mathrm{~m}$ convencional e para haste de $3 \mathrm{~m}$ tratada com bentonita

Figura 26 - Ferragens do poste

Figura 27 - Detalhes técnicos dos sistemas de aterramento utilizados. (a) sistema de aterramento convencional. (b) sistema de aterramento com hastes envolvidas em concreto...85

Figura 28 - Comportamento da resistência de terra em um sistema de aterramento com configuração convencional (aterramento tradicional) e com haste envolvida em concreto durante o período chuvoso.

Figura 29 - Comportamento da resistência de terra em um sistema de aterramento com configuração convencional (aterramento tradicional) e com haste envolvida em concreto durante o período seco

Figura 30 - Malha com tratamento químico.

Figura 31 - Comportamento da resistência de terra em um sistema de aterramento com configuração convencional (aterramento tradicional) e com haste com tratamento quimico durante o período chuvoso.

Figura 32 - Comportamento da resistência de terra em um sistema de aterramento com configuração convencional (aterramento tradicional) e com haste com tratamento químico durante o período seco

Figura 33 - Composto envolvendo a haste de aterramento ...................................................90

Figura 34 - Pilotos de resistividade em profundidade g e h................................................91

Figura 35 - Piloto de resistividade, utilizado para medir a resistividade ................................92

Figura 36 - Campo experimental em solo rochoso de calcário ..............................................93

Figura 37 - Campo experimental em solo de rocha vulcânica ...............................................93

Figura 38 - Resistência de terra de hastes de aterramento localizadas no solo rochoso de calcário

Figura 39 - Resistência de terra de hastes de aterramento localizadas em solo de rocha vulcânica 
Figura 40 - Medições de resistividade obtidas pelos pilotos para a substância 4 (pó químico)

Figura 41 - Medições de resistividade obtidas pelos pilotos para a substância 4 (pó químico)

Figura 42 - Medições de resistência de terra obtidas pelos pilotos com o composto 2 em solo de rocha vulcânica

Figura 43 - Medições de resistência de terra obtidas pelos pilotos com o composto 2

em solo rochoso e calcário para haste de aterramento

Figura 44 - Malha padrão CELTINS (12 hastes).

Figura 45 - Simulação dos casos 7 a 10.

Figura 46 - Influência do espaçamento entre hastes (resistência de terra casos 1, 2, 3 e 6)... 102

Figura 47 - Influência do espaçamento entre hastes (tensão de toque casos 1, 2, 3 e 6)........103

Figura 48 - Influência do espaçamento entre hastes (tensão de passo casos 1, 2, 3 e 6)........ 103

Figura 49 - Influência do comprimento da haste (casos 3, 4, 5). 105

Figura 50 - Influência do comprimento da haste (tensão de toque casos 3, 4 e 5)..... 105

Figura 51 - Influência do comprimento da haste (tensão de passo casos 3, 4, e 5). 106

Figura 52 - Influência da quantidade de hastes e geometria interna da malha (casos $1,7,8$ e 10)

Figura 53 - Influência da quantidade de hastes e geometria interna da malha 108

Figura 54 - Influência da quantidade de hastes e geometria interna da malha 108

Figura 55 - Configuração da malha em triângulo (12 hastes)

Figura 56 - Configuração da malha em anéis (13 hastes)

Figura 57 - Configuração convencional com hastes alinhadas.

Figura 58 - Configuração com hastes e condutores concretados.

Figura 59 - Malha convencional em forma de V

Figura 60 - Malha convencional e malha concretada ( $\left.\rho_{\text {solo }} 100 \Omega . m\right)$

Figura 61 - Malha convencional x Malha concretada ( $\left.\rho_{\text {solo }} 1000 \Omega . m\right)$ 122 
Figura 62 - Malha convencional x Malha concretada $\left(\rho_{\text {solo }} 3000\right.$ S.m)................................ 122

Figura 63 - Malha convencional x Condutor concretado $\left(\rho_{\text {solo }} 3000 \Omega . m\right)$............................ 128

Figura 64 - Tensão de passo em baixa frequência (caso 1) ................................................ 131

Figura 65 - Tensão de passo em alta freqüência (caso 1) .................................................... 131

Figura 66 - Tensão de passo em baixa freqüência (caso 7)................................................. 132

Figura 67 - Tensão de passo em alta frequência (caso 7) ................................................. 133

Figura 68 - Configuração de rede de distribuição................................................................ 140

Figura 69 - Configuração utilizada para representar a carga no consumidor. ....................... 141

Figura 70 - Tensão fase-neutro no consumidor. .......................................................... 144

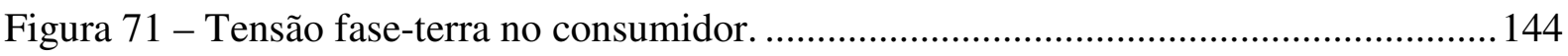

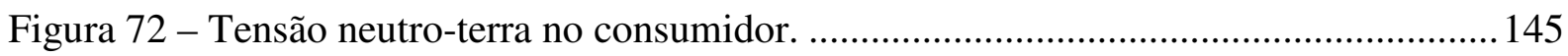

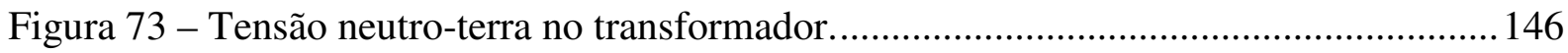




\section{LISTA DE TABELAS}

Tabela 1 - Resistividade de algumas regiões do Brasil. ..........................................................44

Tabela 2 - Valores de resistividade de alguns tipos de solos...............................................45

Tabela 3 - Concentração de umidade em solo arenoso. ........................................................46

Tabela 4 - Influência da concentração de sais na resistividade do solo. ..................................47

Tabela 5 - Materiais comumente utilizáveis em eletrodos de aterramento. ............................54

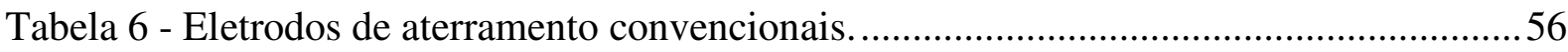

Tabela 7 - Seções mínimas convencionais de condutores de aterramento..............................57

Tabela 8 - Resistência de terra por transformador (COPEL). ............................................67

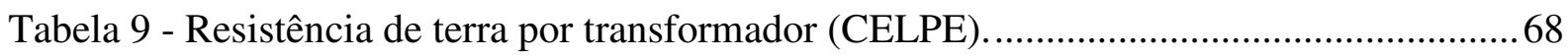

Tabela 10 - Resistência de terra por transformador (CEEE) .............................................69

Tabela 11 - Valores máximos de resistência de terra por potência dos transformadores

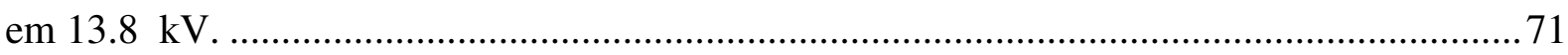

Tabela 12 - Malhas convencionais (aço cobreado). ............................................................ 77

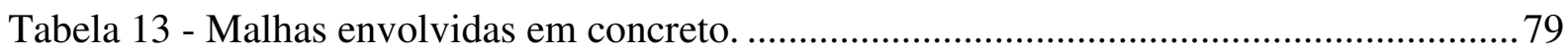

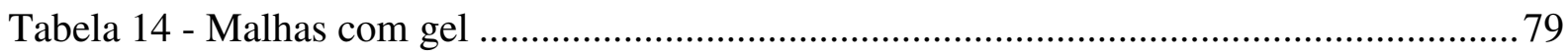

Tabela 15 - Valores de resistência de terra com uso do poste ................................................ 80

Tabela 16 - Resistência de terra do poste de concreto em relação a uma haste de $3 \mathrm{~m}$ de

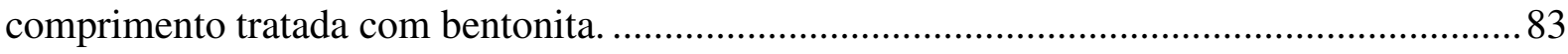

Tabela 17 - Influência do espaçamento entre hastes $(\rho=500 \Omega . m)$..................................... 101

Tabela 18 - Influência do comprimento das hastes ............................................................. 104

Tabela 19 - Quantidade de hastes e geometria interna da malha (Casos 1, 7, 8, 9 e 10)....... 107

Tabela 20 - Valores de resistência de terra e valores máximos de tensão de passo e toque em função da resistividade do solo (casos 1 ao 5) ................................................................ 110 
Tabela 21 - Valores de resistência de terra e valores máximos de passo e toque em função da resistividade do solo (casos 6 ao 10)

Tabela 22 - Valores de resistência de terra para configurações em triângulo e anéis concêntricos.

Tabela 23 - Valores de resistência de terra (1 e 2 hastes).................................................. 117

Tabela 24 - Valores de resistência de terra (3 hastes). ....................................................... 118

Tabela 25 - Valores de resistência de terra (4 hastes). ....................................................... 118

Tabela 26 - Valores de resistência de terra (5 hastes). ......................................................... 119

Tabela 27 - Valores de resistência de terra (6 hastes). ...................................................... 119

Tabela 28 - Valores de resistência de terra (7 a 12 hastes).................................................... 120

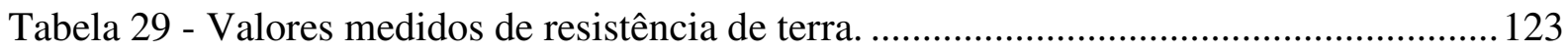

Tabela 30 - Valores de resistência de terra obtidos nas simulações computacionais............. 124

Tabela 31 - Valores de resistência de terra medidos em campo e obtidos nas simulações

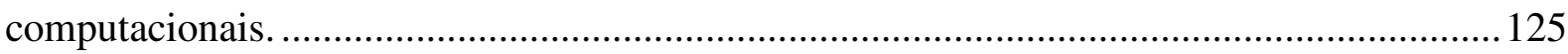

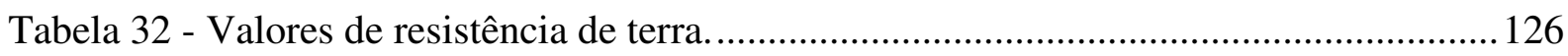

Tabela 33 - Valores de resistência de terra para malha convencional e com o condutor concretado.

Tabela 34 - Valores da impedância de terra (Zat) em função da freqüência para $\mathrm{I}=15 \mathrm{kA}$ e $45 \mathrm{kA}$, para a malha padrão (caso 1 ).

Tabela 35 - Valores da impedância de terra (Zat) em função da freqüência para uma haste envolvida em concreto.

Tabela 36 - Valores da impedância de terra (Zat) em função freqüência para uma haste convencional.

Tabela 37 - Valores da impedância de terra (Zat) em função da frequiência para

2 hastes convencionais alinhadas.

Tabela 38 - Valores da impedância de terra (Zat) em função da frequiência para

2 hastes alinhadas envolvidas em concreto.

Tabela 39 - Valores da impedância de terra (Zat) em função da freqüência para 6 hastes convencionais alinhadas. 
Tabela 40 - Valores da impedância de terra (Zat) em função da frequiência para seis hastes alinhadas envolvidas em concreto. 


\section{LISTA DE SIGLAS}

ABNT - Associação Brasileira de Normas Técnicas

ANEEL - Agência Nacional de Energia Elétrica

ATP - Alternative Transients Program

CAA - Condutor de alumínio com alma de aço

CDE - Conta de Desenvolvimento Energético

CDEGS - Current Distribution, Electromagnetic Fields, Grounding and Soil Structure Analysis

CEEE - SUL - Companhia Estadual de Energia Elétrica do Rio Grande do Sul

CELESC - Companhia Elétrica de Santa Catarina

CELPE - Companhia Energética de Pernambuco

CELTINS - Companhia de Energia Elétrica de Tocantins

CEMIG - Centrais Elétricas de Minas Gerais

CEPEL - Centro de Pesquisas de Energia Elétrica

COELCE - Companhia Energética do Ceará

COPEL - Companhia Paranaense de Energia

CPFL - Companhia Paulista de Força e Luz

IBGE - Instituto Brasileiro de Geografia e Estatística

IEEE - Institute of Electrical and Electronics Engineers

MME - Ministério de Minas e Energia

MRT - Monofilar com retorno por terra

NBR - Norma Brasileira

ONS - Operador Nacional do Sistema Elétrico

PLC - Programa Luz no Campo

RGR - Reserva Global de Reversão 


\section{LISTA DE SÍMBOLOS}

\begin{tabular}{|c|c|}
\hline$\%$ & - porcentagem \\
\hline $\boldsymbol{\Omega}$ & - ohm \\
\hline$\Omega . \mathbf{m}$ & - ohm.m \\
\hline$\rho s$ & - resistividade superficial do solo \\
\hline $\boldsymbol{\mu}$ & - micro \\
\hline${ }^{\circ} \mathbf{C}$ & - grau Celsius \\
\hline $\mathbf{A}$ & - ampère \\
\hline cm & - centímetro \\
\hline d & - diâmetro da haste \\
\hline $\mathbf{H z}$ & - Hertz \\
\hline $\mathbf{k}$ & - quilo \\
\hline $\mathbf{k A}$ & - quiloampère \\
\hline $\mathbf{k} \mathbf{V}$ & - quilovolt \\
\hline $\mathbf{L}$ & - comprimento da haste \\
\hline $\mathbf{m}$ & - metro \\
\hline $\mathbf{m}^{2}$ & - metro quadrado \\
\hline MHz & - megahertz \\
\hline mm & - milímetro \\
\hline $\mathbf{m m}^{2}$ & - milímetro quadrado \\
\hline$\varnothing$ & - diâmetro \\
\hline Rch & - resistência do corpo humano \\
\hline
\end{tabular}


S

$\mathbf{t}$

V

pa

- segundos

- tempo

- volt

- resistividade aparente do solo 


\section{SUMÁRIO}

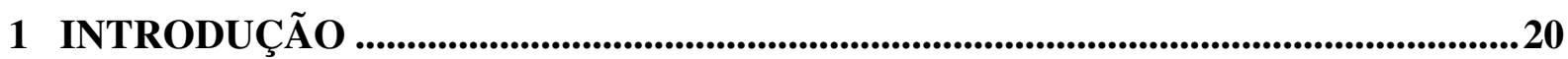

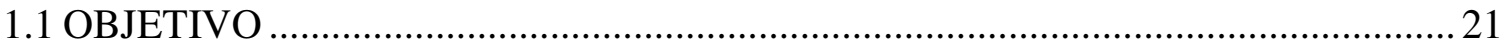

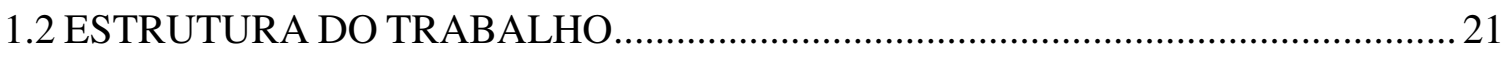

2 SISTEMAS DE DISTRIBUIÇÃO DE ENERGIA ELÉTRICA ......................................23

2.1 COMPOSIÇÃO DO SISTEMA DE DISTRIBUIÇÃO DE ENERGIA

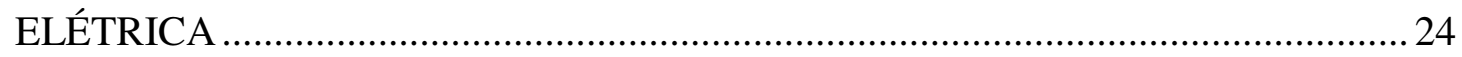

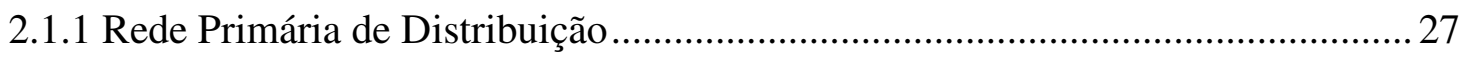

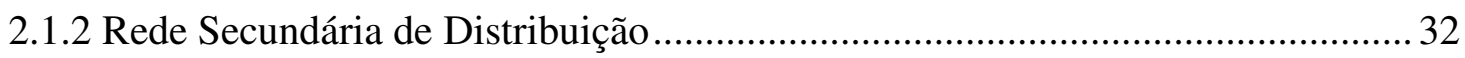

2.2 REDES DE DISTRIBUIÇÃO DE ENERGIA ELÉTRICA RURAL .................................

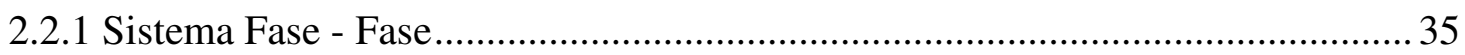

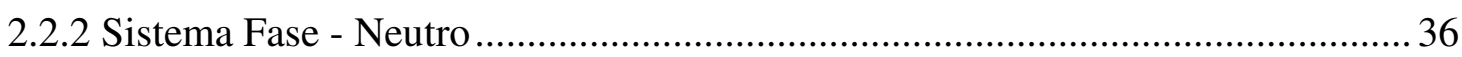

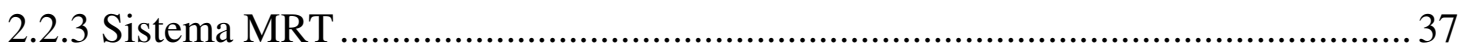

2.3 TENSÕES DE FORNECIMENTO NA REDE PRIMÁRIA ………………………...... 40

2.4 TENSÕES DE FORNECIMENTO NA REDE SECUNDÁRIA .................................... 41

3 ATERRAMENTO ELÉTRICO .....................................................................................42

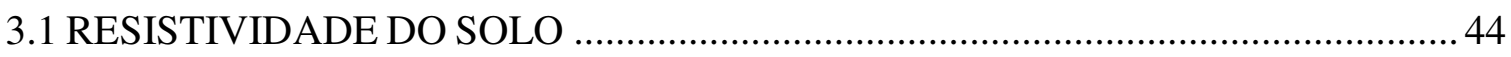

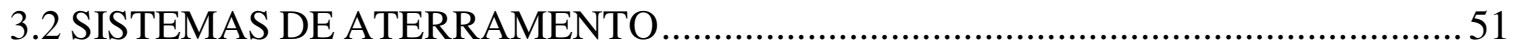

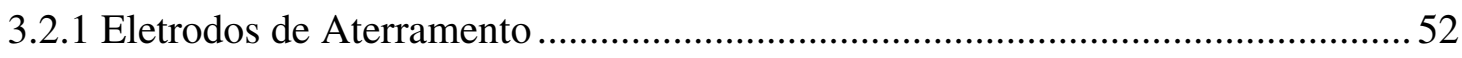

3.2.2 Potenciais de Passo e de Toque ........................................................................58

3.2.3 Comportamento de Sistema de Aterramento em Função da Freqüência............... 62

4 SISTEMAS DE ATERRAMENTO UTILIZADOS NAS REDES DE DISTRIBUIÇÃO URBANAS E RURAIS ..................................................................................................................64

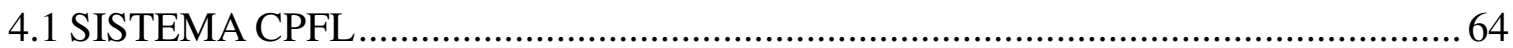

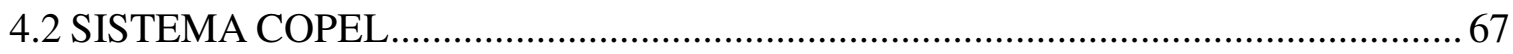

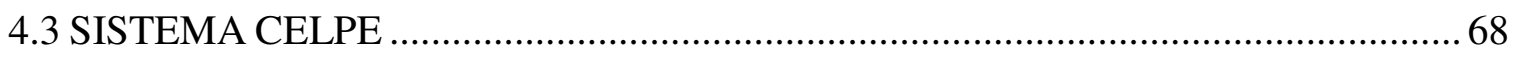

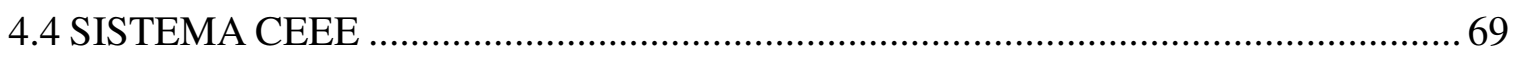

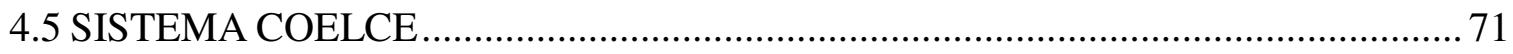

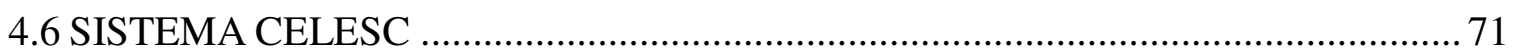

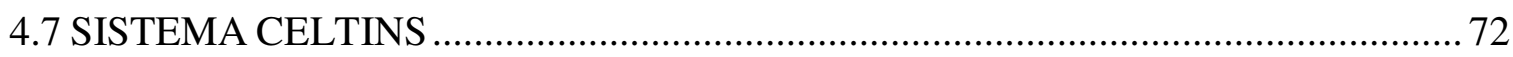

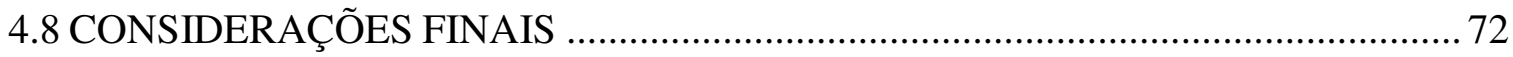




\section{HASTES E CONDUTORES DE ATERRAMENTO ENVOLVIDOS EM CONCRETO}

5.1 MEDIÇÕES DE RESISTÊNCIA DE TERRA EM SISTEMAS DE ATERRAMENTO UTILIZANDO CONDUTORES E HASTES ENVOLVIDOS EM CONCRETO E HASTES CONVENCIONAIS ..........................76

5.2 MEDIÇÃO DE RESISTÊNCIA DE TERRA EM SISTEMA DE ATERRAMENTO TRATADO COM BENTONITA .............................................. 81

5.3 MEDIÇÕES DE RESISTÊNCIA DE TERRA EM SISTEMAS DE ATERRAMENTO COM HASTES CONVENCIONAIS E ENVOLVIDAS EM CONCRETO.

5.4 MEDIÇÕES DE RESISTÊNCIA DE TERRA EM SISTEMAS DE ATERRAMENTO CONSIDERANDO SOLO DE DIFERENTES

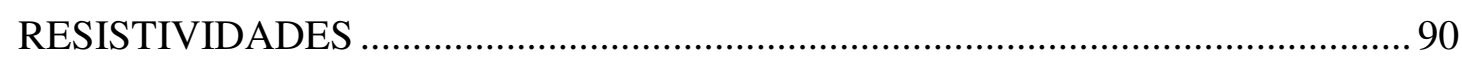

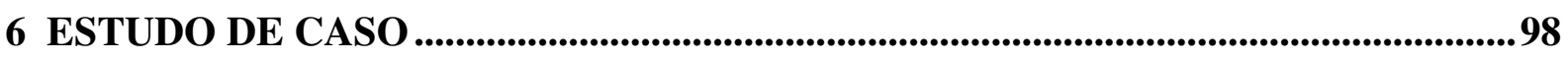

6.1 SISTEMAS DE ATERRAMENTO COM HASTES E CONDUTORES CONVENCIONAIS 99

6.1.1 Configurações de Aterramento Constituídas por Malha Reticulada .................. 100

6.1.2 Outras Configurações de Aterramento .......................................................... 112

6.2 SISTEMAS DE ATERRAMENTO COM HASTES E/OU CONDUTORES ENVOLVIDOS EM CONCRETO

6.2.1 Avaliação do Comportamento de Hastes e Condutores Envolvidos em Concreto

6.2.2 Configurações de Aterramento Constituídas por Malha Reticulada com Hastes e Condutores Envolvidos em Concreto. 126

6.2.3 Configuração condutor de interligação envolvido em concreto 127

6.3 COMPORTAMENTO DA IMPEDÂNCIA DE ATERRAMENTO EM FUNÇÃO DA FREQUÊNCIA.

6.4 ANÁLISE DA INFLUÊNCIA DE RESISTÊNCIA DE TERRA NO CONSUMIDOR DURANTE UMA DESCARGA ATMOSFÉRICA DIRETA NA REDE PRIMÁRIA. 


\section{INTRODUÇÃO}

O aterramento elétrico é de fundamental importância em um sistema distribuição de energia elétrica, sendo uma ligação intencional a terra com o objetivo de fornecer à instalação um caminho de impedância adequada por onde pode circular uma corrente elétrica, seja ela, derivada de uma falta ou descarga atmosférica. A corrente de falta é uma corrente elétrica que circula em um caminho fechado incluindo a fonte e a carga. No caso da descarga atmosférica, a corrente do raio circula pela terra para neutralizar as cargas induzidas no solo. A circulação de correntes no solo dá origem ao aparecimento das tensões de toque e passo.

Os valores de gradientes de tensão que aparecem na superfície do solo devem estar dentro dos limites suportáveis por animais e seres humanos (NBR 14039, 2005) e (CUNHA, 2003), proporcionando uma superfície equipotencial no solo dentro dos valores aceitáveis de tensão de passo e toque.

No desenvolvimento do projeto de sistemas de aterramento são utilizadas a faixa de freqüência industrial (baixa freqüência $50 \mathrm{~Hz}$ e $60 \mathrm{~Hz}$ ) e as freqüências que surgem devido a descargas atmosféricas (alta freqüência 0,5-1,2 $\mathrm{MHz}$ ). O primeiro passo para projetar o sistema de aterramento é conhecer a resistividade do solo e estabelecer um modelo que represente o meio onde as hastes de aterramento serão instaladas (TELLÓ, 2007).

A preocupação no projeto está em reduzir as sobretensões e na determinação do menor valor possível da resistência de terra oferecida ao escoamento da corrente elétrica, não permitindo que sejam ultrapassados os valores de potenciais de toque e passo, que originariam correntes pelo corpo humano acima dos valores permissíveis (RIBEIRO et al, 2003) e (AFFONSO, 2001). Entretanto, as concessionárias de energia, geralmente, encontram dificuldades para atender os requisitos das normas e especificações técnicas, principalmente, em função de valores elevados de resistividade do solo na sua área de concessão.

Este trabalho considera, inicialmente, a malha de aterramento da concessionária de energia elétrica CELTINS, localizada no estado de Tocantins, cuja área de concessão apresenta valores elevados de resistividade do solo.

Para o desenvolvimento do trabalho foi utilizado o software de elementos finitos CDEGS (Current Distribution, Electromagnetic Fields, Grounding and Soil Structure Analysis), versão 
2000 (CDEGS, 2000). Esse programa é de origem canadense e permite a análise da estratificação do solo por camadas, a simulação de malhas de aterramento e o cálculo das tensões de passo e de toque. Os cálculos de potencial de passo, toque e transferência são gerados pelo CDEGS de acordo com as normas definidas pelo usuário. Padrões diferentes podem ser escolhidos (IEEE, IEC).

\subsection{OBJETIVO}

O objetivo do trabalho é a avaliação da utilização de condutores e hastes envolvidos em concreto em sistemas de aterramento, visando à redução dos valores de resistência de terra. A avaliação é realizada através da comparação de resultados de simulações computacionais, considerando-se malhas de aterramento convencionais e malhas com a utilização do concreto nos condutores e/ou nas hastes.

\subsection{ESTRUTURA DO TRABALHO}

O trabalho está organizado em seis capítulos. No capítulo 1 são apresentados os objetivos e a estrutura do trabalho.

O capítulo 2, além da apresentação de uma introdução geral, a eletrificação rural é o destaque deste capítulo, portanto, é feita uma abordagem bibliográfica considerando-se a composição do sistema de distribuição de energia elétrica, constituídas pelas redes primária e secundária, urbanas e rurais. 
No capítulo 3 são apresentados os principais tópicos relacionados ao aterramento elétrico, sendo considerados, a resistividade e o tipo do solo, eletrodos e sistemas de aterramento, potenciais de toque e de passo.

No capítulo 4 é apresentada uma abordagem sobre as configurações de sistemas de aterramento elétrico utilizadas nas redes de distribuição urbana e rural, que são adotadas por algumas concessionárias brasileiras.

O capítulo 5 apresenta as investigações encontradas na literatura sobre a utilização do concreto em sistemas de aterramento, as quais mostram resultados obtidos em medições realizadas no campo.

O capítulo 6 apresenta a avaliação de várias configurações de aterramento, sendo considerada, inicialmente, a malha de aterramento padrão de uma concessionária de energia elétrica. Posteriormente, é analisado o comportamento de malhas com outras configurações. Em seguida, a utilização do concreto em sistemas de aterramento é avaliada, sendo apresentados os resultados e a comparação com as malhas convencionais.

O capítulo 7 apresenta as conclusões da pesquisa e sugestões para trabalhos futuros 


\section{SISTEMAS DE DISTRIBUIÇÃO DE ENERGIA ELÉTRICA}

Na história da sociedade a energia elétrica tem ocupado lugar de destaque, considerandose a melhoria na qualidade de vida e o desenvolvimento econômico.

A energia elétrica é fundamental para o desenvolvimento da sociedade, oferecendo aos cidadãos conforto, bem estar, comodidade, além de proporcionar trabalho, produção de bens e serviços.

De acordo com GOEKING (2010), o uso da energia elétrica teve seu progresso impulsionado pelo surgimento de tecnologias para sua distribuição, que se desenvolveu devido à demanda crescente de indústrias, porém, sua primeira aplicação se deu na iluminação pública e com esse tipo de serviço foi se expandindo, contribuindo para a distribuição da energia elétrica.

Em 1880, a demanda por energia elétrica cresceu em muitas cidades e como a instituição pública não possuía recursos para realizar a implantação adequada e satisfatoriamente, o sistema de concessão para prestação de serviços públicos foi criado para suprir essa necessidade (GOEKING, 2010). Diante desse fato, surgiram, as concessionárias que são responsáveis pela distribuição de energia elétrica aos centros consumidores com o objetivo de satisfazer as necessidades do ser humano.

A distribuição de energia é considerada um monopólio natural. Este serviço de distribuição é um serviço público e o Estado tem o dever de garantir seu funcionamento. Há duas possibilidades para continuar executando essa tarefa: o Estado tem que operar o sistema de distribuição assumindo o papel de empreendedor ou o Estado delegar essa função a empresas privadas, ficando somente a tarefa de regular e fiscalizar a prestação do serviço para o Estado.

Pode-se entender o processo de distribuição de energia elétrica como se fosse uma venda a varejo de um produto, por exemplo, a comercialização de serviços diretamente ao consumidor final. A transmissão seria a venda desse produto no atacado, quer dizer a venda em grande quantidade para determinadas empresas, para posteriormente ser vendida no varejo em pequenos pacotes para os consumidores finais. A energia elétrica é distribuída aos 
consumidores situados no centro urbano e em zonas rurais, através de diversas redes de média e baixa tensão (GRIMONI et al., 2004).

As concessionárias de energia elétrica são responsáveis pela compra de grandes quantidades de energia elétrica das empresas geradoras e pela adequação dos níveis de tensão da energia recebida das empresas transmissoras com o objetivo de transportá-la a grandes e pequenas cidades. Ainda é de responsabilidade das concessionárias de energia elétrica manter a rede de distribuição e as instalações funcionando adequadamente, além de prestar serviço técnico-comercial aos seus consumidores industriais de médio e pequeno porte e residenciais.

A Agência Nacional de Energia Elétrica - ANEEL é responsável pela regulação e fiscalização da produção, transmissão, distribuição de energia elétrica e a comercialização de energia, conforme Resolução 456 de 2000 (ANEEL, 2010).

\subsection{COMPOSIÇÃO DO SISTEMA DE DISTRIBUIÇÃO DE ENERGIA ELÉTRICA}

O sistema de distribuição é composto pela subtransmissão, que recebe energia da rede de transmissão, e pelas redes primária e secundária. O principal objetivo desse sistema é levar energia elétrica para todos os consumidores que desejam adquirir energia e, para que isso ocorra, o consumidor (pessoa física ou jurídica) deve solicitar à concessionária o fornecimento de energia elétrica e assumir a responsabilidade pelo pagamento das faturas e pelas demais obrigações fixadas em normas e regulamentos da ANEEL (ANEEL, 2010).

A subtransmissão recebe energia elétrica da rede de transmissão com objetivo de transferí-la às subestações de distribuição e aos consumidores, em tensão de subtransmissão, através de linhas trifásicas operando, usualmente, em tensões de $138 \mathrm{kV}$ ou $69 \mathrm{kV}$. A Figura 1 ilustra um sistema de distribuição de energia elétrica. 


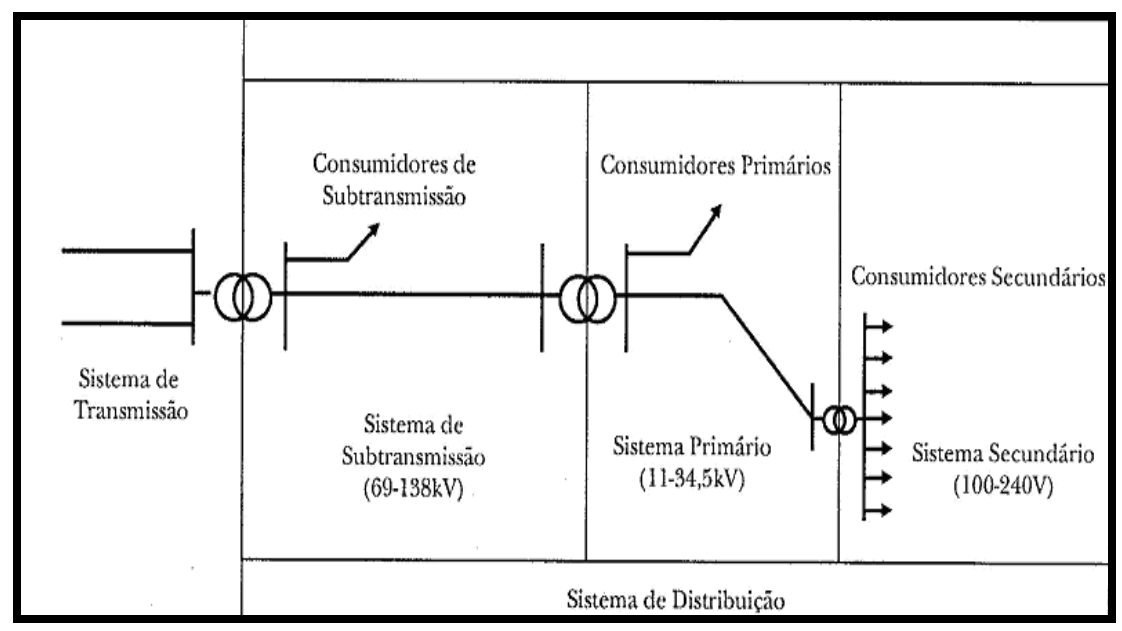

Figura 1 - Sistema de distribuição de energia elétrica.

Fonte: (GRIMONI et al., 2004)

A subtransmissão é composta por subestações terminais da transmissão, linhas de subtransmissão e subestações de distribuição.

As subestações terminais de transmissão têm as funções a seguir:

- reduzir a tensão de transmissão para a tensão de subtransmissão em níveis padronizados pela concessionária de energia da região local;

- receber a energia em áreas próximas dos grandes centros de consumo;

- distribuir a energia elétrica em caminhos de subtransmissão.

A subtransmissão é constituída de linhas e subestações seccionadoras. Há diversos tipos de redes de subtransmissão com qualidade, confiabilidade e custo. A estrutura destas linhas costuma ser aéreas ou subterrâneas, sendo a linha aérea a mais utilizada devido ao seu custo inferior. A linha subterrânea é considerada segura e possui elevado índice de confiabilidade, porém, o custo ainda é muito elevado, permitindo a sua aplicação em situações especiais. As subestações que são atendidas pela rede de subtransmissão têm como responsabilidade a transformação da tensão de subtransmissão para a de distribuição primária. A seguir será apresentado um mapa com os principais centros de carga e linhas de transmissão brasileiras (GRIMONI et al., 2004) e (KAGAN et al., 2005). 


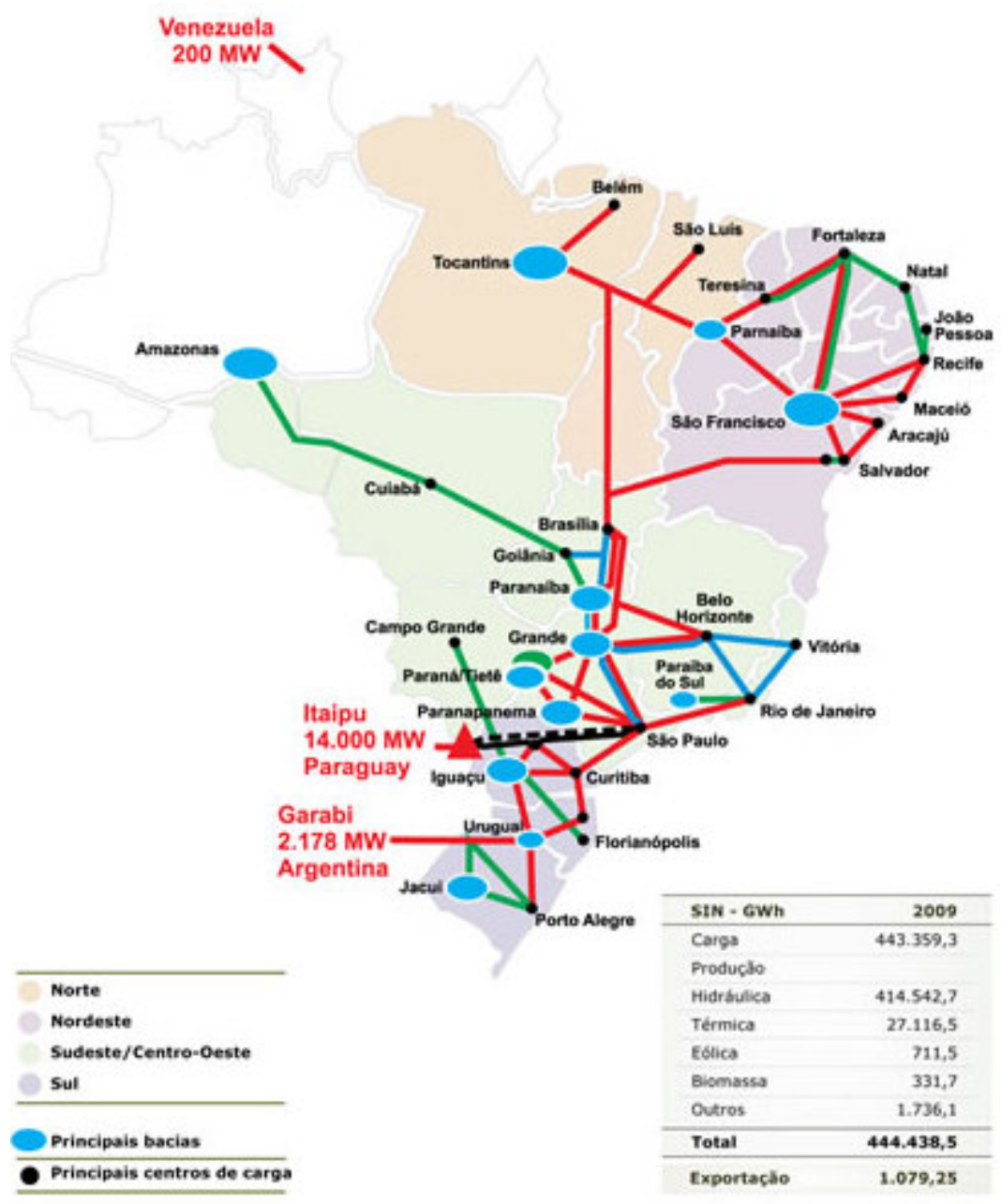

Figura 2 - Integração eletroenergética.

Fonte: (ONS, 2010)

Na Figura 2 podem ser observados os principais centros de carga, as principais bacias de geração de energia elétrica e as linhas de transmissão que variam de $138 \mathrm{kV}$ a $750 \mathrm{kV}$. A interligação destas linhas de transmissão é necessária para maior confiabilidade e a possibilidade de troca entre áreas, pois os ciclos hidrológicos são diferentes em algumas regiões do Brasil. Por exemplo, em São Paulo o período das chuvas corresponde ao verão e do Paraná ao inverno. Portanto, a operação interligada permite que no inverno o Paraná exporte energia para São Paulo e no verão importe energia elétrica de São Paulo, como se fossem estações interligadas por linhas de transmissão (ONS, 2010). 


\subsubsection{Rede Primária de Distribuição}

As redes de distribuição de energia elétrica podem operar tanto em configuração radial, anel ou malhada e um exemplo é apresentado na Figura 3. A escolha de uma destas configurações dependerá de uma série de fatores e da concessionária da região local, que possui normas de construção, manutenção e padrões de operação.

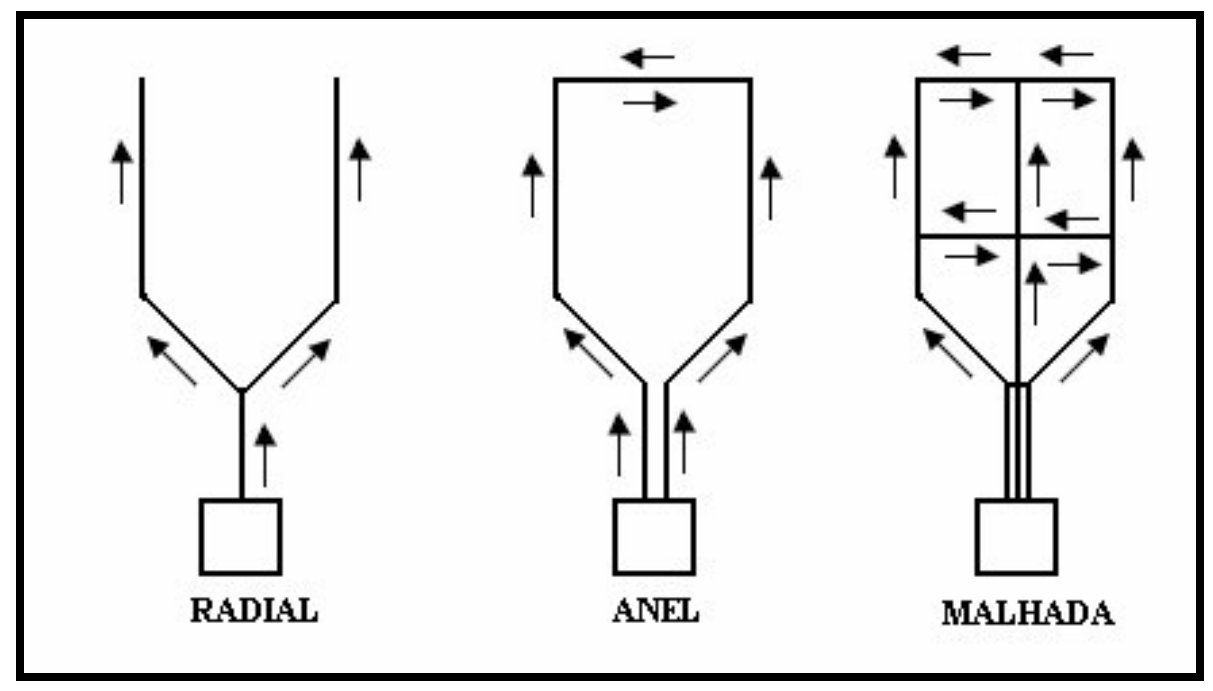

Figura 3 - Configuração das redes de distribuição.

Fonte: SOUZA, 2006.

As configurações geralmente utilizadas nos sistemas de distribuição são levemente malhadas, mas normalmente operando em configuração radial. Portanto, caso ocorra um defeito na linha, será possível fazer uma reconfiguração isolando o ramal com defeito e deixando o mínimo de consumidores sem o fornecimento de energia (SOUZA, 2006).

As redes primárias de distribuição podem ser convencionais aéreas ou subterrâneas. A rede de distribuição primária aérea opera, radialmente, possibilitando a transferência de carga entre circuitos em condição de limite, permitindo à manutenção preventiva ou corretiva. 
Essas redes atendem os consumidores primários e os transformadores de distribuição, onde está conectada a rede secundária.

Os consumidores primários são constituídos de indústrias de porte médio, conjuntos comerciais e instalações de iluminação pública. Como já mencionado anteriormente, as linhas de distribuição de energia podem ser aéreas ou subterrâneas, sendo a linha aérea a mais difundida pelo seu menor custo. A linha subterrânea é mais empregada em áreas de maior densidade de carga ou onde existem restrições paisagísticas (KAGAN et al., 2005) e (JUNIOR, 2009).

As redes primárias aéreas apresentam as seguintes configurações:

Redes aéreas - Primário radial

Estas redes são construídas utilizando-se postes de concreto, tanto em zonas urbanas como em zonas rurais, porém o mais comum em zonas rurais são postes de madeira que suportam cruzetas com 2 metros de comprimento. Costuma-se utilizar condutores de alumínio com alma de aço (CAA) ou sem alma de aço. Em alguns casos, utilizam-se condutores de cobre.

Este tipo de rede conta com um tronco principal do qual são derivados ramais, que geralmente são protegidos por fusíveis. Possui chaves seccionadoras que operam na condição normalmente fechadas (NF) e servem para isolar blocos de carga, permitindo a manutenção corretiva e preventiva. É normal instalar-se no mesmo circuito, ou em circuitos diferentes, chaves que operam normalmente abertas (NA), podendo ser fechadas em manobras de transferência de carga (KAGAN et al., 2005).

Na Figura 4 são apresentados dois circuitos que se derivam da mesma subestação (SE). Na ocorrência de defeito entre as chaves Ch.01 e Ch.02, do circuito 01, haverá a abertura do disjuntor (D) na saída da subestação. 


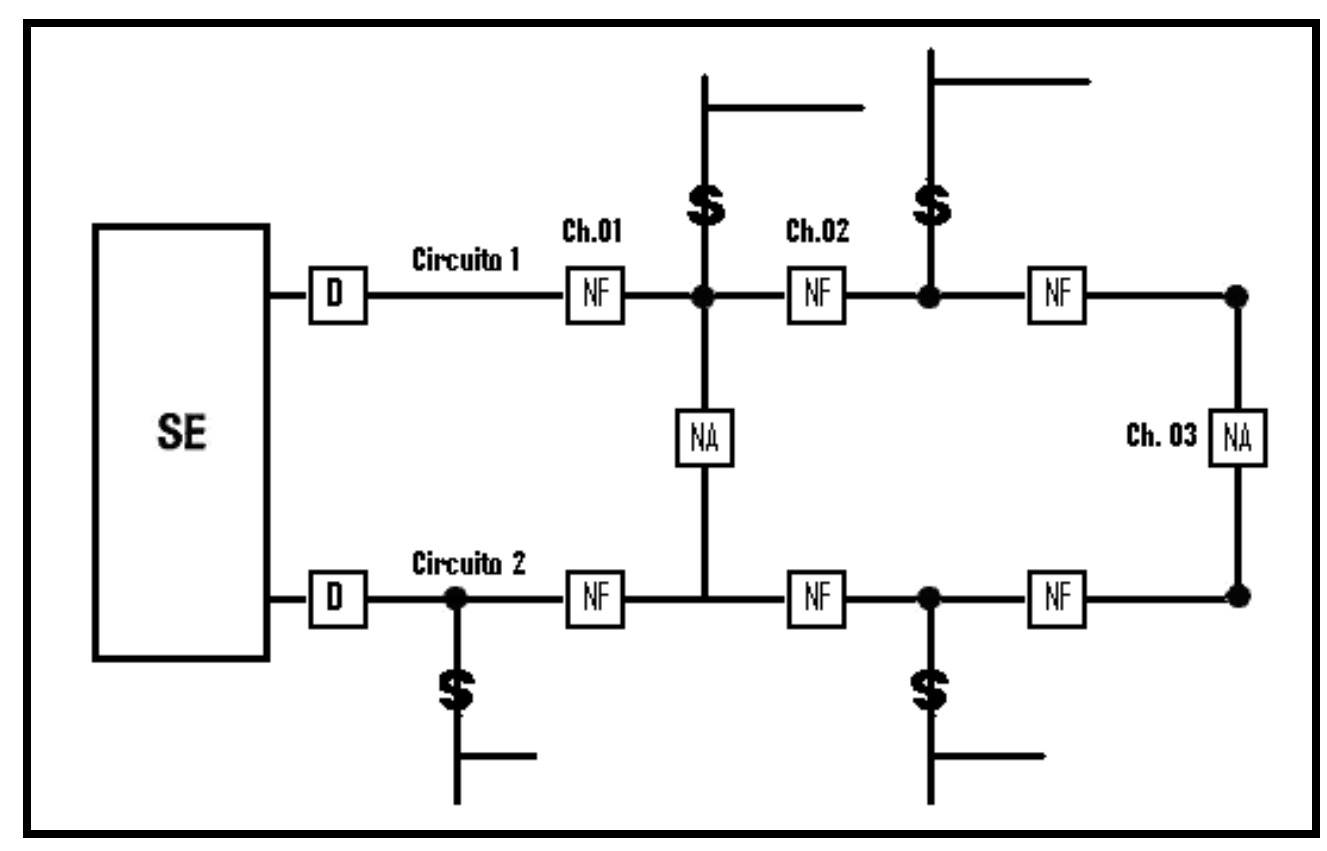

Figura 4 - Diagrama unifilar primário radial.

Fonte: (KAGAN et al., 2005)

O trecho com defeito poderá ser isolado pela abertura das chaves Ch.01 e Ch.02. Após a isolação do trecho com defeito, o disjuntor da subestação é acionado e os consumidores existentes no trecho até a chave 01 são energizados, permanecendo os consumidores da chave Ch.02 desenergizados. O fechamento da chave Ch.03 (NA) restabelecerá o suprimento de energia desses consumidores através do circuito 2 .

Redes aéreas e subterrâneas - Primário seletivo

O primário seletivo se aplica às redes aéreas e subterrâneas, sendo a linha construída em circuito duplo. Os consumidores são ligados nos dois circuitos através de chaves de transferência (cht), ou seja, o consumidor conectado em um dos circuitos é transferido automaticamente para outro circuito em caso de emergência. A chave de transferência do circuito é automática e possui relé que detecta tensão nula em seus terminais, com objetivo de comandar o motor de operação da chave, transferindo o consumidor para outro circuito. $\mathrm{Na}$ Figura 5 é apresentado o diagrama unifilar, onde constam uma subestação e dois circuitos. 


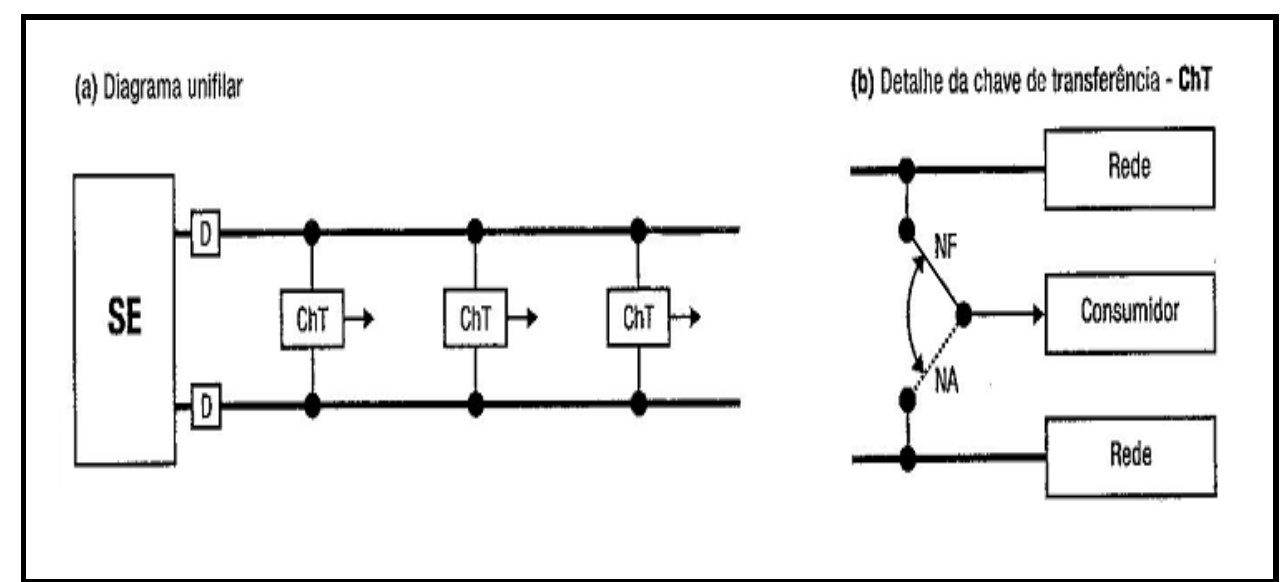

Figura 5 - Diagrama unifilar primário seletivo.

Fonte: (KAGAN et al., 2005)

Redes subterrâneas - Primário em malha aberta

Este circuito opera em malha aberta e apresenta custo elevado, sendo recomendado em regiões de altas densidades de carga, por exemplo, grandes centros comerciais. Costuma ser construído em alimentadores subterrâneos. A Figura 6 apresenta o diagrama unifilar primário em malha aberta. Os consumidores são agrupados em barramentos que contam com dois dispositivos de comando nas extremidades (disjuntores) e o alimentador, que se deriva de duas subestações, sendo seccionado em um ponto onde opera aberto na condição NA. Quando ocorre um defeito num trecho qualquer da rede, tem-se a sua isolação, com a abertura dos dois disjuntores das extremidades, e os barramentos restantes passam a ser supridos pelo disjuntor NA (normalmente aberto) que tem seu acionamento comandado automaticamente. 


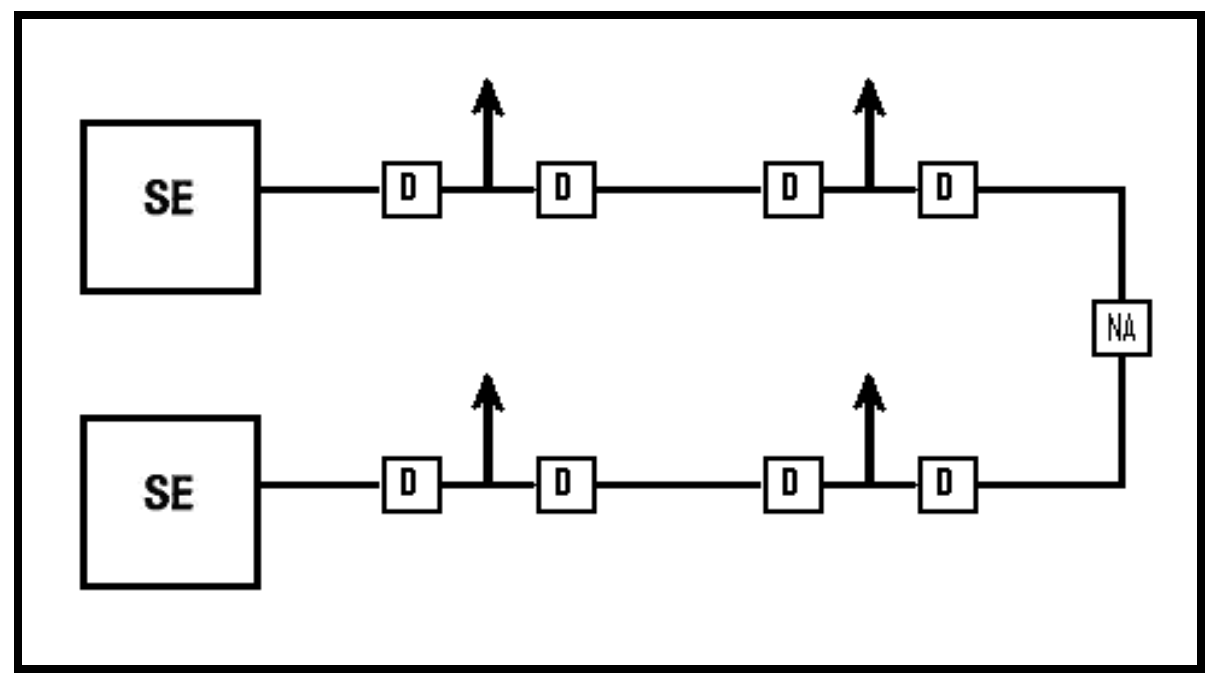

Figura 6 - Diagrama unifilar primário em malha aberta.

Fonte: (KAGAN et al., 2005)

Há também a rede spot network, cuja confiabilidade é muita alta, porém, sendo o custo muito elevado, a sua aplicação é feita em áreas de grande densidade de carga. Em Brasília, a rede do planalto foi construída em spot network com dois e três circuitos que são derivados de subestações distintas. Na Figura 7 são apresentados dois circuitos que são derivados da mesma subestação.

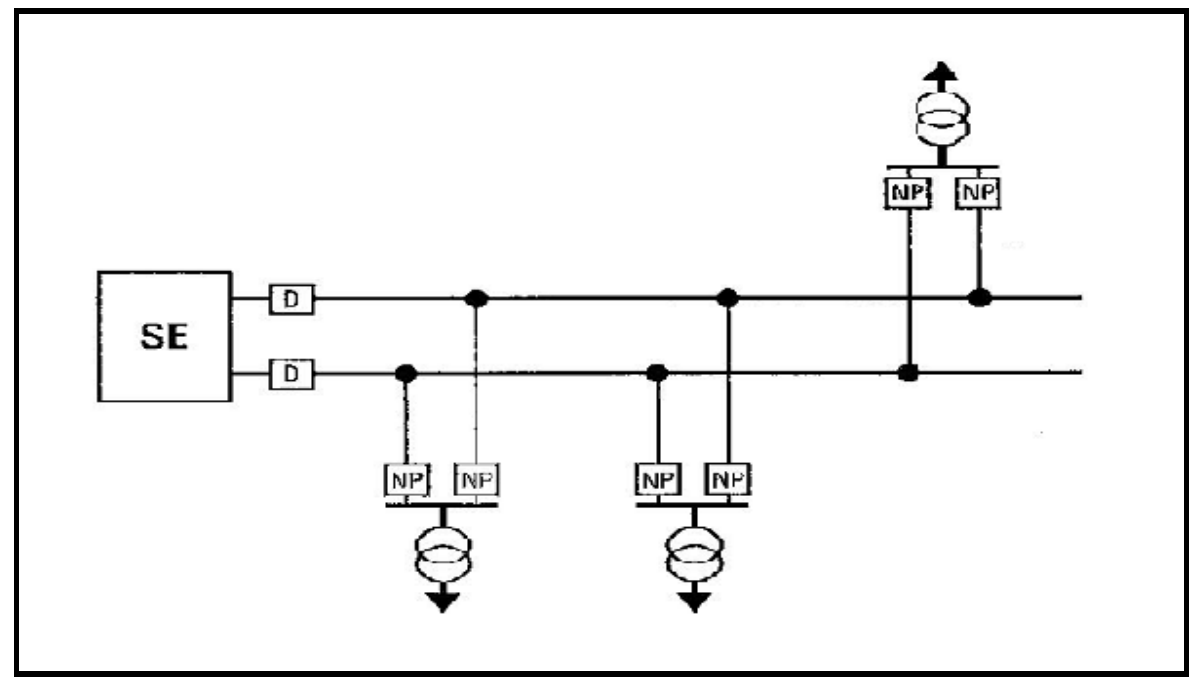

Figura 7 - Diagrama unifilar de uma rede spot network.

Fonte: (KAGAN et al., 2005) 
Os transformadores possuem chaves NP (network protector). Esta chave tem por função proteger a rede, impedindo o fluxo de potência no sentido inverso. Como exemplo, caso ocorra um curto-circuito em um dos trechos da rede, todas as chaves de proteção do circuito onde se estabeleceu o defeito irão se abrir, isolando-se, após a abertura do disjuntor da subestação, todo o circuito com defeito. Conseqüentemente, as cargas do circuito serão alimentadas por outro circuito (KAGAN et al., 2005).

\subsubsection{Rede Secundária de Distribuição}

As redes secundárias de distribuição de energia elétrica podem operar em malhas ou radial e supre os consumidores de baixa tensão residenciais, comércio e pequenas indústrias. Cada rede secundária é derivada de um transformador e, geralmente, o comprimento usual de cada rede é inferior a $1000 \mathrm{~m}$.

A rede que opera em malhas é constituída por um conjunto de malhas que são supridas por transformadores trifásicos com os terminais de baixa tensão conectados nos nós da malha. Para aumentar a capacidade e a confiabilidade do sistema, é normal entre dois nós, utilizar, em cada fase, três cabos em paralelo (KAGAN et al., 2005) e (JUNIOR, 2009).

\subsection{REDES DE DISTRIBUIÇÃO DE ENERGIA ELÉTRICA RURAL}

A eletrificação rural é um dos passos decisivos no combate à migração rural que ocorre há vários anos no País. No Brasil, cerca de $90 \%$ das famílias que vivem no meio rural possuem renda familiar abaixo de três salários mínimos e baixo índice de desenvolvimento humano (IBGE, 2000; MME, 2006; BERTOLLO, 2008).

A energia elétrica é fundamental para o desenvolvimento de um país. Uma das causas do subdesenvolvimento da região rural é a falta de energia elétrica para atender as seguintes necessidades: iluminação, saúde, educação e bombeamento de água para irrigação. 
No que tange à qualidade de vida dos habitantes rurais, a principal melhoria da eletrificação é a iluminação. A energia elétrica implica maior facilidade de educação e melhores condições de higiene; esses são alguns dos benefícios que ela possibilita (URMEE, 2009). Com a chegada da energia elétrica, torna-se possível a aquisição de aparelhos eletrodomésticos podendo proporcionar melhora da produtividade e elevação da renda da família com outras atividades.

A eletrificação rural substitui o uso de vários combustíveis comumente utilizados pela população rural (como por exemplo a lenha) que podem ser prejudiciais a saúde do ser humano. Durante a queima de biomassa para a cocção, são emitidos muitos poluentes, tais como: monóxido de carbono, óxidos de nitrogênio e diversos compostos orgânicos cancerígenos.

$\mathrm{Na}$ ausência da energia elétrica, várias atividades exigem muito tempo e esforço para serem realizadas. O processo de obtenção manual de água em poços, por exemplo, pode ser dispensado com a eletrificação, ou seja, com a instalação de bombas de água. Outro exemplo é o uso de refrigeradores para conservação dos alimentos nas residências e das vacinas nos postos de saúde, o que contribui para a manutenção da saúde da população (RIBEIRO et al., 2003) e (GUSMÃO et al., 2004).

Diante da exclusão de energia elétrica na área rural, o Programa lançado em 1999 durante o governo Fernando Henrique Cardoso, após um longo período sem uma política pública definida para este fim, constitui-se na iniciativa que prevê a eletrificação rural de um milhão de propriedades em quatro anos. Subdividiu-se em dois programas: fontes alternativas e eficiência energética nas instalações. Os investimentos somaram R \$ 3,2 bilhões.

Nos projetos de eletrificação, a verba destinada às concessionárias de energia elétrica do Programa Luz no Campo (PLC) limitou-se a 10\% do montante total do investimento. Com isso, uma grande parcela do investimento teria que ser arcada pelo consumidor rural. Isto provocou desinteresse de boa parte dos consumidores. Entretanto, até janeiro de 2004, foram executadas 634.594 ligações em todo o Brasil, distribuídas em 3.711 municípios. O PLC não alcançou a meta estabelecida de 1.000.000 de ligações previstas. Na época, a magnitude dos números atingidos, converteu o PLC, no maior programa de eletrificação rural desenvolvido no país (SOUZA, CLAUDIO; ANJOS, FLAVIO, 2007). 
No início do primeiro mandato do presidente Luis Inácio Lula da Silva, o assunto da eletrificação rural é retomado e o Brasil cria o Programa Luz para Todos, em 11 de novembro de 2003, por meio da Lei 10.762, que possibilitou o atendimento da população das áreas rurais: a total gratuidade da ligação da energia elétrica. Essa ligação foi possível graças a uma adaptação financeira que envolveu diversas partes: o governo federal, com fundos da RGR Reserva Global de Reversão e a CDE - Conta de Desenvolvimento Energético, sendo a CDE lançada a fundo perdido, como subvenção e a RGR na forma de financiamento; os governos estaduais e os agentes concessionários e permissionários, sem qualquer contribuição financeira por parte do consumidor rural a ser ligado. Segundo CAMARGO (2010), essa estrutura de custo viabilizou a ligação de mais de dois milhões e cem mil domicílios e mais de $60 \%$ desses atendimentos foram em famílias com renda familiar abaixo de um salário mínimo. O autor menciona que o problema que se coloca é que o Programa tem prazo para acabar: 31 de dezembro de 2010, com isso, retornando às normas anteriores do Programa, que possuem viés excludente. Ou seja, o retorno das normas da Resolução número 456, de 29 de novembro de 2000, que estabelece o atendimento até o limite da propriedade e a partir desse ponto, os custos serão por conta do consumidor. Portanto, com o fim do Programa haverá uma situação de exclusão, pois o consumidor não terá condições financeiras para levar energia elétrica para dentro de sua residência, comprometendo, também, as futuras gerações.

O Brasil teve a introdução da eletrificação baseada nos sistemas existentes em outros países, como Canadá, Estados Unidos e alguns países da Europa. A energia era distribuída por linhas sem neutro, constituídas de circuitos trifásicos com circuitos bifásicos derivados.

Nos Estados Unidos, em 1935, surgiu uma técnica de distribuição, utilizando condutor neutro ligado a terra, com isso, constituindo circuitos trifásicos multiaterrados com sistemas monofásicos (fase-neutro). Essa técnica proporcionou uma economia de investimento da ordem de 40\% em relação à existente. Em 1952, fora adotada pela CEMIG (Centrais Elétricas de Minas Gerais) (MACIEL, 1982).

Os países desenvolvidos e subdesenvolvidos analisam criteriosamente a aplicação de recursos públicos na construção e manutenção dos serviços de utilidade pública de redes elétricas rurais, por isso constroem suas redes no sistema monofásico (ELETROBRÁS, 2001).

No Brasil, a COPEL, em 1967, inicia o uso de sistemas monofilares para eletrificação rural em sua área de concessão. Neste mesmo ano é construída a primeira linha MRT em 
34,5 kV para iluminação do complexo turístico de Vila Velha (AFFONSO, 2001), entretanto, somente a partir de 2001 é que foi observado maior difusão do seu uso pela criação de um grupo de trabalho pela Eletrobrás com o objetivo de estudar e divulgar os aspectos e diretrizes básicas para sua utilização a nível nacional.

Em 1986, o Brasil contava com $40.921 \mathrm{~km}$ de linhas de distribuição rural atendendo 124.328 consumidores. Sendo que, deste total incluem-se todos os sistemas MRTs implantados.

O sistema MRT foi criado pelo engenheiro Lloyd Mandeno na Nova Zelândia, em 1925. Em 1941, durante a segunda guerra mundial, foi feito o primeiro uso do sistema MRT, passando a ser a solução preferida na Nova Zelândia. Posteriormente, expandiu-se para a Austrália, Canadá, EUA e África do Sul (AFFONSO, 2001) e (SOUZA, 2006).

O Canadá, Estados Unidos, Rússia e França têm resolvido o problema da eletrificação rural com o sistema MRT, pois são mais econômicos que os convencionais. Com o passar do tempo, as linhas foram sendo substituídas por linhas trifásicas de maior potência para atender o crescimento das cargas elétricas. O desenvolvimento da região não teria ocorrido se não fosse o baixo custo do sistema MRT.

A principal razão para o uso do MRT em países desenvolvidos como a Nova Zelândia, Austrália, Estados Unidos e Rússia foi o atendimento a pequenas cargas nas zonas rurais (SILVA, 2006).

\subsubsection{Sistema Fase - Fase}

Sistema constituído de dois condutores fase derivado de rede trifásica para atendimento monofásico, sendo uma estrutura muito utilizada na França (ELETROBRÁS, 2001) e (ELETROBRÁS, 2002). Neste método, a energia é fornecida por duas fases. Este sistema de distribuição apresenta maior capacidade comparada ao sistema com uma única fase. A Figura 8 ilustra o padrão utilizado no sistema fase/fase (ELETROBRÁS, 2001). 


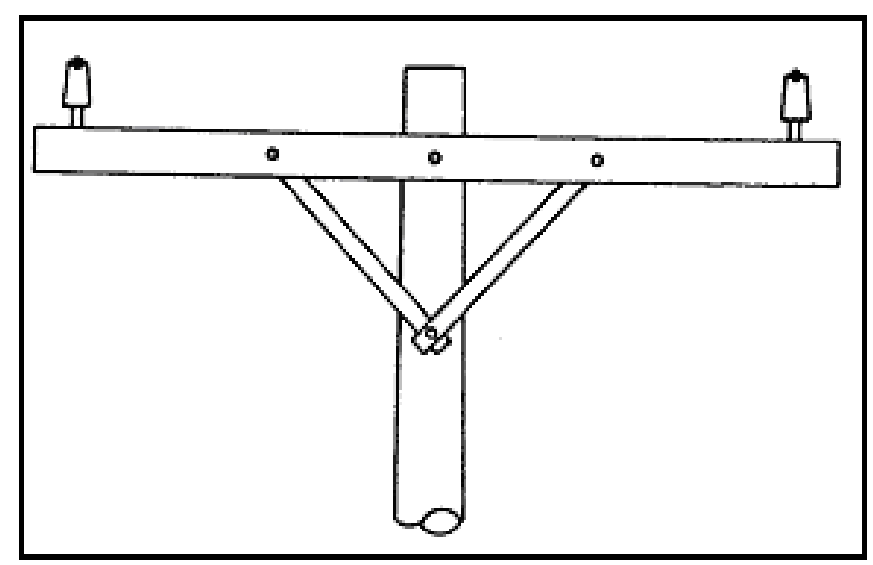

Figura 8 - Sistema de configuração de duas fases.

Fonte: (ELETROBRÁS, 2001)

\subsubsection{Sistema Fase - Neutro}

O desenvolvimento da eletrificação rural nos Estados Unidos foi quase que totalmente alcançado por meio deste sistema, conforme ilustrado na Figura 9.

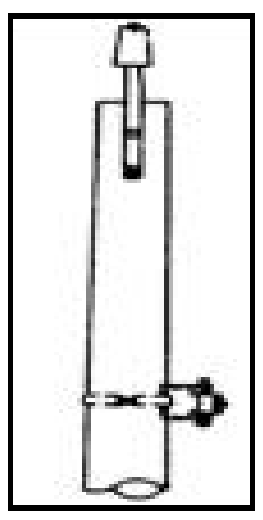

Figura 9 - Sistema fase/neutro.

Fonte: (ELETROBRÁS, 2001)

Uma das vantagens desse sistema é a eliminação da cruzeta, das ferragens e de um isolador de alta tensão por poste. A construção é simplificada, mais rápida de construir e possui menor custo. 
Os transformadores são mais simples e de manter custo, possuindo somente uma bucha de alta tensão e, conseqüentemente, um único pára-raios e uma chave monofásica. Esse sistema alcança aproximadamente $20 \%$ de redução no custo em relação ao sistema fase/fase.

\subsubsection{Sistema MRT}

O sistema de distribuição MRT utiliza apenas um condutor fase, sendo o retorno da corrente através do solo. Ao invés de três cabos de alumínio utiliza-se apenas um cabo de aço ou uma cordoalha de três arames de aço, material muito mais resistente que suporta maior tensão de tração. Portanto, se o terreno for plano e se o condutor for de aço pode-se utilizar um poste a cada 300 metros ao invés de $30 \mathrm{~m}$. O poste pode ser de madeira e as ferragens adequadas para suportar apenas um condutor. $\mathrm{O}$ transformador pode ser de pequeno porte, por exemplo, de 3 kVA (RIBEIRO, 1993).

\section{Sistema MRT convencional}

Esta configuração constitui-se de um único condutor metálico ligado diretamente a uma das fases de uma linha trifásica, tendo o solo como o caminho de retorno da corrente. A Figura 10 representa um esquema simples do MRT convencional (COELCE, 2006) e (AFFONSO, 2001). 


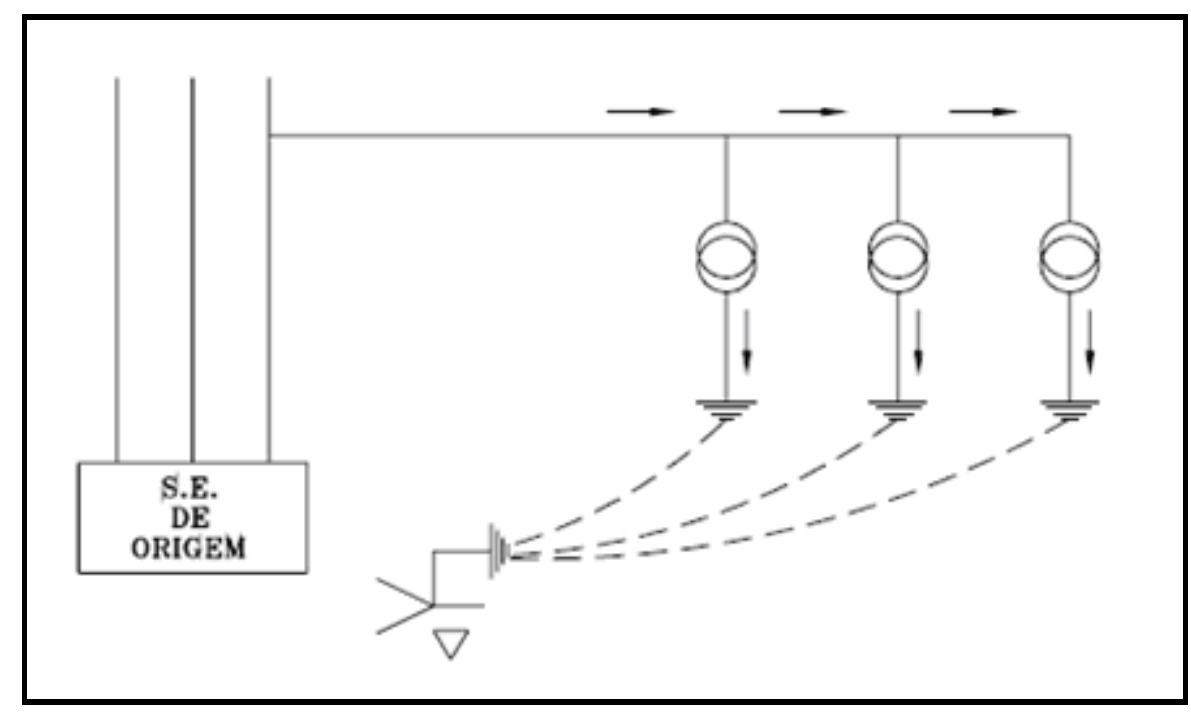

Figura 10 - Configuração simples do MRT.

Fonte: (COELCE, 2006)

Os transformadores de distribuição têm seus enrolamentos primários ligados entre o condutor fase e o solo. Este sistema só pode ser derivado de alimentadores trifásicos cuja saída da subestação de origem derive de um transformador com enrolamento secundário ligado em estrela-aterrado para garantir o fechamento do circuito de carga, ou seja, o primário do transformador deverá ser fechado em delta e o secundário em estrela.

Sistema monofilar com transformador isolador

Esta versão consiste de um transformador de isolamento entre os ramais MRT e o alimentador trifásico com o objetivo de confinar a corrente de retorno dentro dos limites do ramal MRT. O transformador de isolamento tem seu enrolamento primário ligado a duas fases do sistema trifásico. No enrolamento secundário deriva-se um condutor metálico que transporta energia até aos transformadores de distribuição, tendo o solo como caminho de retorno da corrente até o secundário do transformador de isolamento, como mostrado na Figura 11. 


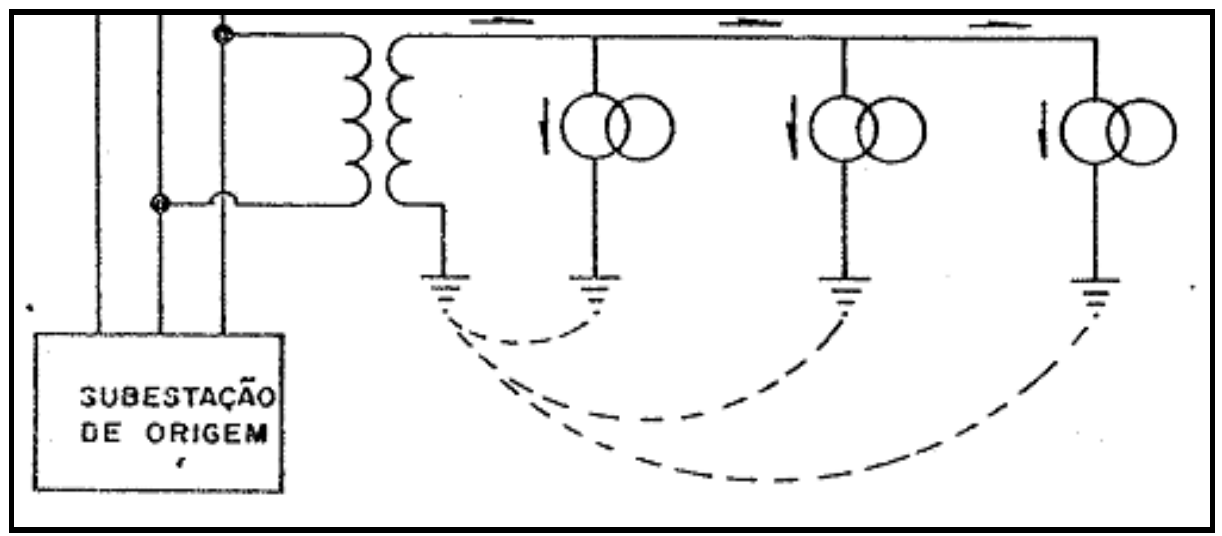

Figura 11 - Sistema monofilar com transformador isolador.

Fonte: (AFFONSO, 2001)

As vantagens que podem justificar a utilização deste sistema:

Adequar a tensão aos valores nominais padronizados (através dos tap’s), limitar a corrente de retorno eliminando os problemas de interferências dos sinais de comunicação, limitar a corrente de curto-circuito.

As desvantagens, além do custo adicional do transformador, são:

Limitação da potência que o transformador irá impor ao sistema quando ocorrer a necessidade de aumento de consumo; necessidade de reforçar o sistema de aterramento, pois uma falha no aterramento pode desligar todo o ramal; custos do transformador para implantação, operação e manutenção.

Sistema monofilar com neutro parcial

Este sistema é idêntico ao MRT convencional, com a diferença de possuir condutores interligando os aterramentos dos transformadores da rede. Geralmente é empregado para solos de alta resistividade. Com este sistema, formando uma única malha, há a diminuição dos valores de resistência de terra. Este procedimento, entretanto, é economicamente desaconselhável. A configuração típica é apresentada na Figura 12. 


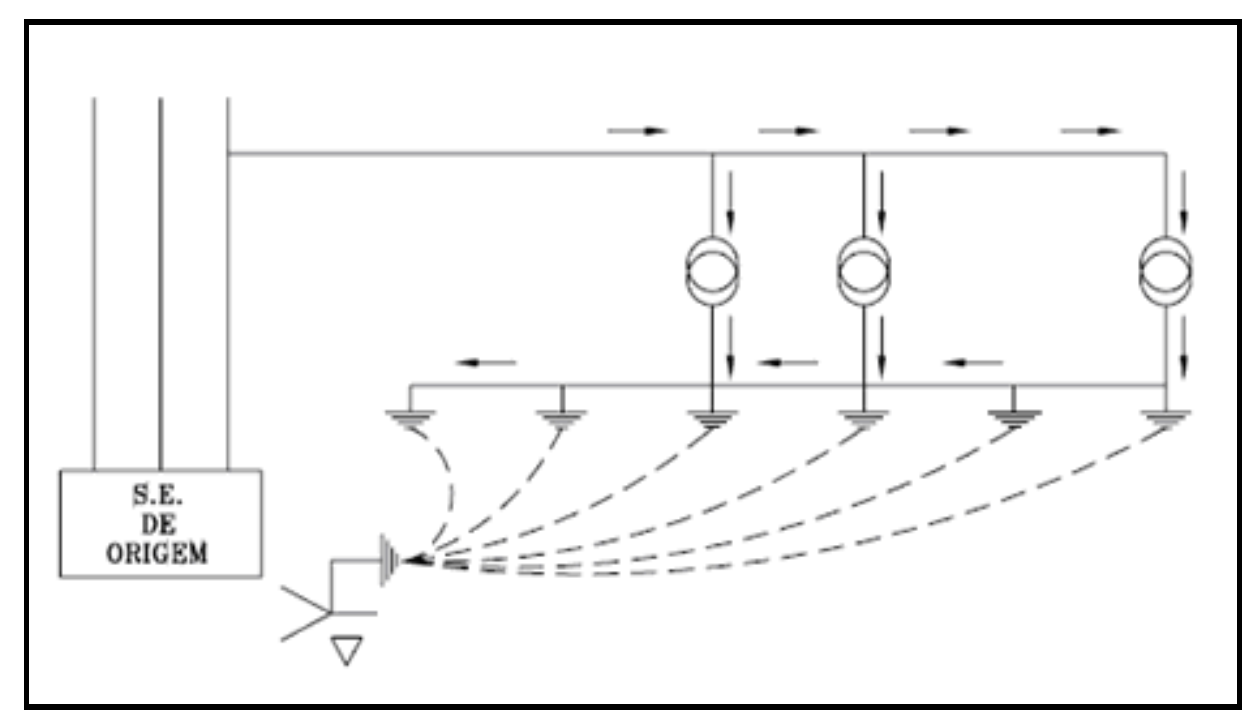

Figura 12 - Sistema monofilar com neutro parcial.

Fonte: (COELCE, 2006)

Quando este sistema é usado, as correntes mais freqüentemente induzidas que resultam da incidência de raios encontram uma multiplicidade de caminhos próximos, ligados em paralelo entre o neutro e a terra. As correntes de falta ou de surto atmosférico dividem-se entre os diferentes caminhos possíveis, resultando em menores potenciais de passo e de toque. Este multi-aterramento é parte da proteção pessoal que algumas empresas usam nos ambientes urbanos densamente povoados.

\subsection{TENSÕES DE FORNECIMENTO NA REDE PRIMÁRIA}

No Brasil, a maioria das redes de distribuição foi construída para operar na tensão nominal de 13,8 kV. O circuito primário de distribuição é constituído de três condutores fases, com 13,8 kV entre fases. As tensões primárias recomendadas no Brasil são: 13,8, 15, 23, 25 e $34,5 \mathrm{kV}$, em sistemas trifásicos. 
Com essas tensões entre fases obtêm-se as tensões entre fase e terra utilizadas nas redes rurais de distribuição monofilares com retorno por terra, ou seja, 7,97, 8,67, 13,28, 14,45 e 19.92 kV (CEPEL, 2000; KAGAN et. al., 2005; CPFL, 2009).

Estas tensões são as que alimentam os transformadores primários que suprem as cargas dos consumidores.

\subsection{TENSÕES DE FORNECIMENTO NA REDE SECUNDÁRIA}

No Brasil, a tensão de distribuição secundária está padronizada em sistema trifásico com tensões nominais de 380/220 V e 220/127 V.

Há outras tensões recomendadas para entrada dos consumidores residenciais, como por exemplo, tensão nominal 230/115 V.

O esquema praticado consiste na utilização de transformadores trifásicos, com resfriamento a óleo, com entrada do primário ligado em triângulo e o secundário ligado em estrela, com centro estrela aterrado. Alguns sistemas utilizam transformadores monofásicos com ligação triângulo aberto no secundário. $\mathrm{O}$ transformador que supre os consumidores monofásicos de baixa tensão a dois ou três fios possui secundário com derivação central, apresentando tensão nominal não padronizada 230/115 V (KAGAN et. al., 2005; GRIMONI et al., 2004; CAVALIN, 2007). 


\section{ATERRAMENTO ELÉTRICO}

O aterramento elétrico é basicamente uma conexão elétrica ao solo onde a eficácia está no valor da impedância de terra. A principal função é a proteção de pessoas, animais e equipamentos.

O aterramento constitui-se, fundamentalmente, de uma estrutura condutora que é enterrada no solo, de modo a garantir um bom contato elétrico com a terra através de eletrodos de aterramento (mais conhecidos como hastes de aterramento elétrico). Eletrodo de aterramento é o termo normalizado pela Associação Brasileira de Normas Técnicas (ABNT).

Os objetivos do aterramento são:

- O estabelecimento de uma tensão de referência para o sistema de energia;

- O funcionamento dos dispositivos de proteção de pessoas contra choques elétricos;

- Escoar as cargas estáticas geradas nas partes metálicas dos equipamentos;

- Dissipar a corrente de descargas atmosféricas no solo;

- Sensibilização de equipamentos de proteção para isolamento rápido das falhas à terra;

- Assegurar que os potenciais produzidos pelas correntes de falta mantenham-se dentro de limites de segurança para não causar fibrilação do coração de seres vivos;

- Usar a terra como retorno da corrente no sistema monofilar com retorno por terra e referencial de tensão (KINDERMAN, 1998; VISACRO, 2002; TELLO, 2007).

As características e a eficácia dos aterramentos devem satisfazer as prescrições de segurança das pessoas e da instalação.

O valor da impedância de terra deve satisfazer as condições de proteção e de funcionamento da instalação elétrica, de acordo com o aterramento utilizado. A NBR 14039:2005, menciona que o arranjo e as dimensões do sistema de aterramento são mais importantes que o próprio valor da impedância de terra. Entretanto, recomendam-se valores 
de impedância de terra de ordem de $10 \mathrm{ohms,} \mathrm{como} \mathrm{forma} \mathrm{de} \mathrm{reduzir} \mathrm{os} \mathrm{gradientes} \mathrm{de}$ potencial no solo, ou seja, baixos valores de impedância de terra contribuem na redução da tensão de passo. Reconhece-se que em solos com resistividade elevada é difícil conseguir valores dessa ordem.

A ligação intencional à terra é feita para fornecer à instalação um caminho de impedância adequada à corrente de falta, ou seja, a terra deve ser considerada como um elemento do circuito por onde pode circular uma corrente elétrica, seja ela derivada de uma falta ou descarga atmosférica. No caso da corrente de falta é produzida uma corrente elétrica que circula num caminho fechado incluindo a fonte e a carga. Entretanto, no caso da descarga atmosférica, a corrente do raio circula pelo aterramento elétrico para neutralizar as cargas induzidas no solo e, conseqüentemente, apresenta tensão de toque e passo.

Portanto, o objetivo do aterramento elétrico é proporcionar uma superfície equipotencial no solo dentro dos valores aceitáveis, ou seja, os valores de gradientes de tensão que aparecem na superfície do solo deverão estar dentro dos limites suportáveis por animais e seres humanos (NBR 14039, 2005) e (CUNHA, 2003). Durante o desenvolvimento do projeto são calculados os valores dos gradientes de tensão para verificar se estão dentro de limites aceitáveis.

Na elaboração de um projeto do sistema de aterramento é de fundamental importância ter conhecimento das características do solo, principalmente de sua resistividade elétrica. Baseado em levantamento destas características será definida a configuração adequada (TELLÓ, 2007).

No projeto de sistemas de aterramento são utilizadas a faixa de freqüência industrial (baixa freqüência $50 \mathrm{~Hz}$ e $60 \mathrm{~Hz}$ ) e as freqüências que surgem devido a descargas atmosféricas (alta frequiência 0,5 - 1,2 MHz). Para condições de baixa freqüência e baixa resistividade do solo, são desprezíveis os efeitos capacitivos e de ionização do solo, ou seja, na freqüência industrial, considera-se que o solo comporta-se como uma resistência pura. Entretanto, para freqüências muito altas, caso das ondas impulsivas de correntes associadas a descargas atmosféricas, há a necessidade de considerar os efeitos indutivos e capacitivos (TELLÓ, 2007). 


\subsection{RESISTIVIDADE DO SOLO}

O solo possui propriedades elétricas que são determinantes para o dimensionamento dos condutores, pois é o meio no qual ficarão imersos as hastes ou eletrodos de aterramento. A resistividade do solo é definida como a resistência elétrica medida entre as faces de um cubo de solo homogêneo, com arestas iguais a 1 metro, sua unidade é $\Omega . m$ (VISACRO, 2002).

O solo em seu estado natural é um mau condutor de eletricidade, com resistividade na faixa de 100 a $1.000 \Omega$.m, enquanto que a resistividade do cobre é de 1,67 x $10^{-8} \Omega . m$, ou seja, da ordem de um bilhão de vezes menor. Vale citar que a faixa de resistividade mencionada constitui-se apenas em uma referência, pois, em locais específicos, os valores de resistividade podem afastar-se muito das médias regionais (LEITE, 1996) e (VISACRO, 2002).

As principais substâncias constituintes do solo são: óxido de silício (areia), silicatos de alumínio (argilas), carbonato de cálcio e de sódio e água, de forma que a condução de corrente através do solo se faz pelo processo eletrolítico, o qual necessita de água para sua realização (LEITE, 1996) e (VISACRO, 2002).

Na Tabela 1 são mostrados alguns valores típicos de resistividade do solo em algumas regiões do Brasil.

Tabela 1 - Resistividade de algumas regiões do Brasil.

\begin{tabular}{|l|c|}
\hline \multicolumn{1}{|c|}{ Região } & Valores típicos de resistividade do solo $(\Omega . m)$ \\
\hline Minas Gerais & 2.450 \\
\hline São Paulo & 700 \\
\hline Paraná & $200-1.000$ \\
\hline Mato Grosso & $500-2.000$ \\
\hline Pernambuco & $100-2.000$ \\
\hline
\end{tabular}

Fonte: Visacro, 2002. 
Tipo de solo

Segundo KINDERMAN (1998), os tipos de solo não são claramente definidos, então, não é possível atribuir-lhe um valor de resistividade. Entretanto, é possível caracterizar faixas de valores característicos para os diversos tipos de solo, conforme mostrado na Tabela 2.

Tabela 2 - Valores de resistividade de alguns tipos de solos.

\begin{tabular}{|l|c|}
\hline Tipos de solos & $\begin{array}{c}\text { Resistividade } \\
(\mathbf{\Omega} \text {. } \mathbf{~})\end{array}$ \\
\hline Solos aráveis & 50 a 500 \\
\hline Argila & 300 a 5.000 \\
\hline Areia & 1.000 a 8.000 \\
\hline Calcário & 500 a 5.000 \\
\hline Granito e arenito & 100 a 10.000 \\
\hline
\end{tabular}

Fonte: Kinderman, 1998.

A Tabela 2 mostra que, dependendo do tipo de solo, a resistividade elétrica do mesmo pode variar de 50 a $10.000 \Omega$. $\mathrm{m}$.

Umidade do solo e concentração de sais no solo

A resistividade do solo sofre alterações com a umidade, conforme ilustra a Tabela 3. Uma porcentagem maior faz com que os sais presentes no solo se dissolvam formando um meio eletrolítico favorável à passagem da corrente iônica (KINDERMAN, 1998). 
Tabela 3 - Concentração de umidade em solo arenoso.

\begin{tabular}{|c|c|}
\hline $\begin{array}{c}\text { Índice de Umidade } \\
\text { (\% por peso) }\end{array}$ & $\begin{array}{c}\text { Resistividade }(\mathbf{\Omega . m}) \\
(\text { solo arenoso) }\end{array}$ \\
\hline 0 & $>100.000$ \\
\hline 2,5 & 1.500 \\
\hline 5,0 & 430 \\
\hline 10,0 & 185 \\
\hline 15,0 & 105 \\
\hline 20,0 & 63 \\
\hline 30,0 & 42 \\
\hline & \\
\hline
\end{tabular}

Fonte: Kinderman, 1998; Visacro, 2002.

Conforme mostra a Tabela 3, a resistividade do solo é bastante sensível ao teor de umidade, podendo ser observado que o valor cai bruscamente com 2,5\% de umidade. Por sua vez, essa quantidade de água varia de acordo com uma série de fatores, tais como clima, época do ano, temperatura e natureza do solo.

No seu estado natural, dificilmente é encontrado um solo realmente seco ou com umidade acima de 40\%. Quando se adiciona água a um solo seco, todos os vazios vão sendo preenchidos e, uma vez preenchidos o solo atinge a sua saturação, ou seja, o solo chega a sua umidade de saturação (OLIVEIRA, 2008). Acrescentando mais água ao solo já saturado, começará o processo de fragmentação e este começará a dissolver, podendo aumentar a resistividade.

Outro fator que influencia muito a resistividade é a quantidade de sais minerais presentes no solo, conforme apresentado na Tabela 4. Pode-se dizer que a água pura seria um isolante perfeito, ou seja, resistividade quase infinita, caso não contivesse sais que, através da ionização, permitem a condução de correntes elétricas, conforme mencionado em VISACRO (2002). 
Tabela 4 - Influência da concentração de sais na resistividade do solo.

\begin{tabular}{|c|c|}
\hline Sal adicionado (\% em peso) & Resistividade ( $\Omega . \mathrm{m})$ Solo arenoso \\
\hline 0 & 107 \\
\hline 0,1 & 18 \\
\hline 1,0 & 1,6 \\
\hline 5,0 & 1,9 \\
\hline 10,0 & 1,3 \\
\hline 20,0 & 1,0 \\
\hline
\end{tabular}

Fonte:Visacro, 2002.

Temperatura do solo

Segundo KINDERMAN (1998), com uma temperatura elevada, próxima de $100^{\circ} \mathrm{C}$, o estado de vaporização deixa o solo mais seco, com a formação de bolhas internas, dificultando a condução de corrente elétrica e, conseqüentemente, contribuindo para elevação da sua resistividade, conforme pode ser observado na Figura 13.

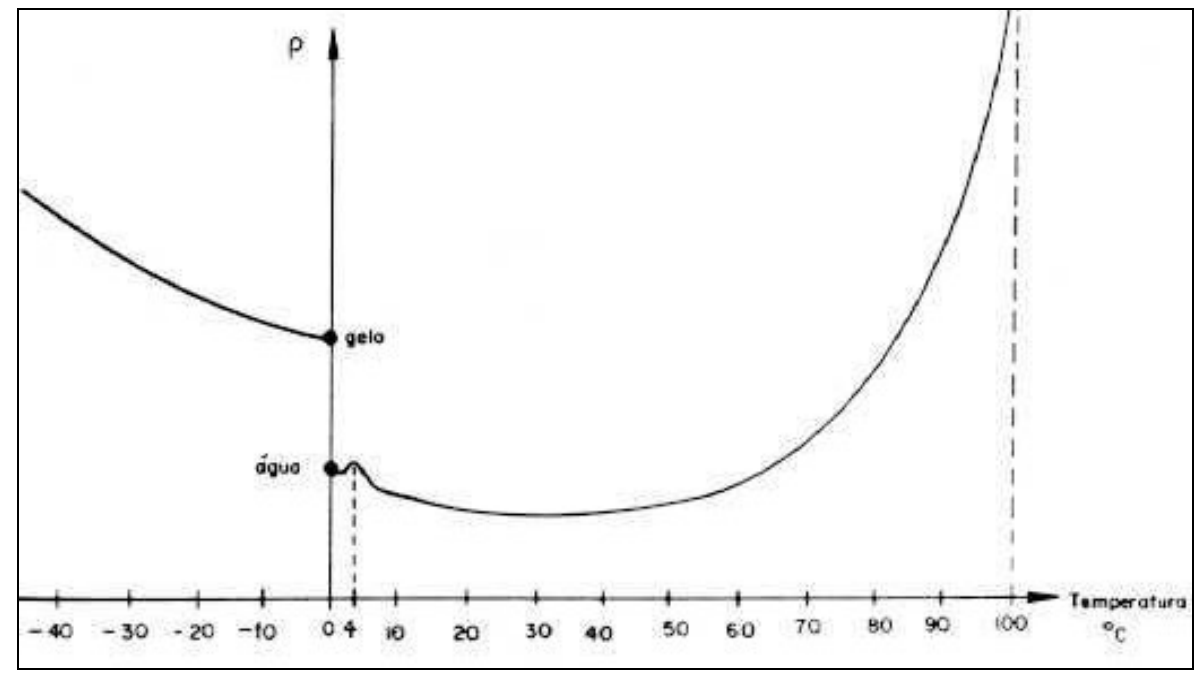

Figura 13 - Variação da resistividade com a temperatura

Fonte: (KINDERMAN, 1998) 
Observe na Figura 13 que no ponto de temperatura $0^{\circ} \mathrm{C}$ (água), a curva sofre descontinuidade, aumentando o valor da resistividade no ponto $0^{\circ} \mathrm{C}$ (gelo). Isto ocorre devido a uma mudança brusca no estado da ligação entre os grânulos que formam a concentração eletrolítica. Portanto, com um maior decréscimo na temperatura há uma concentração no estado molecular tornando o solo mais seco, aumentando assim a sua resistividade. No ponto de temperatura $4^{\circ} \mathrm{C}$, ocorre uma reaproximação das moléculas, provocando um pequeno aumento de temperatura (KINDERMAN, 1998).

\section{Estratificação do solo}

Na maioria das vezes, os solos não são homogêneos e sim formados por diversas camadas de resistividade e profundidades distintas. Dependendo da formação geológica, essas camadas podem ser horizontais ou verticais. Na maioria dos casos são horizontais e paralelas à superfície do solo (KINDERMAN, 1998).

O valor da resistividade do solo é importante para utilização no cálculo dos valores máximos permitidos de resistência de terra, tensão de passo e toque. O cálculo da resistência de terra é simplificado quando o solo é homogêneo, ou seja, o valor da resistividade não varia com a profundidade ou com a distância.

Na prática, esta condição de homogeneidade é muita rara, daí a necessidade da estratificação do solo, representando o solo por camadas onde cada camada é uniforme e tem um valor de resistividade e uma determinada espessura. 
Medição da Resistividade do solo

A determinação dos valores de resistividade do solo é de fundamental importância para um projeto de aterramento. Esses valores são determinados através de medições e, posteriormente, utilizados para estratificação do solo.

Para levantamento da resistividade do solo pode-se empregar diversos métodos, tais como:

- Método de Wenner

- Método de Lee

- Método de Schulumbeger

O método de Wenner é o mais utilizado por ser um dos mais simples e preciso dentre os métodos existentes (TELLO, 2007) e (IEEE-80, 2000), sendo então descrito a seguir. Este método consiste em cravar quatro hastes cilíndricas no solo, de aproximadamente $50 \mathrm{~cm}$ de comprimento e diâmetro entre 10 e 15 mm, igualmente espaçadas por uma distância (a) e dispostas em linha, conforme mostra a Figura 14. O diâmetro das hastes não deve exceder a um décimo de (a) e as profundidades atingidas pelas hastes (h) devem ser iguais. Injeta-se no terminal 4 uma corrente no solo, a qual retorna à fonte pelo terminal 1.

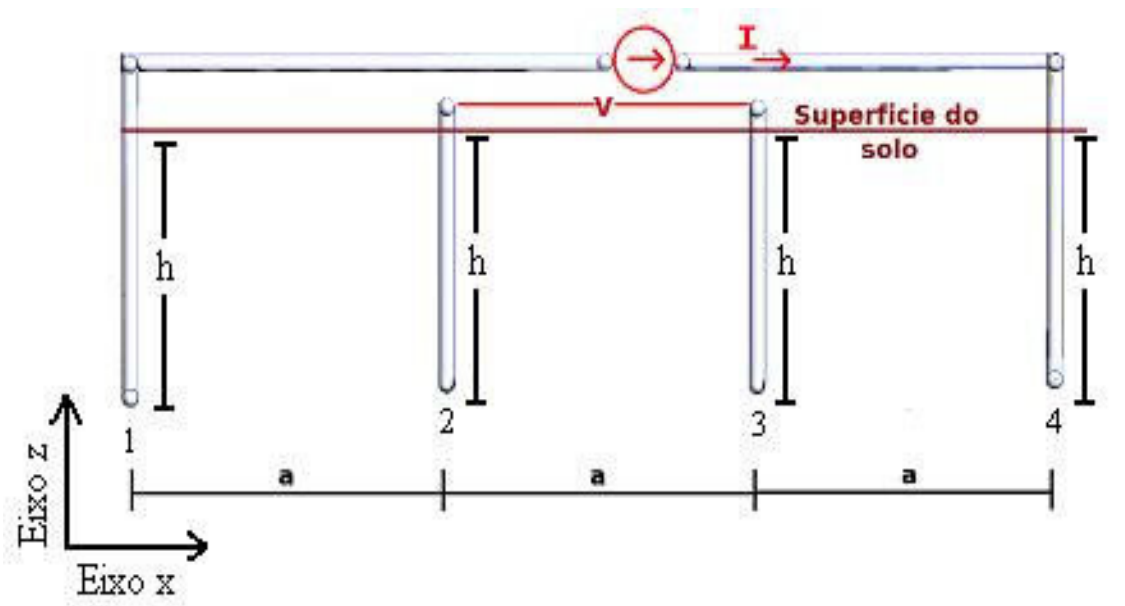

Figura 14 - Método de Wenner para medição da resistividade do solo. 
A queda de tensão causada pela corrente entre os terminais 2 e 3 fornecerá uma resistência $\mathrm{R}$ (em $\Omega$ ), que será medida através do aparelho Megger. Aplicado o valor encontrado pelo aparelho na equação 1, resultará em um valor de resistividade no solo a uma profundidade em relação ao espaçamento entre hastes (IEEE-80, 2000).

$$
\rho=2 \pi \mathrm{aR}(\Omega . \mathrm{m})
$$

O método considera que, praticamente $58 \%$ da distribuição de corrente que passa entre as hastes externas, ocorre a uma profundidade igual ao espaçamento entre hastes. A corrente atinge uma profundidade maior e conseqüentemente uma área de dispersão maior. Portanto, este método considera que o valor da resistência elétrica lida no aparelho é relativo a uma profundidade “a”. Esta técnica também é conhecida como resistividade aparente.

As medições também podem ser realizadas com um voltímetro e um amperímetro, conforme pode ser visto na Figura 15. Injeta-se nos terminais extremos uma corrente no solo, a qual é medido com um voltímetro a tensão entre os terminais interiores e em seguida dividese esta pelo valor de corrente que apresenta no amperímetro para achar o valor da resistência (IEEE-80, 2000).

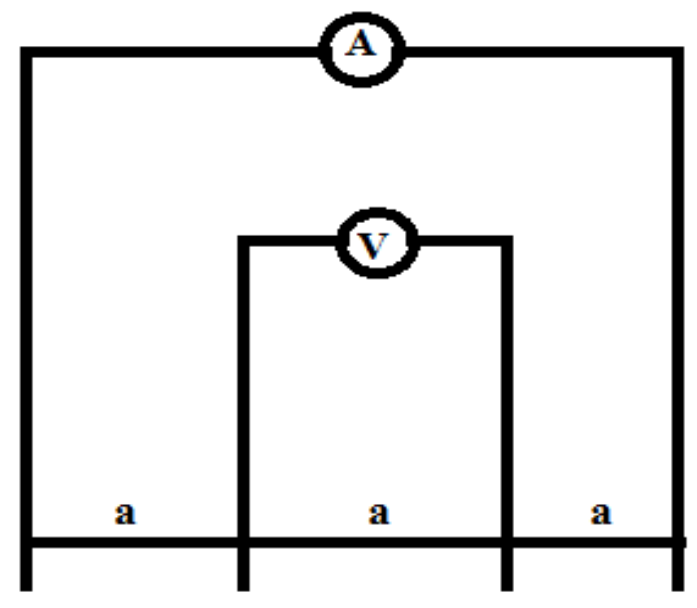

Figura 15 - Método para medição da resistividade do solo utilizando voltímetro e amperímetro.

Fonte: Adaptada (IEEE - 80, 2000) 
Faz-se necessário conhecer a resistividade do solo em diversas profundidades, o que pode ser feito variando-se o valor de a.

Espaçamentos comumente utilizados são: 2, 4, 8, 16 e 32 m. Estas distâncias poderão ser maiores dependendo do projeto de aterramento.

\subsection{SISTEMAS DE ATERRAMENTO}

Os sistemas de aterramento são apresentados em diversas geometrias e configurações, podendo ser uma haste vertical, hastes em paralelo, hastes em triângulo, quadrado, circunferência e malha. Recomendam-se os mesmos espaçamentos entre hastes para otimização das configurações. Dentre estas configurações citadas, a mais eficiente é o sistema em malha.

O material utilizado na haste não interfere na resistência de terra, devido à sua resistividade ser muito baixa em relação à resistividade do solo. Tampouco o aterramento com uma única haste fornecerá a resistência de aterramento desejada. Analisando a equação (2) podem ser observados os parâmetros que influenciam na redução do valor da resistência de terra (KINDERMAN, 1998).

$$
\mathrm{R}_{\text {lhaste }}=\frac{\rho \mathrm{a}}{2 \pi L} \ln \left(\frac{4 \mathrm{~L}}{\mathrm{~d}}\right)
$$

$\rho \mathrm{a}=$ Resistividade aparente do solo $(\Omega . \mathrm{m})$

$\mathrm{L}=$ Comprimento da haste $(\mathrm{m})$

$\mathrm{d}=$ Diâmetro da haste $(\mathrm{m})$

Alguns fatores que podem influenciar na resistência de terra são: 
- Resistividade do solo;

- Comprimento da haste;

- Diâmetro da haste;

- Tratamento químico;

- Geometria da malha.

Segundo KINDERMAN (1998), um solo com várias camadas apresenta resistividade diferente para cada tipo de sistema de aterramento. A passagem de corrente para o solo depende da composição do solo, da geometria e das dimensões do sistema de aterramento.

Portanto, faz-se importante calcular a resistividade aparente que representa a integração entre o sistema de aterramento em relação às suas dimensões. $\mathrm{O}$ tamanho do sistema de aterramento corresponde à profundidade de penetração da corrente escoada. Esta penetração determina as camadas do solo, e conseqüientemente a resistividade aparente.

\subsubsection{Eletrodos de Aterramento}

O eletrodo de aterramento é um condutor ou conjunto de condutores enterrados no solo e eletricamente ligados à terra, por exemplo, barras de cobre ou placas de alumínio, ou outro tipo de material que seja bom condutor de eletricidade. O eletrodo pode ser natural ou convencional, segunda a norma NBR 14039 (2005).

Eletrodo nartural

O eletrodo natural são as armaduras de aço das fundações das construções em alvenaria, que estão sendo aproveitadas como parte do aterramento elétrico. O eletrodo convencional foi desenvolvido para ser instalado especificamente para o sistema de aterramento, sendo constituído de condutores em anel, hastes verticais ou inclinadas e condutores horizontais radiais. Não devem ser usados como eletrodo de aterramento canalizações de fornecimento de água e outros serviços, segundo (NBR 14039, 2005) e (NBR 5410, 2004). 
O eletrodo natural mais utilizado é constituído pelas armaduras de aço embutidas em concreto das fundações da edificação. Para as edificações de concreto armado poderá ser implantado um sistema de proteção contra descargas atmosféricas (SPDA) com descidas externas ou, opcionalmente, poderão ser utilizadas como descidas as armaduras do concreto, segundo a NBR 5419 (2005). Nas edificações em alvenaria, o aterramento pode ser constituído por fita, barra ou cabo de aço galvanizado imerso em concreto das fundações, formando um anel em todo o perímetro da edificação. A norma recomenda que a barra, fita ou cabo deve ser envolvido por uma camada de concreto de no mínimo $5 \mathrm{~cm}$ de espessura, a uma profundidade de no mínimo $0,5 \mathrm{~m}$. Na Tabela 5 são mostradas as seções mínimas da fita, barra ou cabo, conforme recomenda a NBR 5410 (2004). 
Tabela 5 - Materiais comumente utilizáveis em eletrodos de aterramento.

\begin{tabular}{|c|c|c|c|c|c|c|}
\hline \multirow[b]{2}{*}{ Material } & \multirow[b]{2}{*}{ Superfície } & \multirow[b]{2}{*}{ Forma } & \multicolumn{4}{|c|}{ Dimensões mínimas } \\
\hline & & & $\begin{array}{l}\text { Diâmetro } \\
\text { (mm) }\end{array}$ & $\begin{array}{l}\text { Seção } \\
\left(\mathrm{mm}^{2}\right)\end{array}$ & $\begin{array}{c}\text { Espessura } \\
\text { do } \\
\text { material } \\
(\mathrm{mm})\end{array}$ & $\begin{array}{c}\text { Espessura } \\
\text { média do } \\
\text { revestimento } \\
(\mu \mathrm{m})\end{array}$ \\
\hline \multirow{7}{*}{ Aço } & \multirow{5}{*}{$\begin{array}{l}\text { Zincada a quente }^{1} \\
\text { ou inoxidável }^{1)}\end{array}$} & Fita $^{2}$ & & 100 & 3 & 70 \\
\hline & & Perfil & & 120 & 3 & 70 \\
\hline & & $\begin{array}{l}\text { Haste de } \\
\text { seção } \\
\text { circular }^{3}\end{array}$ & 15 & & & 70 \\
\hline & & $\begin{array}{l}\text { Cabo de } \\
\text { seção } \\
\text { circular }\end{array}$ & & 95 & & 50 \\
\hline & & Tubo & 25 & & 2 & 55 \\
\hline & Capa de cobre & $\begin{array}{l}\text { Haste de } \\
\text { seção } \\
\text { circular }^{3}\end{array}$ & 15 & & & 2000 \\
\hline & $\begin{array}{l}\text { Revestida de } \\
\text { cobre por } \\
\text { eletrodeposição }\end{array}$ & $\begin{array}{l}\text { Haste } \\
\text { circular }^{3}\end{array}$ & 15 & & & 254 \\
\hline \multirow{5}{*}{ Cobre } & \multirow{4}{*}{$\mathrm{Nu}^{1}$} & Fita & & 50 & 2 & \\
\hline & & $\begin{array}{c}\text { Cabo } \\
\text { seção } \\
\text { circular }\end{array}$ & & 50 & & \\
\hline & & Cordoalha & $\begin{array}{c}1,8 \text { (cada } \\
\text { veio) }\end{array}$ & 50 & & \\
\hline & & Tubo & 20 & & 2 & \\
\hline & Zincada & Fita $^{2}$ & & 50 & 2 & 40 \\
\hline \multicolumn{7}{|c|}{${ }^{1}$ Pode ser utilizado para embutir no concreto. } \\
\hline \multicolumn{7}{|c|}{${ }^{2}$ Fita com cantos arredondados. } \\
\hline $\operatorname{arae}$ & $\mathrm{de}$ & & & & & \\
\hline
\end{tabular}

Fonte: NBR 5410, 2004. 
Os materiais dos eletrodos de aterramento e as suas dimensões devem ser selecionados de modo a resistir à corrosão e apresentar resistência mecânica adequada.

Devem ser tomadas precauções contra os efeitos da corrosão eletrolítica, quando forem utilizados diferentes metais na infra-estrutura de aterramentos.

Quando a infra-estrutura de aterramento da edificação for constituída pelas armaduras embutidas no concreto das fundações, pode-se considerar que as interligações naturalmente existentes entre estes elementos são suficientes para se adquirir um eletrodo de aterramento com características adequadas, sendo dispensável qualquer medida suplementar (NBR 14039, 2005) e (NBR 5410, 2004).

Eletrodo convencional

O eletrodo convencional foi desenvolvido especificamente para fazer parte do sistema de aterramento elétrico e a seleção e instalação dos componentes do aterramento devem ser tais que:

- o valor da resistência de terra não se modifique consideravelmente ao longo do tempo;

- o projeto de aterramento deve considerar um possível aumento da resistência de terra devido à corrosão dos eletrodos;

- resistam às solicitações térmicas, termodinâmicas e eletromecânicas;

- o tipo e a profundidade de instalação dos eletrodos de aterramento não provoquem uma grande variação na resistência de terra quando da ocorrência de mudanças nas condições do solo (secagem);

- sejam adequadamente robustos ou possuam proteção mecânica apropriada para atender as condições de influências externas (meio ambiente).

A eficiência de qualquer eletrodo de aterramento depende da sua distribuição espacial e das condições locais do solo, devendo ser selecionado um eletrodo adequado às condições do solo, ao valor da resistência de terra exigida pelo sistema de aterramento adotado e à tensão de contato máxima de acordo com norma técnica (NBR 14039, 2005). 
Na Tabela 6 são indicados os eletrodos que podem ser utilizados como aterramento convencional.

Tabela 6 - Eletrodos de aterramento convencionais.

\begin{tabular}{|c|c|c|}
\hline e eletrodo & nas & ões \\
\hline $\begin{array}{l}\text { Tubo de aço } \\
\text { Zincado }\end{array}$ & $\begin{array}{l}2,40 \mathrm{~m} \text { de comprimento e diâmetro de } \\
25 \mathrm{~mm}\end{array}$ & \\
\hline $\begin{array}{l}\text { Perfil de aço } \\
\text { Zincado }\end{array}$ & $\begin{array}{l}\text { Cantoneira de }(20 \mathrm{~mm} \times 20 \mathrm{~mm} \times 3 \\
\mathrm{mm}) \text { com } 2,40 \mathrm{~m} \text { de comprimento }\end{array}$ & \\
\hline $\begin{array}{l}\text { Haste de aço } \\
\text { Zincado }\end{array}$ & $\begin{array}{l}\text { Diâmetro de } 15 \mathrm{~mm} \text { com } 2,00 \mathrm{~m} \mathrm{ou} \\
2,40 \text { de comprimento }\end{array}$ & $\begin{array}{l}\text { Enterramento } \\
\text { vertical }\end{array}$ \\
\hline cobre & $\begin{array}{l}\text { Diâmetro de } 15 \mathrm{~mm} \text { com } 2,00 \mathrm{~m} \text { ou } \\
2,40 \mathrm{~m} \text { de comprimento }\end{array}$ & $\begin{array}{l}\text { Enterramento } \\
\text { vertical }\end{array}$ \\
\hline Fita & $\begin{array}{l}\text { ão, } 2 \mathrm{~mm} \text { de espessura e } \\
\text { imento }\end{array}$ & $\begin{array}{l}\text { Profundidade mínima de } 0,60 \\
\text { m. Posição horizontal }\end{array}$ \\
\hline $\begin{array}{l}\text { Fita de aço } \\
\text { galvanizado }\end{array}$ & $\begin{array}{l}100 \mathrm{~mm}^{2} \text { de seção, } 3 \mathrm{~mm} \text { de espessura e } \\
10 \mathrm{~m} \text { de comprimento }\end{array}$ & $\begin{array}{l}\text { Profundidade mínima de } 0,60 \\
\text { m. Posição horizontal }\end{array}$ \\
\hline $\mathrm{Cab}$ & 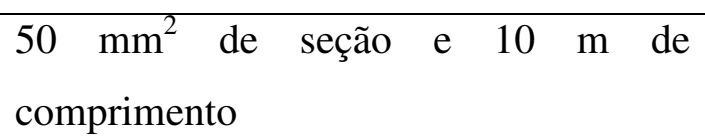 & $\begin{array}{l}\text { Profundidade mínima de } 0,60 \\
\text { m. Posição horizontal }\end{array}$ \\
\hline $\begin{array}{l}\text { Cabo de } \\
\text { Zincado }\end{array}$ & $\begin{array}{l}95 \mathrm{~mm}^{2} \text { de seção e } 10 \mathrm{~m} \text { de } \\
\text { comprimento }\end{array}$ & $\begin{array}{l}\text { Profundidade mínima de } 0,60 \\
\text { m. Posição horizontal }\end{array}$ \\
\hline $\begin{array}{l}\text { Cabo de aço } \\
\text { cobreado }\end{array}$ & $\begin{array}{l}50 \mathrm{~mm}^{2} \text { de seção e } 10 \quad \mathrm{~m} \text { de } \\
\text { comprimento }\end{array}$ & $\begin{array}{l}\text { Profundidade mínima de } 0,60 \\
\text { m. Posição horizontal }\end{array}$ \\
\hline
\end{tabular}

Fonte: NBR 14039, 2005

Condutores de aterramento

Os condutores de aterramento servem para interligação das hastes ou eletrodos de aterramentos. Quando o condutor de aterramento estiver enterrado no solo, sua seção mínima deverá estar de acordo com a Tabela 7 (NBR 14039, 2005). 
Tabela 7 - Seções mínimas convencionais de condutores de aterramento.

\begin{tabular}{|l|l|l|}
\hline & Protegido mecanicamente & Não protegido mecanicamente \\
\hline Protegido contra corrosão & $\begin{array}{c}\text { Cobre: } 2,5 \mathrm{~mm}^{2} \\
\text { Aço: } 10 \mathrm{~mm}^{2}\end{array}$ & $\begin{array}{l}\text { Cobre: } 16 \mathrm{~mm}^{2} \\
\text { Aço: } 16 \mathrm{~mm}^{2}\end{array}$ \\
\hline Não protegido contra corrosão & Cobre: $16 \mathrm{~mm}^{2}$ (solos ácidos) \\
& \multicolumn{2}{|c|}{$25 \mathrm{~mm}^{2}$ (solos alcalinos) } \\
& Aço: $50 \mathrm{~mm}^{2}$ \\
\hline
\end{tabular}

Fonte: NBR 14039, 2005.

Os condutores de aterramento devem atender as prescrições gerais, ou seja, a seção de proteção dos condutores deve ser calculada de acordo com a equação 3 (NBR 14039, 2005).

$$
\mathrm{S}=\frac{\sqrt{\mathrm{I}^{2} \cdot \mathrm{t}}}{\mathrm{k}}
$$

Onde:

S é a seção do condutor $\left(\mathrm{mm}^{2}\right)$;

I é o valor (eficaz) da corrente de falta que pode circular pelo dispositivo de proteção, para uma falta direta (A);

t é o tempo de atuação do dispositivo de proteção (s);

$\mathrm{k}$ é o fator que depende das temperaturas iniciais e finais e do material do condutor de proteção, de sua isolação.

A seção não deve ser inferior ao valor determinado pela equação (3) (aplicável apenas para tempos de atuação dos dispositivos de proteção que não excedam 5 s). 


\subsubsection{Potenciais de Passo e de Toque}

O choque elétrico é a manifestação física que ocorre quando uma corrente elétrica flui através do corpo humano ou de um animal. O efeito do choque elétrico, dependendo das condições e da intensidade da corrente, pode ocasionar desde uma ligeira contração superficial até uma violenta contração muscular que pode levar à morte.

Os tipos mais prováveis de choque elétrico são aqueles em que a corrente elétrica circula da palma de uma das mãos à palma da outra mão, ou da palma da mão até o pé (KINDERMAN, 1998).

Existem outras categorias de choque elétrico:

- Choque produzido por contato com circuito energizado (o contato durará enquanto o circuito não for desligado);

- Choque por corpo eletrizado (a duração por este tipo de choque é muito pequena, sendo produzido por carga estática).

Uma descarga atmosférica pode entrar em contato direto ou indireto com o corpo humano ou de animais e provocar o mesmo efeito de choque elétrico, com intensidade mais elevada em relação ao choque comum.

Limite da corrente elétrica para não causar fibrilação ventricular:

Charles Dalziel concluiu que $99,5 \%$ das pessoas com peso de $50 \mathrm{~kg}$ podem suportar, sem efeito de fibrilação ventricular, a corrente determinada pela equação (4), (IEEE-80, 2000). Os cálculos devem ser efetuados para correntes elétricas alternadas (CA) de 50 a $60 \mathrm{~Hz}$ no corpo humano, levando em consideração o tempo de duração do choque.

$$
\text { Ichoque }=\frac{0,116}{\sqrt{t}}
$$

Sendo: $0,03 \mathrm{~s} \leq \mathrm{t} \leq 3 \mathrm{~s}$ 
$\mathrm{t}=$ Tempo de duração do choque $(s)$

As equações (4) e (5) são usadas na obtenção do limite permissível e aceitável de corrente para não causar fibrilação durante o tempo em que a pessoa ficar submetida à tensão de passo ou toque. Segundo Dalziel, recomenda-se que caso a população média seja de $70 \mathrm{~kg}$, deve-se usar a equação (5) (IEEE-80, 2000).

$$
\text { Ichoque }=\frac{0,157}{\sqrt{\mathrm{t}}}
$$

$\mathrm{t}=$ Tempo de duração do choque $(s)$

Potencial de toque

O potencial de toque é definido como sendo a diferença de potencial entre a estrutura metálica situada ao alcance da mão de uma pessoa e um ponto no chão situado a $1 \mathrm{~m}$ da base da estrutura, conforme ilustra a Figura 16. O potencial máximo durante o período de defeito não deverá produzir uma corrente superior à limitada por Dalziel (IEEE-80, 2000). 


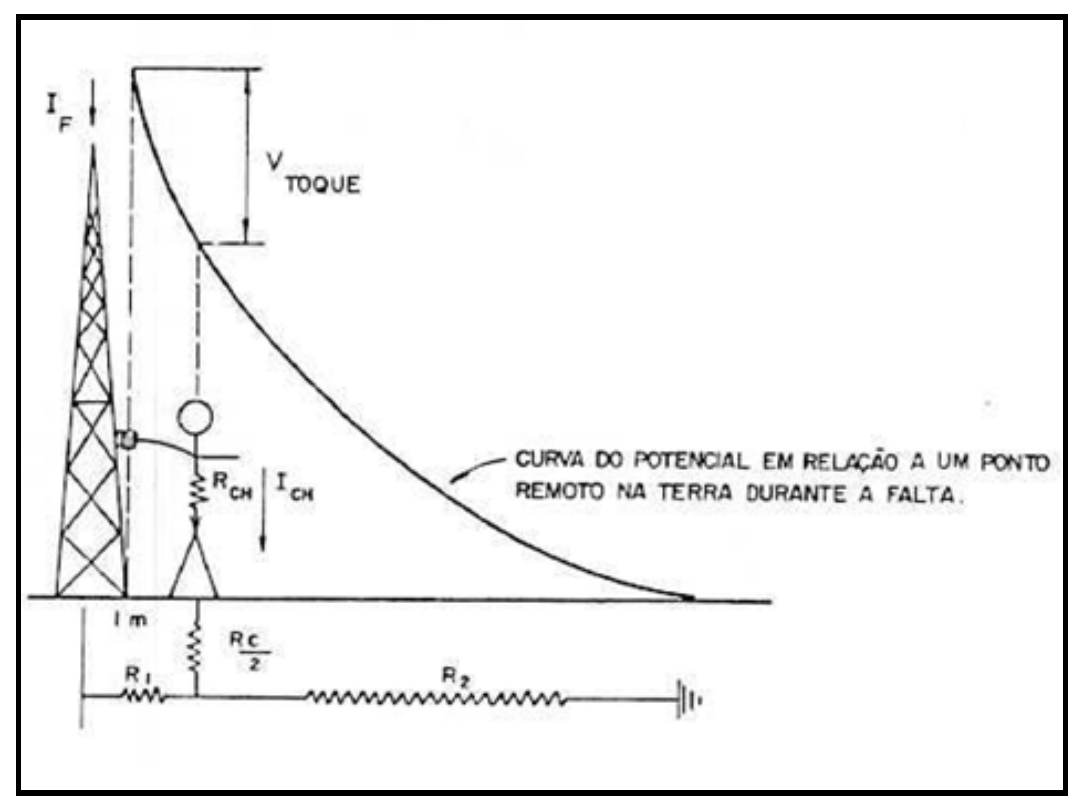

Figura 16 - Potencial de toque.

Fonte: Adaptado (KINDERMAN, 1998)

A equação (6) é utilizada para obter o potencial de toque máximo permissível entre a mão e o pé, para não causar fibrilação ventricular.

$$
\text { Vtoque }=\left(\mathrm{Rch}+\frac{\mathrm{Rc}}{2}\right) \mathrm{xIchoque} \quad(\mathrm{V})
$$

Rch = Resistência do corpo humano $1000 \Omega$ (Fig. 16).

$R c=$ Resistência de contato que pode ser considerada 3 x $\rho s$ ( $\rho s=$ resistividade superficial do solo), de acordo com IEEE-80, $2000(\Omega)$ (Fig. 16).

Ich $=$ I choque $=$ Corrente admissível pelo corpo humano (A) (Fig. 16).

R1 e R2 = Resistência dos trechos de terra $(\Omega)$.

A equação pode ser escrita da seguinte forma:

$$
\text { Vtoque.máx }=(1000+1,5 \rho,) \text { xIchoque }
$$


Potencial de passo

O potencial de passo é causado pela circulação de corrente entre dois pontos na superfície do solo, considerando estes dois pontos a distância de um passo de uma pessoa, que geralmente é de 1,0 m. Isso acontece porque os membros inferiores se encontram sobre linhas equipotenciais diferentes. Estas linhas se formam na superfície do solo, devido ao escoamento da corrente. Se os dois pés estiverem sobre a mesma linha equipotencial, ou se um único pé estiver sendo usado como apoio, não haverá tensão de passo (IEEE-80, 2000). A Figura 17 ilustra a tensão de passo.

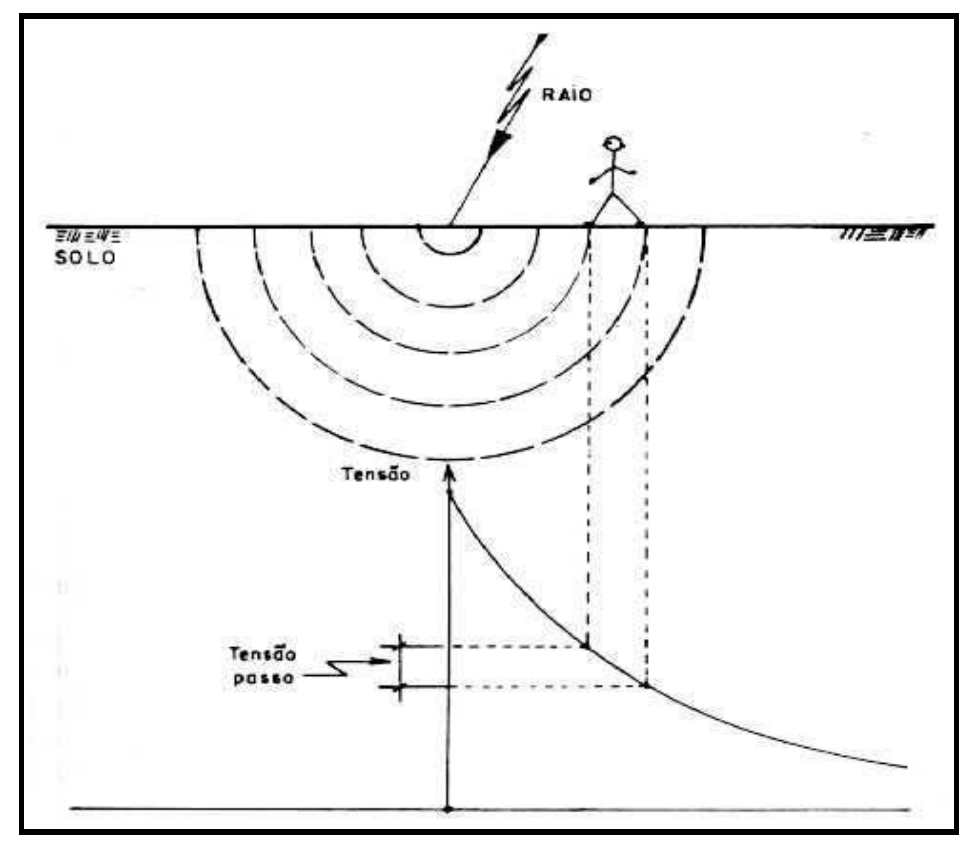

Figura 17 - Tensão de passo.

Fonte: Adaptado (KINDERMAN, 1998)

A equação para determinar o potencial de passo máximo é:

$$
\text { Vpasso }=(\text { Rch }+2 x R c) x I c h o q u e \quad(V)
$$

$\mathrm{Rc}=3 \rho \mathrm{s}($ Resistência de contato) $(\Omega)$

Rch $=$ Resistência do corpo humano $(\Omega)$ 


$$
\text { Vpassomáx. }=\frac{116+0,696 \rho,}{\sqrt{t}}
$$

\subsubsection{Comportamento de Sistema de Aterramento em Função da Freqüência}

Os sistemas de aterramento são representados por resistências, indutâncias e capacitâncias que desempenham papel importante, particularmente quando da incidência de surtos atmosféricos. No sistema de aterramento em freqüência industrial é considerado que o solo comporta-se como uma resistência pura (TELLÓ, 2007).

No entanto, em freqüências muito altas ou frentes de onda muito rápidas, a capacitância do solo deverá ser levada em consideração, pois a resistência de terra passa a ser considerada uma impedância.

Quando uma haste de aterramento é atingida por uma onda impulsiva ocorre a ionização do solo, em que a área do eletrodo é aumentada devido aos canais de descarga formados ao redor da haste. Por exemplo, o comportamento de um aterramento elétrico sob descarga atmosférica apresenta dois efeitos. O primeiro é um aumento da temperatura na parte do solo envolta do condutor devido à grande quantidade de energia dissipada no solo por efeito joule - aumenta a resistividade do solo. O segundo é a mudança de condução elétrica do solo devido ao elevado campo elétrico que se estabelece na vizinhança do eletrodo e acima de certos valores, contribuindo para a redução da impedância de terra durante o tempo de duração da descarga atmosférica (PEREIRA, 2008).

A Figura 18 mostra, de acordo com a IEC 100-4-5: 1995, a forma de onda padronizada de um impulso de tensão, que é utilizada para verificar o comportamento de isolações frente a descargas atmosféricas. 


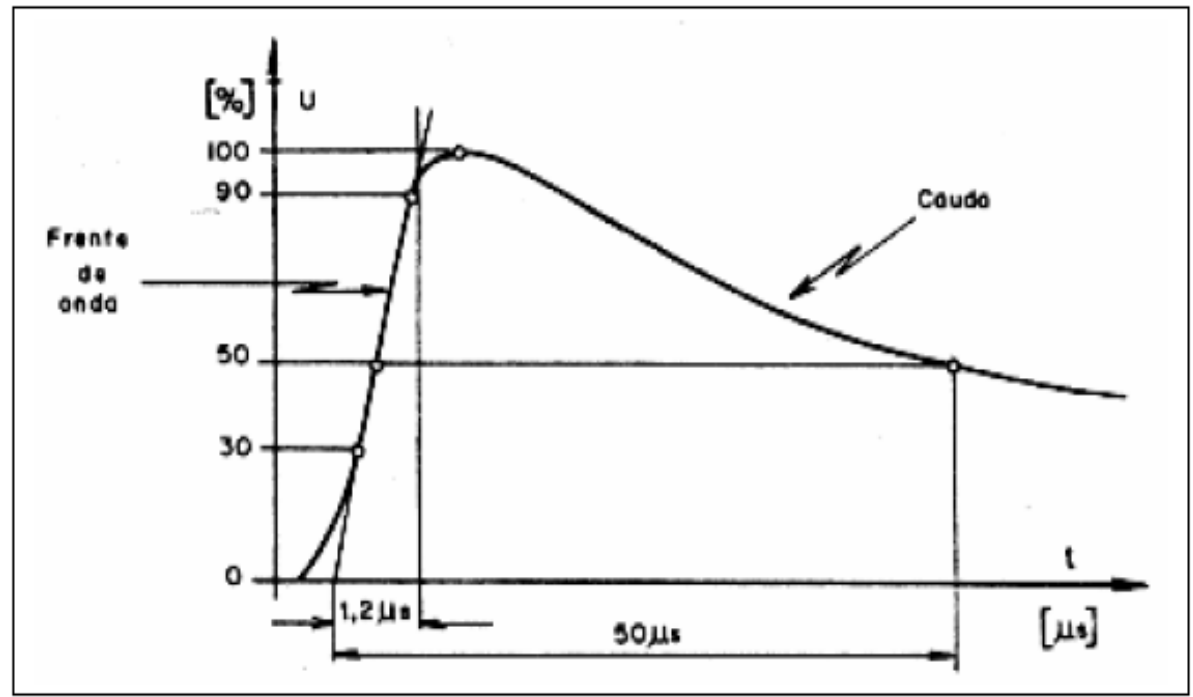

Figura 18 - Impulso atmosférico normalizado.

Fonte: (PEREIRA, 2008)

O tempo de frente é o tempo para atingir o valor de crista (valor máximo) e o tempo de cauda é o tempo para decaimento até a metade do valor de crista da onda. Com relação a Figura 18, é comum, adotar-se o valor de 1,2 x $50 \mu$ s $(1,2 / 50 \mu \mathrm{s})$ para onda de tensão e 8 x $20 \mu$ s para onda de corrente (ROSADO, GLÁUCIO, 2008). Os valores 1,2 x $50 \mu$ s e 8 x $20 \mu \mathrm{s}$ são impulsos atmosféricos normalizados pela NBR 6939: 2000. 


\section{SISTEMAS DE ATERRAMENTO UTILIZADOS NAS REDES DE DISTRIBUIÇÃO URBANAS E RURAIS}

Neste capítulo são apresentadas algumas configurações de aterramento adotadas por algumas concessionárias de energia elétrica. São apresentados os sistemas da CPFL, COPEL, CELPE, CEEE, COELCE, CELESC e CELTINS. Inicialmente, são descritas as configurações de aterramento da Companhia Paulista de Força e Luz (CPFL).

\subsection{SISTEMA CPFL}

O aterramento simples da CPFL (CPFL, 2008) utilizado na zona urbana constitui-se, basicamente, de um determinado comprimento de arame de aço zincado de 6,05 $\mathrm{mm}$ de diâmetro conectado a uma haste cantoneira de aço zincado de 2,40 m de comprimento. Este aterramento só pode ser aplicado desde que exista o neutro contínuo e multiaterrado.

Deve ser instalado nos seguintes pontos da rede de distribuição urbana:

- transformadores de distribuição e nos pára-raios;

- nos seccionamentos e fins de linhas das redes secundárias, excluindo-se os construídos unicamente para sustentação mecânica do cruzamento do secundário;

- a cada $300 \mathrm{~m}$, de modo que nenhum ponto de rede fique a mais de $200 \mathrm{~m}$ de um ponto de aterramento, seja este simples ou especial.

$\mathrm{Na}$ zona rural, o aterramento simples é aplicado em alimentadores com neutro multiaterrado (CPFL, 2009), nos seguintes pontos: 
- a cada $300 \mathrm{~m}$, de modo que nenhum ponto de rede fique a mais de $200 \mathrm{~m}$ de um ponto de aterramento;

- em circuito de telefonia e sinalização;

- telecomando com o condutor superior multiaterrado, no mesmo espaçamento do primeiro item.

$\mathrm{O}$ aterramento com três hastes de aço galvanizado constitui-se de três hastes cantoneira de 2,40 m de comprimento, interligadas em linha com arame de aço zincado. Segundo a CPFL, esta configuração deve ser instalada onde existe o neutro contínuo e multiaterrado na rede de distribuição, na zona urbana, nos seguintes pontos:

- nos transformadores de distribuição em fim de linha;

- nos pára-raios em fim de linha.

$\mathrm{O}$ aterramento especial na rede com neutro multiaterrado constitui-se de três hastes cilíndricas cobreadas, com 14,5 mm de diâmetro e $3 \mathrm{~m}$ de comprimento, a interligação deverá ser feita através de cabo de cobre nu 02 AWG.

Deve ser instalado nos seguintes pontos da rede de distribuição urbana e rural:

- bancos de capacitores;

- chaves tripolares com operação em carga (com ou sem controle remoto de operação);

- reguladores de tensão em poste;

- religadores e seccionalizadores.

Entretanto, na zona rural esse tipo de aterramento só pode ser utilizado quando houver neutro contínuo e multiaterrado.

Outra configuração utilizada pela empresa é o aterramento especial com anéis concêntricos, recomendado para ser utilizado tanto na área urbana quanto na área rural (CPFL, 2008) e (CPFL, 2009). O aterramento especial é constituído de anéis concêntricos de cabo de cobre nu 2 AWG, enterrados com diferentes profundidades, conectado às 4 hastes cilíndricas cobreadas com diâmetro de $14,5 \mathrm{~mm}$ e $3 \mathrm{~m}$ de comprimento, que poderá ser 
completado por módulos adicionais constituídos de duas hastes. As interligações dos cabos devem ser feitas através de cabos de cobre nu com seção de $50 \mathrm{~mm}^{2}$, e no mínimo $60 \mathrm{~cm}$ de profundidade do solo.

Caso não seja obtido o valor máximo de resistência de terra estipulado pela concessionária, é permitido o uso de até 8 módulos (1 módulo é igual a duas hastes), sendo que o número de hastes não poderá ser superior a 20, como mostrado na Figura 19. Não atingindo o valor máximo admissível com 20 hastes, é recomendado o estudo da utilização de hastes profundas, que depende da estratificação do solo no local onde se pretende construir o aterramento.

Este tipo de aterramento é utilizado para os aterramentos de religadores, bancos de capacitores, chaves tripolares de operação em carga, reguladores de tensão em postes e plataforma, sempre que não houver neutro contínuo e multiaterrado.

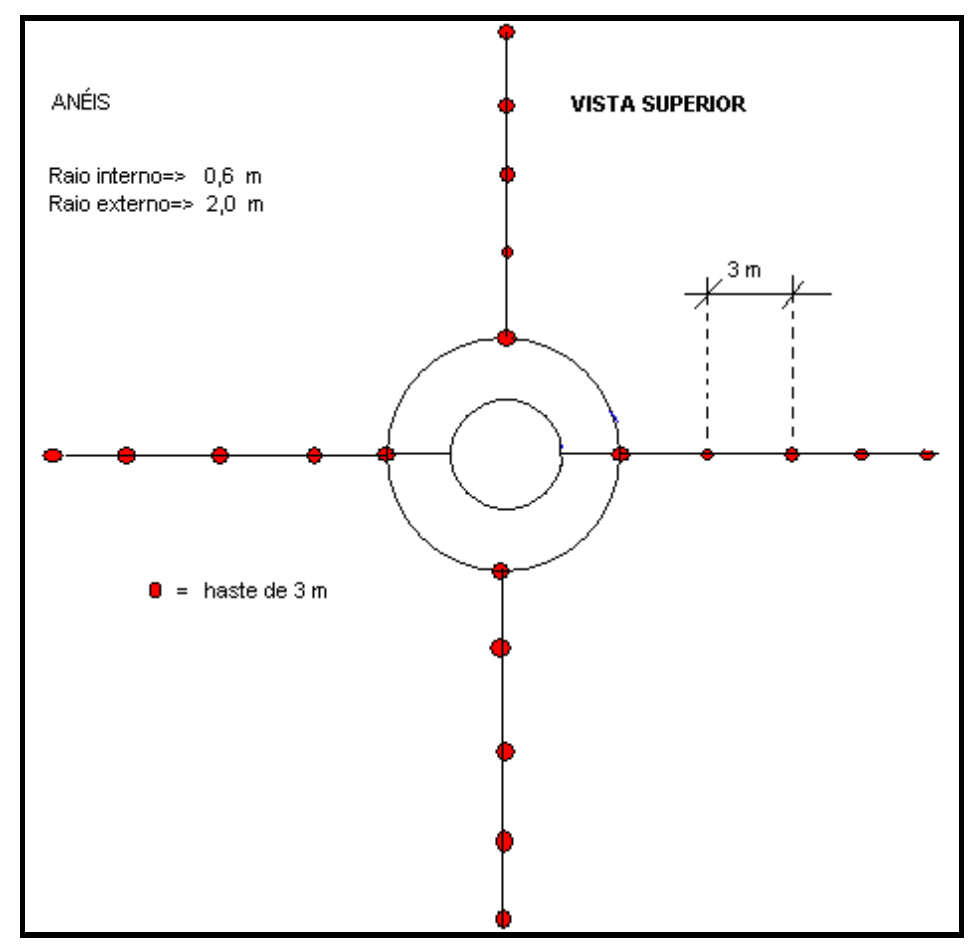

Figura 19 - Configuração de aterramento especial.

Fonte: Adaptado (AFFONSO, 2001)

Como o aterramento especial com anéis concêntricos é também recomendado para ser utilizado no aterramento dos transformadores da zona rural, é imprescindível que os 
transformadores rurais fiquem no mínimo a $30 \mathrm{~m}$ de distância das edificações que abriguem pessoas e animais para evitar riscos de exposição às tensões de toque e passo na ocorrência de descargas atmosféricas e curto-circuito. O condutor de descida ao aterramento deverá ser conectado na carcaça do transformador e nos pára-raios. O neutro da rede secundária rural deverá ser aterrado um vão antes das residências e de outros pontos de consumo (CPFL, 2008) e (CPFL, 2009).

Segundo (AFFONSO, 2001), a execução para esse tipo de aterramento é complexa e de custo elevado, sem que no final da instalação se possa garantir os valores de resistência de terra especificados pela concessionária de energia elétrica, que são $10 \mathrm{ohms} \mathrm{em} \mathrm{terreno} \mathrm{úmido}$ e 25 ohms para terreno seco, tanto para redes de distribuição urbana quanto para redes de distribuição rural.

\subsection{SISTEMA COPEL}

O valor máximo de resistência de terra estipulado pela COPEL (Companhia Paranaense de Energia) é de $20 \mathrm{ohms}$ para as tensões $13,8 \mathrm{kV}$ e $10 \mathrm{ohms}$ para $34,5 \mathrm{kV}$. Caso não seja possível obter os valores de resistência de terra mencionados para transformadores monofásicos alimentados em 34,5 e $13,8 \mathrm{kV}$, no sistema MRT, quando colocados até três hastes profundas, são adotados, por razões econômicas, os valores apresentados na Tabela 8.

Tabela 8 - Resistência de terra por transformador (COPEL).

\begin{tabular}{|c|c|}
\hline Transformadores & Resistência de terra (ohms) \\
\hline $10 \mathrm{kVA}$ & 50 \\
\hline $15 \mathrm{kVA}$ & 33 \\
\hline $25 \mathrm{kVA}$ & 20 \\
\hline
\end{tabular}

Fonte: COPEL, 2004. 
$\mathrm{Na}$ área urbana, o valor de resistência de terra estipulado é de $10 \mathrm{ohms}$ para os atendimentos em $13,8 \mathrm{kV}$ e $34,5 \mathrm{kV}$, com transformação até $75 \mathrm{kVA}$.

$\mathrm{O}$ aterramento utilizado para obter os valores de resistência de terra recomendados pode ser constituído de hastes ou malhas, com até no máximo 6 hastes (COPEL, 2004). Entretanto, nas áreas onde a resistividade do solo é elevada pode-se admitir o espaçamento entre hastes de aterramento de até $10 \mathrm{~m}$, sendo que a extensão total da malha não deverá ultrapassar $50 \mathrm{~m}$, considerando-se que após a $5^{\circ}$ haste a redução de resistência de terra se torna desprezível (COPEL, 2002).

\subsection{SISTEMA CELPE}

Na área de concessão da CELPE (Companhia Energética de Pernambuco), deve ser feita a estratificação do solo no local onde será construído o aterramento. Os valores de resistência de terra devem estar de acordo com a Tabela 9 (CELPE, 2008).

Tabela 9 - Resistência de terra por transformador (CELPE).

\begin{tabular}{|c|c|c|}
\hline Potência do Transformador & \multicolumn{2}{|c|}{ Resistência de terra limite (ohms) } \\
\hline kVA & Terreno seco & Terreno molhado \\
\hline 3 & 65 & 33 \\
\hline 5 & 40 & 20 \\
\hline 10 & 20 & 10 \\
\hline 15 & 15 & 8 \\
\hline
\end{tabular}

Fonte: CELPE, 2008.

Os valores de resistência de terra devem ser verificados sem a interferência dos aterramentos de baixa tensão. Caso o terreno na qual à medição será feita esteja molhado, deve ser considerado o valor de resistência indicado na Tabela 9, entretanto, sempre que possível, deve ser evitada a medição em terreno molhado. O valor de resistência de terra estipulado pela concessionária para área urbana é de no máximo 10 ohms. 
As resistências de terra nas estruturas de transformadores monofásicos em MRT só devem ser mantidas no limite, em solos desfavoráveis, quando já tiverem sido empregadas 5 ou mais hastes, com espaçamentos de $4 \mathrm{~m}$. Entretanto, quando esses valores não são atingidos, o sistema de neutro parcial deverá ser utilizado.

$\mathrm{Na}$ área urbana, a configuração de aterramento possui as mesmas características do aterramento mencionado para a área rural. As interligações das hastes são feitas através de cabos nus, com no mínimo $25 \mathrm{~mm}^{2}$ de seção. A haste de aterramento deverá ser de aço revestido de cobre, com diâmetro de 16 mm e ter no mínimo 2,4 m de comprimento (CELPE, 2009).

\subsection{SISTEMA CEEE}

O aterramento elétrico recomendado para o sistema MRT na distribuidora de energia elétrica CEEE (Companhia Estadual de Energia Elétrica), utiliza malha de aterramento com até no máximo 13 hastes de aterramento para atingir a resistência de terra mínima estipulada pela concessionária de energia. Os valores de resistência de terra devem estar conforme os valores apresentados na Tabela 10.

Tabela 10 - Resistência de terra por transformador (CEEE).

\begin{tabular}{|c|c|c|}
\hline Transformadores & Tensão & Resistência de terra (ohms) \\
\hline $15 \mathrm{kVA}$ & - & 20 \\
\hline $25 \mathrm{kVA}$ & $23 / \sqrt{3} \mathrm{kV}$ & 15 \\
\hline $25 \mathrm{kVA}$ & $13,8 / \sqrt{3} \mathrm{kV}$ & 10 \\
\hline
\end{tabular}

Fonte: Affonso, 2001

O valor de 20 ohms é estipulado para o transformador alimentado em qualquer tensão; $15 \mathrm{ohms}$ é para o transformador alimentado em $23 / \sqrt{ } 3 \mathrm{kV}$ e o valor de $10 \mathrm{ohms}$ para o

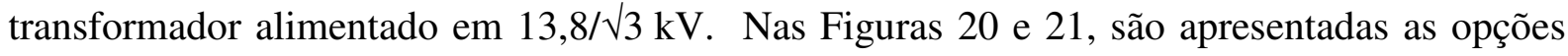


de configuração de aterramento com 13 hastes. Deve-se iniciar o aterramento com a primeira haste, junto ao poste, e posteriormente acrescentar hastes adicionais até que seja atingido o valor de resistência de terra. O espaçamento entre hastes é de $2 \mathrm{~m}$, independente do comprimento da haste.

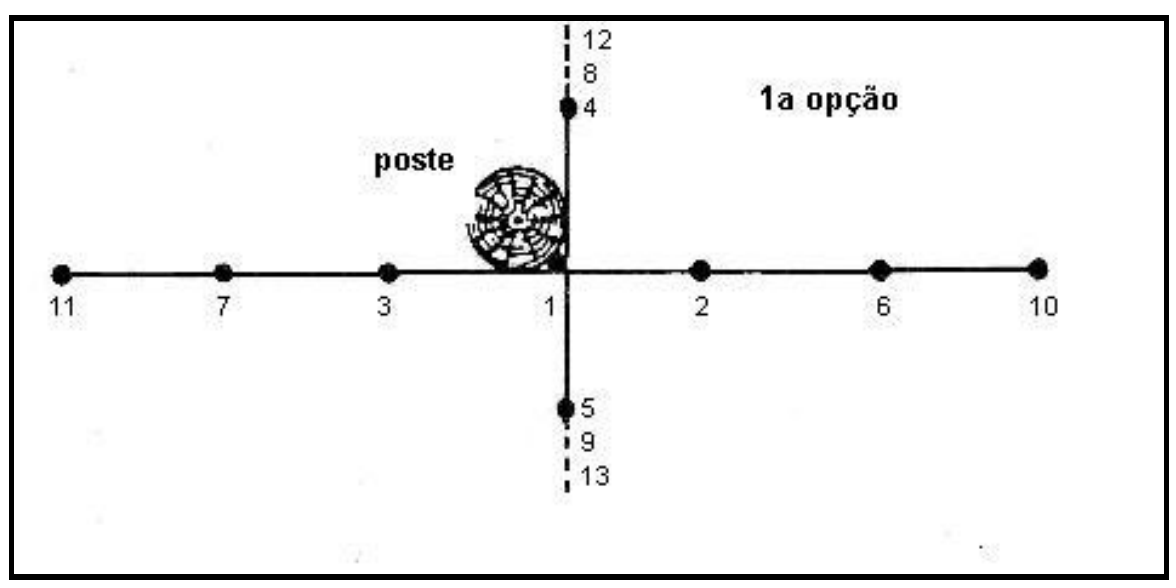

Figura 20 - Configuração de aterramento CEEE-RS $1^{\mathrm{a}}$ opção.

Fonte: (AFFONSO, 2001)

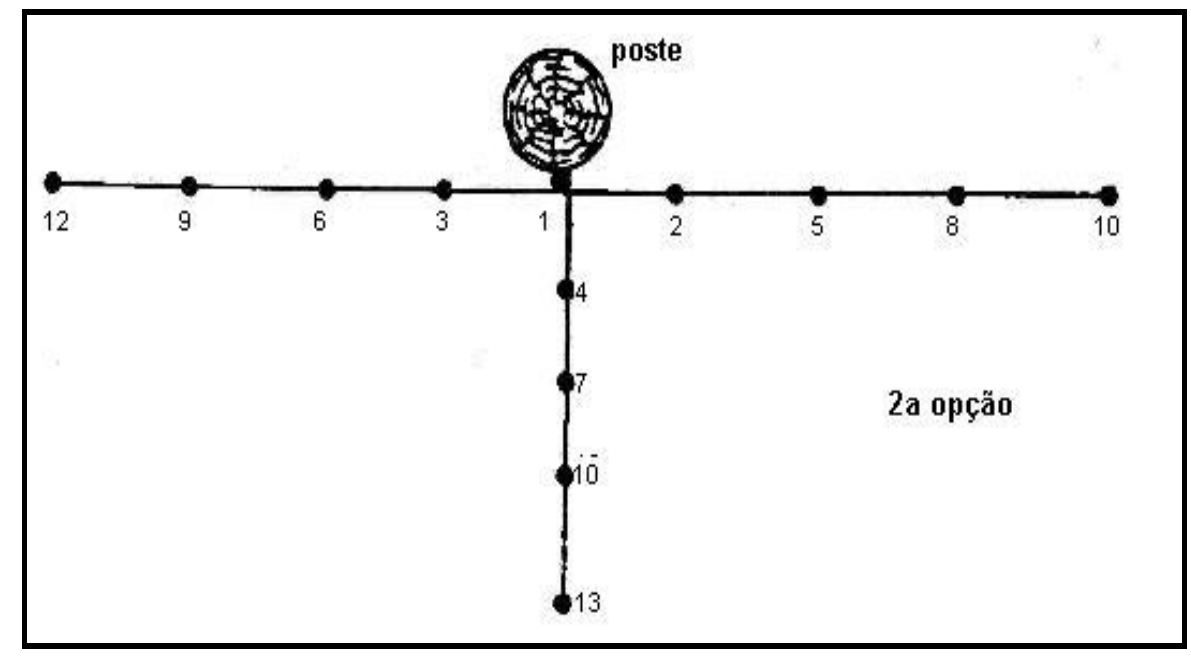

Figura 21 - Configuração de aterramento CEEE-RS $2^{\mathrm{a}}$ opção.

Fonte: (AFFONSO, 2001)

A configuração do aterramento urbano consiste de 1 a 3 hastes de aterramento (CEEE, 2008). 


\subsection{SISTEMA COELCE}

A COELCE (Companhia Energética do Ceará) recomenda uma malha padrão com três hastes de aterramento para atingir os valores especificados de resistência de terra, com a possibilidade de fixar mais três hastes, caso não seja atingido o valor especificado de resistência de terra. Não obtendo o valor de resistência de terra limite com 6 hastes, deve-se optar pelo aterramento com neutro parcial. Os valores de resistência de terra a serem obtidos devem estar de acordo com a Tabela 11 (COELCE, 2006).

Tabela 11 - Valores máximos de resistência de terra por potência dos transformadores em $13.8 \mathrm{kV}$.

\begin{tabular}{|c|c|}
\hline Transformadores & Resistência de terra (ohms) \\
\hline $5 \mathrm{kVA}$ & 40 \\
\hline $10 \mathrm{kVA}$ & 20 \\
\hline
\end{tabular}

Fonte: COELCE, 2006.

O aterramento padrão consiste de três hastes alinhadas, com dois metros de distância entre hastes. O valor de resistência de terra estipulado para a área urbana é de 10 ohms e devem ser utilizadas no mínimo 6 hastes alinhadas espaçadas de $3 \mathrm{~m}$.

\subsection{SISTEMA CELESC}

Na CELESC (Centrais Elétricas de Santa Catarina), o aterramento constitui-se de no mínimo 5 hastes em linha, com $15 \mathrm{~mm}$ de diâmetro, $2400 \mathrm{~mm}$ de comprimento mínimo. A distância mínima entre hastes deve ser de $3 \mathrm{~m}$. O condutor de interligação das hastes deve possuir seção mínima de $25 \mathrm{~mm}^{2}$. 
O valor da resistência de terra não deve ultrapassar $10 \mathrm{ohms} \mathrm{em} \mathrm{qualquer} \mathrm{época} \mathrm{do} \mathrm{ano}$ (CELESC, 2001). Caso não seja atingido o valor de resistência de terra, o projetista deverá utilizar quantas hastes forem necessárias para atingir o valor estipulado.

\subsection{SISTEMA CELTINS}

A distribuidora de energia elétrica CELTINS (Companhia de Energia Elétrica de Tocantins) recomenda para o sistema MRT uma configuração de aterramento de livre escolha, desde que atenda o valor de resistência de terra especificado de $20 \mathrm{ohms}$. No entanto, o sistema de aterramento padrão utiliza malha reticulada com até no máximo 20 hastes de aterramento para atingir a resistência de terra especificada pela concessionária de energia. $\mathrm{O}$ espaçamento mínimo entre hastes é de $2400 \mathrm{~mm}$, sendo o comprimento da haste $2400 \mathrm{~mm}$ e o diâmetro de $16 \mathrm{~mm}$. As interligações das hastes são feitas através de cabos nus, com $25 \mathrm{~mm}^{2}$ de diâmetro, na posição horizontal. Na área urbana, o sistema de aterramento possui as mesmas características do aterramento rural, porém, com o número de hastes reduzido, ou seja, com até 6 hastes de aterramento, sendo o valor de resistência de terra especificado de 20 ohms (CELTINS, 2009).

\subsection{CONSIDERAÇÕES FINAIS}

Conclui-se que, com relação aos valores de resistência de terra estipulados pelas concessionárias de energia elétrica, existe uma faixa de valores típicos que varia de 10 a 20 ohms, dependendo se a rede é urbana ou rural.

O tipo de haste mais utilizado no sistema de aterramento é o aço zincado revestido de cobre. As configurações de aterramento variam de 3 a 20 hastes de aterramento. Comparando todas as configurações de aterramento, tanto para área rural quanto para urbana, constata-se 
que os sistemas de aterramento utilizados pelas concessionárias de energia são semelhantes, com exceção de algumas concessionárias, tais como a CPFL, CEEE, CELESC e a CELTINS, que recomenda sistemas de aterramento acima de 6 hastes, caso não seja atingido o valor de resistência de terra.

A maioria das concessionárias de energia elétrica costuma utilizar sistemas de aterramento com hastes alinhadas, com até três hastes de $2400 \mathrm{~mm}$ de comprimento, sendo o espaçamento entre hastes de 3m (CONTI; VISACRO, 2007). 


\section{HASTES E CONDUTORES DE ATERRAMENTO ENVOLVIDOS EM CONCRETO}

A técnica de envolver a haste de aterramento em concreto foi criada pelo engenheiro Helbert Ufer, durante a segunda guerra mundial (E.J. FAGAN; R.H. LEE, 1970). Os Estados Unidos, na época, necessitavam de um aterramento confiável em seus depósitos para evitar a detonação de explosivos durante a ocorrência de descargas atmosféricas. Este tipo de aterramento é conhecido na literatura como aterramento UFER. Os resultados de Ufer consideram que o metal encapsulado com concreto atua como eletrodo de aterramento eficaz.

Desde 1925, a União Alemã das Centrais Elétricas possui diretrizes para utilização das armaduras das fundações como eletrodos de aterramento. A norma alemã publicou em 1979 (caderno 35 da VDE) a inclusão no sistema de aterramento das fundações dos edifícios residenciais.

No fim da década de 70, os americanos incluíram recomendações para utilização de sistemas de aterramento com condutores embutidos em concreto. O Green Book (ANSI/IEEE Standard 142-1982), que trata especificamente de sistemas de aterramento, menciona em várias seções as vantagens de se utilizar as armaduras do concreto como eletrodos de aterramento (CAVALCANTE et al., 2005) e (GOMES, 2007).

Devido a esta antiga utilização, as normas de proteção de estruturas contra descargas atmosféricas, NBR 5419/2005, NBR 5410/2005 e internacional IEC 61024-1-2/1998, permitem a utilização das ferragens das fundações das edificações como parte integrante do sistema de aterramento, segundo (SUETA, 2005).

Entretanto, estas normas descrevem que as armaduras de aço interconectadas e embutidas em concreto podem ser utilizadas desde que cumpram determinados requisitos, ou seja, cuidados especiais devem ser tomados nas conexões no sentido de prevenir danos mecânicos no concreto. A norma brasileira NBR 5419/2005 descreve as condições em que as ferragens podem ser utilizadas e como devem ser feitas as interligações com as colunas das estruturas e as avaliações e testes no sistema de aterramento. 
A vantagem da utilização das armaduras do concreto é que o mesmo fica sob o nível do solo, mantendo sempre certo grau de umidade, assim seu valor de resistividade é baixo, comumente muito menor do que o valor do próprio solo onde está sendo construído o sistema de aterramento. Portanto, contribui para a redução da resistência de terra, com consequiente diminuição das diferenças de potencial de toque e de passo.

O concreto é um material composto de cimento, areia, pedras britadas e água, além de outros materiais eventuais, tais como aditivos. O concreto é higroscópico, ou seja, absorve umidade rapidamente e perde lentamente.

Um bloco de concreto enterrado no solo se comporta como um semicondutor com resistividade variando entre 30 e $90 \Omega$.m (IEEE, 2000). Para uma haste convencional, o valor da resistência de terra pode ser obtido pela equação (10):

$$
\mathrm{R}_{\mathrm{at}}=\frac{\rho_{\mathrm{a}}}{2 \pi \times \mathrm{L}} \ln \left(\frac{4 \mathrm{~L}}{\mathrm{~d}}\right)
$$

Onde:

$\mathrm{R}_{\mathrm{at}}=$ Resistência de terra $(\Omega)$

$\rho_{\mathrm{a}}=$ Resistividade aparente do solo $(\Omega . \mathrm{m})$

$\mathrm{L}=$ Comprimento da haste $(\mathrm{m})$

$\mathrm{d}=$ Diâmetro da haste $(\mathrm{m})$

A expressão (11) pode ser utilizada para calcular o valor da resistência de terra de uma haste de aterramento envolvida em concreto (IEEE, 2000):

$$
\mathrm{R}_{\mathrm{CE}}=\frac{1}{2 \pi \times \mathrm{L}_{\mathrm{r}}}\left\{\rho_{\mathrm{c}}\left[\ln \left(\mathrm{D}_{\mathrm{c}} / \mathrm{d}\right)\right]+\rho\left[\ln \left(8 \mathrm{~L}_{\mathrm{r}} / \mathrm{D}_{\mathrm{c}}\right)-1\right]\right\}
$$

Onde: 
$\mathrm{R}_{\mathrm{CE}}=$ Resistência de terra de uma haste envolvida em concreto $(\Omega)$

$\rho=$ Resistividade do solo $(\Omega . \mathrm{m})$

$\rho_{\mathrm{c}}=$ Resistividade do concreto $(\Omega . \mathrm{m})$

$\mathrm{d}=$ Diâmetro da haste $(\mathrm{m})$

$\mathrm{D}_{\mathrm{c}}=$ Diâmetro do encapsulamento de concreto (m)

$\mathrm{L}_{\mathrm{r}}=$ Comprimento da haste $(\mathrm{m})$

5.1 MEDIÇÕES DE RESISTÊNCIA DE TERRA EM SISTEMAS DE ATERRAMENTO UTILIZANDO CONDUTORES E HASTES ENVOLVIDOS EM CONCRETO E HASTES CONVENCIONAIS

Um exemplo de utilização de concreto em sistemas de aterramento é mostrado em (CLAUSEN et al., 2004) onde foi realizada uma pesquisa experimental considerando-se malhas com hastes convencionais e hastes e condutores envolvidos em concreto. Foram utilizadas hastes de cobre como base para construção da maioria das malhas. Na primeira etapa da pesquisa foram consideradas cinco configurações: 1 haste simples; 3 e 5 hastes em linha; 3 hastes em V e 3 hastes em triângulo. Quando necessário, as interligações das hastes foram feitas através de cabo de cobre nu, de $25 \mathrm{~mm}^{2}$ de seção nominal. O local onde estas malhas foram construídas possuem solo homogêneo, do tipo arenoso escuro (bastante comum no litoral do estado de Santa Catarina), com resistividade em torno de 1000 S.m. A Tabela 12 mostra os resultados encontrados na primeira etapa da pesquisa. 
Tabela 12 - Malhas convencionais (aço cobreado).

\begin{tabular}{|c|c|c|c|c|c|c|}
\hline $\begin{array}{c}\text { Configuração } \\
\text { da malha }\end{array}$ & $\begin{array}{c}\mathrm{N}^{\mathrm{o}} \text { de } \\
\text { hastes }\end{array}$ & $\begin{array}{c}\mathrm{L} \\
(\mathrm{mm})\end{array}$ & $\begin{array}{c}\mathrm{e} \\
(\mathrm{mm})\end{array}$ & $\begin{array}{c}\varnothing \\
(\mathrm{mm})\end{array}$ & $\begin{array}{c}\rho \\
(\Omega . \mathrm{m})\end{array}$ & $\begin{array}{c}\text { Rat } \\
\text { convencional } \\
(\Omega)\end{array}$ \\
\hline Haste simples & 1,0 & 2400 & & 13 & 1000 & 392,3 \\
\hline Haste alinhada & 3,0 & 2400 & 3000 & 13 & 1000 & 175,0 \\
\hline Haste alinhada & 5,0 & 2400 & 3000 & 13 & 1000 & 118,0 \\
\hline Hastes em V & 3,0 & 2400 & 3000 & 13 & 1000 & 169,7 \\
\hline Triângulo & 3,0 & 2400 & 3000 & 13 & 1000 & 160,0 \\
\hline
\end{tabular}

Segundo (CLAUSEN et al., 2004) os valores obtidos demonstram que, dependendo do valor da resistividade do solo, torna-se difícil a obtenção dos valores tradicionais de aterramento especificados em normas (10 a $25 \mathrm{ohms}$ ). Diante da dificuldade prática de obtenção de baixos valores de resistência de terra através de pequenas malhas de aterramento e a dificuldade de espaço adequado para execução de uma malha de maior porte, a CELESC optou em testar técnicas de aterramento com melhor desempenho que ainda não haviam sido utilizadas. Baseado nas normas NBR 5410 e NBR 5419 que recomenda a utilização das ferragens estruturais das edificações como parte do sistema de aterramento elétrico, a concessionária de energia elétrica optou por fazer uso de concreto em hastes de aterramento.

Para efeito de comparação, foram construídas na segunda etapa da pesquisa duas configurações com as mesmas características citadas anteriormente, sendo com 1 haste simples e 3 hastes em linha, todas envolvidas em concreto, na proporção de cinco porções de areia grossa para uma de cimento. Após o uso do concreto, as hastes e os condutores ficaram com diâmetro de $40 \mathrm{~cm}$. As Figuras 22 e 23 mostram os aterramentos com uma e três hastes em linha. 


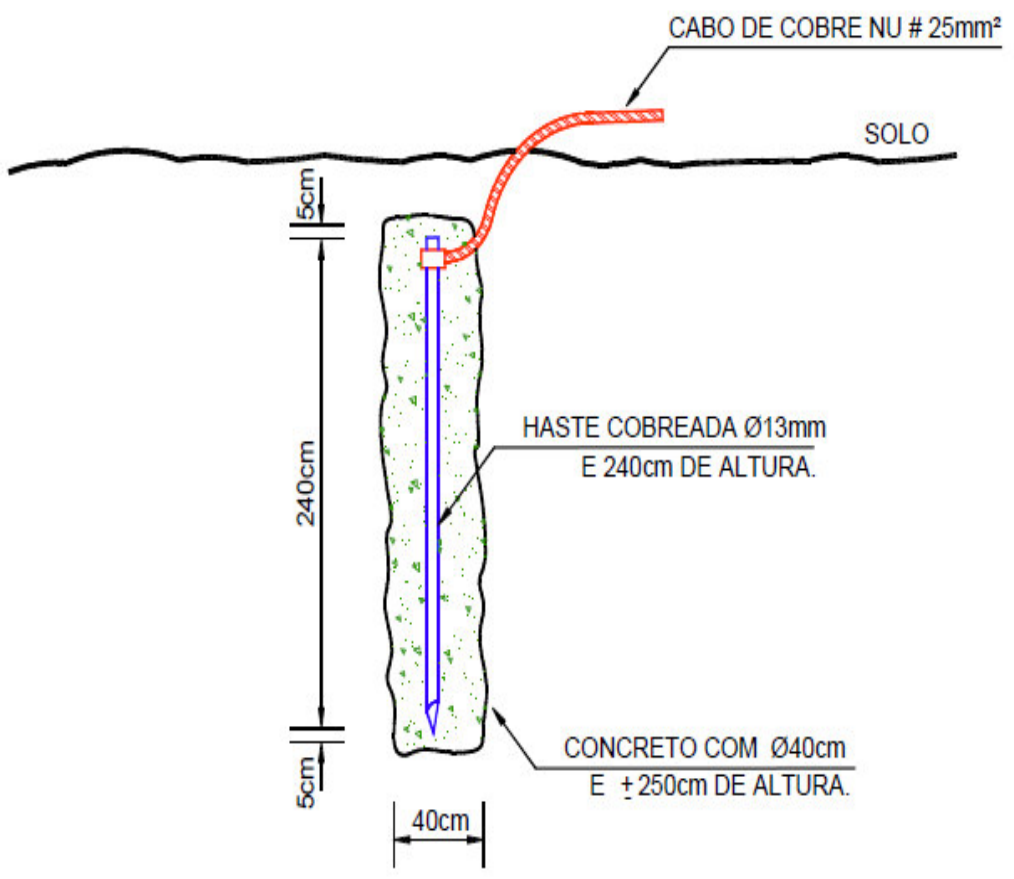

Figura 22 - Sistema de aterramento com uma haste envolvida em concreto.

Fonte: (CLAUSEN, et al., 2004)

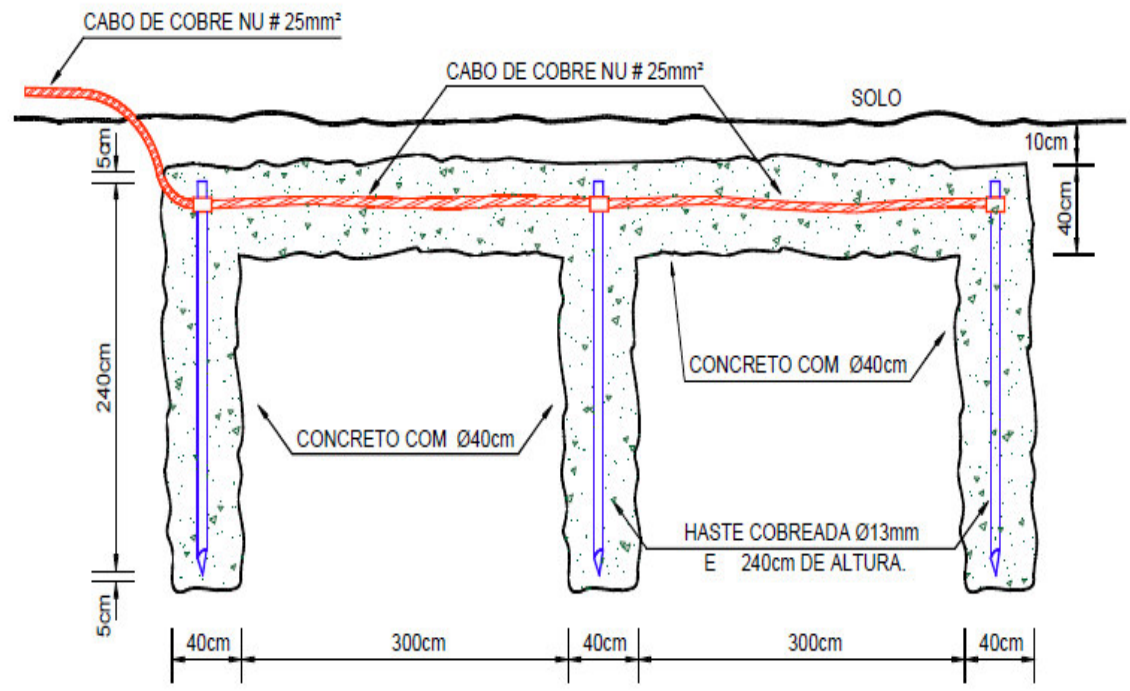

Figura 23 - Sistema de aterramento com três hastes envolvidas em concreto.

Fonte: (CLAUSEN, et al., 2004). 
A Tabela 13 mostra os resultados encontrados na segunda etapa do trabalho.

Tabela 13 - Malhas envolvidas em concreto.

\begin{tabular}{|c|c|c|c|c|c|c|c|}
\hline $\begin{array}{c}\text { Configuração } \\
\text { da malha }\end{array}$ & $\begin{array}{c}\mathrm{N}^{\mathrm{o}} \mathrm{de} \\
\text { hastes }\end{array}$ & $\begin{array}{c}\mathrm{L} \\
(\mathrm{mm})\end{array}$ & $\begin{array}{c}\mathrm{e} \\
(\mathrm{mm})\end{array}$ & $\begin{array}{c}\emptyset \\
\text { Haste } \\
\text { convencional } \\
(\mathrm{mm})\end{array}$ & $\begin{array}{c}\emptyset \\
\text { haste } \\
\text { concretada } \\
(\mathrm{cm})\end{array}$ & $\begin{array}{c}\rho \\
(\Omega . \mathrm{m})\end{array}$ & $\begin{array}{c}\text { Rat } \\
\text { concreto } \\
(\Omega)\end{array}$ \\
\hline Haste simples & 1,0 & 2400 & & 13 & 40 & 1000 & 211,7 \\
\hline Haste alinhada & 3,0 & 2400 & 3000 & 13 & 40 & 1000 & 89 \\
\hline
\end{tabular}

Fonte: Clausen, et al., 2004

Os resultados da pesquisa comprovaram a eficiência do uso do concreto nas hastes de aterramento. A redução de resistência de terra com o uso do concreto foi de $38 \%$ em relação à convencional. No caso da malha com três hastes alinhadas, a redução foi de 33,90\% com o uso do concreto.

Os autores construíram na terceira etapa da pesquisa outro sistema de aterramento com as mesmas características das hastes concretadas, porém utilizando gel, que é a alternativa utilizada pela CELESC quando da necessidade de obter melhor desempenho do aterramento. O gel químico é formado por uma mistura de diversos sais e água tornando-o quimicamente estável, insolúvel em água, higroscópico e de longa duração. A Tabela 14 mostra os resultados encontrados.

Tabela 14 - Malhas com gel

\begin{tabular}{|c|c|c|c|c|c|c|}
\hline $\begin{array}{c}\text { Configuração } \\
\text { da malha }\end{array}$ & $\mathrm{N}^{\mathrm{o}}$ de hastes & $\begin{array}{c}\mathrm{L} \\
(\mathrm{mm})\end{array}$ & $\begin{array}{c}\mathrm{e} \\
(\mathrm{mm})\end{array}$ & $\begin{array}{c}\varnothing \\
(\mathrm{mm})\end{array}$ & $\begin{array}{c}\rho \\
(\Omega . \mathrm{m})\end{array}$ & $\begin{array}{c}\text { Rat gel. } \\
(\Omega)\end{array}$ \\
\hline Haste simples & 1,0 & 2400 & & 13 & 1000 & 288,7 \\
\hline Haste alinhada & 3,0 & 2400 & 3000 & 13 & 1000 & 90 \\
\hline
\end{tabular}

Fonte: Clausen, et al., 2004

O tratamento com gel reduziu a resistência de terra em $12 \%$ em relação à configuração convencional, porém comparado com a haste envolvida em concreto ficou $13,4 \%$ maior. $\mathrm{Na}$ configuração com três hastes o gel reduziu o valor em 30\% e ficou com 12,5\% acima do valor 
obtido com a mesma configuração envolvida em concreto. Os resultados da pesquisa comprovaram melhor desempenho do uso do concreto nas hastes de aterramento em comparação ao uso com gel.

Na sequiência da pesquisa os autores testaram o uso de postes convencionais como hastes de aterramento. $\mathrm{O}$ valor foi medido na ferragem da estrutura do mesmo, próximo ao solo. O primeiro poste avaliado é do tipo T, de $11 \mathrm{~m}$ de altura, instalado há muitos anos. Para realização das medidas foram quebrados os quatros cantos do poste para expor totalmente sua ferragem. A Tabela 15 mostra os resultados dos valores de resistência de terra.

Tabela 15 - Valores de resistência de terra com uso do poste

\begin{tabular}{|l|c|c|c|}
\hline Configuração & $N^{\circ}$ do Poste & $\begin{array}{c}\mathrm{L} \\
(\mathrm{mm})\end{array}$ & $\begin{array}{c}\text { Rat } \\
\text { poste } \\
(\Omega)\end{array}$ \\
\hline Poste duplo T & & 11000 & 130 \\
\hline Poste circular & 1,0 & 10000 & 129 \\
\hline Poste circular & 2,0 & 10000 & 277 \\
\hline Poste circular & 3,0 & 11000 & 255 \\
\hline Poste circular & 4,0 & 11000 & 231 \\
\hline Poste circular & 5,0 & 11000 & 150 \\
& & & \\
\hline
\end{tabular}

Fonte: Clausen, et al., 2004

Os cinco postes foram interligados entre si, através de um cabo aéreo de $25 \mathrm{~mm}^{2}$, como em uma rede de distribuição. $\mathrm{O}$ espaçamento entre postes era de $23 \mathrm{~m}$ em média. $\mathrm{O}$ valor de resistência de terra medido foi de $35 \mathrm{ohms}$, para o conjunto com 5 postes interligados.

Deste modo, os autores apresentaram resultados de medições que possibilitaram a proposição de um sistema de aterramento para as redes de distribuição de energia, utilizando o próprio poste duplo "T" como parte do aterramento elétrico. 


\subsection{MEDIÇÃO DE RESISTÊNCIA DE TERRA EM SISTEMA DE ATERRAMENTO TRATADO COM BENTONITA}

Em (CAVALCANTE et al., 2005) foi desenvolvido um projeto de pesquisa na área de concessão da CPFL-Piratininga com o objetivo de desenvolver novas tecnologias a serem implantadas como solução em sistemas de aterramento na rede de distribuição de energia elétrica. Foram feitas várias experiências com vários tipos de aterramento e materiais. $\mathrm{Na}$ área de concessão da CPFL-Piratininga em Jundiaí foram instaladas algumas configurações de aterramento com hastes de 1,5 a $3 \mathrm{~m}$ de comprimento. A haste de 1,5 $\mathrm{m}$ de comprimento foi tratada com $60 \mathrm{~kg}$ do produto bentonita misturada com terra na proporção de $50 \%$ para ambos. A haste de $3 \mathrm{~m}$ de comprimento foi tratada com $120 \mathrm{~kg}$ de bentonita na mesma proporção de $50 \%$ de terra e $50 \%$ de bentonita. A Figura 24 mostra o valor de resistência de terra para haste de $1,5 \mathrm{~m}$ convencional e para a haste de $1,5 \mathrm{~m}$ tratada.

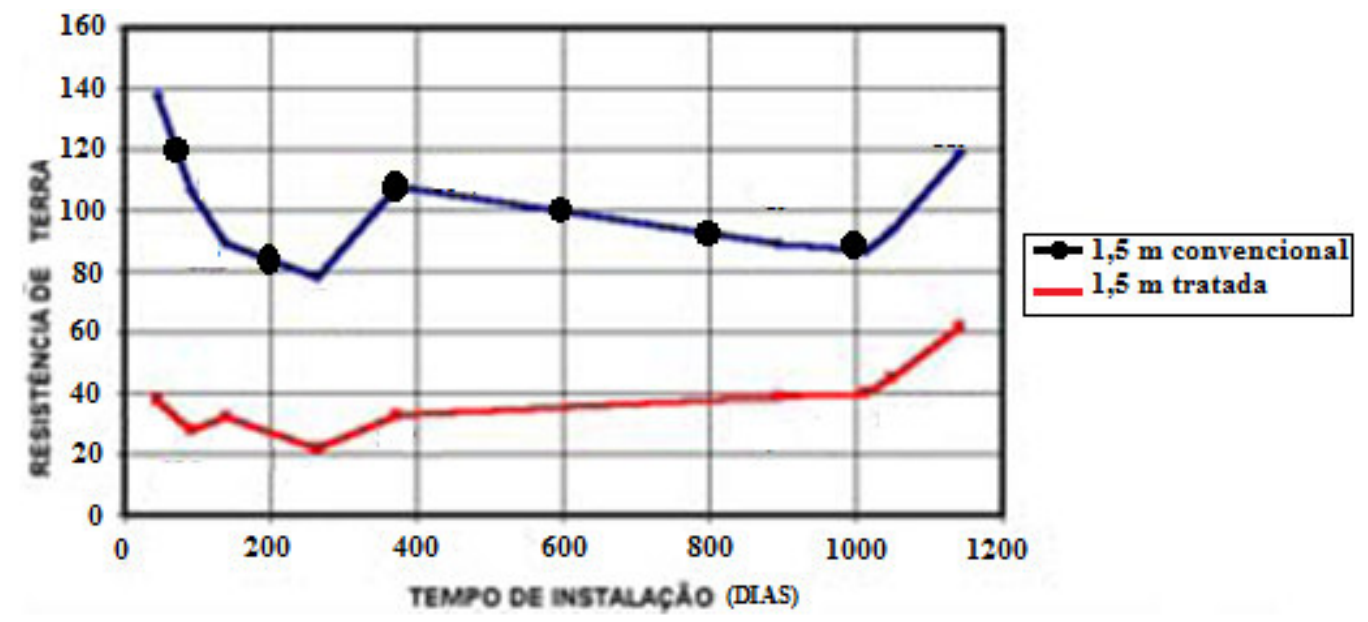

Figura 24 - Valores de resistência de terra para haste de 1,5 m convencional e para haste de 1,5 m tratada com bentonita .

Fonte: Adaptada (CAVALCANTE et al., 2005) 
Pode-se observar na Figura 24 a considerável redução da resistência de terra quando a haste está imersa na mistura de terra com bentonita e que após 1112 dias após a instalação a bentonita continua atuando na redução da resistência de terra. A Figura 25 mostra o valor da resistência de terra para haste de $3 \mathrm{~m}$ convencional e para haste de $3 \mathrm{~m}$ tratada.

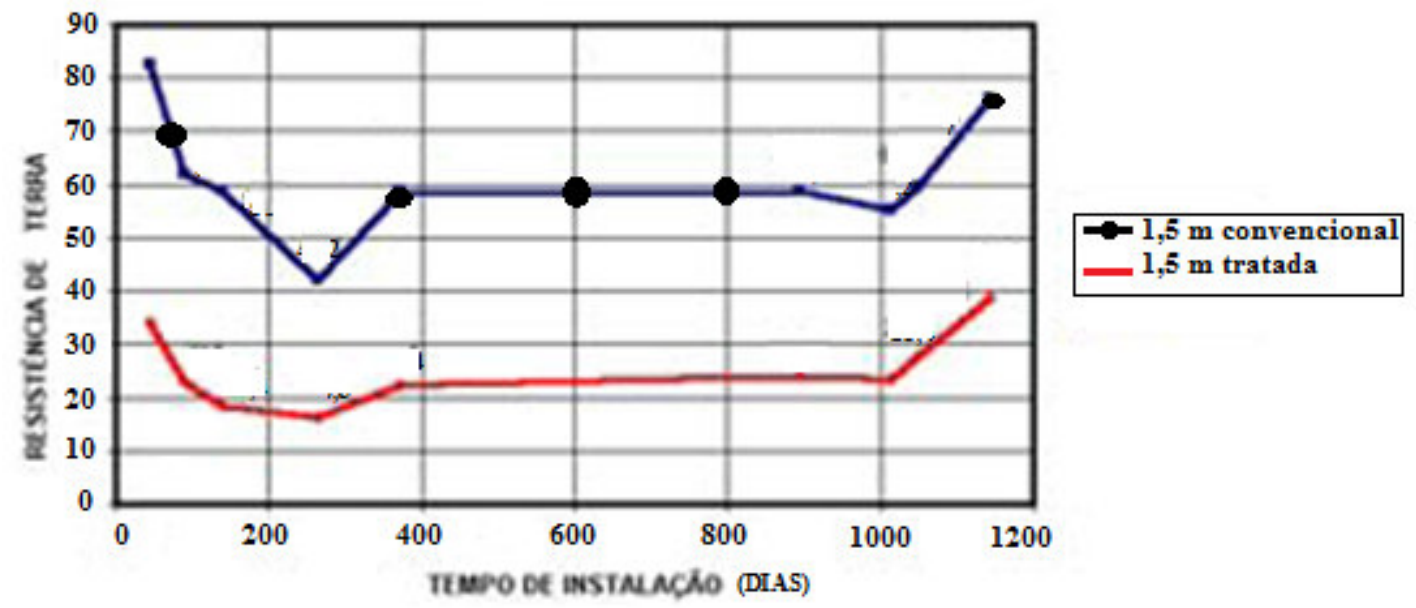

Figura 25 - Valores de resistência de terra para haste de $3 \mathrm{~m}$ convencional e para haste de $3 \mathrm{~m}$ tratada com bentonita.

Fonte: Adaptada (CAVALCANTE et al., 2005)

O efeito da bentonita nas hastes de $3 \mathrm{~m}$ também foi considerável. Os resultados obtidos indicaram uma longa duração do efeito da bentonita, contribuindo para a redução da resistência de terra.

Em (CAVALCANTE et al., 2005) foi também estudada a utilização das ferragens do poste de concreto como condutor de descida do aterramento da rede de distribuição, com o objetivo de avaliar se este aproveitamento das ferragens poderia ser tecnicamente viável. A experiência foi desenvolvida de forma que basicamente não houvesse diferença construtiva em relação a um poste de concreto normal, a não ser pela existência de solda em dois dos anéis que dão forma tubular ao poste. Os anéis soldados situam-se junto ao furo existente próximo ao topo utilizado para introdução do condutor de descida do aterramento e o outro furo na base do poste permite a saída do condutor para o aterramento. Aos anéis soldados aos vergalhões também foram soldados os condutores bimetálicos de aço de cobre 6 AWG de 0,3 
m de comprimento para possibilitar a interligação no topo do condutor a ser aterrado na rede de distribuição e na base a interligação com as hastes do sistema de aterramento da estrutura. A Figura 26 mostra o aterramento com as ferragens do poste.

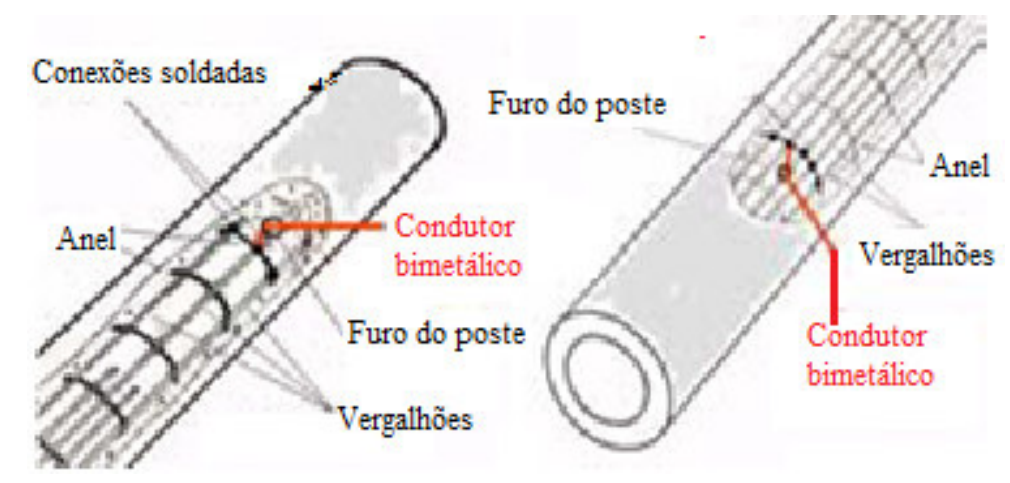

Figura 26 - Ferragens do poste

Fonte: Adaptada (CAVALCANTE et al., 2005)

A Tabela 16 mostra os resultados dos valores de resistência de terra em comparação com uma haste de aterramento de $3 \mathrm{~m}$ de comprimento tratada com bentonita.

Tabela 16 - Resistência de terra do poste de concreto em relação a uma haste de $3 \mathrm{~m}$ de comprimento tratada com bentonita.

\begin{tabular}{|c|c|c|c|}
\hline Condição do solo & $\begin{array}{c}\text { Rat } \\
\text { poste de } 11 \mathrm{~m} \\
(\Omega)\end{array}$ & $\begin{array}{c}\text { Rat } \\
\text { poste de } 9 \mathrm{~m} \\
(\Omega)\end{array}$ & $\begin{array}{c}\text { Rat } \\
\text { Haste de } 3 \mathrm{~m} . \\
(\Omega)\end{array}$ \\
\hline Muito úmido & 34 & 44,6 & 49,6 \\
\hline Normal & 47,5 & 49,6 & 56,5 \\
\hline Úmido & 45 & 51 & 55,9 \\
\hline
\end{tabular}

Fonte: Cavalcante et al., 2005. 
Os valores de resistência de terra em campo utilizando as ferragens do poste como parte do sistema de aterramento elétrico são próximos dos valores apresentados com a haste de $3 \mathrm{~m}$ de comprimento utilizando bentonita. 


\subsection{MEDIÇÕES DE RESISTÊNCIA DE TERRA EM SISTEMAS DE ATERRAMENTO COM HASTES CONVENCIONAIS E ENVOLVIDAS EM CONCRETO}

Em (SOUZA et al., 2007) foram analisadas alternativas para a construção de malhas de aterramento num solo com alta resistividade elétrica, baseando-se em resultados obtidos em medições. Para este projeto foram construídas três malhas de aterramento, com as mesmas configurações, a partir de hastes horizontais e cabos verticais. Foi utilizada para cada aterramento hastes com diâmetro de $12,7 \mathrm{~mm}$ e comprimento de 2,0 m. A distância entre hastes foi igual a $2 \mathrm{~m}$ e interligadas através de cabos de cobre nu, de $50 \mathrm{~mm} 2$. As conexões foram feitas através de condutores de aperto.

$\mathrm{Na}$ primeira etapa do trabalho foram construídas duas malhas em triângulo, uma com hastes convencionais (a) e outra com hastes concretadas (b), de acordo com a Figura 27.

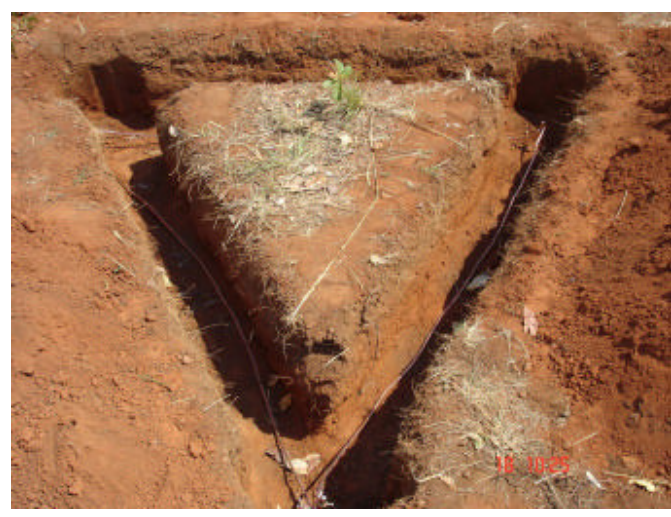

(a)

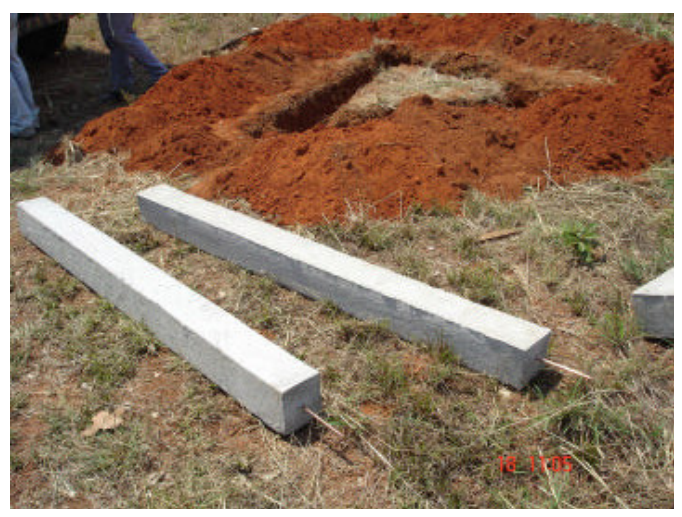

(b)

Figura 27 - Detalhes técnicos dos sistemas de aterramento utilizados. (a) sistema de aterramento convencional. (b) sistema de aterramento com hastes envolvidas em concreto

Fonte: (SOUZA et al., 2007)

A malha, utilizando hastes concretadas foi construída com a mesma mistura de concreto que é usada para construção de postes das redes de distribuição de energia elétrica. As hastes ficaram com dimensões de $(15 \mathrm{~cm}$ x $15 \mathrm{~cm})$ após concretagem. 
Após a construção das duas malhas, foram iniciadas as medições através da utilização de um terrômetro digital de quatro pontas. Os valores de resistência de terra foram obtidos durante dois períodos (chuvoso e seco). O aterramento que utilizou hastes concretadas apresentou valores de resistência de terra significativamente menores quando comparados com a malha de aterramento convencional. Para o período seco, a malha com haste concretada apresentou redução de $61 \%$ do valor de resistência de terra em comparação com o valor da malha convencional. O valor de resistência para o período chuvoso apresentou redução de $34 \%$ em relação à malha convencional.

Os gráficos das Figuras 28 e 29 representam o comportamento da resistência de terra nos períodos chuvoso e seco, respectivamente.

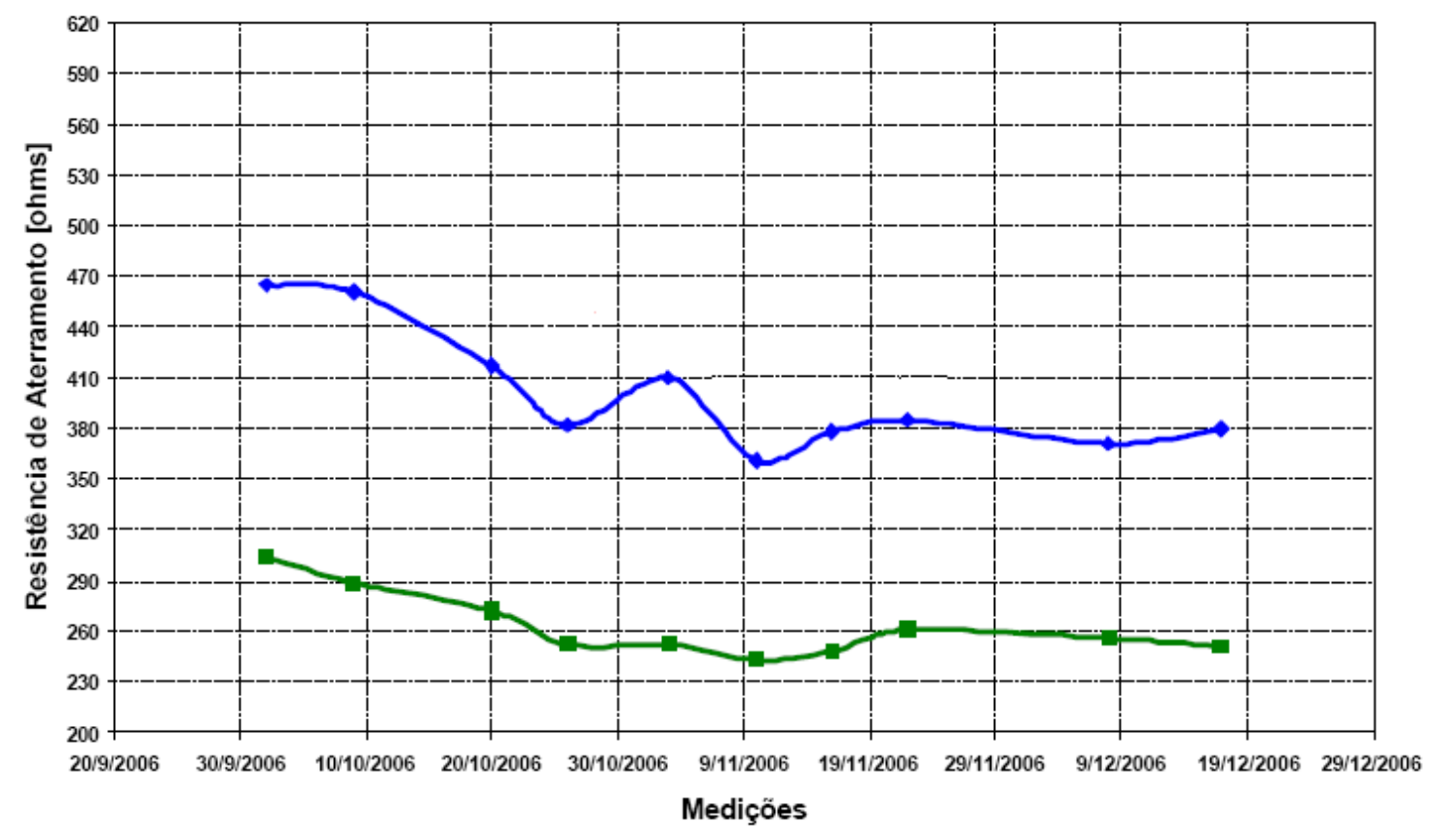

Aterr. Tradicional $=$ Haste Concretada

Figura 28 - Comportamento da resistência de terra em um sistema de aterramento com configuração convencional (aterramento tradicional) e com haste envolvida em concreto durante o período chuvoso

Fonte: Adaptada de (SOUZA et al., 2007). 


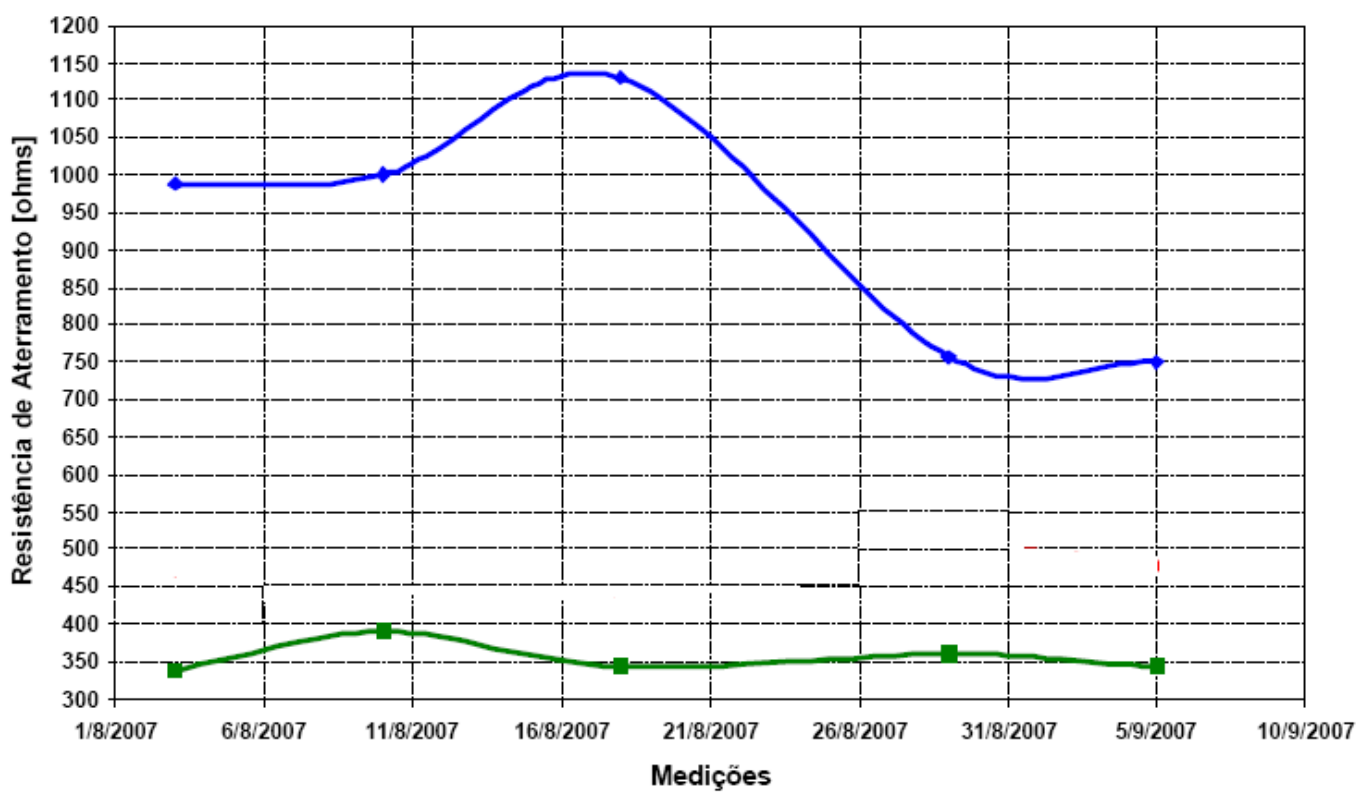

-Aterr. Tradicional $=$ Haste Concretada

Figura 29 - Comportamento da resistência de terra em um sistema de aterramento com configuração convencional (aterramento tradicional) e com haste envolvida em concreto durante o período seco

Fonte: Adaptada de (SOUZA et al., 2007).

Na segunda etapa do trabalho, os autores avaliaram o comportamento da resistência de terra em um sistema de aterramento com configuração convencional e quimicamente tratado com gel despolarizante, material que apresenta um alto grau de higroscopia. A Figura 30 mostra o solo tratado com gel despolarizante. 


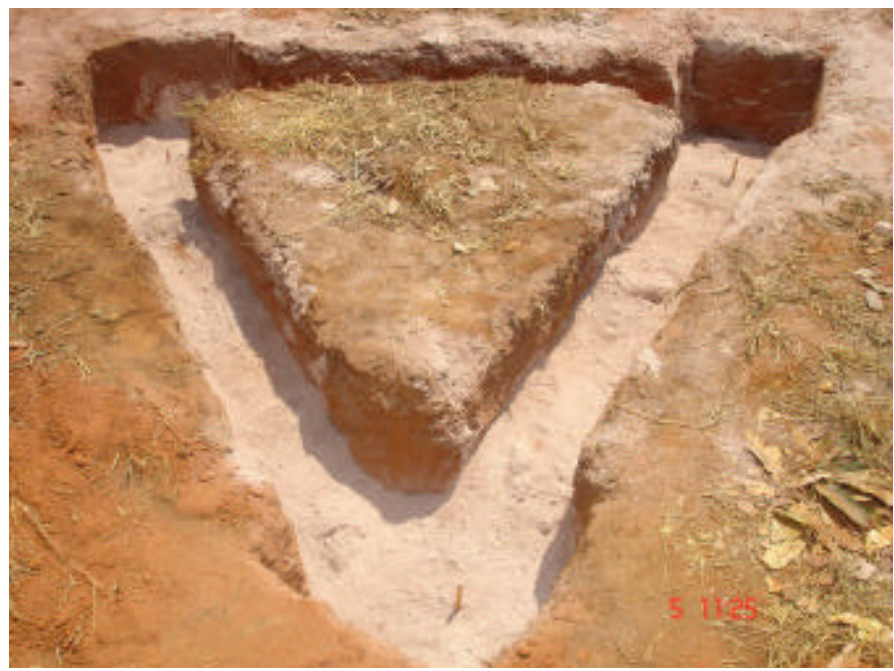

Figura 30 - Malha com tratamento químico.

Fonte: (SOUZA et al., 2007).

Os valores de resistência de terra foram medidos durante dois períodos do ano: chuvoso, de setembro a dezembro, e seco, entre agosto e setembro.

Os gráficos das Figuras 31 e 32 representam o comportamento da resistência de terra nos períodos chuvoso e seco, respectivamente.

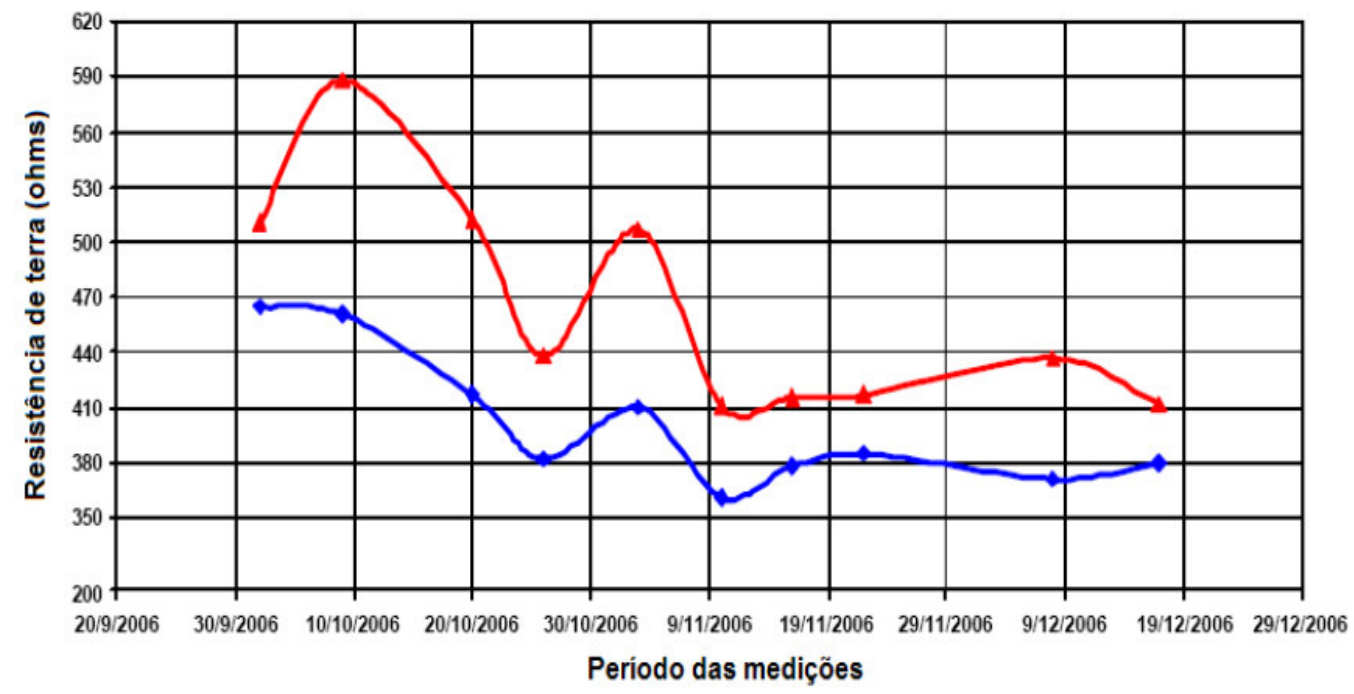

Aterr. Tradicional $=$ Trat. Químico

Figura 31 - Comportamento da resistência de terra em um sistema de aterramento com configuração convencional (aterramento tradicional) e com haste com tratamento quimico durante o período chuvoso

Fonte: Adaptada de (SOUZA et al., 2007). 


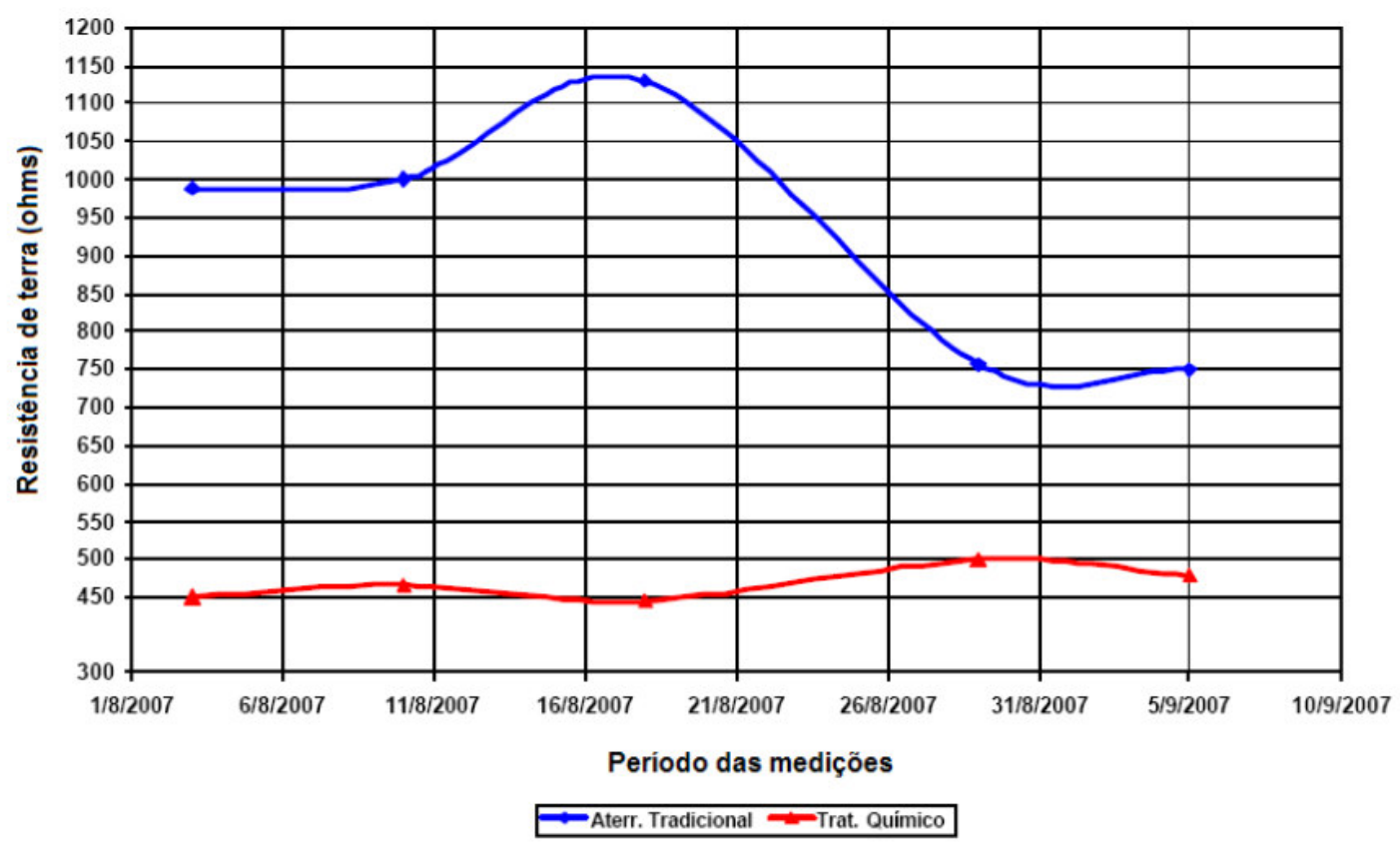

Figura 32 - Comportamento da resistência de terra em um sistema de aterramento com configuração convencional (aterramento tradicional) e com haste com tratamento químico durante o período seco

Fonte: Adaptada de (SOUZA et al., 2007).

No período chuvoso, o aterramento com tratamento químico apresentou valores de resistência de terra superiores, comparados com os valores medidos no aterramento convencional. Segundo os autores, estes dados estão relacionados com a má compactação do solo, causando espalhamento do material em função da infiltração da água na malha de aterramento. Entretanto, para condição de solo seco, a malha apresentou valores de resistência de terra consideravelmente inferiores aos medidos na malha convencional.

Segundo os autores, esta prática, na maioria das vezes, não é economicamente viável devido aos elevados custos das manutenções periódicas (reposição dos materiais) a fim de manter a eficácia dos produtos utilizados. 


\subsection{MEDIÇÕES DE RESISTÊNCIA DE TERRA EM SISTEMAS DE ATERRAMENTO CONSIDERANDO SOLO DE DIFERENTES RESISTIVIDADES}

Em (GALVAN et al., 2009), foram construídos sistemas de aterramento elétrico em dois campos experimentais, sendo um em solo vulcânico rochoso e o outro em solo rochoso calcário. Estes aterramentos foram construídos em pé de torres de linha de transmissão, a fim de obter dados práticos, tendo em vista o estudo do comportamento do aterramento quando da ocorrência de descarga atmosférica. Em alguns casos foram construídos experimentos para avaliar a resistividade e a resistência de terra de alguns compostos utilizados. As medições de resistividade do solo e das resistências de terra foram realizadas mensalmente durante um período de 18 meses. A Figura 33 ilustra a instalação da haste de aterramento.

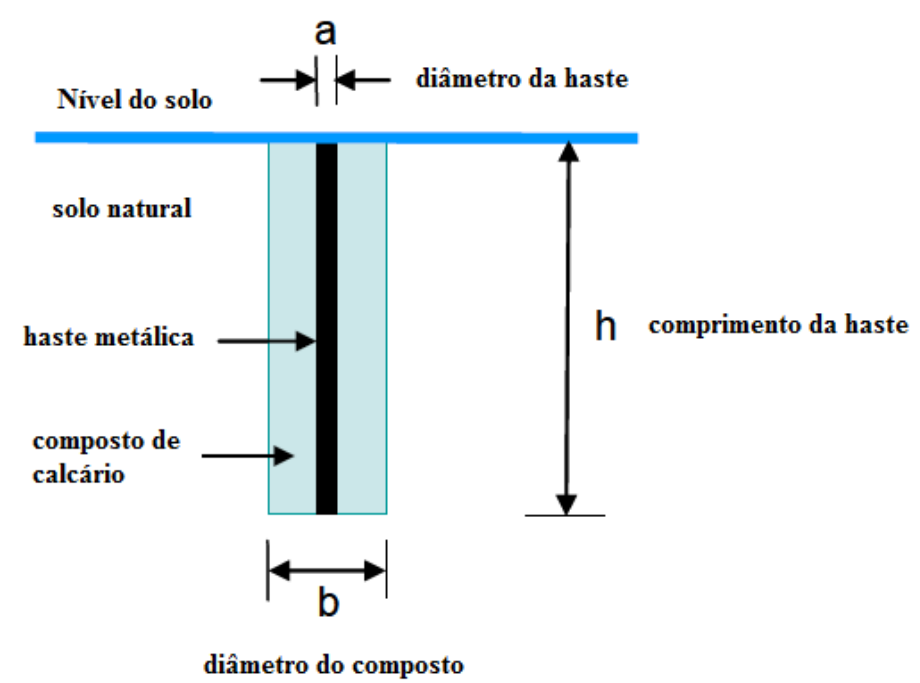

Figura 33 - Composto envolvendo a haste de aterramento Fonte: Adaptada (GALVAN et al., 2009)

O solo onde os aterramentos foram construídos é raramente homogêneo e a resistividade do solo varia em diferentes profundidades. Para efeito de comparação, as hastes de $16 \mathrm{~mm}$ de diâmetro (a) foram envolvidas utilizando pó químico, pó de solo da própria escavação da região vulcânica, pó de calcário da própria escavação da região de calcário e haste envolvida em concreto. Após o uso dos compostos envolvendo as hastes, as mesmas 
ficaram com diâmetro de 15,4 cm (b). As hastes utilizadas foram de $1,9 \mathrm{~m} \mathrm{e} 3,0 \mathrm{~m}$ de comprimento (h) (GALVAN et al., 2009)

Dois experimentos pilotos de resistividade foram construídos em diferentes profundidades, sendo preenchidos com material composto. Um local de medida foi no sudeste do México (solo calcário) o outro na região central (solo vulcânico). A Figura 34 mostra o piloto instalado a $0,8 \mathrm{~m}$ de profundidade. $\mathrm{O}$ outro piloto foi instalado na profundidade $\mathrm{h}$.

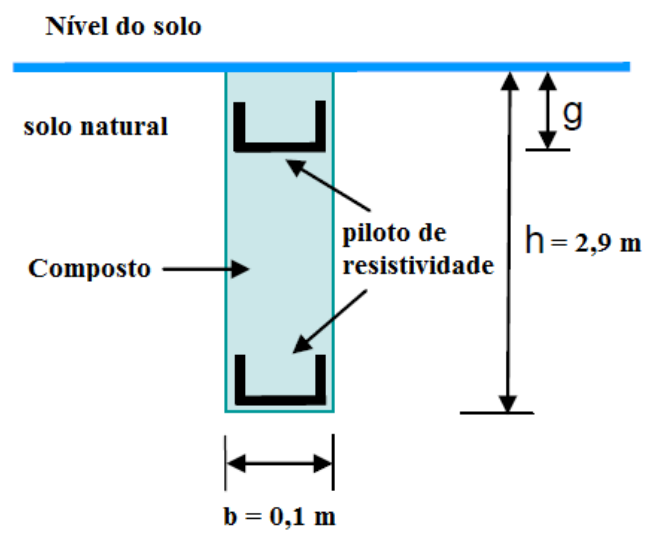

Figura 34 - Pilotos de resistividade em profundidade g e h.

Fonte: Adaptada (GALVAN et al., 2009)

Cada piloto de resistividade consiste de duas placas metálicas, que formam um cubo de $0.1 \times 0.1 \times 0.1 \mathrm{~m}$ com uma base dielétrica, conforme mostra a Figura 35 . O piloto permite avaliar a resistividade dos compostos em diferentes profundidades, avaliar o comportamento físico dos compostos e, também, relacionar a resistividade com a resistência de terra (GALVAN et al., 2009). 


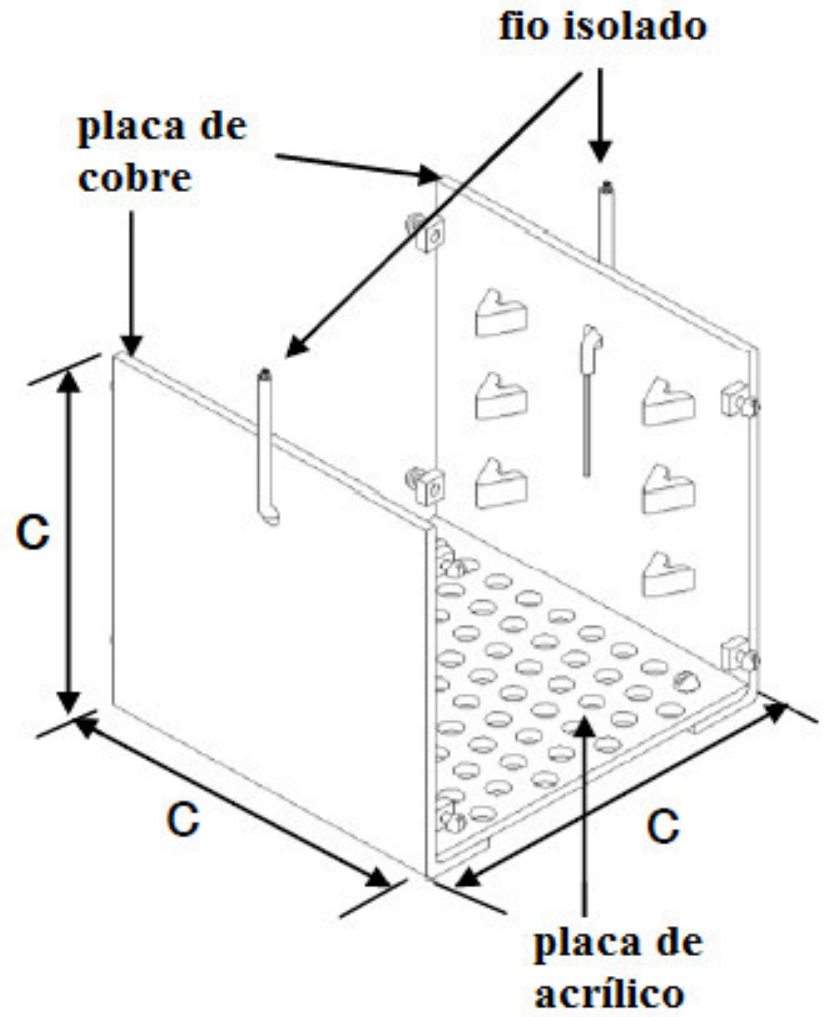

Figura 35 - Piloto de resistividade, utilizado para medir a resistividade do composto $(\mathrm{C}=0,1 \mathrm{~m})$

Fonte: Adaptada (GALVAN et al., 2009)

No primeiro caso, o campo experimental foi na linha de transmissão VAD BLM Y NIZ torre 265 (Figura 36). No segundo caso, o campo experimental foi na de linha de transmissão A3U50 TOPILEJO, entre as torres de 76 e 77 (Figura 37). Segundo os autores a haste de aterramento envolvida em concreto não foi instalada devida a razões de ordem prática, apenas resistividade experimental foi instalada (GALVAN et al., 2009). 


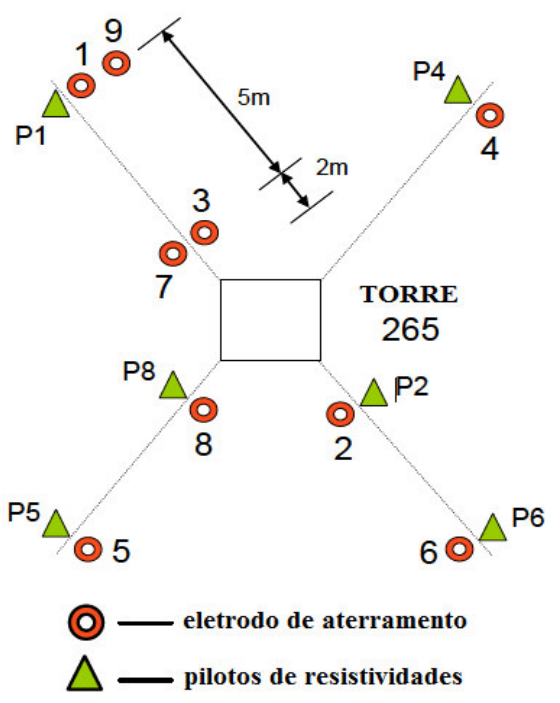

Figura 36 - Campo experimental em solo rochoso de calcário

Fonte: Adaptada (GALVAN et al., 2009)

As hastes de aterramento $1,2,4,5$ e 6 foram preenchidas com pó químico. $O$ aterramento 8 foi preenchido com concreto. A haste de aterramento 3 foi preenchida com o produto da escavação (pó de calcário). A haste de aterramento 7 foi preenchida com solo orgânico e 9 foi preenchido com bentonita.

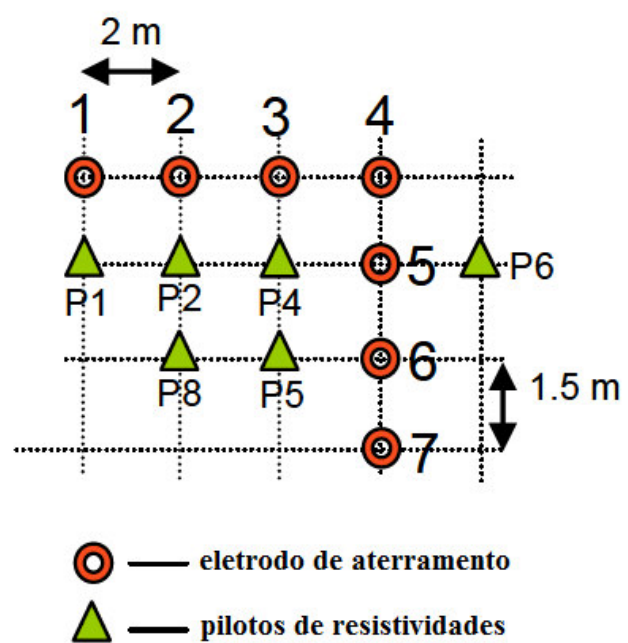

Figura 37 - Campo experimental em solo de rocha vulcânica

Fonte: Adaptada (GALVAN et al., 2009) 
As hastes de aterramento 1, 2, 4, 5 e 6 foram preenchidas com pó químico, a haste de aterramento 3 foi preenchido com o produto da própria escavação (pó de rocha vulcânica). A haste de aterramento 7 foi preenchida com solo orgânico, conforme apresentado na Figura 37. As Figuras 38 e 39 mostram os valores de resistência de terra das hastes instaladas em solo de calcário e solo de rochas vulcânicas, respectivamente.

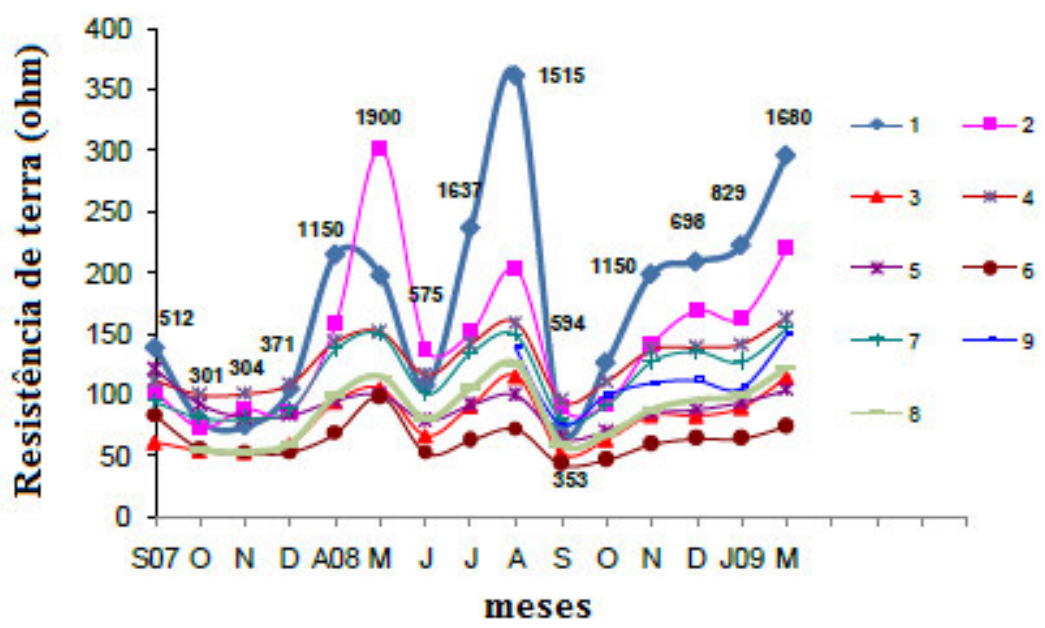

Figura 38 - Resistência de terra de hastes de aterramento localizadas no solo rochoso de calcário Fonte: Adaptada (GALVAN et al., 2009)

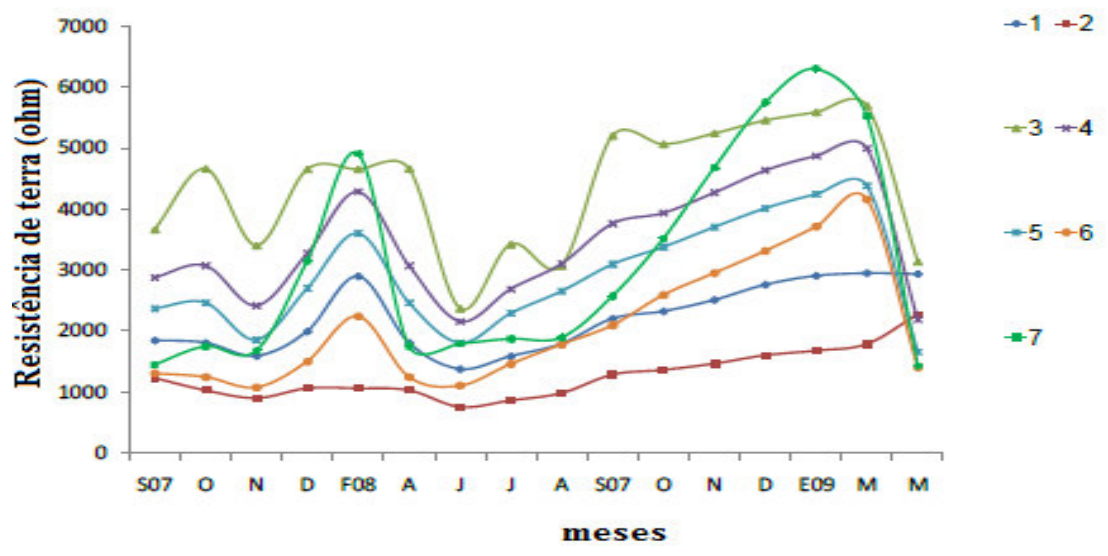

Figura 39 - Resistência de terra de hastes de aterramento localizadas em solo de rocha vulcânica Fonte: Adaptada (GALVAN et al., 2009) 
As Figuras 40 e 41 mostram os valores de resistividade do composto (4) em solo rochoso calcário e no solo rochoso vulcânico, respectivamente, medidos a partir dos pilotos localizados em diferentes profundidades. Pode-se observar que a resistividade é menor para os pilotos mais profundos quando comparado com os pilotos com menor profundidade.

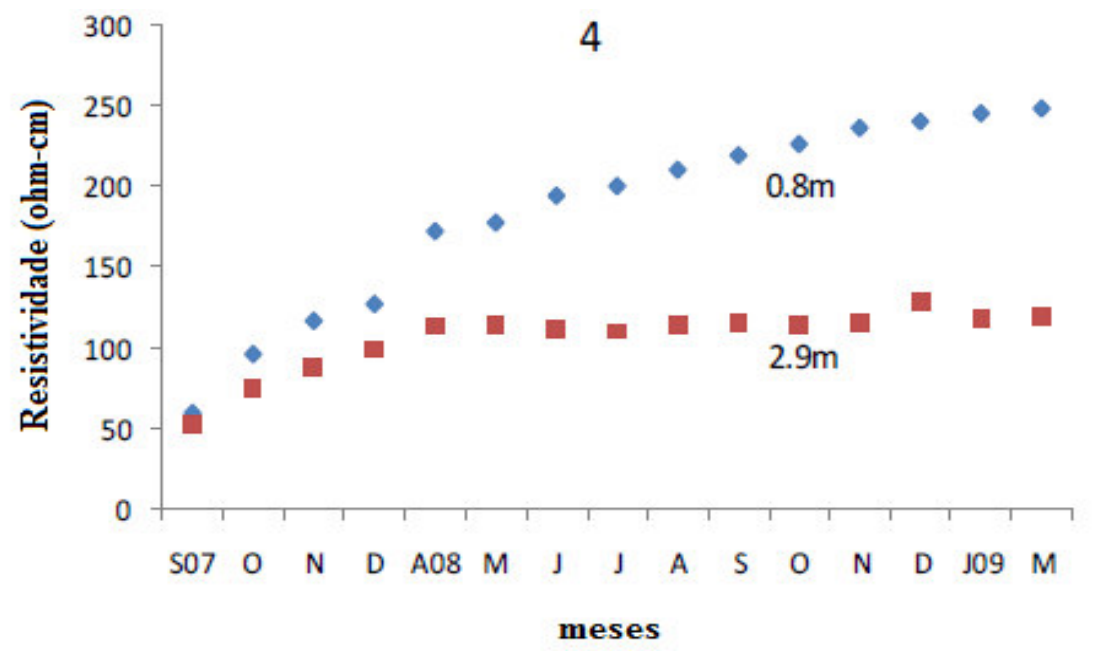

Figura 40 - Medições de resistividade obtidas pelos pilotos para a substância 4 (pó químico) em solo calcário rochoso. A profundidade dos pilotos é mostrada em cada curva Fonte: Adaptada (GALVAN et al., 2009)

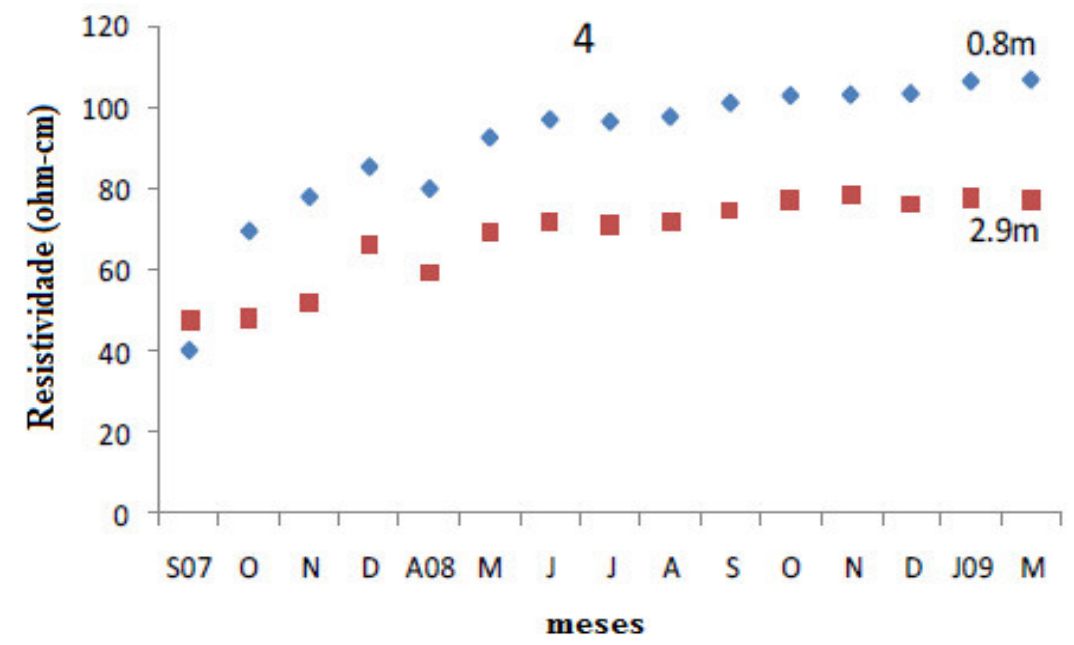

Figura 41 - Medições de resistividade obtidas pelos pilotos para a substância 4 (pó químico) em solo de rocha vulcânica. A profundidade dos pilotos é mostrada em cada curva.

Fonte: Adaptada (GALVAN et al., 2009) 
As Figuras 42 e 43 mostram os valores de resistência de terra da haste de aterramento e os valores de resistência medidos com o experimento piloto em solo de região vulcânica em solo em região de calcário para o composto 2.

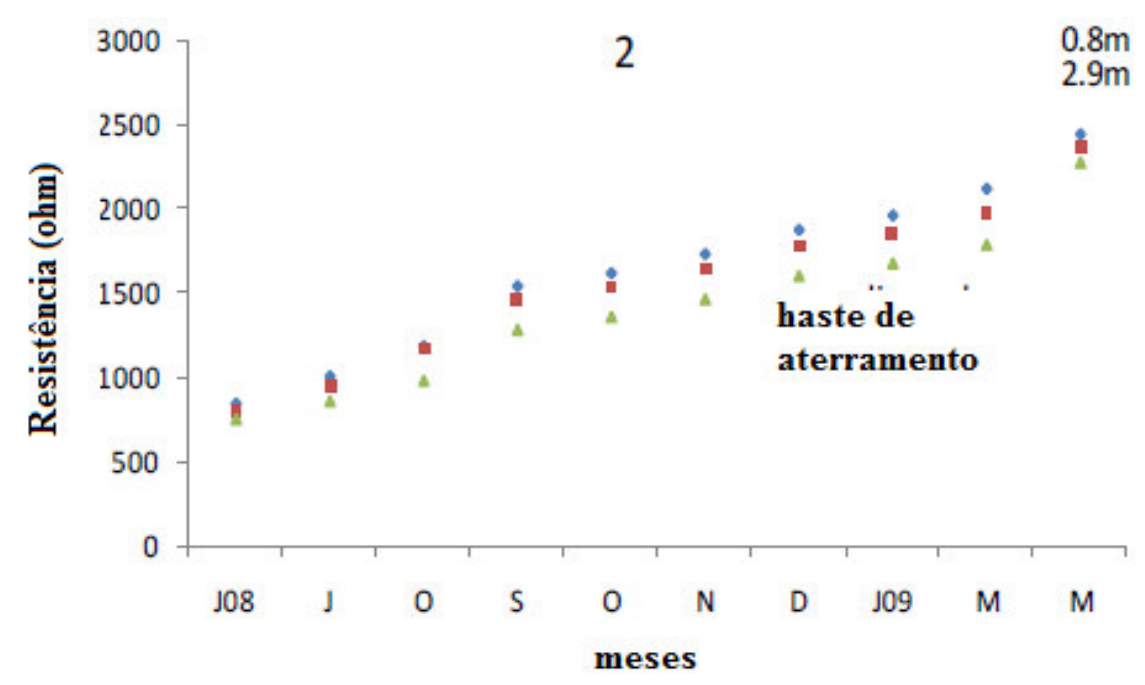

Figura 42 - Medições de resistência de terra obtidas pelos pilotos com o composto 2 em solo de rocha vulcânica.

Fonte: Adaptada (GALVAN et al., 2009)

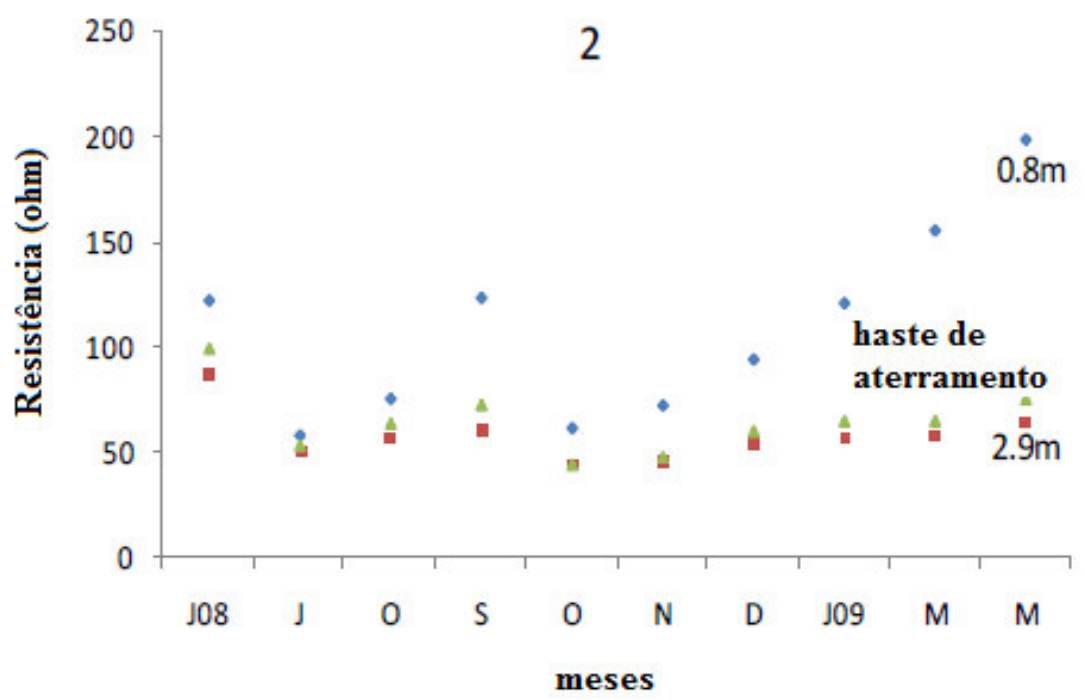

Figura 43 - Medições de resistência de terra obtidas pelos pilotos com o composto 2 em solo rochoso e calcário para haste de aterramento

Fonte: Adaptada (GALVAN et al., 2009) 
Segundo os autores, utilizando o composto 2 (partículas de rochas vulcânicas) em solo de rocha de calcário e resistividade variando de $200 \Omega$. m a $500 \Omega$. m a redução da resistência de terra foi de $30 \%$, e no mesmo solo, onde a resistividade era maior que $500 \Omega$. m a redução foi de $50 \%$. O composto 2 sendo utilizado em solo de região vulcânica com resistividade variando de $500 \Omega$. m a $1000 \Omega$. m a redução foi de $40 \%$, e onde a resistividade apresentava valor acima de $1000 \Omega$. m a redução foi de $65 \%$, ou seja, mais significativa.

Os autores consideraram que em ambos os solos os resultados foram satisfatórios, porém, os resultados são marginais não apresentando redução satisfatória ao longo do tempo. Segundo os autores, o melhor resultado foi obtido com a haste envolvida em concreto, ou seja, o valor resistência de terra se manteve constante durante as medições, além de apresentar redução acima das outras configurações utilizadas.

Os resultados mostrados em (CLAUSEN et al, 2004; SOUZA, et al., 2007; GALVAN, 2009) foram obtidos através de medições no campo, não sendo realizadas comparações com cálculos teóricos.

A utilização de eletrodos envolvidos em concreto como parte do sistema de aterramento elétrico foi a que apresentou resultado mais satisfatório dentre os estudos apresentados com diferentes técnicas para redução do valor de resistência de terra. Os resultados consideram que o metal encapsulado com concreto atua como eletrodo de aterramento eficaz. A partir de então outros estudos foram desenvolvidos nessa área de pesquisa. Ao longo do texto são apresentados trabalhos de autores que obtiveram excelentes resultados com a utilização da haste de aterramento envolvida em concreto. A vantagem é que o mesmo fica sob o nível do solo, mantendo sempre certo grau de umidade, assim seu valor de resistividade é baixo, comumente muito menor do que o valor do próprio solo onde está sendo construído o sistema de aterramento. Portanto, contribui para a redução da resistência de terra, com conseqüente diminuição das diferenças de potencial de toque e de passo.

Os resultados apresentados neste capítulo serviram de motivação para o estudo do aterramento considerando-se hastes e condutores envolvidos em concreto, com objetivo de reduzir a resistência de terra. $\mathrm{O}$ estudo de caso com a aplicação desta técnica é apresentado no capítulo 6. 


\section{ESTUDO DE CASO}

No estudo de caso foi considerada como base a malha de aterramento padrão utilizada no sistema MRT da concessionária de energia elétrica CELTINS, localizada no estado de Tocantins. O objetivo foi o estudo da malha de aterramento visando a redução da resistência de terra. São apresentados resultados de valores de resistência de terra em baixa e alta frequiência e as tensões de passo e de toque da malha do sistema de distribuição MRT. Os valores, obtidos em simulações, são apresentados dentro de faixas de resistividades do solo encontrados na própria região onde os sistemas de aterramento estão instalados.

Para o desenvolvimento do trabalho foi utilizado o software de elementos finitos CDEGS (Current Distribution, Electromagnetic Fields, Grounding and Soil Structure Analysis), versão 2000 (CDEGS, 2000) e (L. VALLEJOS et al. 2009). Esse programa é de origem canadense e dentre várias aplicações, permite a análise da estratificação do solo por camadas, a simulação de malhas de aterramento e o cálculo das tensões de passo e de toque (mais detalhes no anexo I).

Os casos estudados tiveram como parâmetros o espaçamento entre hastes, comprimento das hastes, área de instalação de sistemas de aterramento, quantidade de hastes e geometria interna da malha. Outras configurações de aterramento foram determinadas para análise do comportamento da resistência de terra, sendo consideradas configurações em triângulo, anéis concêntricos e, principalmente, malha reticulada.

Em seqüência, foram analisados os sistemas de aterramento considerando-se a utilização de hastes e condutores de malhas envolvidos em concreto. Simulações computacionais foram realizadas, sendo obtidos os valores de resistência de terra, passo e toque. Também foi estudado o comportamento da impedância de aterramento em função da frequiência. Com as informações e os resultados obtidos, foi possível avaliar os sistemas de aterramento e determinar quais configurações apresentam melhor desempenho em relação àquela que normalmente é utilizada na rede de distribuição. Outro fator importante neste trabalho é a avaliação de malhas de aterramento utilizando hastes e condutores envolvidos em concreto, principalmente em solos que apresentam alta resistividade. 


\subsection{SISTEMAS DE ATERRAMENTO COM HASTES E CONDUTORES CONVENCIONAIS}

A área de concessão da CELTINS apresenta valores elevados de resistividade do solo, sendo encontrados desde $500 \Omega$.m até $10.000 \Omega$.m. Como consequiência, os valores de resistência de terra nem sempre atendem os requisitos estabelecidos.

A configuração de aterramento padrão utilizado no sistema MRT da CELTINS é constituída por uma malha reticulada com 12 hastes cilíndricas, cravadas na vertical, com $60 \mathrm{~cm}$ abaixo da superfície do solo. O espaçamento entre hastes é de $5000 \mathrm{~mm}$, sendo o comprimento da haste $2400 \mathrm{~mm}$ e o diâmetro de $16 \mathrm{~mm}$. A primeira haste está, no mínimo, a $1 \mathrm{~m}$ do poste e as interligações das hastes são feitas através de cabos nus, com $25 \mathrm{~mm}^{2}$ de diâmetro, na posição horizontal. A Figura 44 ilustra a configuração da malha padrão de aterramento, conforme apresentado em CELTINS (2008) e CELTINS (2009).

Tendo-se por objetivo avaliar a configuração de aterramento padrão, foram realizadas simulações considerando valores típicos de resistividade do solo. Foram feitas alterações nessa configuração para verificar a influência do espaçamento entre hastes e do comprimento das hastes. Foi avaliada também a influência da profundidade de hastes e da geometria interna da malha.

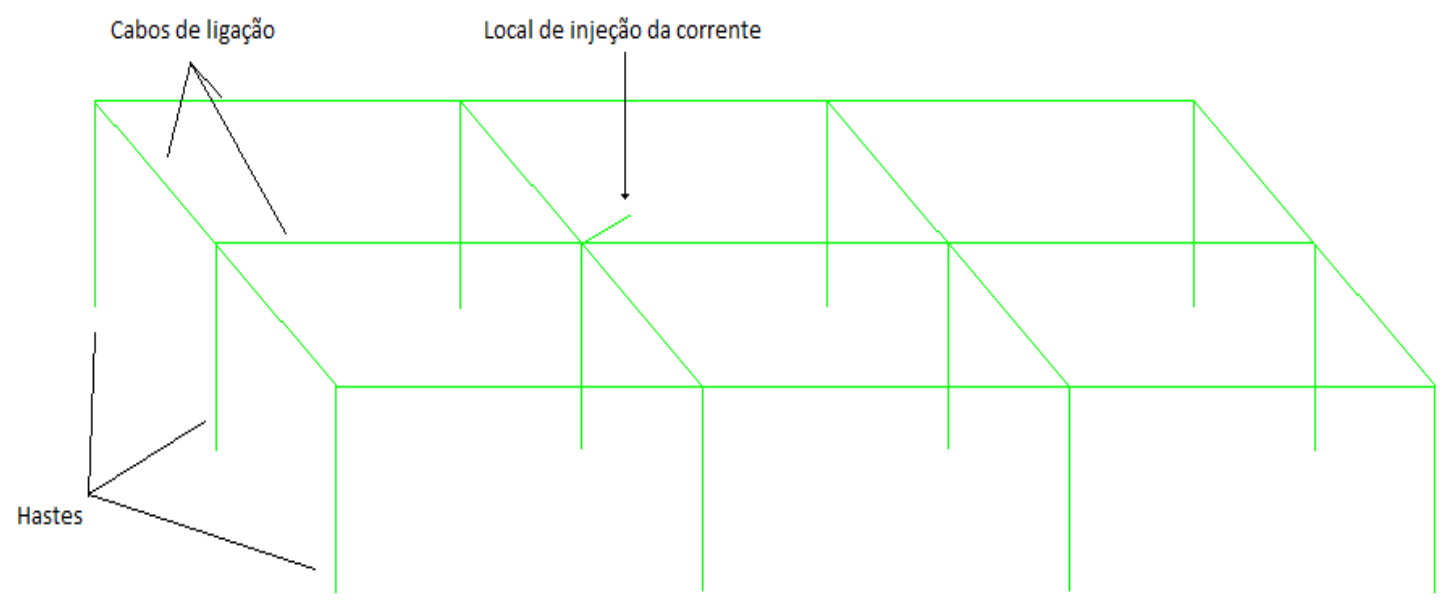

Figura 44 - Malha padrão CELTINS (12 hastes). 
6.1.1 Configurações de Aterramento Constituídas por Malha Reticulada

A seguir, serão apresentadas as simulações referentes aos dez casos estudados:

- caso 1 - configuração de aterramento padrão da CELTINS;

- caso 2 - sistema de configuração com as mesmas características do caso 1 , alterando somente o espaçamento entre hastes de $5000 \mathrm{~mm}$ para $6000 \mathrm{~mm}$;

- caso 3 - sistema de configuração com as mesmas características do caso 1 , alterando somente o espaçamento entre hastes de $5000 \mathrm{~mm}$ para $8000 \mathrm{~mm}$;

- caso 4 - sistema de configuração com as mesmas características do caso 3, alterando o comprimento da haste de $2400 \mathrm{~mm}$ para $3000 \mathrm{~mm}$;

- caso 5 - sistema de configuração com as mesmas características do caso 3, utilizando haste profunda de $6000 \mathrm{~mm}$ de comprimento;

- caso 6 - sistema de configuração com as mesmas características do caso 1, alterando somente o espaçamento entre as hastes de $5000 \mathrm{~mm}$ para $10000 \mathrm{~mm}$;

- caso 7 - sistema de configuração com a mesma área utilizada no caso 1 , alterando o número de 12 hastes para 7 e a geometria interna da malha;

- caso 8 - sistema de configuração com a mesma área utilizada no caso 1, alterando o número de hastes para 9 e a geometria interna da malha;

- caso 9 - sistema de configuração com as mesmas características do caso 7, alterando o número de hastes para 9 ;

- caso 10 - sistema de configuração com as mesmas características do caso 7, porém, com 6 hastes.

Para os casos 7 a 10 foram alterados a geometria e o número de hastes da malha, conforme ilustra a Figura 45. 


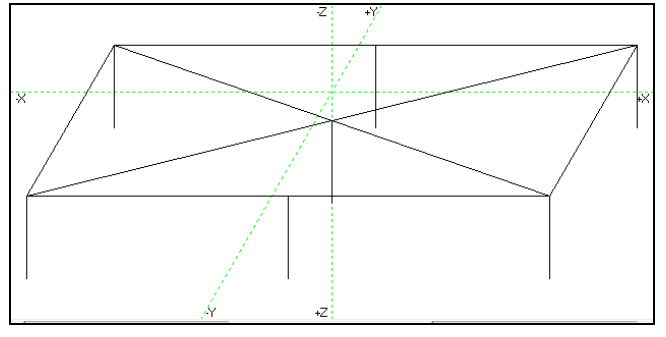

a) caso 7 (7 hastes)

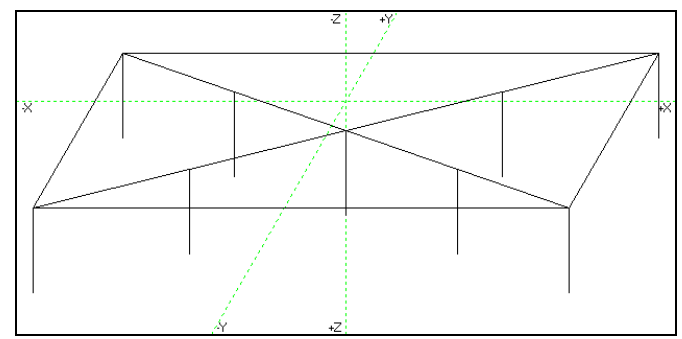

c) caso 9 (9 hastes)

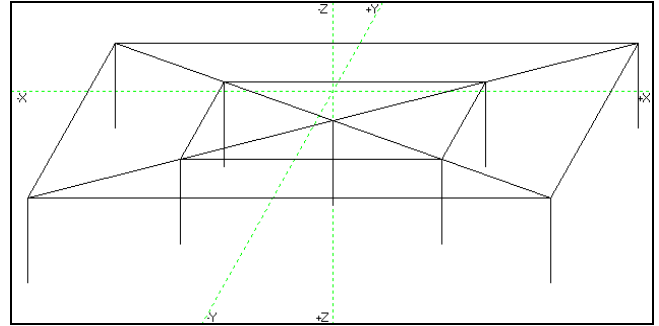

b) caso 8 (9 hastes)

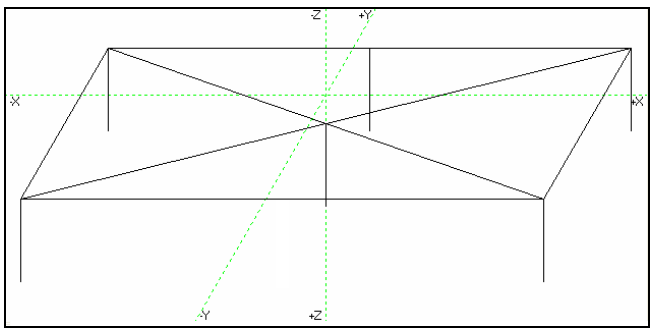

d) caso 10 (6 hastes)

Figura 45 - Simulação dos casos 7 a 10.

A Tabela 17 apresenta a influência do espaçamento entre hastes. A partir do caso 1, aumentando o espaçamento, a área de instalação do sistema de aterramento também aumenta. Para diminuir o valor de resistência de terra em 41,74\%, é necessário o aumento do espaçamento entre hastes para $10.000 \mathrm{~mm}$, ou seja, uma área quatro vezes a área do caso 1.

Tabela 17 - Influência do espaçamento entre hastes $(\rho=500 \Omega . m)$

\begin{tabular}{|c|c|c|c|c|c|c|}
\hline Casos & Hastes (total) & $\begin{array}{c}\mathrm{e} \\
(\mathrm{mm})\end{array}$ & $\begin{array}{c}\mathrm{L} \\
(\mathrm{mm})\end{array}$ & $\begin{array}{c}\emptyset \\
(\mathrm{mm})\end{array}$ & $\begin{array}{c}\text { Área } \\
\left(\mathrm{m}^{2}\right)\end{array}$ & $\begin{array}{c}\text { Rat } \\
(\Omega)\end{array}$ \\
\hline 1 & 12 & 5.000 & 2.400 & 16 & 150 & 16,63 \\
\hline 2 & 12 & 6.000 & 2.400 & 16 & 216 & 14,52 \\
\hline 3 & 12 & 8.000 & 2.400 & 16 & 384 & 11,61 \\
\hline 6 & 12 & 10.000 & 2.400 & 16 & 600 & 9,69 \\
\hline
\end{tabular}


De modo geral, o espaçamento entre hastes é da ordem de uma ou duas vezes o comprimento da haste, a fim de se otimizar o espaçamento entre as mesmas, colocando-as fora de suas zonas de influência (AREND, 2007) e (LUZ, 2009).

A interligação de hastes em paralelo diminui consideravelmente o valor da resistência de terra. Entretanto, o cálculo da resistência de hastes paralelas não segue a lei simples do paralelismo de resistências elétricas devido às interferências nas zonas de atuação das superfícies equipotenciais (JUNIOR, 2007) e (PEREIRA, 2008).

$\mathrm{O}$ aumento do espaçamento entre hastes faz com que a interferência diminua, porém, um aumento muito grande do espaçamento não é economicamente viável e necessita uma área de instalação muito maior. A Figura 46 mostra os resultados referentes ao aumento do espaçamento entre hastes e a respectiva diminuição dos valores de resistência de terra, considerando-se valores de resistividade do solo iguais a 500, 1000 e $3000 \Omega \mathrm{m}$.

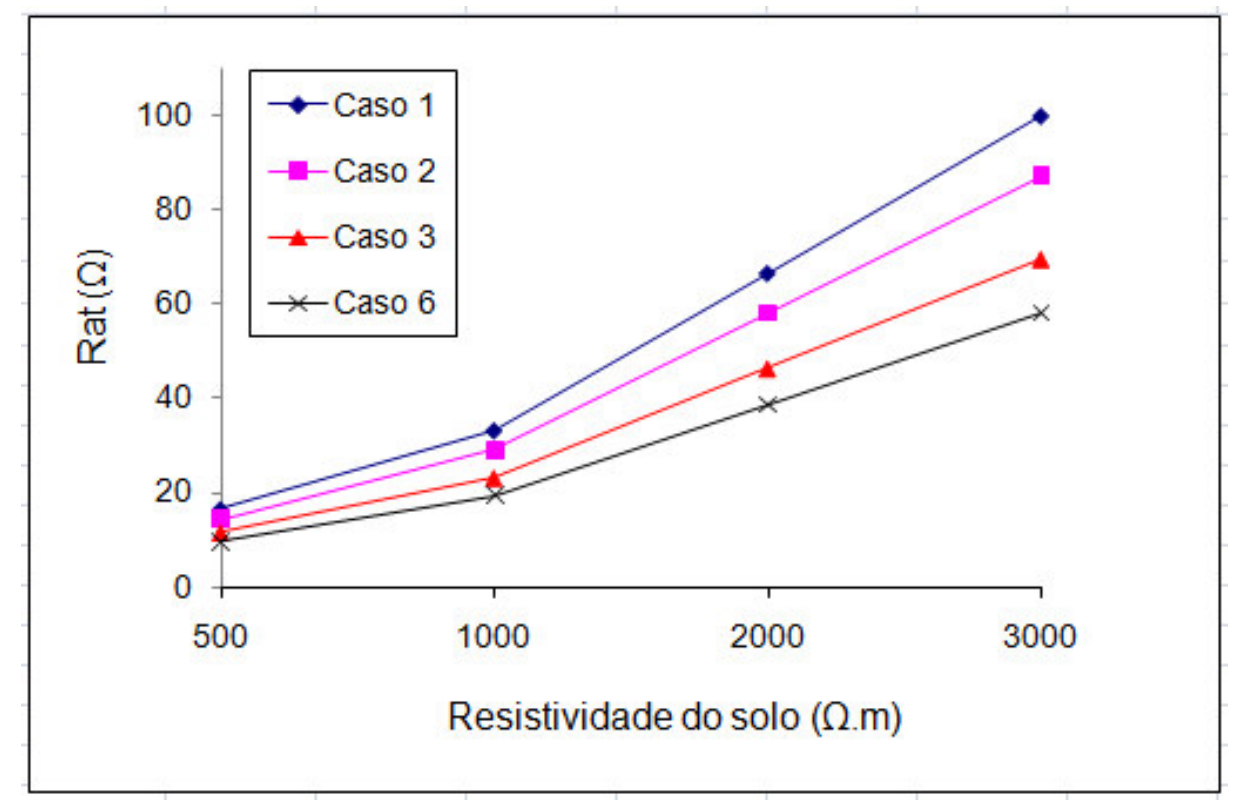

Figura 46 - Influência do espaçamento entre hastes (resistência de terra casos 1, 2, 3 e 6).

Com o aumento do espaçamento entre hastes há a diminuição das tensões de passo e de toque, conforme ilustrado nas Figuras 47 e 48. 


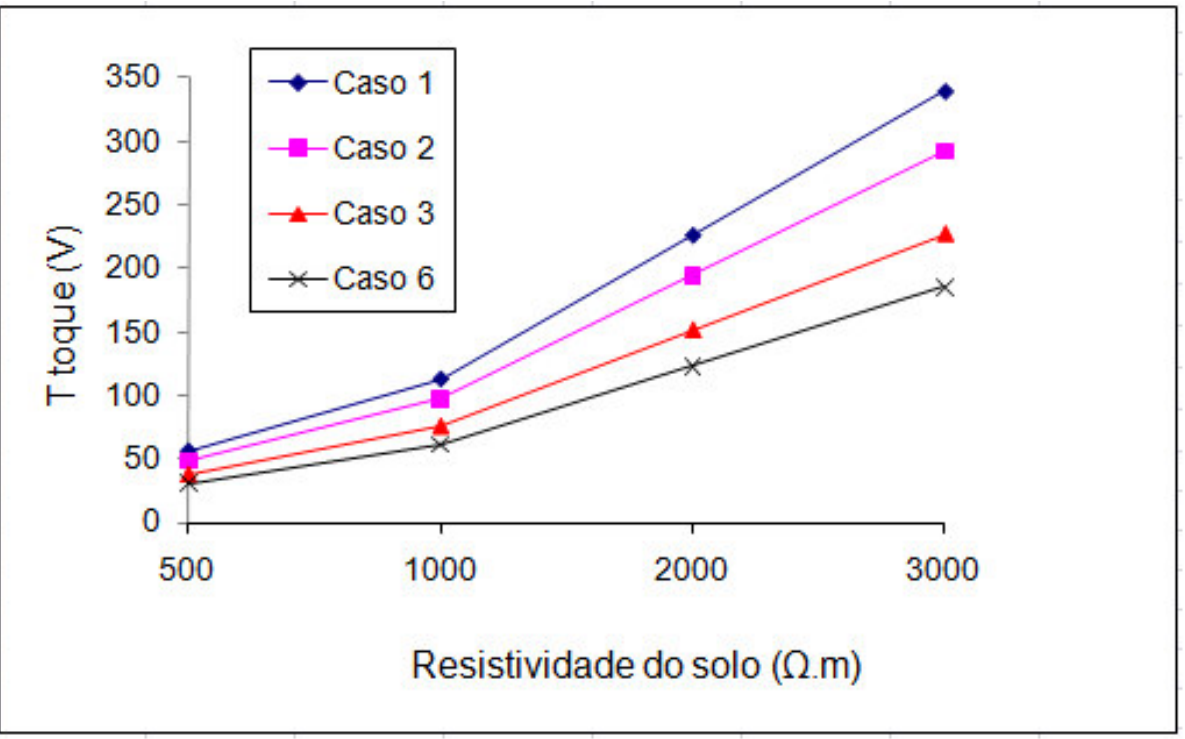

Figura 47 - Influência do espaçamento entre hastes (tensão de toque casos 1, 2, 3 e 6).

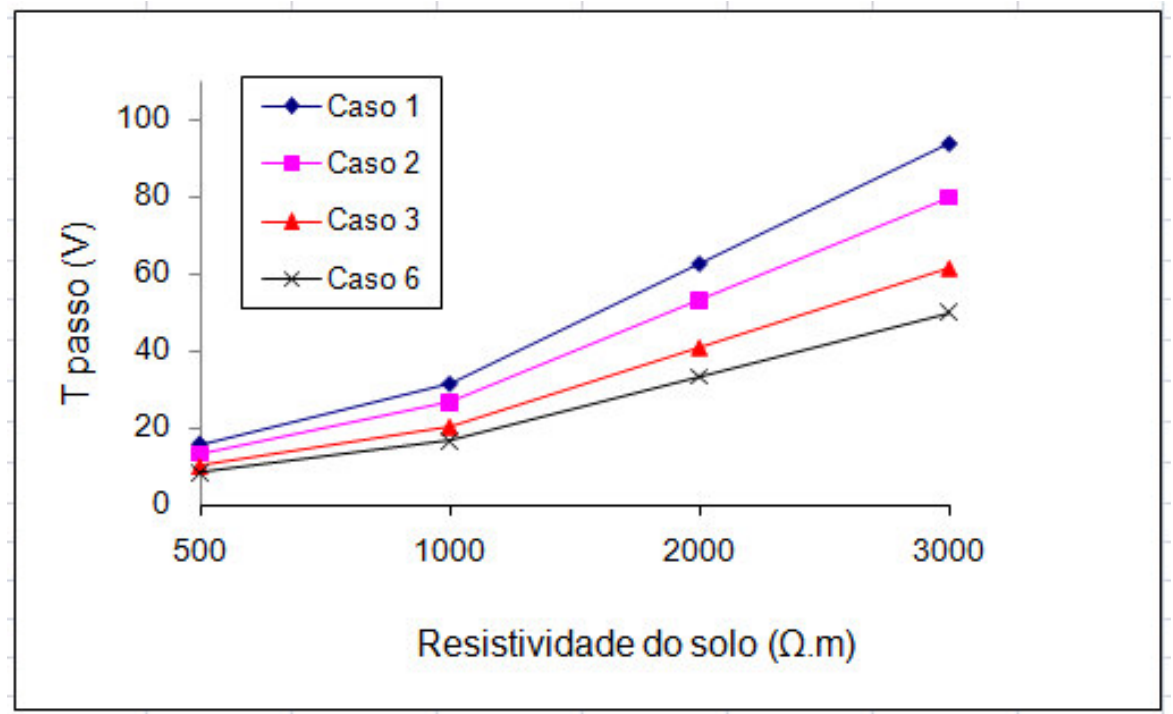

Figura 48 - Influência do espaçamento entre hastes (tensão de passo casos 1, 2, 3 e 6).

A diminuição ocorre devido aos menores valores de resistência de terra. Para redução dos efeitos de resistências de terra mútuas, tradicionalmente emprega-se um espaçamento mínimo igual ao comprimento da haste de aterramento.

A Tabela 18 apresenta a influência do comprimento das hastes. Comparando-se os casos 3, 4 e 5, verifica-se que há redução nos valores de resistência de terra. 
Em (CAVALCANTE et al., 2005), os autores pesquisaram, junto à CPFL Piratininga, métodos alternativos para redução da resistência de terra (Rat) vinculadas aos aterramentos de uma rede de distribuição. Foi concluído que, independente da condição do solo (seco, úmido ou normal), há uma redução significativa do valor de resistência de terra em função do comprimento total da haste.

Tabela 18 - Influência do comprimento das hastes

\begin{tabular}{|c|c|c|c|c|c|c|}
\hline Casos & Hastes (total) & $\begin{array}{c}\mathrm{e} \\
(\mathrm{mm})\end{array}$ & $\begin{array}{c}\mathrm{L} \\
(\mathrm{mm})\end{array}$ & $\begin{array}{c}\varnothing \\
(\mathrm{mm})\end{array}$ & $\begin{array}{c}\text { Área } \\
\left(\mathrm{m}^{2}\right)\end{array}$ & $\begin{array}{c}\text { Rat } \\
(\Omega)\end{array}$ \\
\hline 3 & 12 & 8.000 & 2.400 & 16 & 384 & 11,61 \\
\hline 4 & 12 & 8.000 & 3.000 & 16 & 384 & 11,39 \\
\hline 5 & 12 & 8.000 & 6.000 & 16 & 384 & 9,93 \\
\hline
\end{tabular}

O objetivo principal do aumento do comprimento da haste é atingir as camadas mais profundas, onde o solo costumar ter maior umidade e, portanto, resistividade mais baixa, favorecendo a diminuição de resistência de terra (LANGUTH, 2006; LUZ; DULAR, 2007; AREND, 2009).

A dispersão de corrente se dá na região mais profunda de menor resistividade, o que geralmente atenua consideravelmente os gradientes de potencial na superfície do solo. No entanto, mesmo considerando o solo homogêneo, conseguiu-se uma redução de 14,47\%, utilizando haste de $6.000 \mathrm{~mm}$ (caso 5) ao invés de haste de $2.400 \mathrm{~mm}$ (caso 3).

A Figura 49 ilustra a influência do comprimento da haste, considerando-se valores de resistividade do solo de $500 \Omega . \mathrm{m}$ a $3.000 \Omega$.m. 


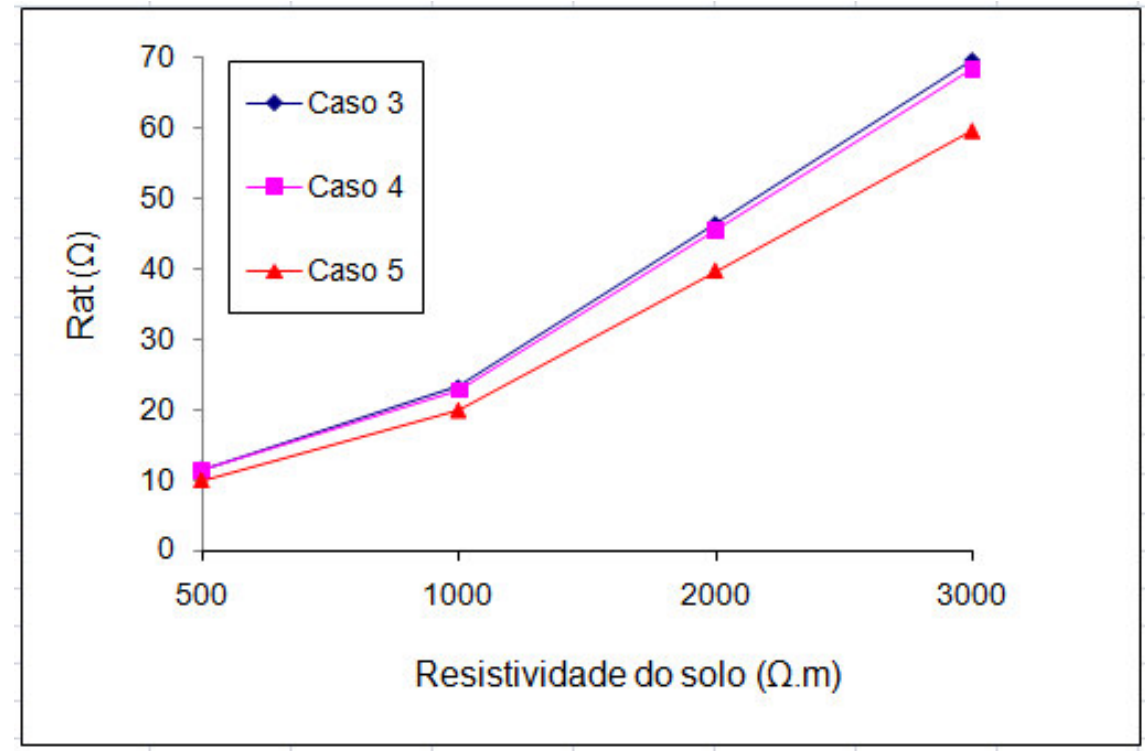

Figura 49 - Influência do comprimento da haste (casos 3, 4, 5).

Nas Figuras 50 e 51 observa-se que, com o aumento do comprimento da haste, os valores de tensão de toque e de passo diminuem, pois ocorre a diminuição da resistência de terra.

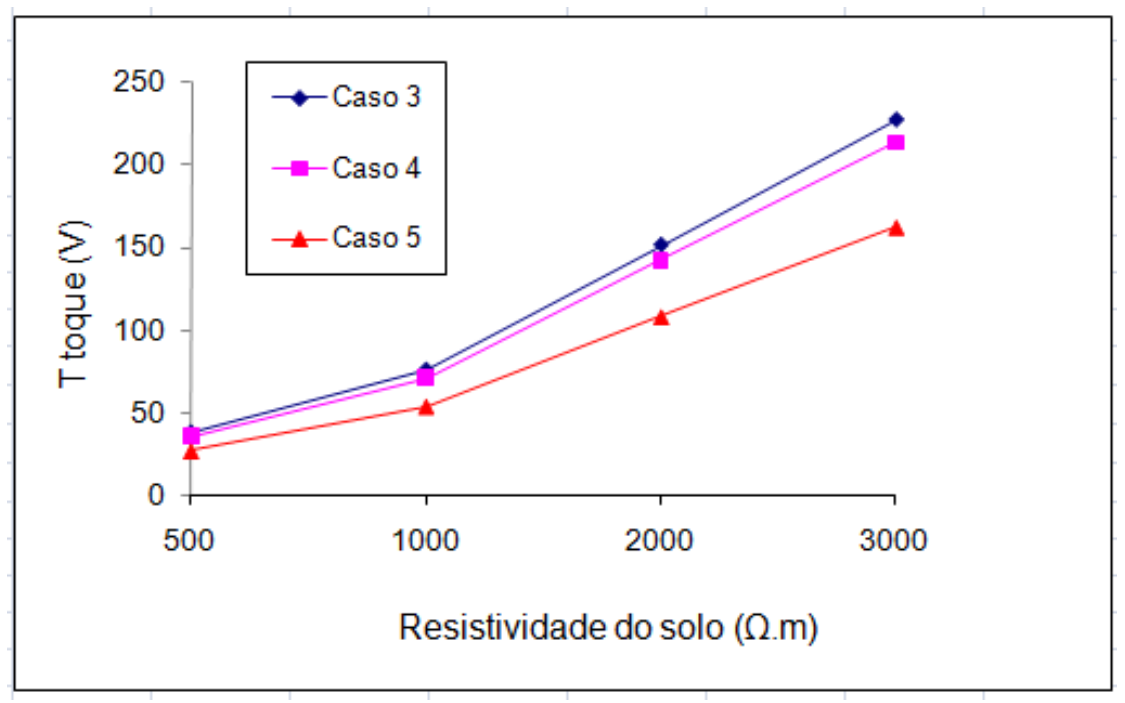

Figura 50 - Influência do comprimento da haste (tensão de toque casos 3, 4 e 5). 


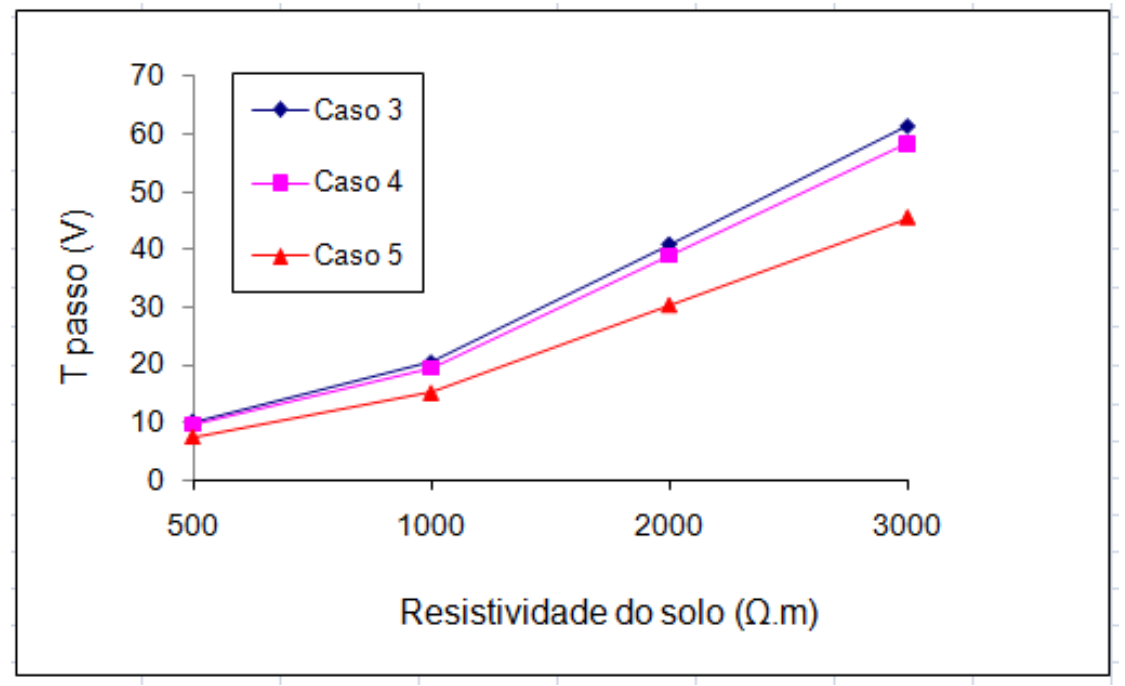

Figura 51 - Influência do comprimento da haste (tensão de passo casos 3, 4, e 5).

Segundo (VICENTE et al., 2009), o aterramento será mais eficiente quanto mais profundas se encontrarem as hastes, ocorrendo um escoamento com maior extensão para o solo e, consequentemente, menores tensões distribuidas no solo adjacente. Convém salientar que um aumento muito acentuado do comprimento da haste, sob o ponto de vista econômico, não é vantajoso.

A Tabela 19 mostra os casos 1, 7, 8, 9 e 10, onde são utilizados espaçamentos diferentes entre hastes, porém, mantendo-se o comprimento e diâmetro. A área da malha de aterramento é a mesma para todos os casos. 
Tabela 19 - Quantidade de hastes e geometria interna da malha (Casos 1, 7, 8, 9 e 10)

\begin{tabular}{|c|c|c|c|c|c|}
\hline Casos & Hastes (total) & $\begin{array}{l}\text { Espaçamento * } \\
(\mathrm{mm})\end{array}$ & $\begin{array}{c}\mathrm{L} \\
(\mathrm{mm})\end{array}$ & $\begin{array}{c}\varnothing \\
(\mathrm{mm})\end{array}$ & $\begin{array}{l}\text { Área } \\
\left(\mathrm{m}^{2}\right)\end{array}$ \\
\hline $\begin{array}{c}1 \\
\text { (Figura 44) }\end{array}$ & 12 & 5.000 & 2.400 & 16 & 150 \\
\hline $\begin{array}{c}9 \\
\text { (Figura 45c) }\end{array}$ & 9 & 4.500 a 15.000 & 2.400 & 16 & 150 \\
\hline $\begin{array}{c}8 \\
\text { (Figura 45b) }\end{array}$ & 9 & 4.500 a 15.000 & 2.400 & 16 & 150 \\
\hline $\begin{array}{c}7 \\
\text { (Figura 45a) }\end{array}$ & 7 & 7.500 a 10.000 & 2.400 & 16 & 150 \\
\hline $\begin{array}{c}10 \\
\text { (Figura 45d) }\end{array}$ & 6 & 9.000 a 15.000 & 2.400 & 16 & 150 \\
\hline
\end{tabular}

* espaçamento entre hastes interligadas com condutores.

A Figura 52 ilustra a influência da quantidade de hastes e da geometria interna da malha em relação aos valores de resistência de terra.

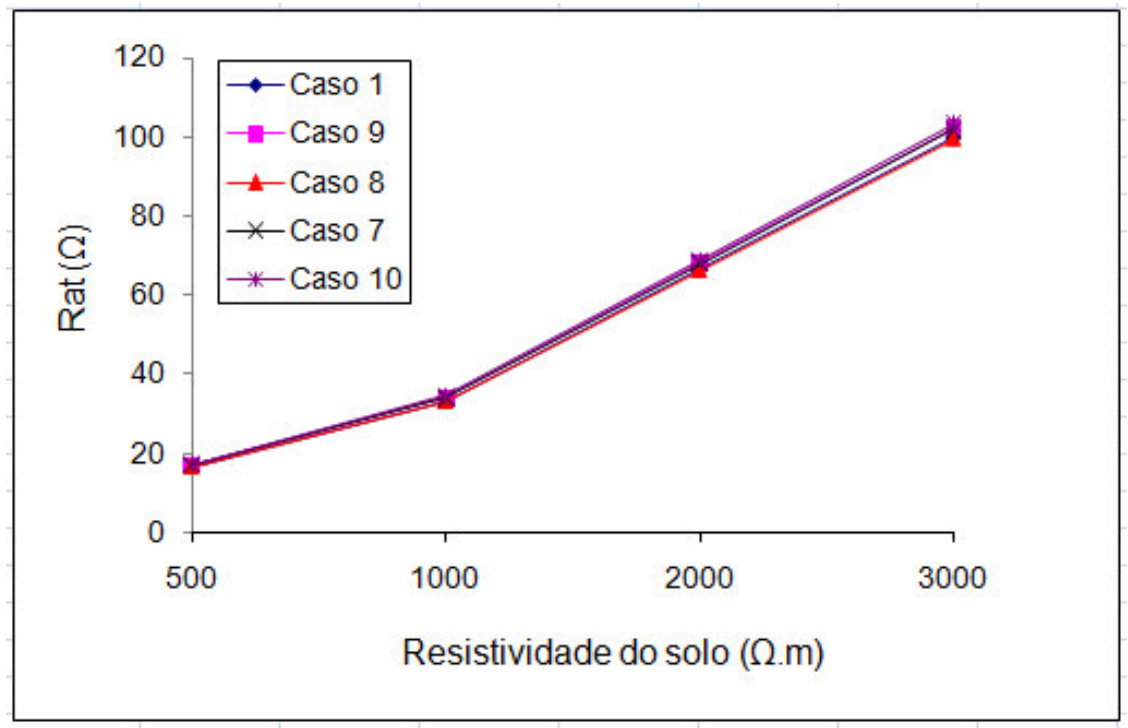

Figura 52 - Influência da quantidade de hastes e geometria interna da malha (casos 1, 7, 8 e 10). 
Observa-se que todos os casos apresentaram valores de resistência de terra de mesma ordem de grandeza em relação ao caso 1 .

As Figuras 53 e 54 mostram os respectivos valores de tensão de passo e a tensão de toque na superfície do solo.

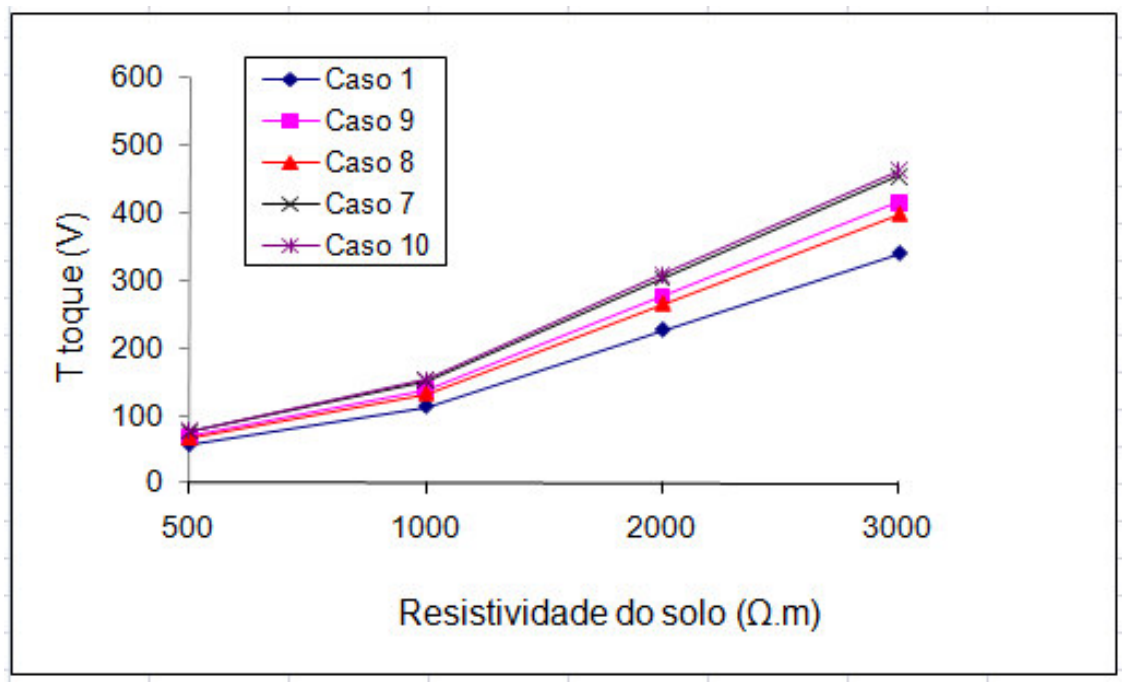

Figura 53 - Influência da quantidade de hastes e geometria interna da malha (tensão de toque casos $1,7,8,9$ e 10)

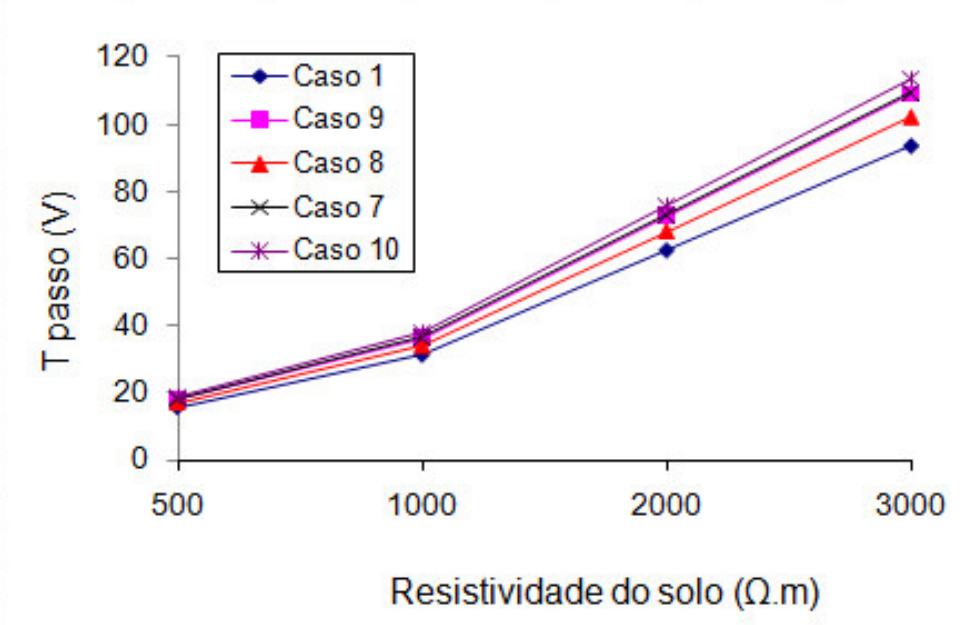

Figura 54 - Influência da quantidade de hastes e geometria interna da malha (tensão de passo casos $1,7,8,9$ e 10) 
Pode-se concluir que, com a alteração da geometria interna da malha (caso 10) e diminuição do número de hastes, é possível obter um valor de resistência de terra próximo ao do caso 1, reduzindo o custo da malha de aterramento. É importante ressaltar que foi mantida a mesma área do sistema de aterramento, ocorrendo um espaçamento maior entre hastes.

Um ponto crítico na utilização de sistemas de aterramento com menor quantidade de hastes, mantendo a mesma área de instalação, é o aumento dos valores tensão de passo e de toque, principalmente para o caso 10, conforme mostram as Figuras 53 e 54.

Os valores de resistência de terra e os valores de tensão de passo e toque foram calculados para os casos 1 a 10. O valor de corrente utilizado para simulação computacional dos casos mencionados foi de $8 \mathrm{~A}$. Este valor de corrente foi adotado porque é o valor máximo considerado pelas concessionárias de energia elétrica ENERSUL e CELTINS para circulação no solo, quando da utilização do sistema monofilar com retorno por terra. As Tabelas 20 e 21 mostram os resultados, sendo considerados valores de resistividades do solo de $500 \Omega . m$ a $10.000 \Omega . \mathrm{m}$. 
Tabela 20 - Valores de resistência de terra e valores máximos de tensão de passo e toque em função da resistividade do solo (casos 1 ao 5).

\begin{tabular}{|c|c|c|c|c|c|c|c|c|c|}
\hline \multicolumn{2}{|r|}{ Casos } & \multicolumn{8}{|c|}{ 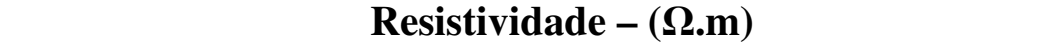 } \\
\hline & & 500 & 1.000 & 2.000 & 3.000 & 4.000 & 6.000 & 8.000 & 10.000 \\
\hline \multirow{3}{*}{ Caso 1} & Rat $(\Omega)$ & 16,63 & 33,26 & 66,52 & 99,78 & 133,00 & 199,50 & 266,00 & 332,50 \\
\hline & T. passo máx. (V) & 15,63 & 31,26 & 62,53 & 93,80 & 125,07 & 187,60 & 250,14 & 312,67 \\
\hline & T. toque máx. (V) & 56,65 & 113,30 & 226,60 & 339,91 & 453,21 & 679,82 & 906,42 & 1133,03 \\
\hline \multirow{3}{*}{ Caso 2} & Rat $(\Omega)$ & 14,52 & 29,04 & 58,08 & 87,12 & 116,16 & 174,24 & 232,32 & 290,4 \\
\hline & T. passo máx. (V) & 13,28 & 26,57 & 53,15 & 79,72 & 106,29 & 159,44 & 212,60 & 265,74 \\
\hline & T. toque máx. (V) & 48,68 & 97,37 & 194,75 & 292,12 & 389,50 & 584,25 & 779,01 & 973,76 \\
\hline \multirow{3}{*}{ Caso 3} & Rat $(\Omega)$ & 11,61 & 23,22 & 46,44 & 69,66 & 92,88 & 139,32 & 185,76 & 232,20 \\
\hline & T. passo máx. (V) & 10,22 & 20,45 & 40,90 & 61,35 & 81,80 & 122,71 & 163,61 & 204,52 \\
\hline & T. toque máx. (V) & 37,85 & 75,71 & 151,42 & 227,14 & 302,85 & 454,28 & 605,70 & 757,13 \\
\hline \multirow{3}{*}{ Caso 4} & Rat $(\mathbf{\Omega})$ & 11,39 & 22,78 & 45,56 & 68,34 & 91,12 & 136,68 & 182,24 & 227,8 \\
\hline & T. passo máx. (V) & 9,74 & 19,48 & 38,96 & 58,45 & 77,93 & 116,90 & 155,86 & 194,83 \\
\hline & T. toque máx. (V) & 35,63 & 71,25 & 142,50 & 213,76 & 285,01 & 427,52 & 570,03 & 712,53 \\
\hline \multirow{3}{*}{ Caso 5} & $\operatorname{Rat}(\Omega)$ & 9,93 & 19,86 & 39,72 & 59,58 & 79,44 & 119,16 & 158,88 & 198,60 \\
\hline & T. passo máx. (V) & 7,60 & 15,18 & 30,36 & 45,55 & 60,73 & 91,10 & 121,47 & 151,83 \\
\hline & T. toque máx. (V) & 27,13 & 54,26 & 108,52 & 162,78 & 217,04 & 325,56 & 434,08 & 542,60 \\
\hline
\end{tabular}


Tabela 21 - Valores de resistência de terra e valores máximos de passo e toque em função da resistividade do solo (casos 6 ao 10).

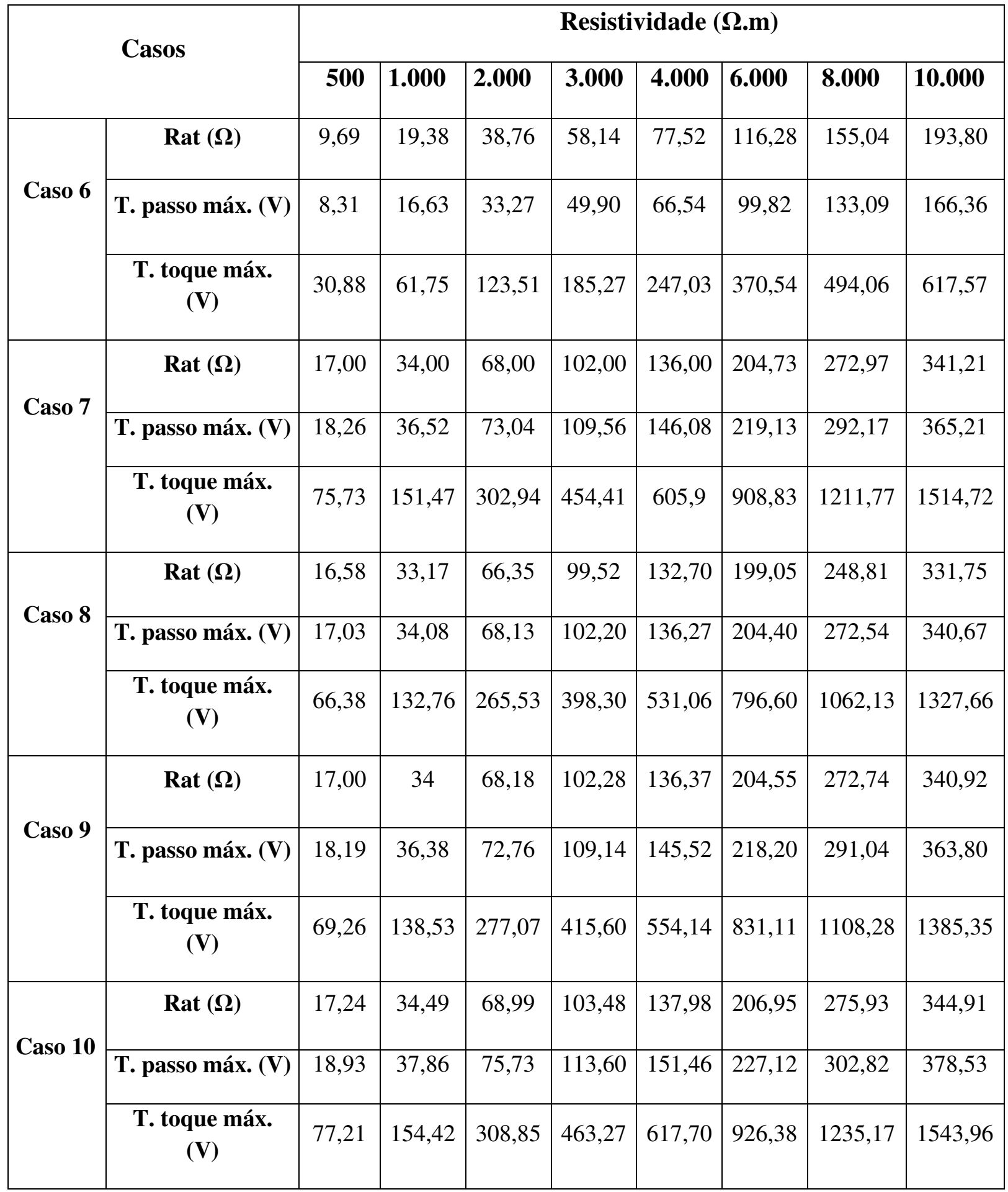


Os valores de resistência de terra e as tensões de passo e de toque são diretamente proporcionais à resistividade do solo para todos os casos, sendo importante salientar que os maiores potenciais de passo e de toque ocorreram nas bordas da malha.

\subsubsection{Outras Configurações de Aterramento}

Com o objetivo de obter valores menores de resistência de terra, foram realizadas simulações considerando outras configurações de aterramento elétrico. Foi utilizada como referência a malha padrão CELTINS, com relação ao número, espaçamento e comprimento das hastes e condutores de interligação, tanto para malha em triângulo quanto para malha em anéis concêntricos.

Malha em triângulo:

O aterramento utilizado é constituído por uma malha triângular com 12 hastes cilíndricas, cravadas na vertical, com $60 \mathrm{~cm}$ abaixo da superfície do solo. O espaçamento entre as hastes é de $5000 \mathrm{~mm}$ na malha externa, sendo o comprimento de cada haste igual a $2400 \mathrm{~mm}$ e diâmetro de $16 \mathrm{~mm}$. A primeira haste está no mínimo a $1 \mathrm{~m}$ do poste e as interligações das hastes são feitas através de cabos nus, com $25 \mathrm{~mm}^{2}$ de diâmetro, na posição horizontal, conforme ilustra a Figura 55. 


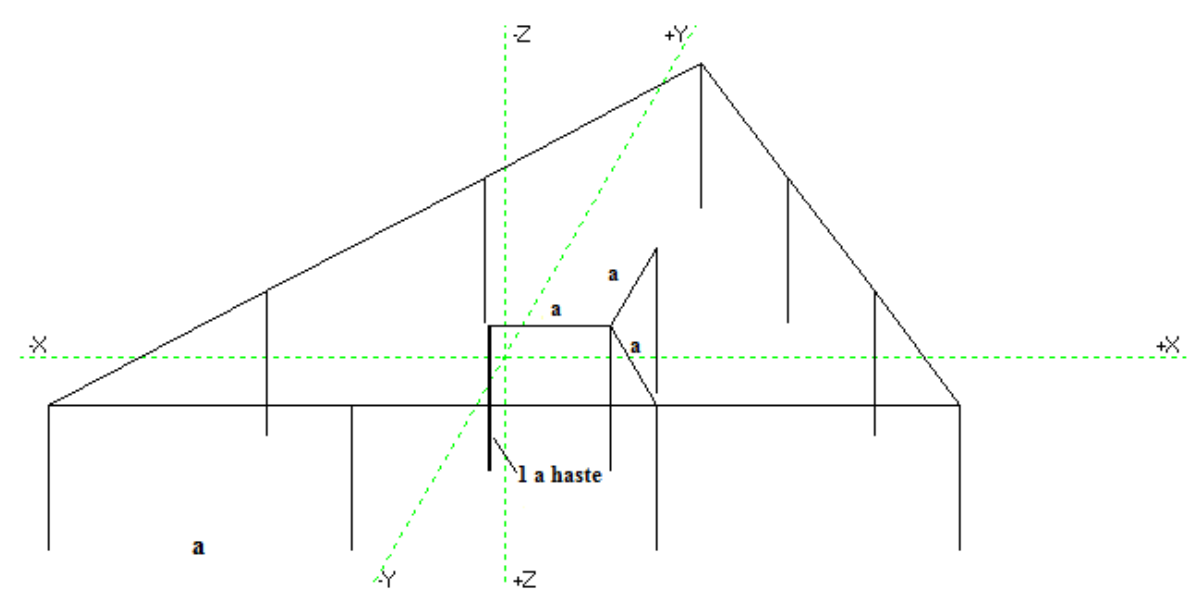

Figura 55 - Configuração da malha em triângulo (12 hastes) $\mathrm{a}=5000 \mathrm{~mm}$

Malha em anéis concêntricos:

O aterramento utilizado é constituído por uma malha em anéis concêntricos com 13 hastes cilíndricas, cravadas na vertical, com $60 \mathrm{~cm}$ abaixo da superfície do solo. O raio do anel interno é $5 \mathrm{~m}$ e o externo $10 \mathrm{~m}$, sendo o comprimento de cada haste $2400 \mathrm{~mm}$ e diâmetro de $16 \mathrm{~mm}$. A primeira haste está no mínimo a $1 \mathrm{~m}$ do poste e as interligações das hastes são feitas através de cabos nus, com $25 \mathrm{~mm}^{2}$ de diâmetro, na posição horizontal, conforme ilustra a Figura 56.

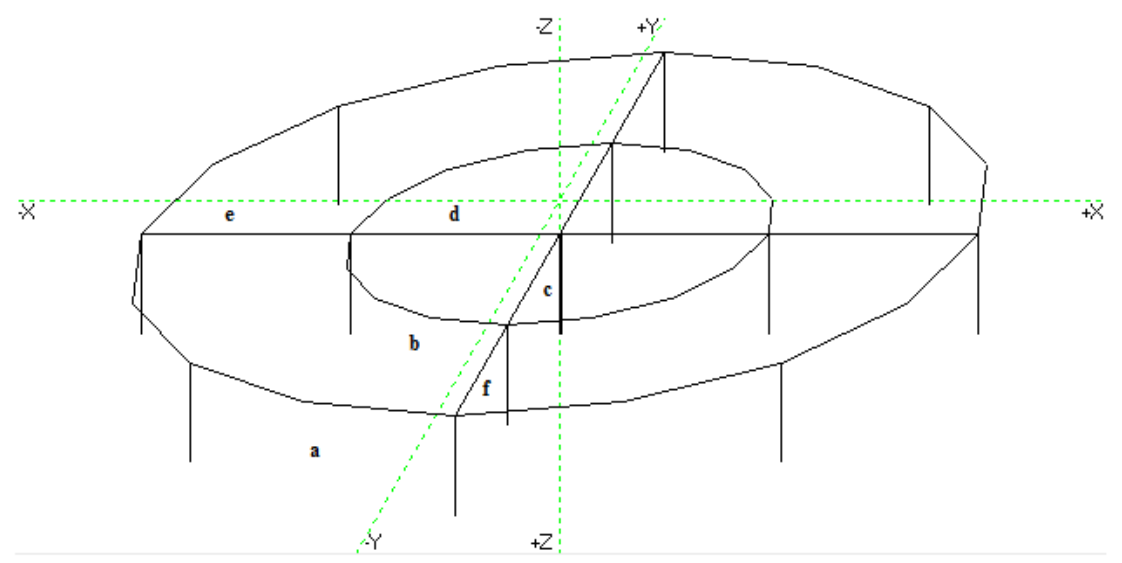

Figura 56 - Configuração da malha em anéis (13 hastes)

$$
a=15,70 \mathrm{~m} ; \mathrm{b}=7,85 \mathrm{~m} ; \mathrm{c}=\mathrm{d}=\mathrm{e}=\mathrm{f}=5 \mathrm{~m} \text {. }
$$


$\mathrm{Na}$ Tabela 22 são apresentados os valores de resistência de terra, obtidos nas simulações computacionais para as configurações em triângulo e em anéis. São apresentados também os resultados da malha reticulada, padrão da CELTINS, considerando a resistividade do solo de $500 \Omega$.m.

Tabela 22 - Valores de resistência de terra para configurações em triângulo e anéis concêntricos.

\begin{tabular}{|l|c|c|c|c|c|}
\hline $\begin{array}{c}\text { Configuração } \\
\text { da malha }\end{array}$ & $\begin{array}{c}\text { Número } \\
\text { de hastes }\end{array}$ & $\begin{array}{c}\text { Espaçamento } \\
\text { entre hastes } \\
(\mathrm{m})\end{array}$ & $\begin{array}{c}\text { Raio da } \\
\text { circunferência } \\
(\mathrm{m})\end{array}$ & $\begin{array}{c}\text { Área de } \\
\text { instalação } \\
\left(\mathrm{m}^{2}\right)\end{array}$ & $\begin{array}{c}\text { Resistência } \\
\text { de terra }(\Omega)\end{array}$ \\
\hline $\begin{array}{l}\text { Reticulada } \\
\text { (padrão } \\
\text { CELTINS) }\end{array}$ & 12 & 5 & - & 150 & 16,63 \\
\hline Triangular & 12 & 5 & - & 97,5 & 19,51 \\
\hline $\begin{array}{l}\text { Anéis } \\
\text { concêntricos }\end{array}$ & 13 & 5 & $\begin{array}{c}\text { interno }=5 \\
\text { externo }=10\end{array}$ & 314 & 13,30 \\
\hline
\end{tabular}

Observa-se na Tabela 22 que a malha de aterramento em anéis concêntricos apresentou menor valor de resistência de terra $(13,30 \Omega)$, porém, com o dobro da área utilizada pela malha padrão CELTINS. A redução apresentada foi de $20 \%$ do valor da resistência de terra. A malha em triângulo apresentou valor de resistência de terra superior ao obtido pela malha reticulada, porém, com uma área de instalação inferior às configurações da malha reticulada e anéis concêntricos.

Os valores de resistência de terra foram menores do que $20 \Omega$, atendendo o requisito estabelecido pela CELTINS. Entretanto, a configuração que apresentou melhor resultado foi a malha com anéis concêntricos, mas com um aumento muito acentuado da área de instalação, o que não seria economicamente viável. 


\subsection{SISTEMAS DE ATERRAMENTO COM HASTES E/OU CONDUTORES ENVOLVIDOS EM CONCRETO}

A pesquisa visando a redução de resistência terra passou a considerar a utilização de hastes e condutores envolvidos em concreto. (mais detalhes sobre o programa computacional no anexo I)

Inicialmente, foram estudadas configurações simples com o objetivo de se analisar o comportamento da haste de concreto em relação à haste convencional. Em seguida, foram consideradas as configurações utilizadas em (CLAUSEN et al., 2004) visando a comparação das medições realizadas em campo com os resultados obtidos em simulações computacionais. As Figuras 57 a 59 mostram as configurações utilizadas nas investigações iniciais.

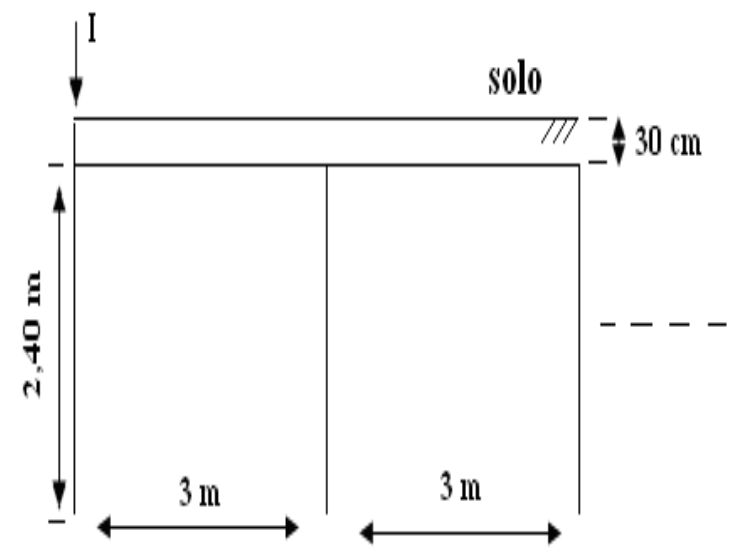

Figura 57 - Configuração convencional com hastes alinhadas. 


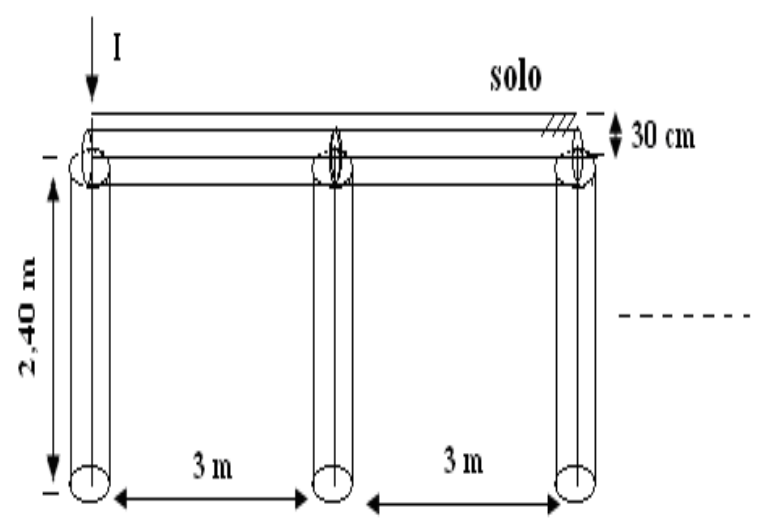

Figura 58 - Configuração com hastes e condutores concretados.

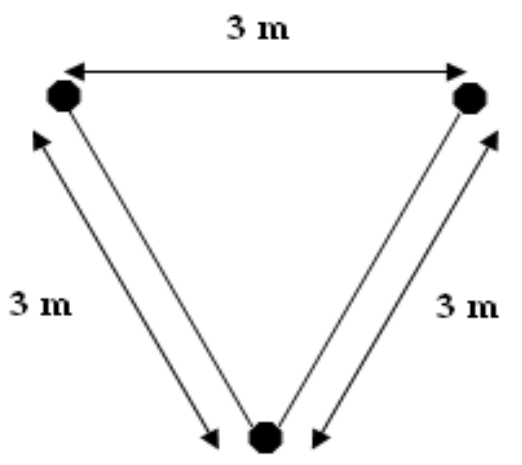

Figura 59 - Malha convencional em forma de V.

Os seguintes passos foram adotados, tendo em vista o estudo do comportamento do concreto em relação às hastes convencionais:

a) Configurar a malha de aterramento convencional com o uso de hastes de cobre;

b) Configurar a malha de aterramento com hastes e condutores de cobre envolvidos em concreto, com as mesmas características da malha convencional;

c) Realizar simulações computacionais considerando-se as malhas de aterramento, (a) e (b), para obtenção do valor de resistência de terra. $\mathrm{O}$ solo foi considerado homogêneo para todas as simulações;

d) Avaliar os resultados da malha de aterramento convencional $\mathrm{x}$ malha com hastes envolvidas em concreto. 
6.2.1 Avaliação do Comportamento de Hastes e Condutores Envolvidos em Concreto

Os resultados apresentados nas Tabelas 23 a 28 são referentes às configurações das malhas de aterramento convencionais e concretadas, mostradas nas Figuras 57 e 58 . As hastes de cobre foram colocadas na posição vertical, $30 \mathrm{~cm}$ abaixo da superfície do solo, e sua interligação foi feita com cabos na posição horizontal. As hastes são cilíndricas e cobreadas, diâmetro de 12,5 mm e 2,4 $\mathrm{m}$ de comprimento. O espaçamento inicial entre hastes foi de 3 metros. As interligações das hastes foram feitas através de cabos nus, com $25 \mathrm{~mm}^{2}$ de diâmetro. Os cálculos foram efetuados considerando o valor de resistividade média de $60 \Omega$.m para o concreto (IEEE-80, 2000) e diâmetro de $20 \mathrm{~cm}$. As simulações foram realizadas considerando a frequiência industrial de $60 \mathrm{~Hz}$. Estão representados nas Figuras 60 a 62 os valores das resistências de terra referentes a uma haste e hastes alinhadas ( 2 a 6 hastes), com resistividades do solo de 100, 1000 e 3000 S.m.

Tabela 23 - Valores de resistência de terra (1 e 2 hastes).

\begin{tabular}{|c|c|c|c|c|}
\hline $\begin{array}{c}\text { Configuração } \\
\text { da malha }\end{array}$ & $\begin{array}{c}\mathrm{N}^{\mathrm{o}} \text { de } \\
\text { hastes }\end{array}$ & $\begin{array}{c}\rho \\
(\Omega . \mathrm{m})\end{array}$ & $\begin{array}{c}\text { Rat } \\
\text { convencional } \\
(\Omega)\end{array}$ & $\begin{array}{c}\text { Rat } \\
\text { concreto } \\
(\Omega)\end{array}$ \\
\hline Haste simples & 1,0 & 100 & 36,7 & 31,2 \\
\hline Haste alinhada & 2,0 & 100 & 19,0 & 16,8 \\
\hline Haste alinhada & 2,0 & 500 & 92,6 & 67,4 \\
\hline Haste alinhada & 2,0 & 1000 & 184,6 & 130,2 \\
\hline Haste alinhada & 2,0 & 2000 & 368,7 & 255,8 \\
\hline Haste alinhada & 2,0 & 3000 & 560,0 & 381,3 \\
\hline
\end{tabular}


Tabela 24 - Valores de resistência de terra (3 hastes).

\begin{tabular}{|c|c|c|c|c|}
\hline $\begin{array}{c}\text { Configuração } \\
\text { da malha }\end{array}$ & $\begin{array}{c}\mathrm{N}^{\mathrm{o}} \text { de } \\
\text { hastes }\end{array}$ & $\begin{array}{c}\rho \\
(\Omega . \mathrm{m})\end{array}$ & $\begin{array}{c}\text { Rat } \\
\text { convencional } \\
(\Omega)\end{array}$ & $\begin{array}{c}\text { Rat } \\
\text { Concreto } \\
(\Omega)\end{array}$ \\
\hline $\begin{array}{c}\text { Haste } \\
\text { alinhada }\end{array}$ & 3 & 100 & 13,9 & 12,6 \\
\hline $\begin{array}{c}\text { Haste } \\
\text { alinhada }\end{array}$ & 3 & 500 & 65,6 & 50,0 \\
\hline $\begin{array}{c}\text { Haste } \\
\text { alinhada }\end{array}$ & 3 & 1000 & 130,1 & 96,4 \\
\hline $\begin{array}{c}\text { Haste } \\
\text { alinhada }\end{array}$ & 3 & 2000 & 259,2 & 189,4 \\
\hline $\begin{array}{c}\text { Haste } \\
\text { alinhada }\end{array}$ & 3 & 3000 & 388,3 & 281,8 \\
\hline
\end{tabular}

Tabela 25 - Valores de resistência de terra (4 hastes).

\begin{tabular}{|c|c|c|c|c|}
\hline $\begin{array}{c}\text { Configuração } \\
\text { da malha }\end{array}$ & $\begin{array}{c}\mathrm{N}^{\mathrm{o}} \text { de } \\
\text { hastes }\end{array}$ & $\begin{array}{c}\rho \\
(\Omega . \mathrm{m})\end{array}$ & $\begin{array}{c}\text { Rat } \\
\text { convencional. } \\
(\Omega)\end{array}$ & $\begin{array}{c}\text { Rat } \\
\text { concreto } \\
\Omega)\end{array}$ \\
\hline Haste alinhada & 4,0 & 100 & 11,6 & 10,7 \\
\hline Haste alinhada & 4,0 & 500 & 52,2 & 40,9 \\
\hline Haste alinhada & 4,0 & 1000 & 102,9 & 78,4 \\
\hline Haste alinhada & 4,0 & 2000 & 204,2 & 153,4 \\
\hline Haste alinhada & 4,0 & 3000 & 305,6 & 228,4 \\
\hline
\end{tabular}


Tabela 26 - Valores de resistência de terra (5 hastes).

\begin{tabular}{|c|c|c|c|c|}
\hline $\begin{array}{c}\text { Configuração } \\
\text { da malha }\end{array}$ & $\begin{array}{c}\mathrm{N}^{\mathrm{o}} \text { de } \\
\text { hastes }\end{array}$ & $\begin{array}{c}\rho \\
(\Omega . \mathrm{m})\end{array}$ & $\begin{array}{c}\text { Rat } \\
\text { convencional } \\
(\Omega)\end{array}$ & $\begin{array}{c}\text { Rat } \\
\text { concreto } \\
(\Omega)\end{array}$ \\
\hline $\begin{array}{c}\text { Haste } \\
\text { alinhada }\end{array}$ & 5,00 & 100 & 10,3 & 9,6 \\
\hline $\begin{array}{c}\text { Haste } \\
\text { alinhada }\end{array}$ & 5,00 & 500 & 44,2 & 35,3 \\
\hline $\begin{array}{c}\text { Haste } \\
\text { alinhada }\end{array}$ & 5,00 & 1000 & 86,3 & 67,2 \\
\hline $\begin{array}{c}\text { Haste } \\
\text { alinhada }\end{array}$ & 5,00 & 2000 & 170,6 & 130,8 \\
\hline $\begin{array}{c}\text { Haste } \\
\text { alinhada }\end{array}$ & 5,00 & 3000 & 254,9 & 194,3 \\
\hline \multicolumn{1}{|c|}{} & & \multicolumn{1}{|c|}{} \\
\hline
\end{tabular}

Tabela 27 - Valores de resistência de terra (6 hastes).

\begin{tabular}{|l|c|c|c|c|}
\hline $\begin{array}{c}\text { Configuração } \\
\text { da malha }\end{array}$ & $\begin{array}{c}\mathrm{N}^{\mathrm{o}} \text { de } \\
\text { hastes }\end{array}$ & $\begin{array}{c}\rho \\
(\Omega . \mathrm{m})\end{array}$ & $\begin{array}{c}\text { Rat } \\
\text { convencional } \\
(\Omega)\end{array}$ & $\begin{array}{c}\text { Rat } \\
\text { concreto } \\
(\Omega)\end{array}$ \\
\hline Haste alinhada & 6,00 & 100 & 9,61 & 8,9 \\
\hline Haste alinhada & 6,00 & 500 & 38,8 & 31,5 \\
\hline Haste alinhada & 6,00 & 1000 & 75,2 & 59,4 \\
\hline Haste alinhada & 6,00 & 2000 & 147,7 & 114,9 \\
\hline Haste alinhada & 6,00 & 3000 & 220,3 & 170,5 \\
\hline
\end{tabular}


Tabela 28 - Valores de resistência de terra (7 a 12 hastes).

\begin{tabular}{|l|c|c|c|c|}
\hline $\begin{array}{c}\text { Configuração } \\
\text { da malha }\end{array}$ & $\begin{array}{c}\mathrm{N}^{\mathrm{o}} \text { de } \\
\text { hastes }\end{array}$ & $\begin{array}{c}\rho \\
(\Omega . \mathrm{m})\end{array}$ & $\begin{array}{c}\text { Rat } \\
\text { convencional } \\
(\Omega)\end{array}$ & $\begin{array}{c}\text { Rat } \\
\text { concreto. } \\
(\Omega)\end{array}$ \\
\hline Haste alinhada & 7,0 & 3000 & 193,4 & 152,2 \\
\hline Haste alinhada & 8,0 & 3000 & 175,8 & 139,0 \\
\hline Haste alinhada & 9,0 & 3000 & 160,0 & 128,0 \\
\hline Haste alinhada & 10,0 & 3000 & 148,2 & 119,0 \\
\hline Haste alinhada & 11,0 & 3000 & 138,0 & 111,0 \\
\hline Haste alinhada & 12,0 & 3000 & 129,4 & 105,0 \\
\hline
\end{tabular}

A Figura 60 ilustra os resultados de 1 a 6 hastes em linha ( $\rho_{\text {solo }} 100 \Omega$.m). Com uma haste há redução de $15,53 \%$ no valor da resistência de terra quando é utilizado o concreto. Com a cravação da segunda haste foi obtida redução de $11,57 \%$. Ao aumentar o número de hastes, os valores de resistência de terra entre a haste convencional e a haste concretada são próximos. Nota-se que a resistividade do concreto é da mesma ordem de grandeza da resistividade do solo.

A Figura 61 mostra que o valor da resistência de terra foi reduzido em 29,46\% com a utilização de duas hastes concretadas. Comparando-se o valor com três hastes concretadas, houve redução de $25,90 \%$ e, quando se aumenta o número de hastes, a diferença entre os valores diminui.

Observa-se na Figura 62, que o valor de resistência de terra foi reduzido em 31,01\% com a utilização de duas hastes concretadas. No entanto, com a terceira haste houve redução de 27,42\%. Quando comparados os valores de resistências de terra da malha, alterando somente os valores de resistividade do solo, observa-se que com a resistividade do solo maior, há uma redução mais significativa na resistência de terra da malha com a utilização da haste envolvida em concreto, tornando-se mais eficiente o uso do mesmo em solos com resistividades elevadas.

Na tabela 26, são mostradas simulações com até 12 hastes, tanto para malha convencional como para malha envolvida em concreto. Desta forma, observa-se que também 
existe uma saturação na diminuição da resistência de terra com o aumento do número de hastes. Alterando-se somente o espaçamento entre hastes de $3 \mathrm{~m}$ para $5 \mathrm{~m}$, o valor da resistência de terra foi reduzido em $20,00 \%$, tanto para malha convencional como para malha envolvida em concreto. $\mathrm{O}$ aumento do espaçamento entre as hastes faz com que a interferência das linhas equipotenciais seja reduzida.

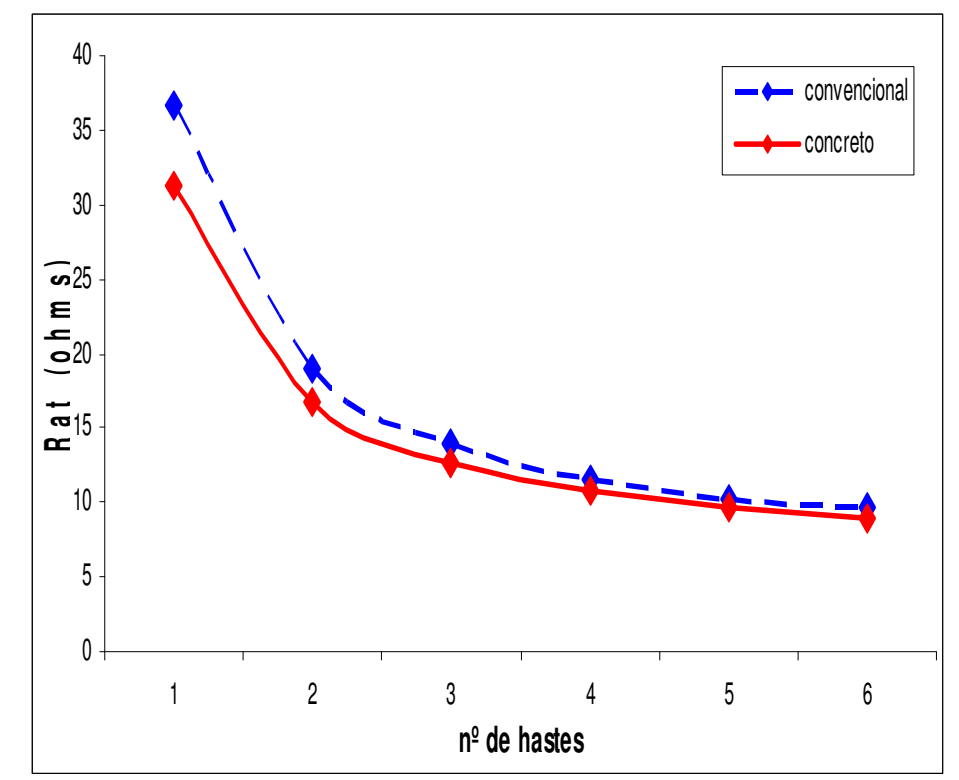

Figura 60 - Malha convencional e malha concretada $\left(\rho_{\text {solo }} 100 \Omega . \mathrm{m}\right)$

Com os resultados obtidos, considerando-se configurações simples (hastes alinhadas), foi possível verificar o comportamento do aterramento com hastes e condutores concretados em relação às hastes convencionais. Portanto, o próximo passo foi avaliar o comportamento das configurações em (CLAUSEN et al., 2004), considerando-se valores medidos e calculados. 


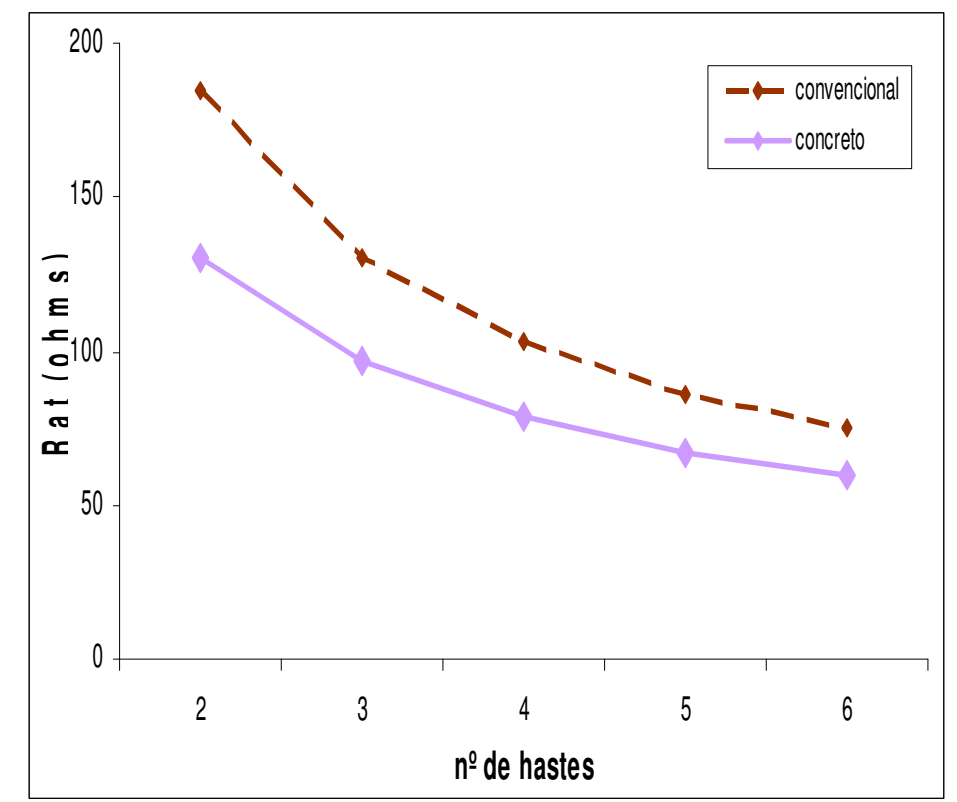

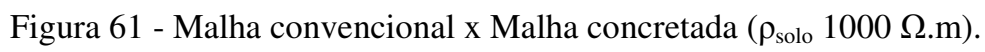

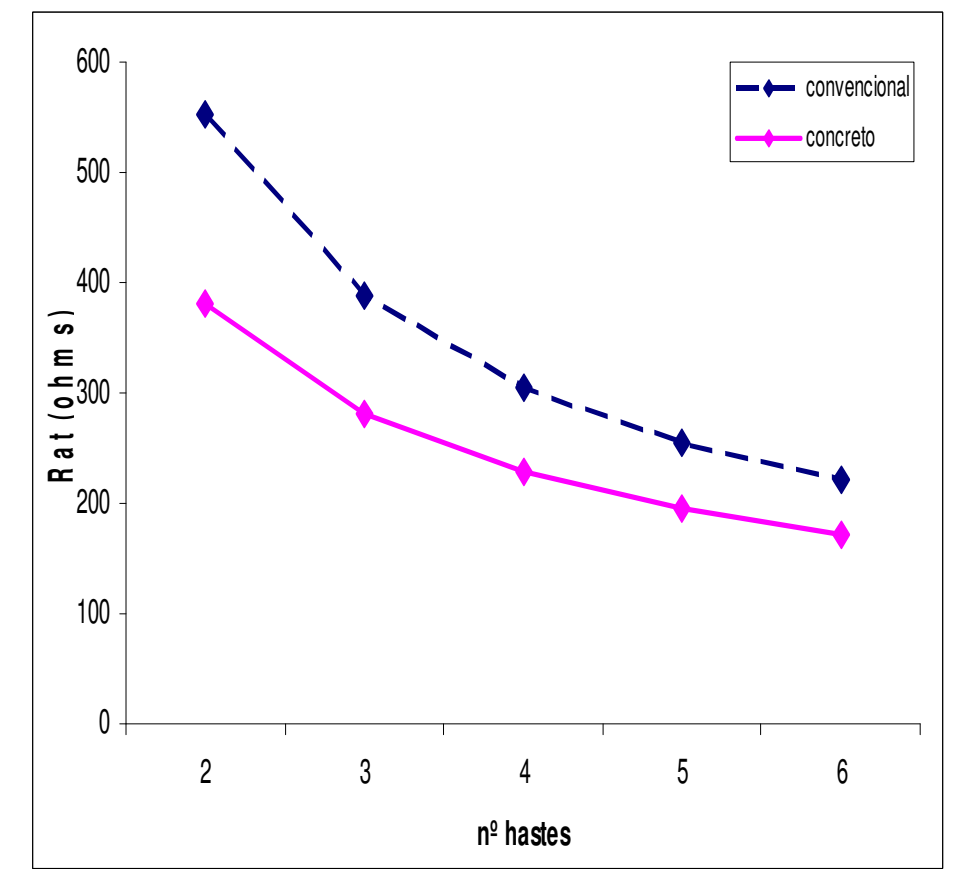

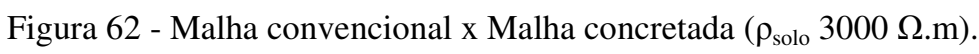

As Tabelas 29 e 30 mostram os valores da resistência de terra medidos em campo (CLAUSEN et al., 2004) e os resultados de simulações realizadas com o CDEGS, 
respectivamente. As configurações das malhas foram constituídas de hastes cilíndricas cobreadas, com diâmetro de 13 mm e 2,4 m de comprimento, cravadas na vertical, com $30 \mathrm{~cm}$ abaixo da superfície do solo e espaçamento entre hastes de 3 metros. As interligações das hastes, quando necessário, foram feitas através de cabos nus, com $25 \mathrm{~mm}^{2}$ de seção, na posição horizontal. Na Tabela 29, não são mostradas medições para algumas configurações (CLAUSEN et al., 2004).

Nas simulações efetuadas o solo foi considerado homogêneo, com resistividade de

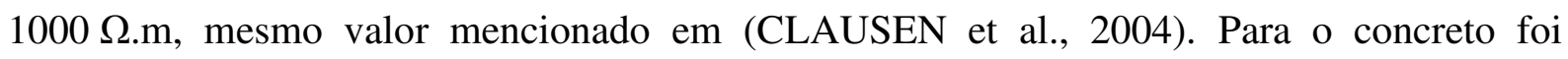
adotado o valor de resistividade média igual a $60 \Omega$.m (IEEE, 2000) e utilizado o diâmetro de $40 \mathrm{~cm}$ (CLAUSEN et al., 2004). Todas as configurações de aterramento foram simuladas considerando-se a freqüência industrial de $60 \mathrm{~Hz}$.

Tabela 29 - Valores medidos de resistência de terra.

\begin{tabular}{|c|c|c|c|}
\hline $\begin{array}{c}\text { Configuração } \\
\text { da malha }\end{array}$ & $\begin{array}{l}\mathrm{N}^{\circ} \text { de } \\
\text { hastes }\end{array}$ & $\begin{array}{c}\text { Rat } \\
\text { convencional } \\
(\Omega)\end{array}$ & $\begin{array}{c}\text { Rat } \\
\text { concreto } \\
(\Omega)\end{array}$ \\
\hline Haste simples & 1,00 & 392,3 & 201,70 \\
\hline 3 Hastes alinhadas & 3,00 & 134,70 & 80,00 \\
\hline 5 Hastes alinhadas & 5,00 & 118,30 & Sem medição \\
\hline Em "V" & 3,00 & 169,70 & Sem medição \\
\hline Triângulo & 3,00 & 160,00 & Sem medição \\
\hline
\end{tabular}

Fonte: (CLAUSEN et al., 2004). 
Tabela 30 - Valores de resistência de terra obtidos nas simulações computacionais.

\begin{tabular}{|c|c|c|c|}
\hline $\begin{array}{c}\text { Configuração } \\
\text { da malha }\end{array}$ & $\begin{array}{c}\mathrm{N}^{\mathrm{o}} \text { de } \\
\text { hastes }\end{array}$ & $\begin{array}{c}\text { Rat } \\
\text { convencional } \\
(\Omega)\end{array}$ & $\begin{array}{c}\text { Rat } \\
\text { concreto } \\
(\Omega)\end{array}$ \\
\hline Haste simples & 1,00 & 402,00 & 203,90 \\
\hline 3 Hastes alinhadas & 3,00 & 130,00 & 84,00 \\
\hline 5 Hastes alinhadas & 5,00 & 84,00 & 58,75 \\
\hline Em "V" & 3,00 & 136,44 & 92,53 \\
\hline Triângulo & 3,00 & 130,00 & 89,50 \\
\hline
\end{tabular}

A Tabela 31 apresenta uma comparação dos valores de resistência de terra obtidos através de medições no campo (CLAUSEN et al., 2004) e de simulações computacionais. Para uma haste simples envolvida em concreto foi observada uma diferença de $1,10 \%$ entre o valor medido e o calculado. Quando são consideradas 3 hastes envolvidas em concreto, alinhadas e espaçadas entre si de 3 metros, foi obtida uma diferença de 4,76\% entre o valor medido em campo e o valor calculado. Os valores de resistência de terra para as configurações com hastes convencionais apresentaram desvios percentuais de $2,41 \%$ até $28,99 \%$, para mais ou para menos, entre os valores calculados e medidos. 
Tabela 31 - Valores de resistência de terra medidos em campo e obtidos nas simulações computacionais.

\begin{tabular}{|c|c|c|c|c|}
\hline $\begin{array}{c}\text { Configuração da } \\
\text { malha }\end{array}$ & $\begin{array}{c}\text { Rat } \\
\text { convencional } \\
\text { CDEGS } \\
(\Omega)\end{array}$ & $\begin{array}{c}\text { Rat } \\
\text { convencional medido } \\
\text { em campo } \\
(\Omega)\end{array}$ & $\begin{array}{c}\text { Rat } \\
\text { concreto } \\
\text { CDEGS } \\
(\Omega)\end{array}$ & $\begin{array}{c}\text { Rat } \\
\text { concreto medido } \\
\text { em campo } \\
(\Omega)\end{array}$ \\
\hline Haste simples & 402,00 & 392,3 & 203,90 & 201,70 \\
\hline $\begin{array}{c}3 \text { Hastes } \\
\text { alinhadas }\end{array}$ & 130,00 & 134,70 & 84,00 & 80,00 \\
\hline $\begin{array}{c}\text { 5 Hastes } \\
\text { alinhadas }\end{array}$ & 84,00 & 118,30 & 58,75 & Sem medição \\
\hline Em "V" & 136,44 & 169,70 & 92,53 & Sem medição \\
\hline Triângulo & 130,00 & 160,00 & 89,50 & Sem medição \\
\hline
\end{tabular}

Este item apresentou resultados de simulações computacionais de configurações de aterramento considerando-se hastes convencionais e envolvidas em concreto. Foram estudadas configurações simples e, posteriormente, foram consideradas as configurações utilizadas em (CLAUSEN et al., 2004), visando a comparação das medições realizadas em campo com os resultados obtidos em simulações computacionais utilizando o CDEGS. Apesar de não se dispor de um maior número de medições em campo, algumas observações podem ser feitas:

- A utilização de hastes envolvidas em concreto resultou em menores valores de resistência de terra, sendo a redução mais pronunciada para solos de resistividades mais elevadas;

- Para as hastes envolvidas em concreto, os valores de resistência de terra obtidos nas simulações computacionais e as medições realizadas em campo apresentaram desvios de $1,10 \%$ ( 1 haste) e $4,76 \%$ (3 hastes);

- Com relação às hastes convencionais, foram observados desvios de 2,41\% a $29 \%$. 
6.2.2 Configurações de Aterramento Constituídas por Malha Reticulada com Hastes e Condutores Envolvidos em Concreto

A utilização do concreto tem mostrado redução nos valores de resistência de terra, portanto, de modo a verificar o comportamento da malha reticulada, foram realizadas simulações considerando a malha de aterramento padrão da CELTINS e a malha do caso 7 , ambas envolvidas em concreto.

Os resultados são apresentados na Tabela 32, sendo referentes às configurações das malhas de aterramento convencionais e concretadas. As simulações foram efetuadas levandose em consideração o valor de resistividade média $60 \Omega$.m para o concreto, com diâmetro de $20 \mathrm{~cm}$. As simulações foram realizadas considerando-se a frequiência industrial de $60 \mathrm{~Hz}$ e resistividades do solo de 500 e $4000 \Omega$.m. Nas simulações, os condutores de interligação das hastes não foram envolvidos em concreto.

Tabela 32 - Valores de resistência de terra.

\begin{tabular}{|c|c|c|c|c|}
\hline $\begin{array}{c}\text { Configuração } \\
\text { da malha }\end{array}$ & $\begin{array}{c}\mathrm{N}^{\mathrm{o}} \text { de } \\
\text { hastes }\end{array}$ & $\begin{array}{c}\rho \\
(\Omega . \mathrm{m})\end{array}$ & $\begin{array}{c}\text { Rat } \\
\text { convencional } \\
(\Omega)\end{array}$ & $\begin{array}{c}\text { Rat } \\
\text { concreto } \\
(\Omega)\end{array}$ \\
\hline Malha padrão CELTINS & 12,0 & 500 & 16,6 & 15,9 \\
\hline Malha padrão CELTINS & 12,0 & 4000 & 133,0 & 124,6 \\
\hline Malha Reticulada caso 7 & 7,00 & 500 & 17,0 & 16,6 \\
\hline Malha Reticulada caso 7 & 7,00 & 4000 & 136,0 & 131,0 \\
\hline
\end{tabular}

Os resultados obtidos mostram que após o uso do concreto nas hastes de aterramento, não houve redução significativa da resistência de terra em relação à malha de aterramento convencional. Portanto, o uso do concreto para reduzir a resistência de terra não foi efetivo para ambas as malhas de aterramento. 
6.2.3 Configuração condutor de interligação envolvido em concreto

Considerando que o custo de instalação de malhas de aterramento com condutores e hastes envolvidos em concreto pode ser muito elevado em função da dificuldade da execução das hastes concretadas no campo, foram realizadas simulações considerando somente os condutores de interligações envolvidos em concreto, sendo utilizadas hastes convencionais.

Os resultados apresentados na Tabela 33 são referentes às configurações das malhas de aterramento convencionais e malhas com os condutores concretados, mostradas nas Figuras 57 e 58 . As hastes de cobre são colocadas na posição vertical, $30 \mathrm{~cm}$ abaixo da superfície do solo, e sua interligação é feita com cabos na posição horizontal. As hastes são cilíndricas e cobreadas, diâmetro de $12,5 \mathrm{~mm}$ e $2,4 \mathrm{~m}$ de comprimento. $\mathrm{O}$ espaçamento entre hastes é de 3 metros. As interligações das hastes são feitas através de cabos nus, com $25 \mathrm{~mm}^{2}$ de diâmetro. Os cálculos foram efetuados considerando o valor de resistividade média de $60 \Omega$.m para o concreto e diâmetro de $20 \mathrm{~cm}$. As simulações foram realizadas considerando a freqüência industrial de $60 \mathrm{~Hz}$. Estão representados na Figura 63 os valores das resistências de terra

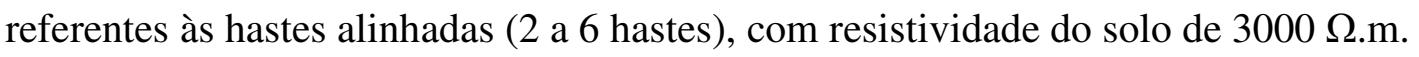

Tabela 33 - Valores de resistência de terra para malha convencional e com o condutor concretado.

\begin{tabular}{|l|c|c|c|c|c|}
\hline $\begin{array}{c}\text { Configuração } \\
\text { da malha }\end{array}$ & $\begin{array}{c}\mathrm{N}^{\mathrm{o}} \text { de } \\
\text { hastes }\end{array}$ & $\begin{array}{c}\rho \\
(\Omega . \mathrm{m})\end{array}$ & $\begin{array}{c}\text { Rat } \\
\text { convencional } \\
(\Omega)\end{array}$ & $\begin{array}{c}\text { Rat * } \\
\text { concretado } \\
(\Omega)\end{array}$ & $\begin{array}{c}\text { Rat ** } \\
\text { concretado } \\
(\Omega)\end{array}$ \\
\hline Hastes alinhadas & 2 & 3000 & 560 & 480 & 381,3 \\
\hline Hastes alinhadas & 3 & 3000 & 388,3 & 317 & 281,8 \\
\hline Hastes alinhadas & 4 & 3000 & 305,6 & 251 & 228,4 \\
\hline Hastes alinhadas & 5 & 3000 & 254,9 & 219 & 170,3 \\
\hline Hastes alinhadas & 6 & 3000 & 220,3 & 179 & 170,5 \\
\hline
\end{tabular}

*condutores de interligação envolvidos em concreto e hastes convencionais

***ondutores de interligação e hastes envolvidos em concreto 


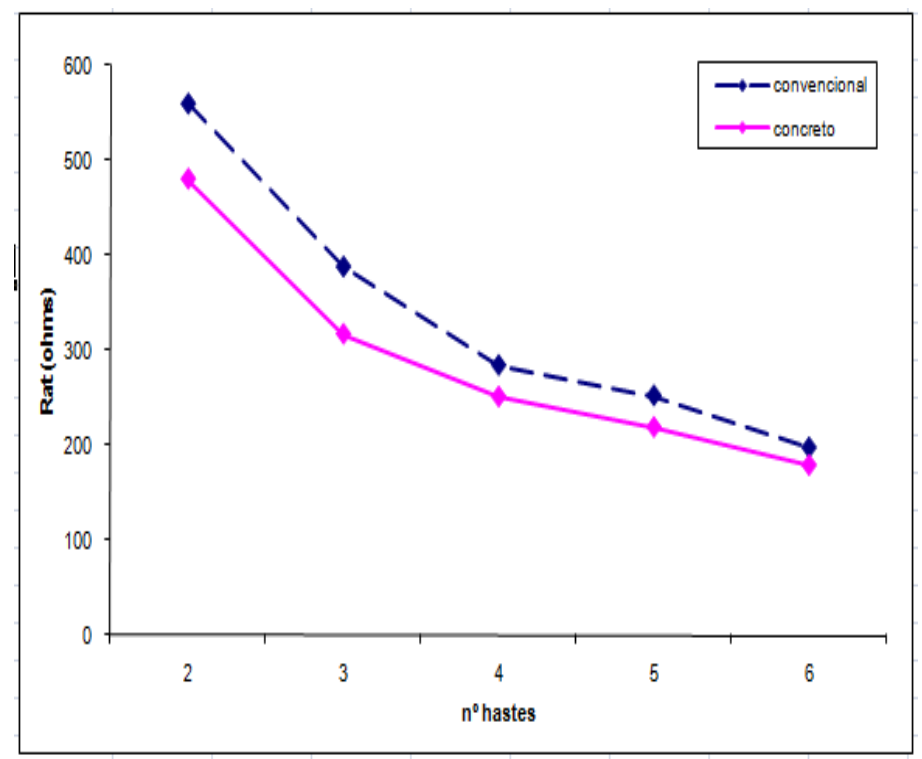

Figura 63 - Malha convencional x Condutor concretado ( $\rho_{\text {solo }} 3000 \Omega . m$ )

A Figura 63 mostra que o valor da resistência de terra foi reduzido em 14,16\% com a utilização do condutor de interligação concretado (2 hastes). Comparando o valor com o condutor de interligação concretado (3 hastes), houve redução de 18,00\% e, quando se aumenta o número de hastes, a diferença entre os valores diminui. Portanto, verifica-se que a utilização de condutores de interligação concretados e hastes convencionais também apresenta uma redução razoável em relação à malha convencional. 


\subsection{COMPORTAMENTO DA IMPEDÂNCIA DE ATERRAMENTO EM FUNÇÃO DA FREQUÊNCIA}

O comportamento do solo em decorrência da injeção de correntes impulsivas mostra que, para o caso de malhas de terra reticuladas com espaçamento entre hastes de $5 \mathrm{~m}$, o efeito da ionização do solo para surtos de corrente com amplitude até $100 \mathrm{kA}$ é muito pequeno, podendo ser desprezado, segundo (GUPTA; THAPAR, 1980; GUPTA; SINGH, 1992). Isso ocorre em função da existência de vários caminhos para a corrente fluir para o solo, ocasionando em redução da densidade de corrente e, em conseqüência, em um campo elétrico com valor menor do que o gradiente crítico de ionização do solo.

A forma de onda do impulso de corrente, 8 x $20 \mu$ s ou 4 x $10 \mu$ s, é freqüentemente aplicada para a medição da impedância dinâmica de surto atmosférico.

As simulações computacionais foram realizadas utilizando correntes impulsivas com tempo de frente igual a $4 \mu$ s e tempo de cauda de $75 \mu$ s, com o tempo para o zero igual a $150 \mu \mathrm{s}$. Através da transformada de Fourier foram obtidos dados de tensão e de corrente para determinados valores de freqüência. Como são considerados valores mais elevados de frequiência, em vez de resistência de terra (Rat) é, agora, considerada a impedância de terra (módulo e fase) - Zat. Os valores complexos de Zat são apresentados em função da freqüência e da resistividade do solo ( $\rho$ ). As simulações foram realizadas, assumindo-se os seguintes valores de amplitude de corrente 15 e $45 \mathrm{kA}$, para verificar o comportamento da impedância em função da frequiência e da amplitude da corrente. $\mathrm{O}$ valor da amplitude da corrente de $45 \mathrm{kA}$ é um valor típico de descarga atmosférica (PIANTINI, et al.,2001) e (VISACRO et al.,2004). O valor de $15 \mathrm{kA}$ foi escolhido por ter uma probabilidade alta de ser excedido, $98 \%$ (VISACRO et al.,2004). Os resultados são mostrados na Tabela 34, considerando-se o valor de corrente igual a $15 \mathrm{kA}$ e $45 \mathrm{kA}$.

Para valores de resistividade do solo maiores que $3.000 \Omega$.m, não houve uma variação significativa do módulo da impedância de terra em relação a freqüência menor que $2,8 \%$. Para o valor de resistividade de $1.000 \Omega$.m ocorreu variação de $42,37 \%$ na impedância de terra com a frequiência. Com menor resistividade, o "efeito pelicular" é mais acentuado, fazendo 
com que a distribuição de corrente varie mais com a freqüência, resultando em variação mais significativa da impedância.

Tabela 34 - Valores da impedância de terra (Zat) em função da freqüência para I = 15 kA e $45 \mathrm{kA}$, para a malha padrão (caso 1).

\begin{tabular}{|c|c|c|c|c|}
\hline \multirow{2}{*}{$\begin{array}{c}\rho \\
(\Omega . \mathrm{m})\end{array}$} & \multicolumn{5}{|c|}{$\mathrm{Za}_{\mathrm{t}}(\Omega)$} \\
\cline { 2 - 5 } & $60 \mathrm{~Hz}$ & $487 \mathrm{kHz}$ & $730 \mathrm{kHZ}$ & $1,2 \mathrm{MHZ}$ \\
\hline 500 & $16,65 \mid \underline{0}$ & $21,77 \mid \underline{31,14}$ & $25,75 \mid \underline{38,78}$ & $34,16 \mid \underline{46,72}$ \\
\hline 1.000 & $33,30 \mid \underline{0}$ & $36,87 \mid \underline{18,87}$ & $39,94 \mid \underline{25,71}$ & $47,41 \mid \underline{35,41}$ \\
\hline 3.000 & $99,92 \mid \underline{0}$ & $101,95 \mid \underline{7,16}$ & $103,59 \mid \underline{10,36}$ & $107,92 \mid \underline{16,18}$ \\
\hline 6.000 & $199,82 \mid \underline{0}$ & $201,39 \mid \underline{3,72}$ & $202,52 \mid \underline{5,43}$ & $205,39 \mid \underline{8,70}$ \\
\hline
\end{tabular}

São apresentadas nas Figuras 64 e 65 as tensões de passo calculadas para um valor de corrente de pico de $45 \mathrm{kA}$, em $60 \mathrm{~Hz}$ e 1,2 MHz, injetada na malha, considerando a resistividade do solo igual a $3.000 \Omega$.m. Não foram observadas variações significativas dos valores máximos da tensão de passo e da distribuição dessa tensão. 


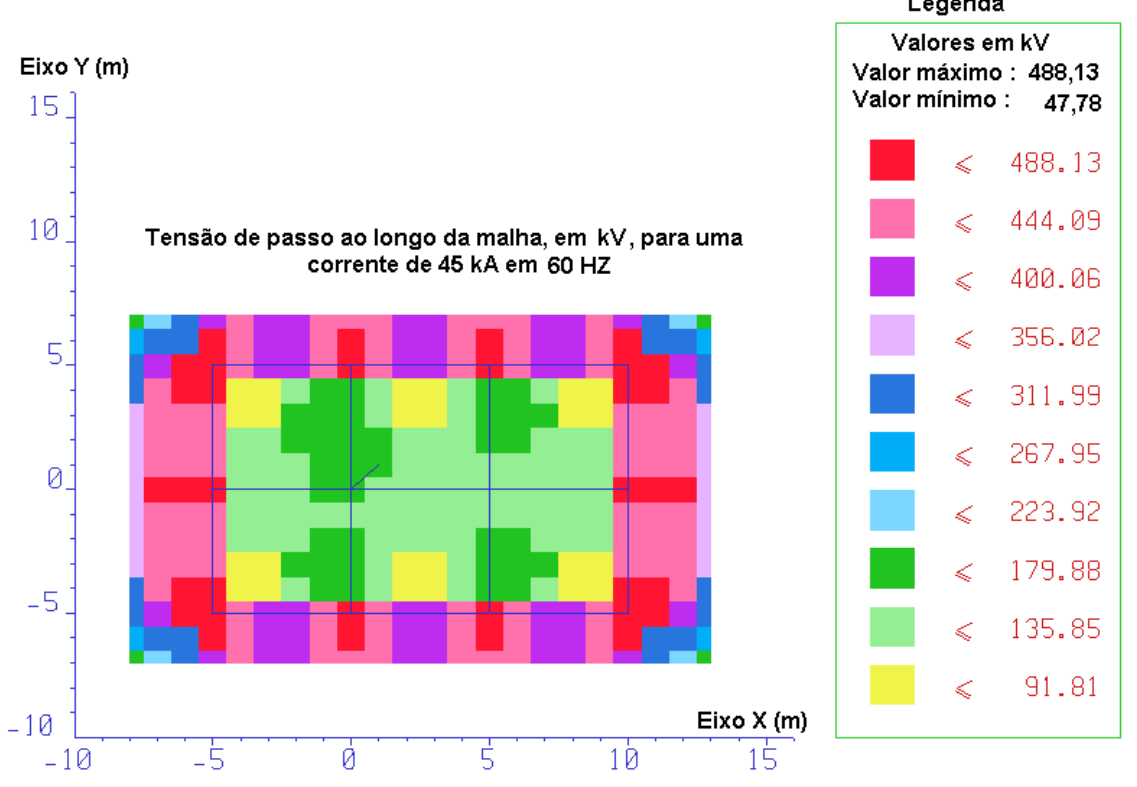

Figura 64 - Tensão de passo em baixa frequência (caso 1).
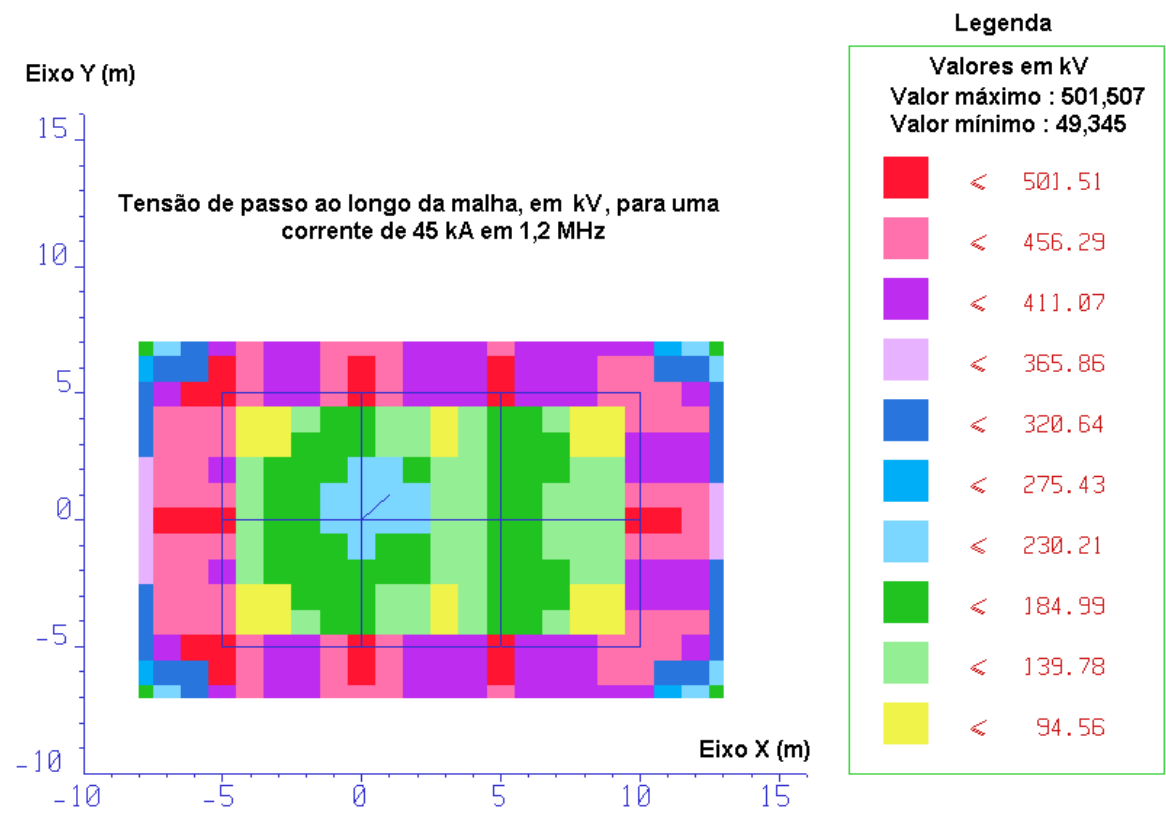

Figura 65 - Tensão de passo em alta freqüência (caso 1). 
Nas Figuras 66 e 67 as tensões de passo foram calculadas para uma corrente de pico de $45 \mathrm{kA}$, em $60 \mathrm{~Hz}$ e 1,2 MHz, injetada na malha do caso 7, considerando a resistividade do solo igual a $3.000 \Omega . m$.

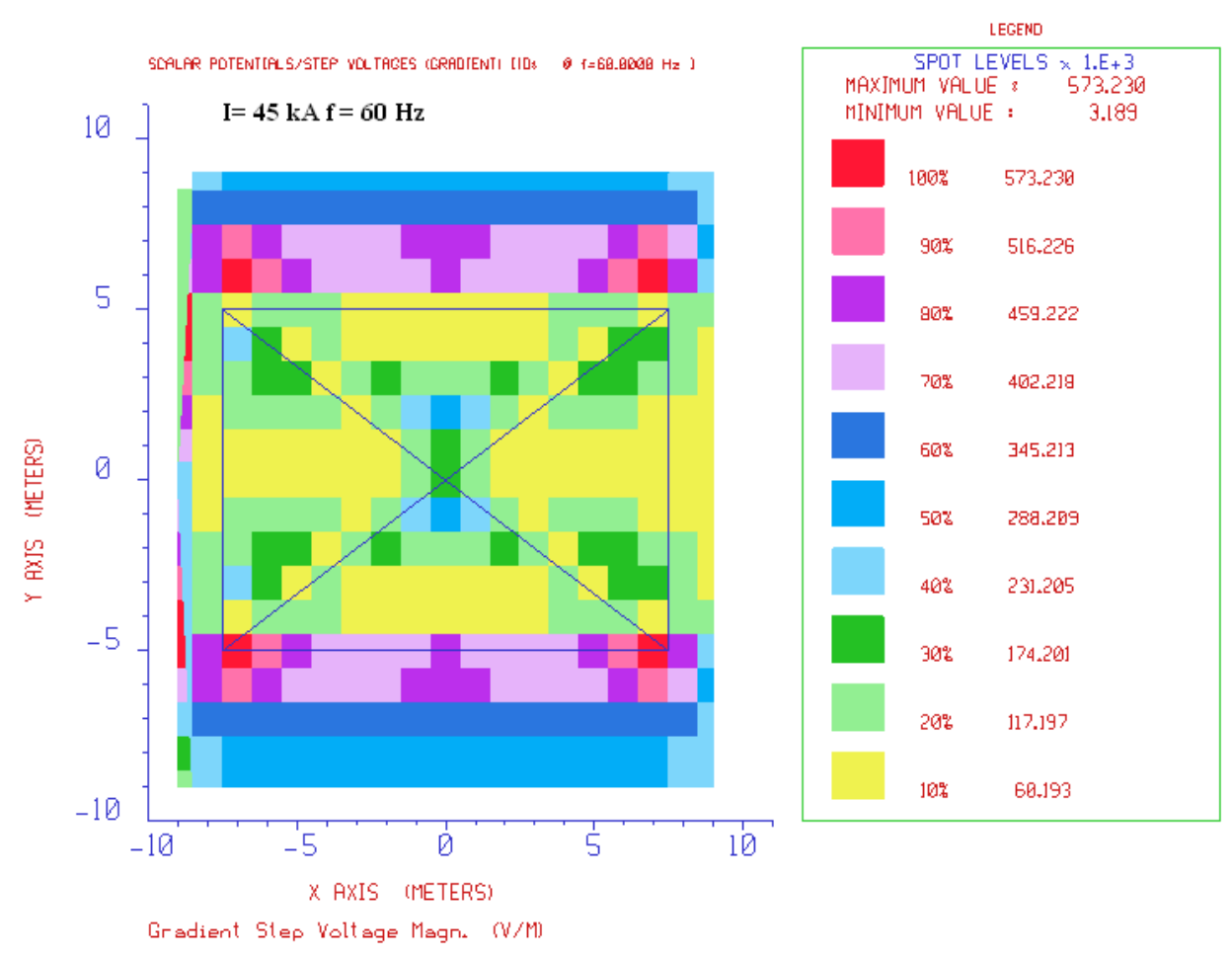

Figura 66 - Tensão de passo em baixa freqüência (caso 7).

Com a alteração da malha, houve variação dos valores máximos e mínimos de tensão de passo em relação à malha de aterramento padrão CELTINS (caso 1), ou seja, a tensão de passo máxima teve uma elevação acima de $100 \%$ para a freqüência de $1,2 \mathrm{MHz}$ e para freqüência de $60 \mathrm{~Hz}$ a elevação foi de 17,43\% em relação ao caso 7 . 


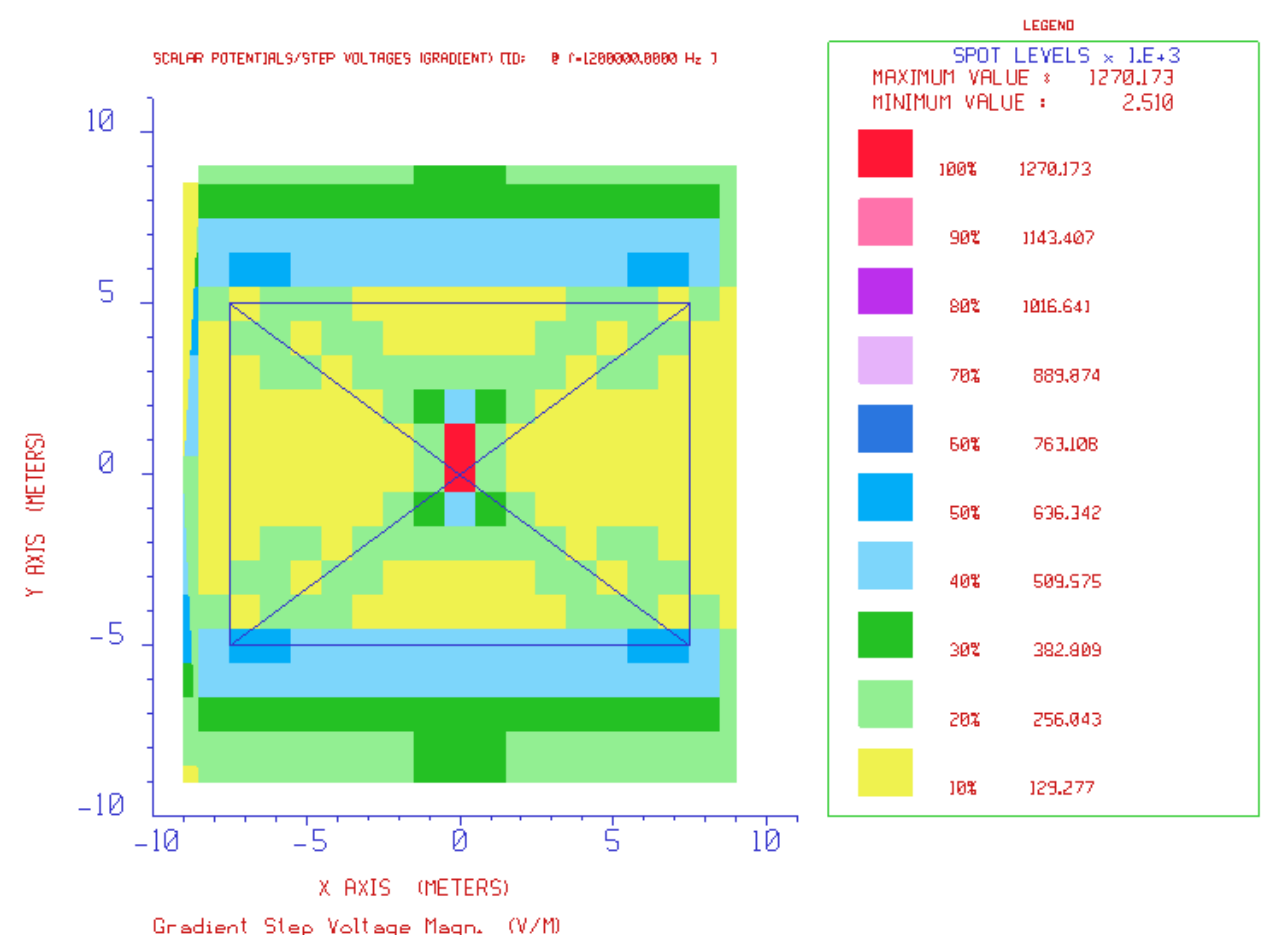

Figura 67 - Tensão de passo em alta frequência (caso 7).

O valor da tensão de passo para freqüência de $1,2 \mathrm{MHz}$ foi duas vezes maior que o valor apresentado com frequiência igual a $60 \mathrm{~Hz}$. Isso ocorre em função do aumento da impedância de terra.

Simulações em baixa e alta frequiência para hastes convencionais alinhadas e envolvidas em concreto

Neste item, são mostradas simulações considerando-se 1, 2 e 6 hastes alinhadas, tanto para malha convencional como para malha envolvida em concreto. São apresentados resultados de simulações computacionais em alta freqüência para verificar o comportamento da malha de terra. A Tabela 35 mostra os valores da impedância de terra (Zat) em função da freqüência para uma haste envolvida em concreto. A Tabela 36 mostra os resultados considerando-se uma haste convencional. 
Tabela 35 - Valores da impedância de terra (Zat) em função da freqüência para uma haste envolvida em concreto.

\begin{tabular}{|c|c|c|c|c|}
\hline \multirow{2}{*}{$\begin{array}{c}\mid 5 \\
\Omega . m)\end{array}$} & $60 \mathrm{~Hz}$ & $487 \mathrm{kHz}$ & $730 \mathrm{kHZ}$ & $1,2 \mathrm{MHZ}$ \\
\cline { 2 - 5 } & $127 \mid \underline{0}$ & $128 \mid \underline{3,21}$ & $128,60 \mid \underline{4,69}$ & $129,94 \mid \underline{7,41}$ \\
\hline 500 & \multicolumn{2}{|c|}{$\mathrm{Za}_{\mathrm{t}}(\Omega)$} \\
\hline 1.000 & $243 \mid \underline{0}$ & $243 \mid \underline{1,75}$ & $244,77 \mid \underline{2,56}$ & $245,81 \mid \underline{4,08}$ \\
\hline 3.000 & $708 \mid \underline{0}$ & $709,64 \mid \underline{0,63}$ & $709,99 \mid \underline{0,93}$ & $710,78 \mid \underline{1,49}$ \\
\hline 6.000 & $1406 \mid \underline{0}$ & $1407 \mid \underline{0}, 32$ & $1407 \mid \underline{0}, 48$ & $1408 \mid \underline{0}, 76$ \\
\hline
\end{tabular}

Tabela 36 - Valores da impedância de terra (Zat) em função frequiência para uma haste convencional.

\begin{tabular}{|c|c|c|c|c|c|c|}
\hline \multirow{3}{*}{$\begin{array}{c}\rho \\
(\Omega . \mathrm{m}) \\
500\end{array}$} & \multicolumn{6}{|c|}{$\mathrm{Za}_{\mathrm{t}}(\Omega)$} \\
\hline & $60 \mathrm{~Hz}$ & $487 \mathrm{kHz}$ & $730 \mathrm{k}$ & kHZ & $1,2 \mathrm{M}$ & ИHZ \\
\hline & $202,48 \mid \underline{0}$ & \begin{tabular}{l|l|l|} 
&
\end{tabular} & 203,69 & 2,78 & 204,69 & 4,42 \\
\hline 1.000 & \begin{tabular}{l|l}
$404,88 \mid \underline{0}$ \\
\end{tabular} & $405,580,98$ & 405,97 & 1,44 & 406,78 & 2,30 \\
\hline 3.000 & $1214 \mid \underline{0}$ & $1215 \mid 0,34$ & 1215 & 0,50 & 1215 & 0,80 \\
\hline 6.000 & $2429 \mid \underline{0}$ & $2429 \mid \underline{0}$ & 2429 & 0,24 & 2430 & $\underline{0}, 40$ \\
\hline
\end{tabular}

Na tabela 37 são apresentados os valores de impedância de terra para 2 hastes convencionais. 
Tabela 37 - Valores da impedância de terra (Zat) em função da freqüência para 2 hastes convencionais alinhadas.

\begin{tabular}{|c|c|c|c|c|}
\hline \multirow{2}{\rho}{$\begin{array}{c}\mid 5 \\
(\Omega . \mathrm{m})\end{array}$} & $60 \mathrm{~Hz}$ & $487 \mathrm{kHz}$ & $730 \mathrm{kHZ}$ & $1,2 \mathrm{MHZ}$ \\
\hline 500 & $93,15 \mid \underline{0}$ & $94,35 \mid \underline{4,42}$ & $95,16 \mid \underline{6,41}$ & $97,13 \mid \underline{10,00}$ \\
\hline 1.000 & $186,51 \mid \underline{0}$ & $187,37 \mid \underline{2,30}$ & $187,95 \mid \underline{3,37}$ & $189,33 \mid \underline{5,35}$ \\
\hline 3.000 & $559,40 \mid \underline{0}$ & $560,08 \mid \underline{0,81}$ & $560,49 \mid \underline{1,18}$ & $561,38 \mid \underline{1,90}$ \\
\hline 6.000 & $1118,70 \mid \underline{0}$ & $1119,00 \mid \underline{0}$ & $1119,52 \mid \underline{0}$ & $1120,00 \mid \underline{0}$ \\
\hline
\end{tabular}

Para uma determinada resistividade do solo, a impedância de terra (módulo e fase) não varia significativamente com a frequiência, conforme mostra a Tabela 37. Observa-se que, para valores com freqüência igual a $60 \mathrm{~Hz}$, o ângulo de fase é igual a zero. Isso acontece porque na frequiência industrial é considerado o comportamento do solo como resistência pura. Esse comportamento é também observado em resistividade do solo elevada, ou seja, valores mais elevados de resistividade implicam em um aumento da influência do ramo RC, o que reduz os efeitos da reatância indutiva (ALIPIO, 2008).

A impedância dinâmica de surto $\mathrm{x}$ tempo $(\mathrm{Z} \times \mathrm{t})$ das hastes de aterramento, pode aumentar ou diminuir, dependendo da resistividade do solo e da malha de aterramento.

A seguir são apresentados resultados de simulações computacionais para verificar o comportamento da malha de terra, com duas hastes alinhadas e envolvidas em concreto, conforme apresentado na Tabela 38. 
Tabela 38 - Valores da impedância de terra (Zat) em função da freqüência para 2 hastes alinhadas envolvidas em concreto.

\begin{tabular}{|c|c|c|c|c|}
\hline \multirow{2}{*}{$\begin{array}{c}\rho \\
(\Omega . \mathrm{m})\end{array}$} & \multicolumn{4}{|c|}{$\mathrm{Za}_{\mathrm{t}}(\Omega)$} \\
\hline & $60 \mathrm{~Hz}$ & $487 \mathrm{kHz}$ & $730 \mathrm{kHZ}$ & $1,2 \mathrm{MHZ}$ \\
\hline 500 & $69,43 \mid \underline{0}$ & \begin{tabular}{l|l}
70,80 & 6,21 \\
\end{tabular} & \begin{tabular}{l|l|}
71,88 & 8,91
\end{tabular} & \begin{tabular}{l|l|l|}
74,53 & 13,56 \\
\end{tabular} \\
\hline 1.000 & $134,84 \mid \underline{0}$ & \begin{tabular}{l|l|l|}
135,92 & 3,39 \\
\end{tabular} & \begin{tabular}{l|l|l|}
136,71 & 4,93 \\
\end{tabular} & \begin{tabular}{l|l|l|}
138,62 & 7,73 \\
\end{tabular} \\
\hline 3.000 & 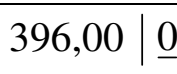 & $397,08 \mid \underline{1,22}$ & $397,67 \mid \underline{1,80}$ & \begin{tabular}{l|l|l|}
398,84 & $\underline{2,87}$
\end{tabular} \\
\hline 6.000 & \begin{tabular}{l|l}
788 & $\underline{0}$
\end{tabular} & \begin{tabular}{l|l|l}
788,26 & $\underline{0}$ \\
\end{tabular} & \begin{tabular}{l|l|l}
$789,00 \mid \underline{0}$ \\
\end{tabular} & \begin{tabular}{l|l|l}
790,00 & $\underline{0}$
\end{tabular} \\
\hline
\end{tabular}

Os valores da impedância de terra para hastes envolvidas em concreto são menores em relação às hastes convencionais e também mostram características semelhantes quanto ao comportamento em função da freqüência. O valor da impedância de terra não varia significativamente com a freqüência.

A seguir são apresentados resultados considerando-se baixa e alta freqüências para verificar o comportamento da malha de terra com seis hastes alinhadas convencionais e concretadas, conforme Tabela 39. 
Tabela 39 - Valores da impedância de terra (Zat) em função da freqüência para 6 hastes convencionais alinhadas.

\begin{tabular}{|c|c|c|c|c|c|}
\hline \multirow{2}{*}{$\begin{array}{c}\rho \\
(\Omega . \mathrm{m})\end{array}$} & \multicolumn{5}{|c|}{$\mathrm{Za}_{\mathrm{t}}(\Omega)$} \\
\hline & $60 \mathrm{~Hz}$ & $487 \mathrm{kHz}$ & 7301 & $\mathrm{kHZ}$ & $1,2 \mathrm{MHZ}$ \\
\hline 500 & \begin{tabular}{l|l}
36,20 & $\underline{0}$
\end{tabular} & \begin{tabular}{l|l|}
49,53 & 27,77
\end{tabular} & 58,31 & 31,75 & \begin{tabular}{l|l|}
72,89 & 33,00
\end{tabular} \\
\hline 1.000 & $72,33 \mid \underline{0}$ & \begin{tabular}{l|l}
82,09 & 18,33 \\
\end{tabular} & 90,14 & $\underline{23,93}$ & $107,24 \mid \underline{30,00}$ \\
\hline 3.000 & \begin{tabular}{l|l|l}
$216,82 \mid \underline{0}$
\end{tabular} & $\begin{array}{l}229,29 \mid \underline{7,31} \\
\end{array}$ & 238,88 & 10,47 & $\begin{array}{l}245,84 \underline{18,13} \\
\end{array}$ \\
\hline 6.000 & \begin{tabular}{l|l|l}
433,60 & $\underline{0}$
\end{tabular} & \begin{tabular}{l|l|}
437,63 & 3,85
\end{tabular} & 440,72 & 5,60 & \begin{tabular}{|l|l|}
448,44 & 10,31
\end{tabular} \\
\hline
\end{tabular}

Analisando a impedância de terra, verifica-se que para valores de resistividade do solo inferiores a 1000 S.m ocorre a variação de até $100 \%$ nos valores das impedâncias com a frequiência. Para valores de $\rho \geq 3000 \Omega$.m, a variação é menos acentuada.

$\mathrm{Na}$ Tabela 40, são mostradas simulações considerando-se 6 hastes para malha envolvida em concreto.

Tabela 40 - Valores da impedância de terra (Zat) em função da frequiência para seis hastes alinhadas envolvidas em concreto.

\begin{tabular}{|c|c|c|c|c|}
\hline \multirow{3}{*}{$\begin{array}{c}\rho \\
(\Omega . \mathrm{m}) \\
500\end{array}$} & \multicolumn{4}{|c|}{$\mathrm{Za}_{\mathrm{t}}(\Omega)$} \\
\hline & $60 \mathrm{~Hz}$ & $487 \mathrm{kHz}$ & $730 \mathrm{kHZ}$ & $1,2 \mathrm{MHZ}$ \\
\hline & $29,89 \mid \underline{0}$ & \begin{tabular}{l|l|l}
44,12 & 28,89
\end{tabular} & \begin{tabular}{l|l|l}
52,10 & 32,00
\end{tabular} & \begin{tabular}{l|l|}
63,84 & 34,00
\end{tabular} \\
\hline 1.000 & \begin{tabular}{l|l}
$58,57 \mid \underline{0}$ \\
\end{tabular} & \begin{tabular}{l|l|l|}
59,81 & $\underline{20,82}$
\end{tabular} & \begin{tabular}{l|l}
78,41 & 25,95 \\
\end{tabular} & \begin{tabular}{l|l|l}
94,82 & $\underline{30,61}$ \\
\end{tabular} \\
\hline 3.000 & $173,25 \mid \underline{0}$ & $179,29 \underline{8,92}$ & \begin{tabular}{ll|l}
185,08 & 12,59 \\
\end{tabular} & \begin{tabular}{ll|l}
198,57 & 20,79 \\
\end{tabular} \\
\hline 6.000 & $345,25 \mid \underline{0}$ & \begin{tabular}{ll|l}
349,83 & 4,76 \\
\end{tabular} & \begin{tabular}{l|l|l}
353,43 & $\underline{6,90}$
\end{tabular} & $362,74 \quad 10,69$ \\
\hline
\end{tabular}


Para valores menores de resistividade do solo $(\rho \leq 1000 \Omega$.m) ocorre a variação de até $100 \%$. Os valores de resistividade $\rho \geq 3000 \Omega$.m, resultam em menores variações da impedância de terra com a freqüência.

Com 6 hastes os valores de impedância são menores do que com 2 hastes, porém, apresenta comportamento mais indutivo. 


\subsection{ANÁLISE DA INFLUÊNCIA DE RESISTÊNCIA DE TERRA NO CONSUMIDOR DURANTE UMA DESCARGA ATMOSFÉRICA DIRETA NA REDE PRIMÁRIA}

Nesta etapa, o objetivo principal foi a análise da influência do sistema de aterramento do consumidor, com haste convencional e haste envolvida em concreto, quando da ocorrência de descarga atmosférica direta na linha de distribuição primária. As análises envolveram simulações computacionais destinadas a avaliar o efeito de descarga direta.

As simulações foram realizadas utilizando-se o programa computacional ATP (Alternative Transients Program). Este software foi desenvolvido no EUA e teve como base o programa EMTP (Eletromagnetic Transients Program) desenvolvido por Herman W. Dommel, na década de 60, com base no trabalho de Frey e Althamimer (Brown Boveri, suíça), na Alemanha.

O estudo considerou um sistema composto de uma linha de distribuição de $34,5 \mathrm{kV}$, uma linha de baixa tensão, ramais de ligação e cargas de consumidores residenciais, conforme apresentado na Figura 68, onde é analisada a sobretensão no consumidor gerada a partir de uma descarga atmosférica transferida do primário do transformador para a rede secundária. Também foi considerada a influência do valor de resistência de terra no transformador utilizando haste convencional e haste envolvida em concreto. Nas simulações, considerou-se uma fonte de corrente com forma de onda triangular com tempo de frente de 5,6 $\mu$ s e tempo até o zero de $150 \mu \mathrm{s}$, com amplitude igual a $45 \mathrm{kA}$. 


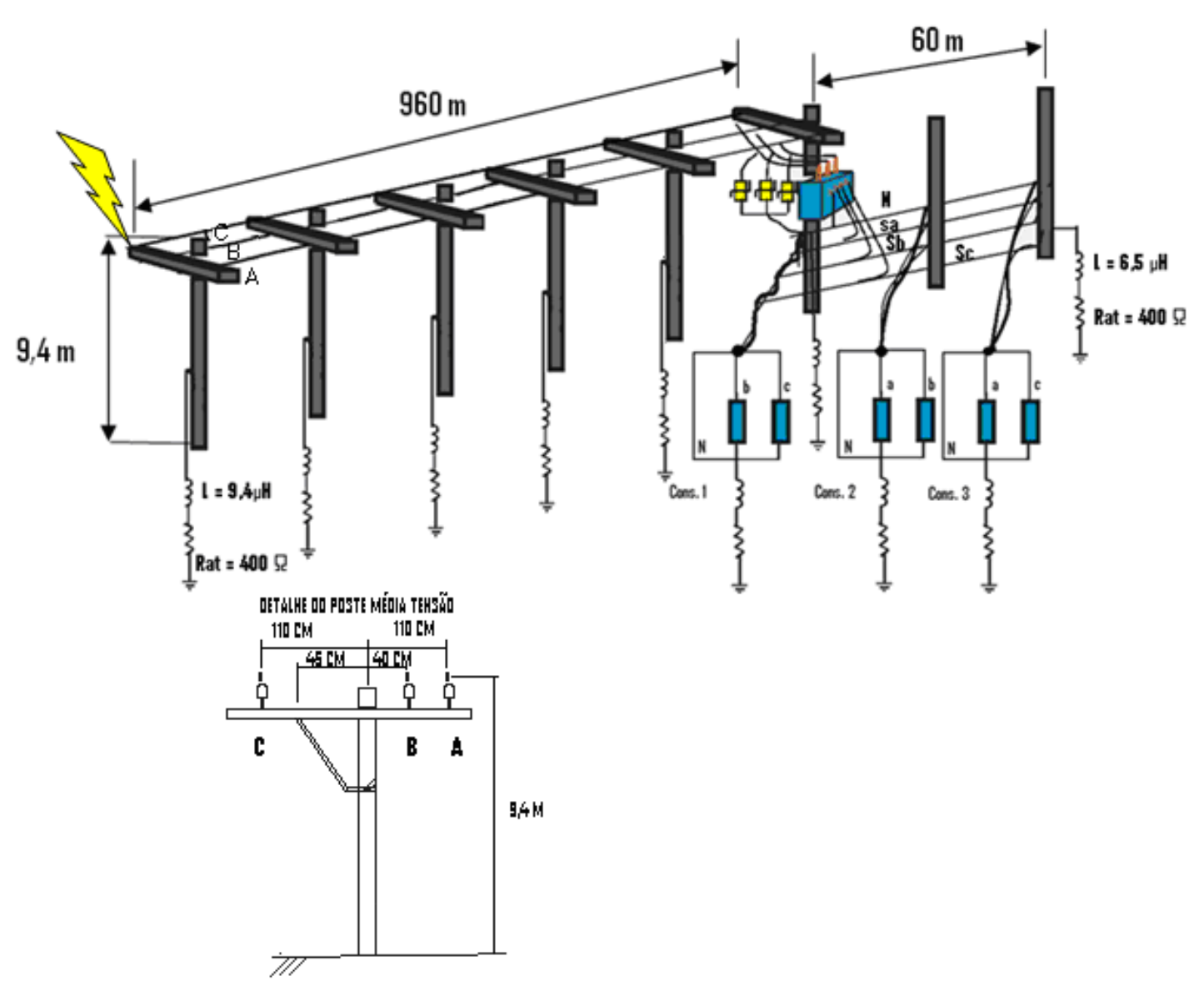

Figura 68 - Configuração de rede de distribuição.

A configuração apresentada na Figura 68 é constituída de uma linha de distribuição trifásica em média tensão $(34,5 \mathrm{kV})$, com 960 m de comprimento e 6 postes, com vãos de 160 $\mathrm{m}$ entre um poste e outro, com a altura dos condutores igual a 9,4 m, a qual alimenta um transformador trifásico de $30 \mathrm{kVA}$, com tensão de entrada de $34,5 \mathrm{kV}$ e saída trifásica de 380/220V. O transformador está ligado em delta no primário e estrela no secundário. Os terminais do primário do transformador são protegidos por pára-raios. A linha secundária (380/220V) é constituída de 2 postes, com vãos de $30 \mathrm{~m}$ entre um poste e outro, com a altura dos condutores igual a 5,9 m e distância entre condutores são de $20 \mathrm{~cm}$. A linha em baixa tensão possui um comprimento de $60 \mathrm{~m}$. Os condutores utilizados nas simulações foram: 
Condutores na linha de média tensão: diâmetro de 2/0 AWG $(1,137 \mathrm{~cm}$, com resistência de $0,4262 \Omega / \mathrm{km})$;

Condutores do secundário e neutro: diâmetro de 4 AWG $(0,588 \mathrm{~cm}$, com resistência de $1,356 \Omega / \mathrm{km})$;

Condutores do ramal de ligação com 30 m de comprimento: multiplexado 3 x $10+10$ $\mathrm{mm}^{2}$, diâmetro $0,3568 \mathrm{~cm}$, com $3,08 \Omega / \mathrm{km}$.

Os consumidores estão interligados no secundário do transformador, no lado da baixa tensão. O primeiro consumidor no lado da baixa está distanciado de $30 \mathrm{~m}$ do transformador de distribuição, o segundo consumidor com 60 m e o terceiro consumidor com 90 m, já considerando o ramal de ligação. Ao final de cada ramal está conectada uma carga, que representa um consumidor residencial, conforme Figura 69. Na simulação foi considerado que em cada poste está conectado, na rede secundária, 1 consumidor, representado por uma indutância de $15 \mu \mathrm{H}$ (Hoidalen, 1998). Os postes foram considerados de concreto e por isso apresenta ferragem cuja indutância foi estimada em $1 \mu \mathrm{H} / \mathrm{m}$, ou seja, a impedância depende da altura do poste, portanto, $(1 \mu \mathrm{H} / \mathrm{m} \times$ altura do poste $)$.

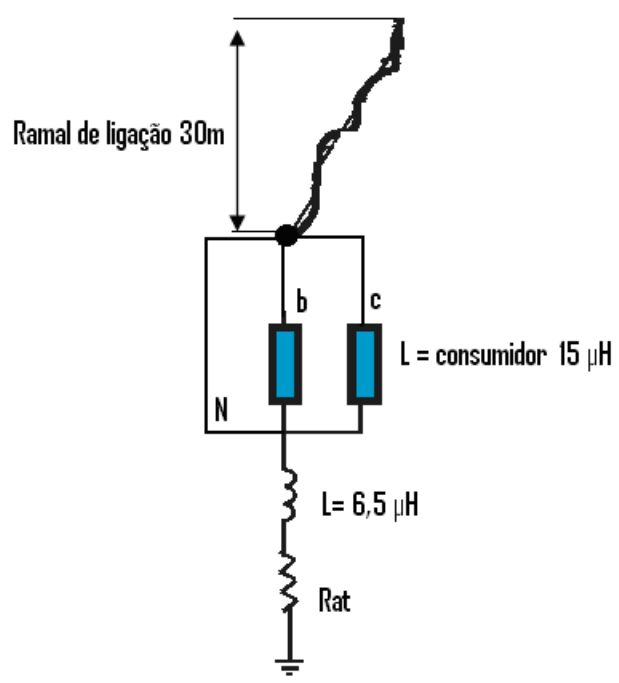

Figura 69 - Configuração utilizada para representar a carga no consumidor.

Na simulação computacional, o valor de resistência de terra adotado para os postes de média e baixa tensão foi de $400 \Omega$, valor considerado o dobro da resistência de terra calculado 
para uma haste de aterramento em solo com resistividade de 500 S.m. Este valor de resistência de terra é considerado para os postes que não possuem aterramento, porque quando ocorre a disrupção do isolador da média ou da baixa tensão o surto de corrente fluirá para terra através de uma resistência cujo o valor é equivalente ao dobro da resistência de terra dos postes que possuem aterramento, segundo (Sekioka et al. 1995).

No ATP não é possível modelar haste envolvida em concreto, portanto, foram adotadas as resistências de terra apresentadas nas Tabelas 35 e 36 para representar aterramento com haste convencional e envolvida em concreto, respectivamente, na resistividade de $500 \Omega$.m porque os valores de resistência de terra são próximos dos encontrados em campo.

Os isoladores foram modelados no ATP, o qual permite a implementação de equações algébricas e processamento lógico. Nas simulações computacionais calcula-se o valor da sobretensão no isolador durante o surto e quando esse valor ultrapassa o CFO (critical impulse flashover voltage), a rotina TACS (no software ATP) curto-circuita os terminais do isolador através de uma chave controlada. O CFO do isolador pode ser obtido por ensaios ou através da NBR 6936 pela equação (12):

$$
\mathrm{U}_{10}=\mathrm{U}_{50} \mathrm{x}(1-1,3 \mathrm{z})
$$

$\mathrm{U}_{10}=$ tensão de descarga disruptiva a $10 \%$ (valor da tensão que provoca descarga disruptiva em $10 \%$ dos casos);

$\mathrm{U}_{50}=$ tensão de descarga disruptiva a $50 \%$ ou CFO (valor da tensão que provoca descarga disruptiva em $50 \%$ dos casos);

$\mathrm{z}=$ desvio convencional da tensão de descarga disruptiva, sendo que para ensaios a seco em isolação de ar, pode ser utilizado o valor por unidade de $\mathrm{z}=0,03$.

Utilizando a equação (12) para a rede de distribuição típica com NBI de $150 \mathrm{kV}$, o valor de CFO é igual a $156 \mathrm{kV}$ para os isoladores. O IEEE STD 1410, considera o CFO total da estrutura, ou seja, o CFO do isolador com o da cruzeta. O CFO total da estrutura consiste 
em somar o valor do CFO do isolador $(156 \mathrm{kV})$ com o do CFO adicional da cruzeta que depende do material e do seu comprimento. Quando se utiliza cruzeta de fibra de vidro ou de madeira o valor do CFO adicional é de $250 \mathrm{kV} / \mathrm{m}$. Para a estrutura mostrada na Figura 68, temos os seguintes valores de $\mathrm{CFO}$ :

Média tensão fase $\mathrm{A}=431 \mathrm{kV}$;
Média tensão fase $\mathrm{B}=256 \mathrm{kV}$;
Média tensão fase $\mathrm{C}=319 \mathrm{kV}$;

O valor de corrente de descarga foi mantido em $45 \mathrm{kA}$, sendo adotados valores diferentes de resistência de terra nos consumidores. Nas simulações computacionais foi considerado solo com resistividade de $500 \Omega$.m. Os valores de resistência de terra adotados foram: $205 \Omega$ para haste convencional e $128 \Omega$ para haste envolvida em concreto, conforme apresentado nas Tabelas 35 e 36.

Salienta-se que não foi considerada disrupção na baixa tensão porque o objetivo foi a comparação da influência da resistência de terra. No circuito foram considerados finais de rede casados para evitar reflexões. A ionização do solo também não foi considerada.

Após a modelagem dos parâmetros que compõe a rede distribuição e da corrente de descarga, foram analisados os seguintes valores de tensão:

- Fase-neutro no consumidor;

- Fase-terra no consumidor;

- Neutro-terra no consumidor;

- Neutro-terra no transformador.

Na Figura 70 têm-se os valores de tensão fase-neutro, considerando-se as resistências de terra de $128 \Omega$ e $205 \Omega$ no sistema de aterramento elétrico do consumidor. 


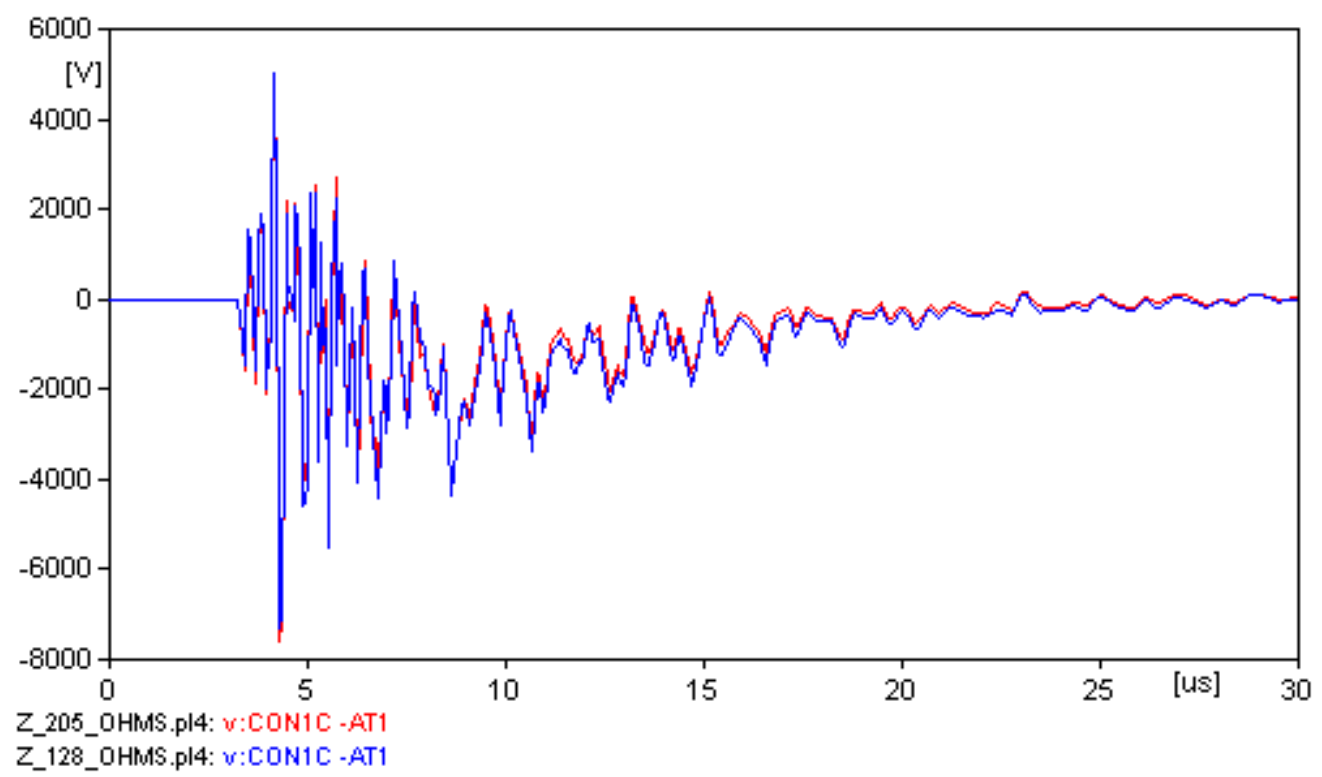

Figura 70 - Tensão fase-neutro no consumidor.

A Figura 70 mostra que as amplitudes das tensões fase-neutro no consumidor são próximas, tanto para haste convencional (205 $\Omega$ ) quanto para haste concretada (128 $\Omega$ ).

$\mathrm{Na}$ Figura 71, são mostrados os valores de tensão fase-terra considerando-se resistências de terra iguais a $128 \Omega$ e $205 \Omega$ no consumidor.

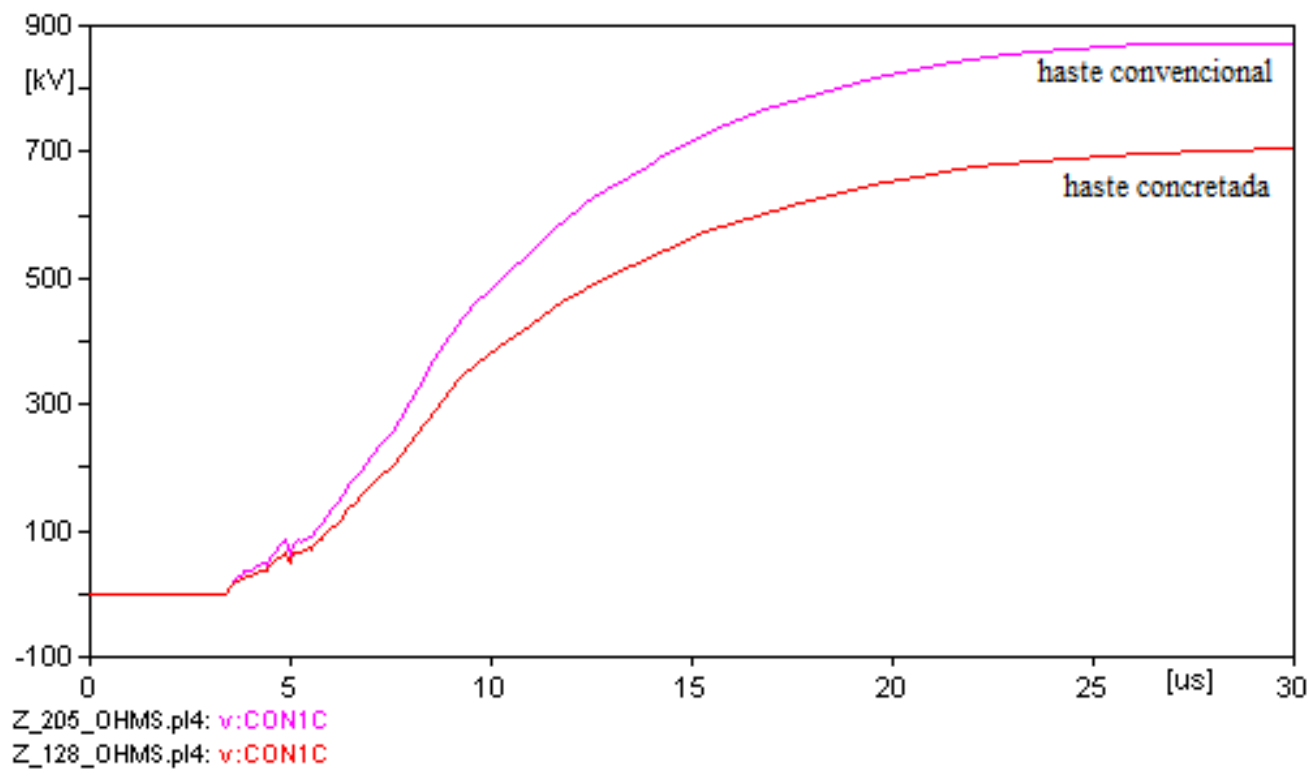

Figura 71 - Tensão fase-terra no consumidor. 
Através da Figura 71, observa-se que, dependendo dos valores de resistência de terra há diminuição dos níveis de tensão entre fase-terra. Verifica-se que quando foi alterado o valor de resistência de terra de $205 \Omega$ para $128 \Omega$, houve redução de $170 \mathrm{kV}$ na amplitude da tensão em $20 \mu \mathrm{s}$.

Na Figura 72 têm-se os valores de tensão neutro-terra, podendo ser observado que os níveis de tensão e a forma de onda foram semelhantes àquelas apresentadas nas tensões faseterra. Houve também uma redução de 170 kV na amplitude da tensão em $20 \mu$ s. A Figura 73 mostra o resultado da tensão neutro-terra no transformador.

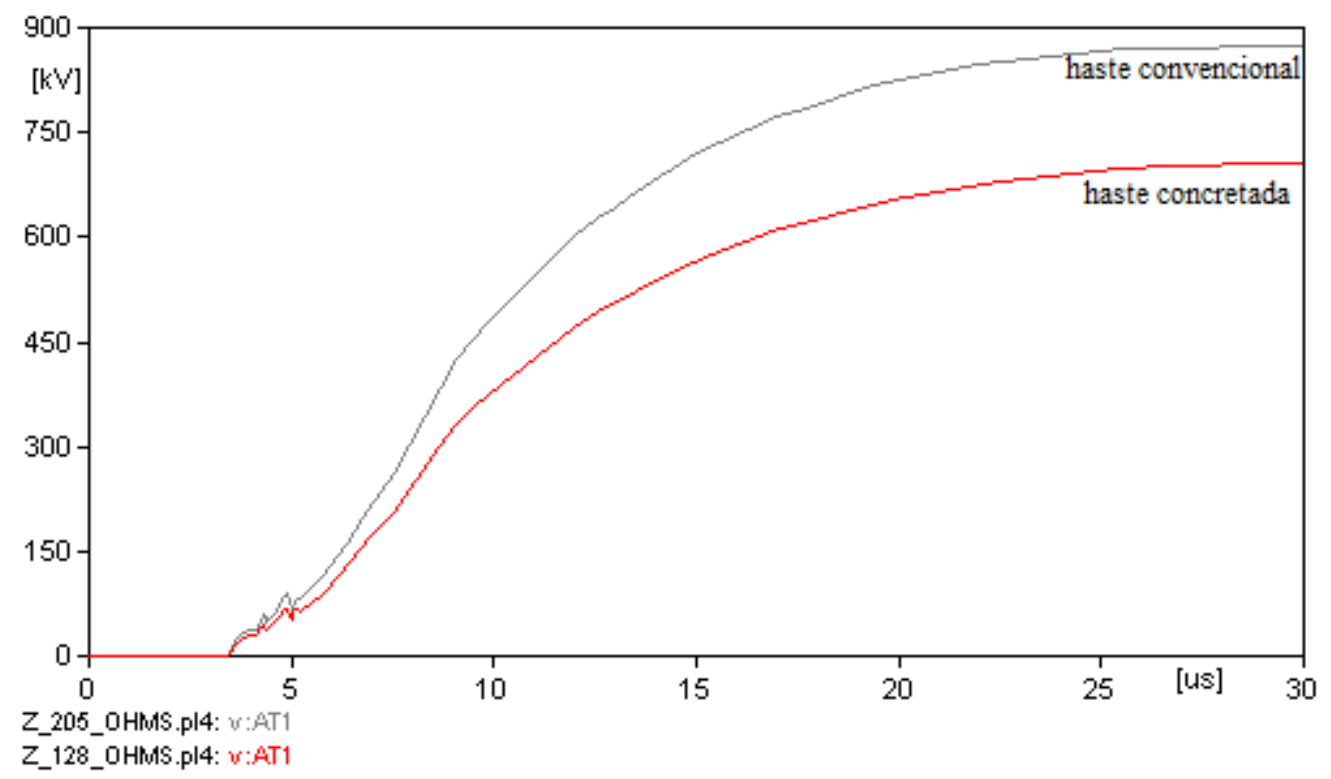

Figura 72 - Tensão neutro-terra no consumidor. 


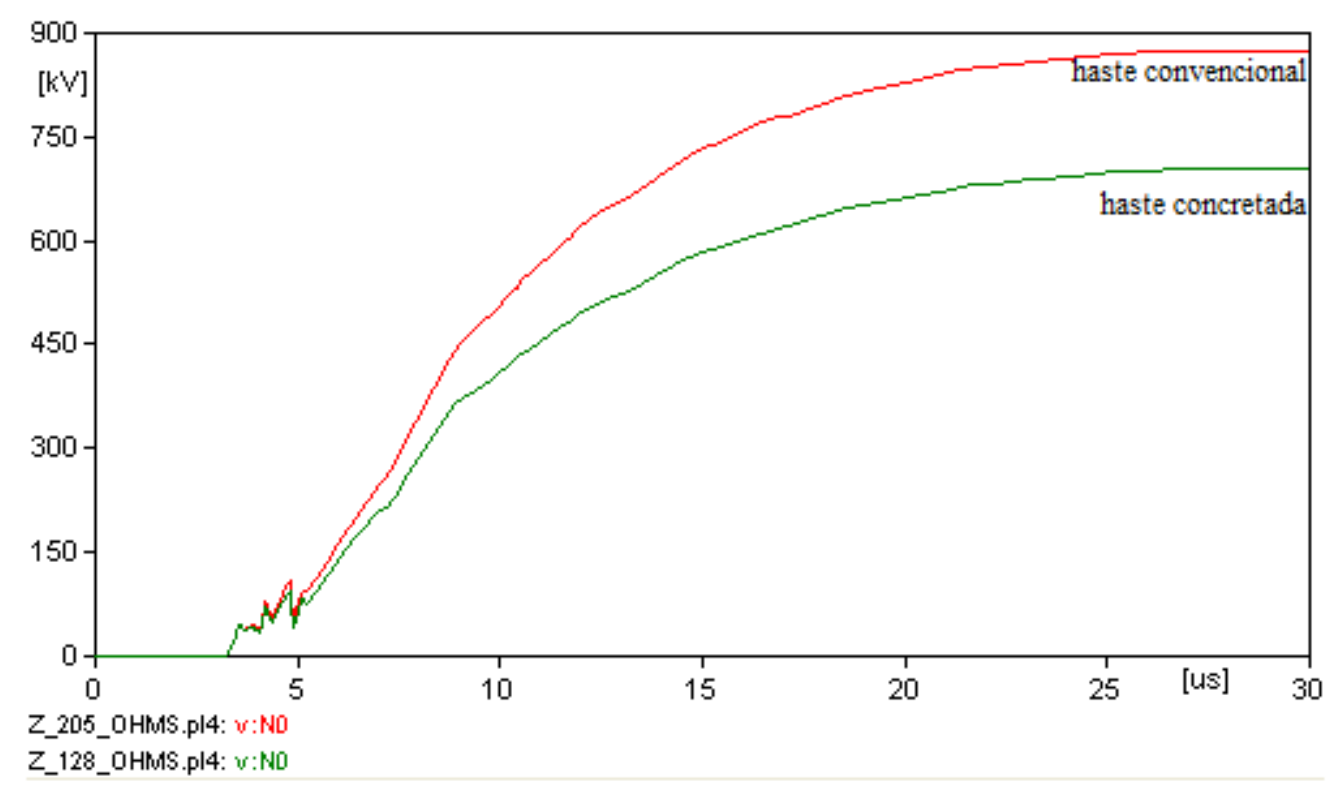

Figura 73 - Tensão neutro-terra no transformador.

Nas Figuras 71, 72 e 73 os níveis de tensão de surto e as formas de onda entre neutroterra, fase-terra e neutro-terra no transformador foram semelhantes apresentando redução de $170 \mathrm{kV}$ na amplitude da tensão em $20 \mu$ s para o valor de resistência de terra em $128 \Omega$ (haste concretada).

De acordo com os resultados obtidos, pode-se afirmar que a resistência de terra possui uma influência direta no nível dos valores da tensão fase-terra e neutro-terra. Quanto maior o valor de resistência tanto maior será o nível de tensão de surto que reflete na baixa tensão.

Para o lado da baixa tensão, principalmente no consumidor, os níveis de tensão de surto são demasiadamente elevados, ou seja, mesmo alterando o valor de resistência de terra o nível de tensão no consumidor não sofreu redução significativa para o caso analisado nas simulações. O valor é muito elevado e pode causar a queima de aparelhos eletro-eletrônicos de um consumidor residencial. Portanto, diante dos resultados apresentados, a adição do protetor de surto (varistor/pára-raio de baixa tensão) será mais eficaz. É importante salientar que a redução de resistência de terra com a utilização de haste concretada neste caso ajudaria a reduzir a tensão de toque e passo, deixando a instalação mais segura para pessoas e animais.

Em relação ao transformador, quanto maior for a resistência de terra tanto maior será o nível da tensão fase-terra e neutro-terra no lado de baixa tensão. Neste caso, o valor da tensão 
apresentada na Figura 73 possivelmente queimaria o transformador porque o CFO calculado foi de $156 \mathrm{kV}$ e o surto de tensão neutro-terra apresentado em $10 \mu$ s é de $508 \mathrm{kV}$ para resistência de terra de $208 \Omega$ (haste convencional) e $409 \mathrm{kV}$ para $128 \Omega$ (haste envolvida em concreto). 


\section{CONCLUSÕES E SUGESTÕES PARA TRABALHOS FUTUROS}

Um sistema de distribuição de energia elétrica deve atender vários requisitos técnicos, incluindo-se aqueles relacionados à proteção de pessoas e equipamentos. Portanto, o aterramento elétrico desempenha uma função muito importante, devendo ser resultado de um projeto adequado, cujos parâmetros devem estar dentro dos limites estabelecidos pelas normas e especificações técnicas. As concessionárias de energia elétrica estabelecem procedimentos para a execução do aterramento elétrico ao longo das redes de distribuição, procurando obter valores de resistência de terra dentro dos limites fixados, o que nem sempre é possível dada às características do local e do tipo de solo.

Este trabalho teve por objetivo a avaliação da utilização de condutores e hastes envolvidos em concreto em sistemas de aterramento, visando à redução dos valores de resistência de terra. Os estudos tiveram início com uma malha de aterramento convencional (malha reticulada), considerada como padrão por uma concessionária de energia elétrica. Foram realizadas várias simulações (casos 1 a 10), alterando-se alguns dos parâmetros, tais como, espaçamento e quantidade de hastes, dimensão e geometria interna da malha, além da utilização de hastes profundas. Outras configurações (anel, anéis concêntricos e triângulo) foram também consideradas, permitindo, deste modo, a comparação dos resultados obtidos com aqueles referentes à malha reticulada.

Em seguida, para verificar a efetividade do uso do concreto, foram realizadas simulações computacionais considerando o sistema de aterramento com a utilização de condutores e hastes envolvidos em concreto.

As seguintes configurações foram investigadas:

a) configurações simples (1 haste e hastes alinhadas), configurações em V (3 hastes) e em triângulo (3 hastes), procurando-se obter sensibilidade quanto ao comportamento de um sistema de aterramento quando o concreto é utilizado. Os resultados possibilitaram a 
comparação dos valores calculados com aqueles obtidos em medições de campo (CLAUSEN et al., 2004);

b) malha reticulada com as hastes envolvidas em concreto, visando à análise do efeito do concreto na malha adotada pela concessionária;

c) configurações simples (hastes alinhadas), considerando-se inicialmente o concreto somente nos condutores de interligação e, posteriormente, nos condutores de interligação e nas hastes. O objetivo foi a comparação dos resultados nas duas condições, pois sabe-se que a execução da concretagem nas hastes é uma atividade que pode ser inviável no campo.

Posteriormente, foi analisado o comportamento da impedância de aterramento em função da freqüência, comparando-se os resultados referentes às hastes alinhadas convencionais e hastes envolvidas em concreto. Por fim, foram realizadas investigações para verificar, no consumidor, a influência da utilização de uma haste convencional em relação a uma haste envolvida em concreto, quando da ocorrência de uma descarga atmosférica direta na rede primária.

As principais conclusões obtidas no trabalho são apresentadas abaixo:

1) Com relação ao uso da malha reticulada convencional, foi observado que os valores de resistência de terra são reduzidos acentuadamente em função do aumento da área da malha, mantendo-se o mesmo número de hastes. Esse resultado era esperado, conforme citado por outros autores. Contudo, como esse procedimento no campo geralmente não é viável, uma alternativa seria manter a área original da malha e reduzir a quantidade de hastes, otimizando a construção da malha. Nesse caso, foi observada pouca alteração nos valores de resistência de terra;

2) Os resultados obtidos em configurações simples (1 haste e hastes alinhadas) mostraram que a utilização do concreto resulta em uma redução significativa dos valores de resistência de terra, tendo sido observado que os resultados das simulações foram próximos daqueles obtidos em medições de campo; 
3) A utilização do concreto, envolvendo condutores e hastes na malha reticulada, não resultou em redução dos valores de resistência de terra que justificasse a adoção desse procedimento, indicando que a utilização do concreto deve ser precedida de estudos técnicos;

4) Foi verificado que a utilização do concreto em configurações simples (1 haste ou hastes alinhadas) com os condutores de interligação e hastes envolvidos em concreto apresenta bons resultados, entretanto, considerando-se que a concretagem das hastes no campo pode ser inviável, uma alternativa é a utilização do concreto somente nos condutores de interligação;

5) Com relação ao comportamento do aterramento em função da freqüência, foi observado que a utilização do concreto em hastes simples ou alinhadas resulta em acentuada redução dos valores de impedância de terra;

6) A análise da influência do sistema de aterramento do consumidor (haste convencional ou haste envolvida em concreto), quando da ocorrência de descarga atmosférica direta na linha de distribuição primária, permite afirmar que, para o lado da baixa tensão, os níveis de tensão de surto (tensões fase-neutro) são demasiadamente elevados. Em outras palavras, mesmo com a utilização da haste concretada (reduzindo os valores de impedância de terra), o nível de tensão no consumidor não sofreu redução significativa. Nesse caso, a haste concretada possibilitaria a redução das tensões de toque e de passo.

Finalizando, o presente trabalho apresentou resultados de várias simulações, permitindo a análise do comportamento de configurações de aterramento, com hastes e condutores envolvidos em concreto, em relação às configurações convencionais. A utilização do concreto nos sistemas de aterramento apresenta redução dos valores de resistência de terra, conforme esperado, entretanto, a sua utilização deve ser precedida de estudos que justifiquem a adoção desse procedimento. Ressalta-se que na literatura, os poucos trabalhos encontrados apresentaram somente resultados experimentais.

Sugestões para trabalhos futuros:

1) Análise do procedimento estabelecido pelo (IEEE-80, 2000) quanto à metodologia de cálculo da resistência de terra quando é utilizado o concreto; 
2) Realização de pesquisa experimental de modo a acompanhar, ao longo do tempo, o comportamento de malhas de aterramento com hastes e/ou condutores envolvidos em concreto;

3) Pesquisa quanto a utilização de outros materiais, além do concreto, que possam ser utilizados para envolver os condutores e as hastes nos sistemas de aterramento. 


\section{REFERÊNCIAS BIBLIOGRÁFICAS}

AFFONSO, O. Simulação do aterramento no sistema MRT. Dissertação (Mestrado) Escola Politécnica, Universidade de São Paulo, São Paulo, 2001.

AGÊNCIA NACIONAL DE ENERGIA ELÉTRICA. Disponível em: <http://www.aneel.gov.br/cedoc/res2000456.pdf 2010>. Acesso em 03 fev.2010.

AREND, E. R. Estudo de aterramento em baixas freqüências usando a formulação eletrocinética associada ao método de elementos finitos. Dissertação (Mestrado) Universidade Federal de Santa Catarina, Santa Catarina, 2009.

ASSOCIAÇÃO BRASILEIRA DE NORMAS TÉCNICAS. NBR 6936: técnica de ensaios elétricos de alta tensão: procedimento. Rio de Janeiro, 1992.

.NBR 5419: proteção de estruturas contra descargas atmosféricas: procedimento. Rio de Janeiro, 2005.

.NBR 14039: instalações elétricas de média tensão de $1,0 \mathrm{kV}$ a $36,2 \mathrm{kV}$. Rio de Janeiro, 2005.

.NBR 5410: instalações eletricas de baixa tensão. Rio de Janeiro, 2004.

BERTOLLO, H. C. Contribuições ao estudo dos aterramentos de sistemas monofilares com retorno por terra. Dissertação (Mestrado), Universidade Federal de Viçosa, Viçosa, 2008.

BRASIL. MINISTERIO DE MINAS E ENERGIA. Brasília: MME, 2010. Disponível em:<

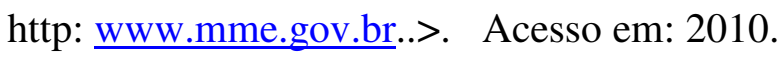

.Programa Luz para Todos. Brasília: MME, 2006. Disponível em:< http: www.mme.gov.br..>. Acesso em: 2010. 
BRASIL. OPERADOR NACIONAL DO SISTEMA ELÉTRICO. Disponível em:< http: www.ons.gov.br.. >. Acesso em: 12 jul. 2010.

CAMARGO, Ednaldo José Silva de. Programa luz para todoș: da eletrificação rural à universalização do acesso à energia elétrica da necessidade de uma política de estado. 2010. 116f. Dissertação (Mestrado) - Programa de Pós-Graduação em Energia, Universidade de São Paulo, São Paulo, 2010.

CAMPOS JUNIOR, I. G. Aterramento do ponto neutro das redes de distribuição através de bobina ressonante. Dissertação (Mestrado) - Universidade Federal de Itajubá, Minas Gerais, 2009.

CAVAlCANTE, C. A.; CIPOLI, J. A.; NOGUEIRA, E. D. B.; PASQUA, L. P. Desenvolvimento de novas tecnologias a serem implantadas como solução em sistemas de aterramento. In: CONGRESSO DE INOVAÇÃO TECNOLÓGICA EM ENERGIA ELÉTRICA, 3. 2005, Florianópolis. Proceedings. CITENEL'2005

CAVALIN, Geraldo; CERVELIN, Severino. Instalações elétricas prediais. 17 ed. São Paulo, : 2007.

CENTRAIS ELÉTRICAS BRASILEIRAS. Aterramento para sistema: MRT. Rio de Janeiro: ELETROBRÁS, 2001. Recomendação Técnica RER - 09, 2001.

Seleção de sistemas : MRT. Rio de Janeiro: ELETROBRÁS, 2002. Recomendação Técnica RER - 05, 2002.

CENTRAIS ELÉTRICAS DE SANTA CATARINA. Fornecimento de energia elétrica em Tensão primária de distribuição. Santa Catarina: CELESC, 2001. NT01-AT - 2001.

CENTRO DE PESQUISAS DE ENERGIA ELÉTRICA. Levantamento das Características dos Sistemas Elétricos Brasileiros de Distribuição Rural no Âmbito do Programa Nacional de Eletrificação Rural "Luz no Campo", Rio de Janeiro: CEPEL, 2000. RELATÓRIO TÉCNICO ADG-A/PER nº 323/2000.

CLAUSEN, W. et al. Nova técnica de aterramento para sistemas de distribuição de energia. In: SEMINÁRIO NACIONAL DE DISTRIBUIÇÃO DE ENERGIA ELÉTRICA, 16.; 2004, Brasília. Anais... Brasília: CEB, 2004 
COMPANHIA DE ELETRICIDADE DE PERNAMBUCO. Projeto de Rede de Distribuição Aérea Rural - 15 kV, Planejamento, Ampliação e Melhoria da Rede Elétrica, Recife:CELPE, 2008.

Norma fornecimento de energia elétrica em tensão primária de distribuição classe 15 kV - CODIGO SM01.00-00.004, Recife: CELPE, 2009.

COMPANHIA DE ENERGIA ELÉTRICA DE TOCANTINS. Efeito das descargas atmosféricas no desempenho de linhas de distribuição e na taxa de falhas de transformadores. São Paulo: IEE-USP/CELTINS, 2008. (CELTINS/RQ 001/CICLO 001/OR).

Efeito das descargas atmosféricas no desempenho de linhas de distribuição e na taxa de falhas de transformadores. São Paulo: IEE-USP/CELTINS, 2009. (CELTINS/RQ 001/CICLO 002/OR).

COMPANHIA ENERGÉTICA DO CEARÁ. Rede de Distribuição Rural Monofilar.

Ceará: COELCE . Projeto CP-003/2006-R-01, 2006.

COMPANHIA ESTADUAL DE ENERGIA ELÉTRICO DO RIO GRANDE DO SUL, Procedimento de Distribuição: codigo: NTD-00.073,. Rio Grande do Sul: CEEE - SUL, 2008.

COMPANHIA PARANAENSE DE ENERGIA. Manual de Instruções Técnicas: módulo aterramento de linha de distribuição, n. ${ }^{\circ}$ 163104, Curitiba: COPEL, 2004.

- Norma Técnica: NTC 831001: Projeto de redes de distribuição rural, Curitiba“COPEL, 2002.

COMPANHIA PAULISTA DE FORÇA E LUZ. Distribuição Fornecimento em tensão 15 kV e 25 kV, vol.1, São Paulo: CPFL, 2008.

Projetos de Redes Aéreas de Distribuição Rural, São Paulo: CPFL, 2009. 
CONTI, Alberto de; VISACRO, Silverio, A Simplified model to represent typical grounding configurations applied in medium-voltage and low voltage distribuition lines. In: INTERNATIONAL SYMPOSIUM ON LIGHTNING PROTECTION, 9., 2007. Foz do Iguaçu. Proceedings. SIPDA. São Paulo: IEE-USP, 2007.

CUNHA, JOAO GILBERTO. Aterramento elétrico, 2003

CURRENT DISTRIBUTION, ELECTROMAGNETIC FIELDS, GROUNDING AND SOIL STRUCTURE ANALYSIS. User's Primers. Quebec: Safe Engineering Services \& Technologies 1td, 2000.

FAGAN, E. J.; LEE, R. H. The use of concrete-enclosed reinforcing rods as grounding electrodes. IEEE Trans. Power Delivery, v. 6, n. 4, p. 337-348, Jul./Aug., 1970.

GALVÁN DIEGO, A. GAONA, E.E; PRETELÍN, G.G. Practical Evaluation of ground enhancing compounds used in grounding rods. In: INTERNATIONAL SYMPOSIUM ON LIGHTNING PROTECTION, 10.,2009. Curitiba. SIPDA. Proceedings. São Paulo : IEEUSP, 2009.

GOEKING, Werusca. Eletricidade e desenvolvimento. Revista o Setor elétrico, n.48, jan. 2010 .

GOMES, Galeno Lemos, Sistema de aterramento e proteção contra raios utilizando ferragens do concreto armado. In ENCONTRO NACIONAL DE INSTALAÇÕES ELÉTRICAS, 11. São Paulo. ENIE 2006. Anais.. São Paulo: Aranda Eventos, 2006.

GRIMONI, José Aquiles Baesso; GALVÃO, Luiz Claudio Ribeiro; UDAETA, miguel edgar morales.(Org.) Iniciação a conceitos de sistemas energéticos para o desenvolvimento limpo. São Paulo: EDUSP, 2004.

GUPTA, B. R; SINGH, V. K. Impulse impedance of rectangular grounding grids. IEEE Transactions on Power Delivery, v. 7, n.1, jan. 1992.

GUPTA, B. R; THAPAR, B. Impulse impedance of grounding grids. IEEE Transactions on Power Apparatus an Systems, v.99, n. 6, Nov/Dec, 1980. 
GUSMÃO; Marcos Vinícius. et al. O programa de eletrificação rural "Luz no Campo": Resultados iniciais. Rio de Janeiro: ELETROBRÁS, 2004.

HOIDALEN, H.K. Lightning-induced voltages in low-voltage systems and its dependency on overhead line terminations. In: International Conference on Lightning Protection, 24. ICLP. Proceedings. Stafford : Staffordshire University, 1998. p.287-292

INSTITUTE OF ELECTRICAL AND ELECTRONICS ENGINEERS. IEEE Std 80: Guide for Safety in AC Substation Grounding. Piscataway, 2000

INSTITUTO BRASILEIRO DE GEOGRAFIA E ESTATÍSTICA. Censo Demográfico 2000. Disponível em: < http://www.ibge.gov.br/censo > Acesso em 03 jan. 2009.

KAGAN, Nelson; Oliveira, BARIONI, Carlos Cesar; ROBBA, Ernesto João. Introdução aos sistemas de distribuição de energia elétrica. São Paulo: Edgard Blucher, 2005

KINDERMAN, G. Aterramento elétrico. 4 ed., Porto Alegre: Editora Sagra, 1998.

LEITE, Moreira Carlos Técnicas de aterramentos elétricos : cálculos, projetos e softwares para aterramentos elétricos. São Paulo : Officina de Mydia, 1996.

LUZ, Mauricio Valencia Ferreira. Analytical and finite element modeling of grounding systems. In: INTERNATIONAL SYMPOSIUM ON LIGHTNING PROTECTION, 9., 2007. FOZ DO IGUAÇU. SIPDA. PROCEEDINGS. SÃO PAULO: IEE-USP, 2007.

MACIEL, NELSON FERNANDES.. Análise do Aterramento da Subestação de Distribuição num Protótipo de sistema Monofilar com Retorno por Terra. Viçosa: Universidade Federal de Viçosa, 1982.

OLIVEIRA, E.M, Utilização da proteção catódica para sistema de dutos e/ ou torres de transmissão mediante geração foto-voltaica. 2008. Dissertação (Mestrado) - Universidade Federal de Pernambuco, Recife, 2008.

OLIVEIRA, L.C., Perspectivas para a eletrificação rural no novo cenário econômicoinstitucional do setor elétrico brasileiro. 116f. Dissertação (Mestrado) - COPPE, Universidade Federal do Rio de Janeiro, Rio de Janeiro, 2001. 
OPERADOR NACIONAL DO SISTEMA. Disponível em: http://www.ons.org.br/download/biblioteca_virtual/publicacoes/dados_relevantes_2009/04Integracao-Eletroenergetica.html. Acesso em 20 mar. 2010.

PEREIRA, Joao Batista José. Modelagem de incertezas em sistemas de aterramento elétricos, 2008. Tese (Doutorado), Universidade de Brasília, Brasília, 2008.

PIANTINI, Alexandre; BASSI, Welson.; MATSUO, Nelson M. Evaluation of currents and charge in surge protective devices in low-voltage distribution networks due to direct lightning strikes. In: INTERNATIONAL CONFERENCE ELECTRCITY DISTRIBUTION, 16., 2001, Amsterdam. CIRED 2001. Technical Papers. London: IEE/ BEAMA, 2001. p. v.2 / 52-55.

RIBEIRO, F.S. Eletrificação rural de baixo custo. 1993.157f. Tese (Livre Docência) Escola Politécnica, Universidade de São Paulo, São Paulo, 1993.

RIBEIRO, F.S., et. al. , O método dos elementos finitos na análise do aterramento do sistema monofilar com retorno por terra. In: ENCONTRO DE ENERGIA NO MEIO RURAL , 3. 2003, Campinas. Anais... Campinas: UNICAMP/SBEA, 2003.

ROSADO, Glaucio Correia. Investigação teórico-experimental sobre a resposta de aterramentos elétricos frente a correntes de descargas atmosféricas, 2008. Dissertação (Mestrado), Universidade Federal de Minas Gerais, Minas Gerais, 2008.

SEKIOKA, S.; YAMAMOTO, K; YOKOYAMA, S. Measurements of a concrete pole impedance with an impulse currents source. In INTERNATIONAL COFERENCE ON POWER SYSTEMS TRANSIENTS. IPST 95. Proceedings., 1995.

SILVA, Marcelo Roger. Avaliação de alternativa para eletrificação rural no contexto dos programas de universalização do atendimento de energia no Brasil, 2006.

Dissertação (Mestrado), Universidade Federal de Minas Gerais, Minas Gerais, 2006.

SOUZA, Claudio; ANJOS, Flavio. Impactos dos Programas de Eletrificação Rural em Comunidades Rurais de Arroio Grande Revista extensão rural. DEAER /CPEGxR - CCR USFM, ANO XIV, JAN 2007, RS, JAN 2007

SOUZA, Julio Cesar Nascimento. Modelagem de redes aéreas com retorno por terra em sistemas de distribuição de energia elétrica para analises de falta de alta impedância. 2006. Dissertação (Mestrado), Universidade do Maranhão, Maranhão, 2006. 
SOUZA, Kaisson; MOURA, Ricardo; CINTRA, Gabriel. Estudo de alternativas para a construção de malhas de aterramento num solo com alta resistividade elétrica. In: CONGRESSO DE PESQUISA E INOVAÇÃO DA REDE NORTE NORDESTE DE EDUCAÇÃO TECNOLÓGICA, 2. 2007, João Pessoa. Anais...Paraíba: CEFET/PB

SOUZA JUNIOR, E. S. Simulação, em ambiente computacional, do método de wenner e obtenção da resistência de um sistema de aterramento usando o FDTD. Dissertação (Mestrado) - Universidade Federal do Pará, Pará, 2007.

SUETA, H. E. Uso de componentes naturais de edificações como parte integrante do sistema de proteção contra descargas atmosféricas: uma visão aos danos físicos. Tese (Doutorado) - Escola Politécnica, Universidade de São Paulo, São Paulo, 2005.

TELLÓ, Marcos; et al. Aterramento elétrico impulsivo, em baixa e alta freqüências. Porto Alegre: EDIPUCRS , 2007

URMEE, Tania; HARRIES,, David; SCHLAPFER, August . Issues related to rural electrification using renewable energy in developing countries of Asia and Pacific. Renewable Energy, v. 34, n.2, p. 354-357, 2009

VALLEJOS ,L. et al. Dimensionamento de electrodos de pusta a tierra tipo anillo para sistemas de transmission HVDC. In:ENCUENTRO REGIONAL IBEROAMERICANO DE CIGRÉ, 13., 2009. Puerto Iguazú.. ERIAC. Trabalhos Técnicos .Puerto Iguazú: CIGRÉ, 2009.

VICENTE, O. et al. Um teste para avaliação da qualidade de aterramentos elétricos. Espaço Energia, n 1, out., 2009.

VISACRO, S. Aterramentos Elétricos: conceitos básicos, técnicas de medição e instrumentação, filosofia de aterramento. São Paulo: Artiliber Editora, 2002.

VISACRO, S. et al. Statistical Analysis of lightning Current parameters: Measurements at Morro do Cachimbo Station. Journal of Geophysical Research, v. 109, n. D01105, p. 1-11, 2004. doi:10.1029/2003JD003662. 


\section{ANEXO I}

O programa CDEGS é composto por oito módulos de engenharia, RESAP, MALT, MALZ, TRALIN, SPLITS, HIFREQ, FCDIST e FFTSES.

O módulo RESAP (Análise de resistividade do solo) é utilizado para interpretação de medições de resistividades do solo, estratificação do solo em múltiplas camadas, horizontais, verticais e determinação da resistividade aparente do solo. O programa permite obter a resistividade do solo através do método de Frank Wenner ou Schlumberger. O método utilizado neste trabalho foi o de Wenner.

O módulo MALT (Análise de aterramento) permite a simulação de estruturas metálicas instaladas e enterradas em solos de múltiplas camadas e a interpretação de resistência de terra e impedância de terra. Usando o MALT é possível modelar um solo de multicamadas e homogêneo. Também permite especificar qualquer número de eletrodos e energizar cada eletrodo individualmente.

O módulo MALZ (Análise do aterramento no domínio da freqüência) analisa o comportamento da malha de aterramento no domínio da freqüência e, com o resultado, é possível interpretar a impedância de terra. O MALZ foi desenvolvido especificamente para investigar problemas que envolvem condutores energizados em alta freqüência. Os condutores podem ser sólidos, revestidos ou não, e podem ser posicionados no solo em qualquer posição. As camadas do solo podem ser verticais ou horizontais de diferentes resistividades. Os sistemas de condutores podem ser energizados em diferentes pontos da malha de aterramento.

HIFREQ é o módulo de software que pode fornecer soluções considerando-se transientes e estado estacionário, na faixa de frequiência de zero a centenas de MHz. Com o HIFREQ é possível obter o cálculo de campos elétricos e magnéticos no solo e no ar, potenciais em condutores no solo e a distribuição de correntes em condutores, considerando elementos aéreos e enterrados.

FFTSES - Este módulo permite a obtenção da resposta no tempo de fenômenos transitórios, pela passagem do domínio da freqüência para o domínio do tempo, dos resultados de simulações realizadas com os programas MALZ e HIFREQ, com o auxílio da transformada de Fourier. 
Os cálculos de potencial de passo, toque e transferência são gerados pelo CDEGS, podendo ser adotada a metodologia proposta no IEEE ou IEC. Neste trabalho foi adotada a metodologia do IEEE.

Uma das principais vantagens do programa foi à possibilidade de envolver a haste em concreto, utilizando um valor típico de resistividade do concreto. 